UNIVERSIDADE DE SÃO PAULO

FACULDADE DE ECONOMIA, ADMINISTRAÇÃO E CONTABILIDADE DEPARTAMENTO DE ADMINISTRAÇÃO

\title{
JIT: UM ESTUDO DE CASOS DOS FATORES CRÍTICOS PARA A IMPLEMENTAÇÃO
}

ROGÉRIO AUGUSTO PROFETA

SÃO PAULO 


\section{UNIVERSIDADE DE SÃO PAULO \\ FACULDADE DE ECONOMIA, ADMINISTRAÇÃO E CONTABILIDADE \\ DEPARTAMENTO DE ADMINISTRAÇÃO}

\section{JIT: UM ESTUDO DE CASOS DOS FATORES CRÍTICOS PARA A IMPLEMENTAÇÃO}

Rogério Augusto Profeta

Tese apresentada à Faculdade de Economia, Administração e Contabilidade da Universidade de São Paulo, para obtenção do título de Doutor em Administração

ORIENTADOR: Prof. Dr. ABRAHAM S. O. YU

\section{SÃO PAULO}


Dedico este trabalho à minha mulher Mara, aos meus filhos Guilherme e Jordana e aos meus pais, Paulina e Darci (em memória) 


\section{Agradecimentos}

Agradeço particularmente ao Prof. Dr. Abraham S. O. Yu, pela expressiva contribuição que trouxe na orientação e ao aluno e amigo Rafael Guilherme Burstein Goldszmidt, pela constante colaboração. 


\section{Sumário}

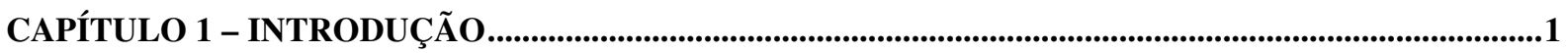

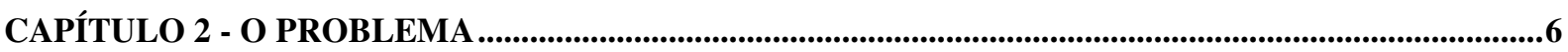

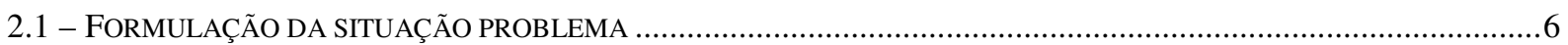

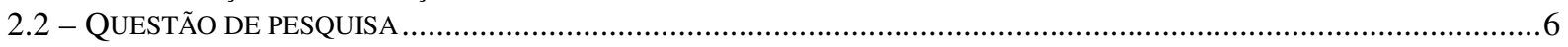

2.3 - DEFINIÇÃO CONCEITUAL E OPERACIONAL ...........................................................................................

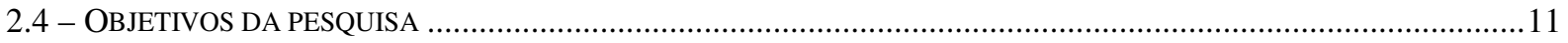

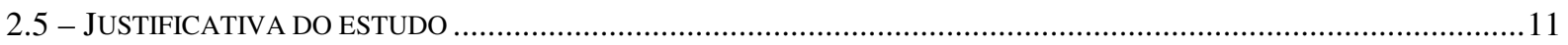

CAPÍTULO 3 - FUNDAMENTAÇÃO TEÓRICA ............................................................................13

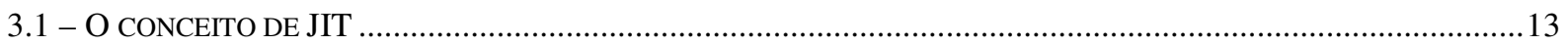

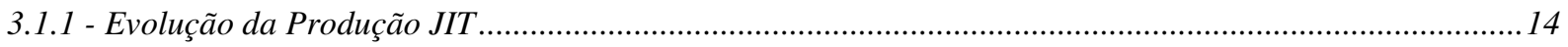

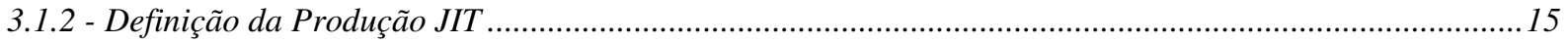

3.1.3 - Como funcionam e onde se aplicam as técnicas JIT ...........................................................................17

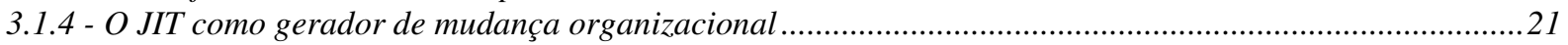

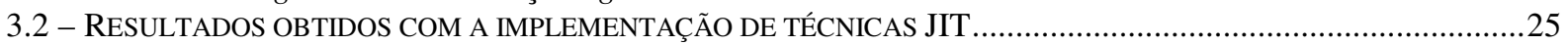

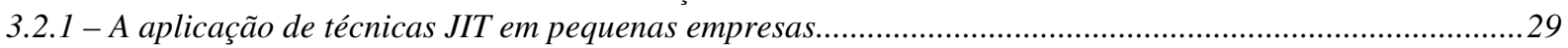

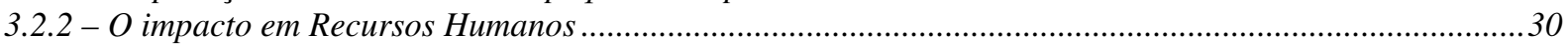

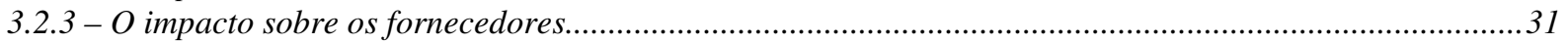

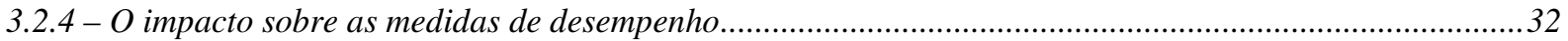

3.2.5 - A implementação de técnicas JIT em diferentes países ..........................................................................32

3.3 - PROBLEMAS ENCONTRADOS NA IMPLEMENTAÇÃO DE TÉCNICAS JIT ………..................................................34

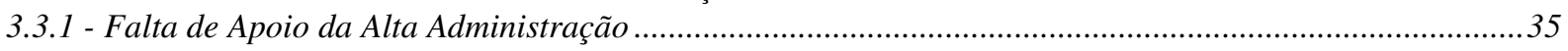

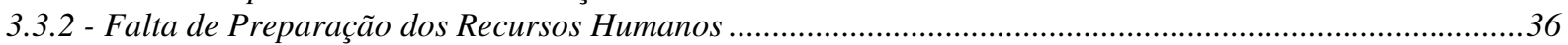

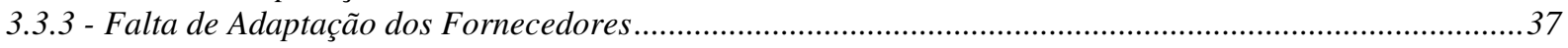

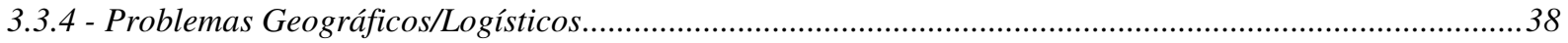

3.3.5 - Problemas Organizacionais ………………….............................................................................. 39

3.4 - FATORES CRÍTICOS NA IMPLEMENTAÇÃO (FCI) DAS TÉCNICAS JIT..............................................................

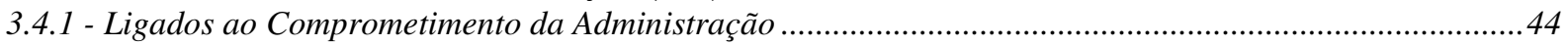

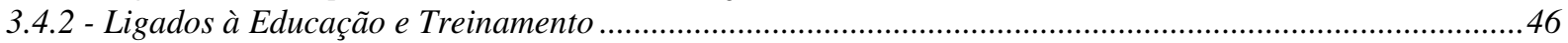

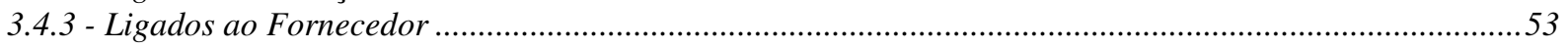

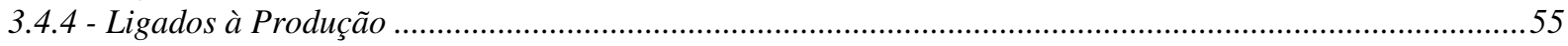

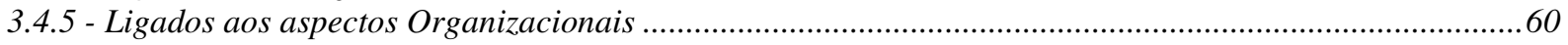

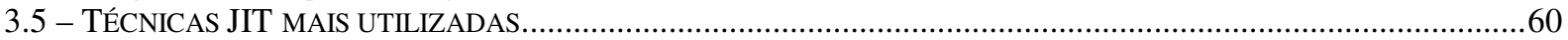

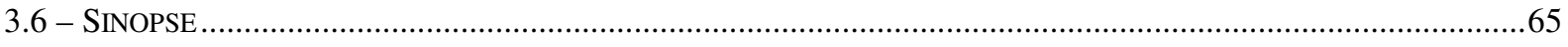

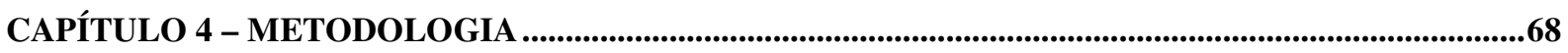

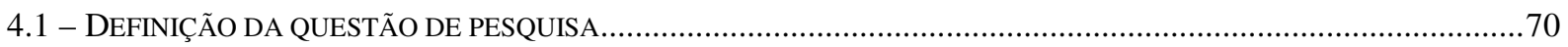

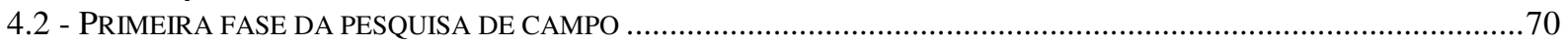

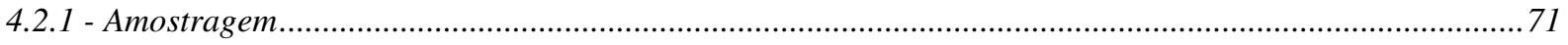

4.2.2 - Pré-teste da primeira fase da pesquisa de campo ..............................................................................71

4.2 .3 - A coleta de dados da primeira fase da pesquisa de campo ...................................................................73

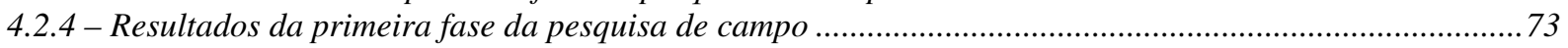

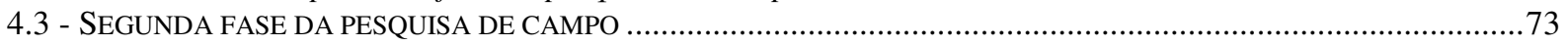

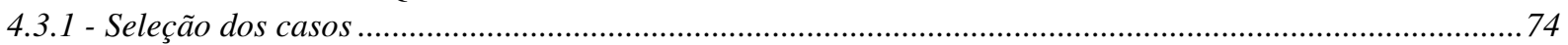

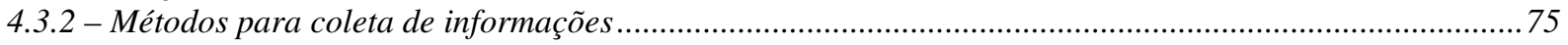

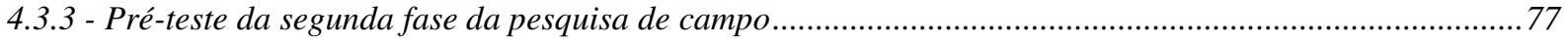

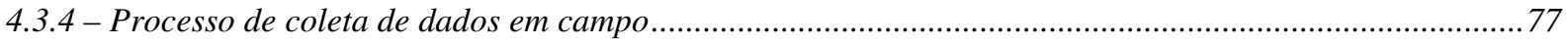

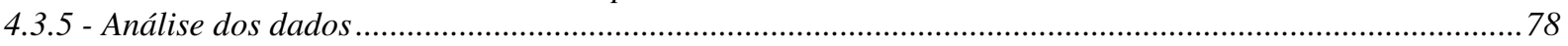

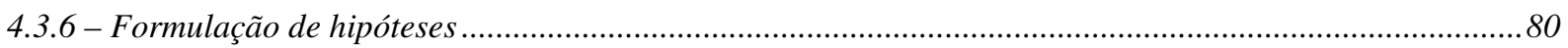

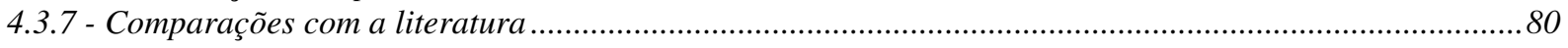

CAPÍTULO 5 - RESULTADOS DA PESQUISA E FORMULAÇÃO DE HIPÓTESES.................................81

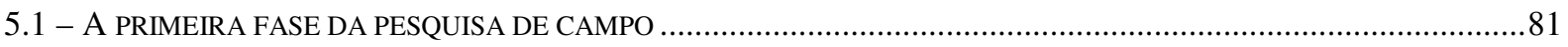

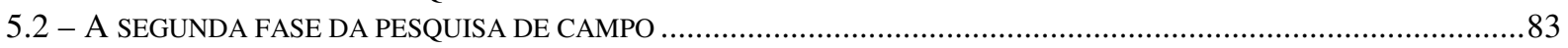

5.3 - PERFIL DAS EMPRESAS, AS ENTREVISTAS E UMA SÍNTESE DA IMPLEMENTAÇãO...............................................84 


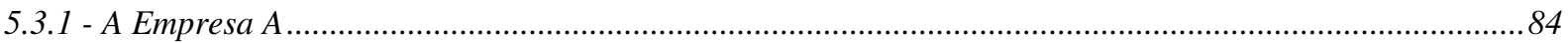

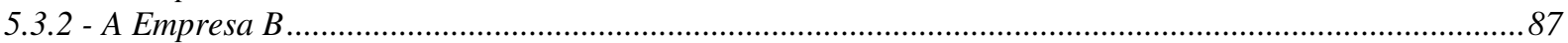

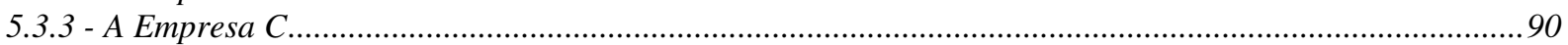

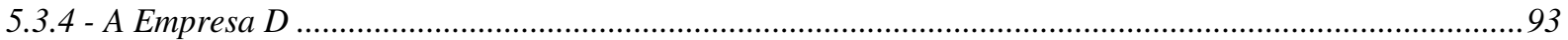

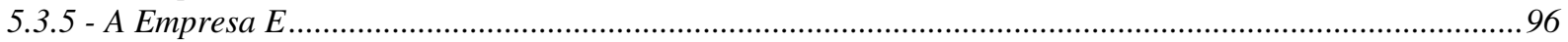

5.4 - ANÁLISE DOS RESULTADOS DA SEGUNDA ETAPA DA PESQUISA DE CAMPO............................................99

5.4 .1 - Análise cronológica dos principais eventos ..............................................................................99

5.4 .2 - Fatores Críticos para a Implementação e os aspectos relacionados: uma visão geral ........................... 101

5.4.3 - Análise dos Fatores Críticos para a Implementação ..................................................................... 104

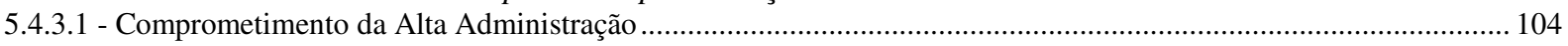

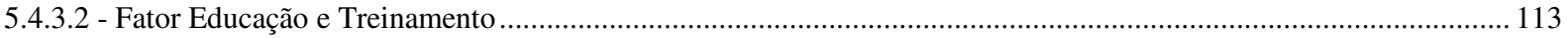

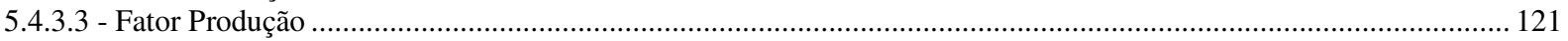

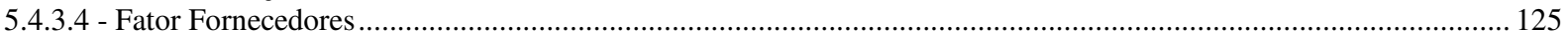

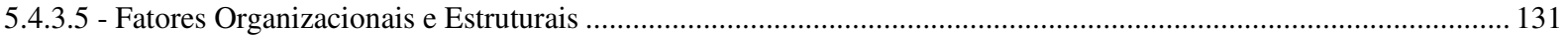

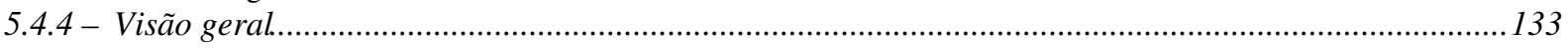

CAPÍTULO 6 - CONCLUSÕES E SUGESTÕES.........................................................................................136

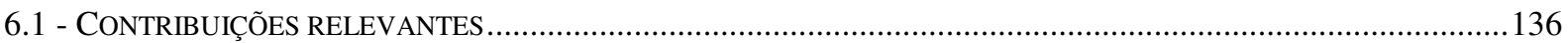

6.1 .1 - Contribuições que são confirmadas pela literatura pesquisada........................................................... 136

6.1 .2 - Contribuições discrepantes em relação à literatura pesquisada...................................................... 138

6.1 .3 - Pontos não abordados na literatura pesquisada.............................................................................. 139

6.1 .4 - Peculiaridades verificadas nas empresas pesquisadas no contexto brasileiro.......................................141

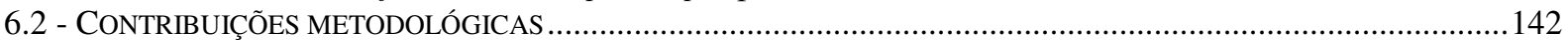

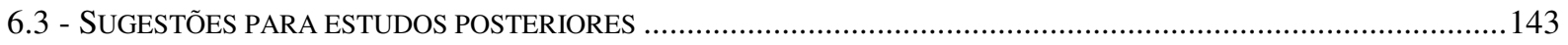

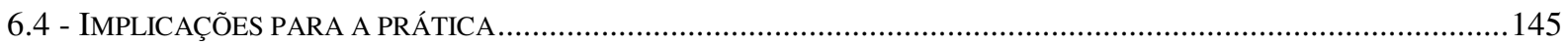

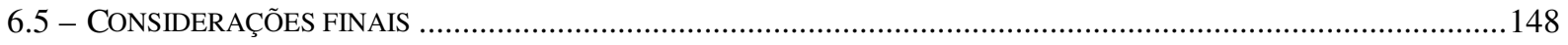

ANEXOS

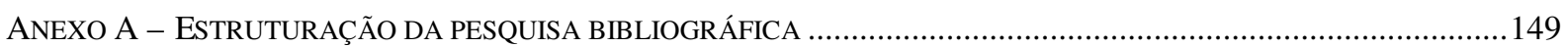

ANEXO B - QUESTIONÁRIO USADO NA PRIMEIRA FASE DA PESQUISA DE CAMPO .............................................. 150

ANEXO C - ROTEIRO USADO NA SEGUNDA FASE DA PESQUISA DE CAMPO................................................... 151

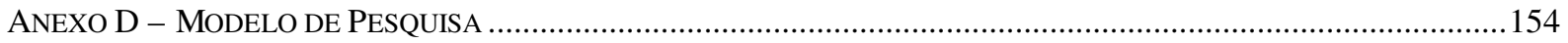

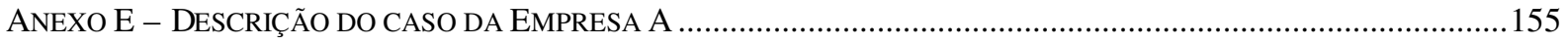

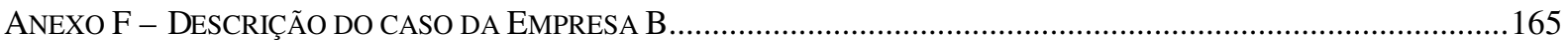

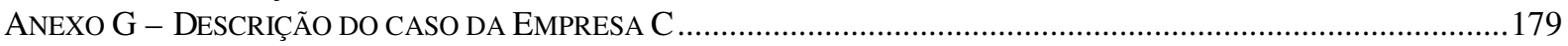

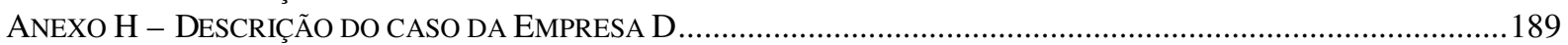

ANEXO I - DESCRIÇÃO DO CASO DA EMPRESA E ................................................................................... 199

ANEXo J - CRONOLOGIA DA INSTALAÇÃo (E DESATIVAÇÃO) DAS FÁBRICAS DE AUTOMÓVEIS, COMERCIAIS

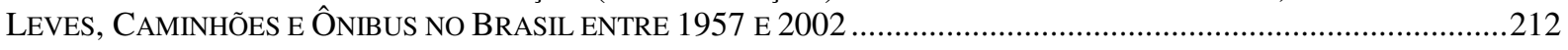

ANEXO L - PRODUÇÃO NACIONAL, IMPORTAÇÕES E EXPORTAÇÕES DE AUTOVEÍCUlOS: AuTOMÓVEIS,

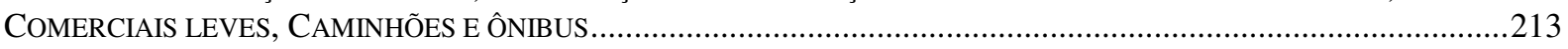

REFERÊNCIAS BIBLIOGRÁFICAS ..........................................................................................214 


\section{Lista de Tabelas}

Tabela 1 - Resultados ou benefícios do uso de técnicas JIT

Tabela 2 - Resultados ou benefícios do uso de técnicas JIT (em curto, médio e longo prazos) .........................27

Tabela 3 - Resultados ou benefícios (mensurados) do uso de técnicas JIT ...............................................28

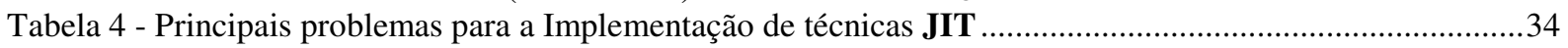

Tabela 5 - Fatores Ligados ao Comprometimento da Administração .........................................................45

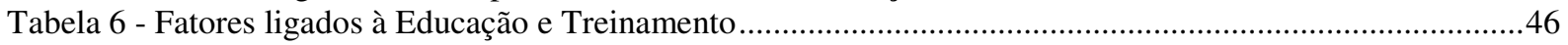

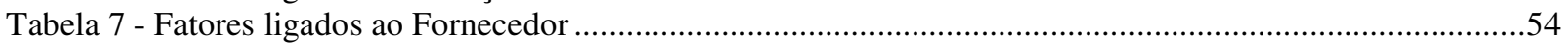

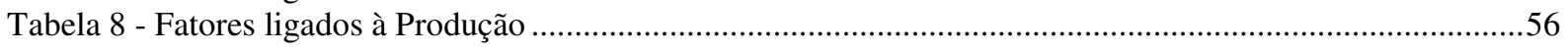

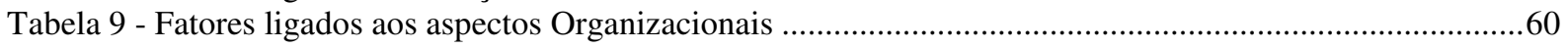

Tabela 10 - Principais Técnicas JIT ...............................................................................................64

Tabela 11 - Processo de Construção de Teorias a partir da Pesquisa de Estudos de Caso.................................69

Tabela 12 - Empresas participantes do pré-teste da primeira fase da pesquisa de campo..................................72

Tabela 13 - Empresas pesquisadas na segunda fase da pesquisa de campo ................................................75

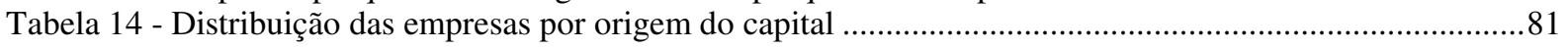

Tabela 15 - Porte das empresas, por número de Funcionários ....................................................................81

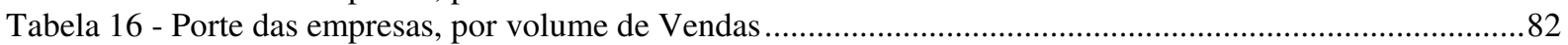

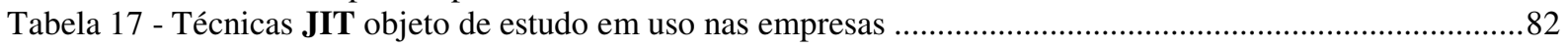

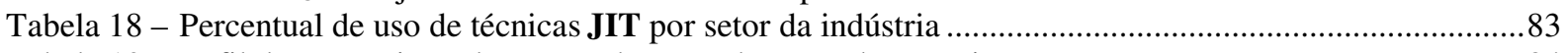

Tabela 19 - Perfil das entrevistas de campo da segunda etapa da pesquisa ...............................................84

Tabela 20 - Evolução cronológica dos principais eventos ocorridos nas empresas pesquisadas durante a

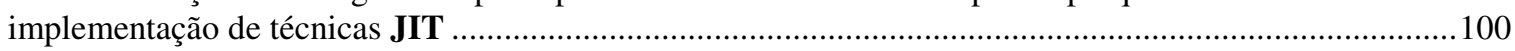

Tabela 21 - Status das empresas quanto aos aspectos do Fator Crítico Comprometimento da Alta Administração .104

Tabela 22 - Status das empresas quanto aos aspectos do Fator Crítico Comprometimento da Alta Administração 105

Tabela 23 - Status das empresas quanto aos aspectos do Fator Crítico Educação e Treinamento ......................113

Tabela 24 - Status das empresas quanto aos aspectos do Fator Crítico Produção ...........................................121

Tabela 25 - Status das empresas quanto aos aspectos do Fator Crítico Fornecedores ....................................126

Tabela 26 - Visão geral do status das empresas em relação aos aspectos de cada Fator Crítico para a Implementação

Tabela 27 - Evidências de resultados da implementação de técnicas JIT por empresa. 134 


\section{Lista de Figuras}

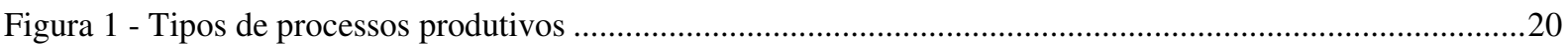

Figura 2 - Artigos sobre resultados de implementação de técnicas JIT ......................................................25

Figura 3 - Artigos publicados sobre implementação de técnicas JIT .................................................40

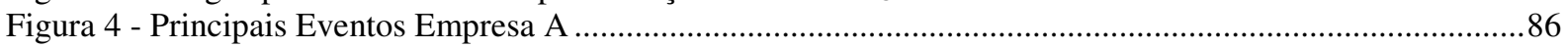

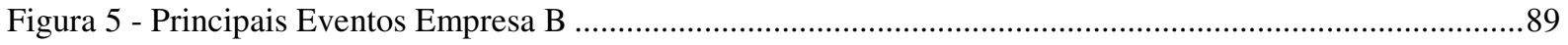

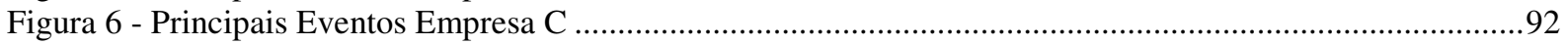

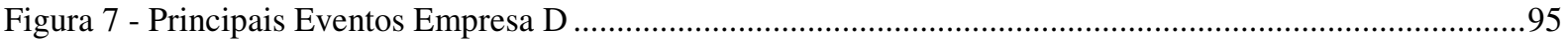

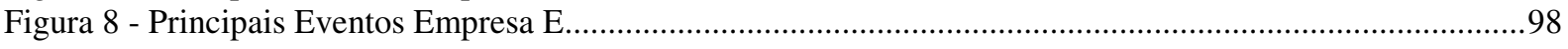

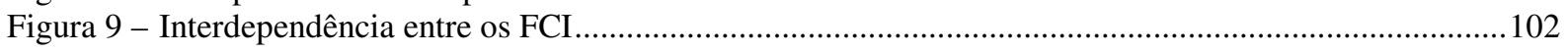




\section{RESUMO}

PROFETA, Rogério A. JIT: Um Estudo de Casos dos Fatores Críticos de Implementação. 2003. 221 pp. Tese de Doutorado - Faculdade de Economia, Administração e Contabilidade, Universidade de São Paulo, São Paulo.

As técnicas JIT, desenvolvidas na Toyota a partir da década de 40, apresentam hoje significativo nível de aplicação, sendo que importantes resultados têm sido atingidos com o seu uso, embora o processo de implementação possa apresentar uma série de problemas. Nesta pesquisa, uma revisão de literatura descreveu o conceito de JIT, resultados obtidos com sua implementação e principais problemas enfrentados. Os Fatores Críticos para a Implementação (FCI) foram definidos como fatores cuja consideração e tratamento são importantes para que a implementação tenha maior probabilidade de atingir os resultados dela esperados. Na revisão de literatura foi possível destacar FCI relacionados principalmente a aspectos ligados ao Apoio da Alta Administração, Educação e Treinamento, Produção, Organizacionais/Estruturais e Fornecedores. Teve-se como objetivo desta pesquisa identificar a forma de tratamento dos FCI das técnicas JIT em um conjunto de empresas industriais de Sorocaba, o que poderia contribuir com o melhor entendimento do processo de implementação. Como metodologia, optou-se pela proposta de Eisenhardt para a construção de teorias a partir de estudos de caso, que permite um maior aprofundamento na questão de pesquisa. A seleção das cinco empresas estudadas foi realizada por amostragem teórica e não estatística, e contou, como apoio, com uma pesquisa quantitativa sobre o uso de técnicas JIT tendo como universo as empresas industriais de Sorocaba. A coleta de dados no estudo de casos, predominantemente de cunho qualitativo, foi efetuada por uma equipe de pesquisa, abrangendo entrevistas pessoais aliadas à observação direta das instalações produtivas. $\mathrm{O}$ processo de análise incluiu a comparação entre os casos, a partir de uma perspectiva cronológica e segmentada por FCI, levando à formulação de hipóteses relacionadas à forma de tratamento destes FCI. Finalmente, compararam-se as constatações da pesquisa de campo com a literatura, propondo-se também implicações para a prática e sugestões para estudos posteriores.

Palavras-chave: Just in time, fatores críticos para a implementação, estudo de casos 


\begin{abstract}
PROFETA, Rogério A. JIT: A Cases Study of Implementation Critical Factors. 2003. 221pp. Tese de Doutorado - Faculdade de Economia, Administração e Contabilidade, Universidade de São Paulo, São Paulo.
\end{abstract}

Developed at Toyota since the 40's, JIT techniques are nowadays intensively spread over the world, leading the organizations that applied them to obtain relevant results. On the other hand, its implementation may present a number of problems. In this research, a literature review described the JIT concept, results obtained by its use and major problems faced. Implementation Critical Factors (ICF) for JIT Techniques were defined as factors whose consideration and treatment are relevant to allow the implementation process to occur with greater probability of achieving the expected results. Five groups of ICF were identified in the literature review: Top Management Support; Education and Training; Manufacturing; Organizational/Structural and Suppliers. This work's objective was to identify the way in which the ICF for JIT techniques were treated by a group of industrial enterprises in Sorocaba-SP. Such a study may contribute to a better understanding of the implementation process. Eisenhardt's proposal for theory building from case study research was applied in the methodological field, allowing a deeper analysis of the research question. Five organizations were elected for the case studies, based on theoretical, not random, sampling. A survey among industrial enterprises of Sorocaba over the use of JIT techniques acted as a support to this choice. The data collection process in the case studies, focused mainly on qualitative information, was carried out by a research team, including personal interviews as well as direct observation of production facilities. This analysis enfolded a comparison between the implementation processes, from a chronological perspective and a cross sectional view, based on the groups of ICF, leading to the design of hypothesis. At last, the field research findings were compared to the existing literature and suggestions for further studies as well as for enterprises undertaking the JIT implementation were proposed.

Key words: Just in time, implementation critical factors, case study 


\section{Capítulo 1 - Introdução}

O termo JIT (Just-in-time) foi originalmente utilizado por Kiichiro Toyoda para descrever o Sistema Toyota de Produção, criado por Taiichi Ohno e aplicado desde o final da Segunda Guerra Mundial nas fábricas de automóveis da Toyota, no Japão. O desenvolvimento das técnicas JIT na Toyota, segundo Vokurka e Davis (1996), iniciou uma mudança no paradigma representado pela produção em massa, que tem premissas próprias, dentre as quais destacam-se: a divisão do trabalho, que gera a especialização; a estratificação da função de "pensar", restrita ao pessoal de staff, enquanto os trabalhadores de linha ficam limitados à função de "executar"; o reconhecimento da existência de variações estatísticas em todos os processos produtivos, de forma que sempre se possa esperar por irredutíveis "taxas de defeito"; a função de comunicação e organização tida como responsabilidade intrínseca da chefia; a manufatura com grandes lotes e equipamentos projetados especificamente para determinadas tarefas e a existência de estoques, vistos como necessários para proteção contra falhas de fornecimento, assumidas como inevitáveis por parte dos fornecedores e até mesmo pelos clientes.

Já a produção com uso de técnicas JIT, por outro lado, assume características opostas. Os estoques são reduzidos; há elevado envolvimento dos trabalhadores no processo produtivo, por meio de participação em atividades de equipe, em que assumem maior responsabilidade; a multifuncionalidade é incentivada para dar suporte à nova gama de responsabilidades; os tempos de set up são reduzidos, possibilitando a redução dos lotes de fabricação, sendo que a produção ocorre em células de produção geridas por Kanban, além de diversas outras peculiaridades.

Ao longo das décadas de 70 e 80, particularmente após a primeira crise do petróleo em 1973, a elevada competitividade dos produtos japoneses chamou a atenção do ocidente para o uso de técnicas JIT como possível forma de melhorar a competitividade dos produtos ocidentais. Este fato foi enfatizado devido a que os produtos já não são mais produzidos somente para atendimento das necessidades locais, mas para um mundo sem fronteiras, entretanto, com barreiras em termos de qualidade e custos. Ferdows (1997) corrobora a afirmação acima destacando que o mundo está caminhando rapidamente para uma era de "manufatura transnacional", em que os bens produzidos em um país são embarcados para outros países para posterior trabalho, estocagem, remontagem ou venda direta. 
Em muitos ramos industriais o ambiente é marcado pela oferta de produtos de alta qualidade com preços baixos e pela mudança de comportamento do consumidor, que busca cada vez mais um maior retorno pelo investimento realizado na compra de um produto. Estes fatores geram uma motivação adicional nas empresas quanto à busca da competitividade para continuar atuando no mercado.

A adoção de técnicas de produção JIT mostrou-se como uma alternativa com níveis significativos de utilização por empresas ao redor do mundo a partir de meados da década de 80 até meados da década de 90 . Um reflexo deste fato pode ser constatado quando se observa a profusão de artigos científicos publicados sobre o tema no período, conforme indicado pela revisão bibliográfica que deu suporte a esta pesquisa. No que tange à realidade contemporânea brasileira, vivemos um momento histórico importante, pois, com a abertura das importações, o controle da inflação, a retomada do crescimento econômico e a recuperação dos investimentos diretos internos e externos, surge um cenário completamente novo para os diversos setores, em que a perspectiva de melhorias nas condições operacionais passa a representar um papel fundamental para os potenciais resultados das empresas como um todo. As empresas industriais em operação no Brasil passam a sentir necessidade e possibilidades de atuar em mercados mais competitivos, como o americano e europeu.

Entretanto, o acesso a estes mercados não é livre, dependendo de forma significativa da competitividade da indústria frente aos seus concorrentes diretos, conforme Haguenauer (1989).

O objetivo principal desta pesquisa foi analisar, à luz da experiência real de cinco empresas industriais nacionais, como está sendo desenvolvido o processo de implementação de técnicas JIT assim como os problemas a que está exposto, uma vez que em nenhum dos casos estudados o processo foi considerado concluído. Este estudo, organizado de forma a interpretar o processo de implementação, propôs ainda o uso da metodologia da construção de teorias a partir de estudos de caso (Eisenhardt, 1989).

Como a utilização de técnicas JIT apresenta resultados positivos, amplamente comprovados pela literatura especializada, que se mostram importantes para que as empresas se tornem competitivas nos mercados em que atuam, passam a chamar a atenção de outras empresas, que se interessam pela sua implementação. No tocante à indústria automobilística, Womack (1992) mostra a superioridade das montadoras orientais sobre as ocidentais em praticamente todos os aspectos, desde a concepção do projeto, passando pelos processos e chegando até as atividades ligadas à venda e distribuição dos produtos. Os resultados, na 
maioria dos casos, mostram-se na forma de redução dos níveis de estoques (com conseqüente redução das áreas de estocagem), redução do lead time (tempo decorrido entre a primeira e a última operação de produção de um produto), redução de perdas e retrabalho, além de aumento na qualidade e produtividade [Hay (1988); Golhar, Stam e Smith (1990); Moras e Dieck (1992); Sohal e Naylor (1992); Garg, Kaul e Deshmukh (1998) entre outros]. Todos estes elementos se traduzem em potenciais melhorias da competitividade.

Entretanto, a implementação de técnicas JIT não é simples. Existem relatos de vários tipos de problemas que podem surgir durante o processo de implementação. Estes problemas podem ter sua origem no apoio da Alta Administração (Walleigh, 1986 e Yasin e Wafa, 1996), na adaptação dos Recursos Humanos (Aggarrwal, 1985 e Golhar e Deshpande, 1993), na adaptação dos Fornecedores (Romero, 1991 e Wafa e Yasin, 1998), em fatores Geográficos/Logísticos (Ohno, 1988 e Kim e Schniederjans, 1990) e Organizacionais (Ansari e Modarress, 1990).

A mudança de paradigma já citada (Vokurka e Davis, 1996) por si só é um motivo para que as dificuldades de implementação surjam e mereçam um estudo mais prolongado. Nesta pesquisa foram estudados os Fatores Críticos para a Implementação (FCI) de técnicas JIT tendo como principal referencial o artigo de Mehra e Inman (1992), os primeiros autores a utilizar esta terminologia para aspectos da implementação de técnicas JIT. Visto que os autores não definiram explicitamente o termo Fator Crítico para a Implementação em seu artigo, nesta pesquisa o mesmo foi entendido como fator cuja consideração e tratativa são importantes para permitir que a implementação aconteça de forma que os resultados esperados dela tenham maior probabilidade de ser atingidos.

Dentre os estudos disponíveis sobre implementação de técnicas JIT, alguns se limitam apenas a descrever e quantificar as principais técnicas JIT utilizadas, sem enfatizar as etapas pelas quais as empresas devem passar para implementá-las, enquanto outros apenas citam e tipificam os principais fatores que devem ser considerados no momento da implementação, sem, no entanto, detalhar o processo de implementação. Esta constatação abriu a possibilidade de que a implementação fosse estudada analisando-se o processo de implementação além de seus fatores e aspectos isoladamente. Tomando como base os Fatores Críticos para a Implementação propostos por Mehra e Inman (1992), foram analisados os principais eventos ocorridos nas empresas durante o processo de implementação das técnicas JIT.

A metodologia adotada nesta pesquisa partiu de um levantamento inicial para identificar as empresas industriais que estivessem em processo de implementação de técnicas 
JIT para gestão de suas unidades industriais. Esta etapa possibilitou também a identificação das técnicas JIT mais utilizadas nas empresas. Foram pesquisadas 89 empresas instaladas na região de Sorocaba - SP.

A segunda etapa da pesquisa teve como principal referencial teórico a proposta de Eisenhardt (1989). Esta etapa, voltada para a construção de teorias a partir de estudos de casos, reuniu cinco empresas industriais, representadas por 22 experientes profissionais, incluindo, entre outros, supervisores de produção, gerentes e diretores industriais, em entrevistas (que totalizaram cerca de 30 horas) e foram complementadas por visitas técnicas às instalações. Desta forma, foi possível a identificação, reunião e análise dos fatores relevantes para a implementação à luz da realidade de empresas industriais em operação no Brasil (fabricantes de autopeças e fornecedoras de peças para montadoras de automóveis), além de permitir que novos fatos viessem à tona pela análise do modo como cada empresa pesquisada organizou a implementação.

Constatou-se que a implementação de técnicas JIT é fortemente contingencial, ou seja, cada empresa assume uma postura própria adequada às suas necessidades e possibilidades (confirmando o pressuposto teórico existente). Não foi detectado um padrão de comportamento nas empresas pesquisadas quanto aos passos a serem seguidos para a implementação de técnicas JIT, a despeito de serem todas do mesmo ramo (fabricantes de autopeças) e de estarem sujeitas ao mesmo ambiente macroeconômico.

Constatou-se também que no Brasil existem condições muito peculiares afetando o processo de implementação de técnicas JIT das empresas que aqui estão em operação. Dentre estas particularidades, destaca-se a "síndrome do final do mês", ou seja, a preferência das empresas revendedoras de peças de reposição em apresentarem seus pedidos nos últimos três dias do mês, o que tem dificultado significativamente o planejamento das empresas fabricantes de autopeças.

Esta pesquisa está estruturada em seis capítulos incluindo esta introdução.

No capítulo 2 - "O Problema", descreveu-se o problema de pesquisa, com a questão central: como foram tratados os Fatores Críticos na Implementação das técnicas JIT nas empresas pesquisadas. Foram descritas também as definições conceitual e operacional adotada, assim como os objetivos e justificativas do estudo.

No Capítulo 3 - "Fundamentação Teórica", desenvolveu-se a revisão bibliográfica, mostrando primeiramente uma breve introdução aos iniciantes no tema JIT (com ênfase na 
evolução histórica do conceito, sua definição, funcionamento e importância na mudança organizacional), os resultados mais evidentes obtidos pelas empresas usuárias de técnicas JIT (envolvendo redução de estoques em processo, redução de espaço físico entre outros), seguido por uma descrição dos problemas mais comuns enfrentados por empresas que já implementaram técnicas JIT (como deficiência da formação educacional fundamental dos funcionários, a fragilidade técnica dos fornecedores e falta de uma coordenação central para a implementação) e finalizou-se com uma conceitualização dos principais Fatores Críticos para a Implementação - FCI (Comprometimento da Alta Administração, Educação e Treinamento, Fornecedores, Produção e Fatores Organizacionais e Estruturais) além de um levantamento das técnicas ou práticas mais comuns que caracterizam o sistema de produção JIT.

No Capítulo 4 - "Metodologia", detalhou-se a metodologia de pesquisa adotada, com destaque para a divisão da pesquisa em duas etapas, sendo a primeira de caráter quantitativo e aplicada exclusivamente às empresas industriais de Sorocaba - SP, voltada para a identificação das principais empresas usuárias de técnicas JIT, e a segunda etapa, desta vez primordialmente de cunho qualitativo, desenvolvida para o estudo de casos do processo de implementação propriamente dito.

No Capítulo 5 - "Resultados da pesquisa e formulação de hipóteses", destacou-se a análise dos resultados, com a caracterização das empresas pesquisadas na etapa de estudo de casos, os resultados obtidos pela comparação entre os casos e a ênfase na construção de teorias a partir das constatações colhidas ao longo das entrevistas e observações físicas das unidades industriais visitadas.

No Capítulo 6 - "Conclusões e sugestões", foram destacadas as contribuições específicas sobre o conhecimento de JIT no Brasil, considerando as particularidades das empresas pesquisadas; relataram-se constatações relevantes sobre 0 processo de implementação de técnicas JIT em empresas instaladas no Brasil; apresentaram-se contribuiçõos à metodologia de pesquisa sobre este tema; foram formuladas sugestões para estudos posteriores, com base nas hipóteses geradas ao longo das entrevistas e da compilação e análise dos resultados e foram analisadas as implicações para a prática de implementação de técnicas JIT, como forma de contribuição específica às empresas que estão envolvidas no complexo processo de implementação das técnicas JIT.

Finalizando, incluíram-se os Anexos e as Referências Bibliográficas. 


\section{Capítulo 2 - O Problema}

A aplicação de técnicas JIT no meio industrial é de importância significativa em âmbito mundial. No Brasil, o setor industrial ocupa lugar de destaque na composição do Produto Interno Bruto, o que por si só mostra a relevância do estudo. Em 2001, a indústria foi responsável por 35,8\% do PIB, sendo que apenas a indústria da transformação respondeu por 21,1\%, segundo dados do Instituto Brasileiro de Geografia e Estatística (IBGE, 2003).

Pretendeu-se, com esta pesquisa, evidenciar como os principais Fatores Críticos para a Implementação de técnicas JIT no ambiente industrial foram tratados nas empresas pesquisadas, destacando-se os principais problemas que ocorreram durante o processo.

\section{1 - Formulação da situação problema}

Existem relatos de implantação do sistema de produção JIT em forma de pesquisas, livros e estudos de caso. As empresas americanas começaram a adoção de técnicas JIT no início dos anos 80, entretanto, a preocupação era o quê implementar no aspecto puramente técnico da questão, sem ênfase explícita nos resultados. Mesmo no âmbito acadêmico não foram constatados estudos que abordassem a questão da implementação com foco mais estratégico naquela época. Somente no final dos anos 80 é que começam a surgir artigos voltados a analisar a melhor maneira de implementar, os resultados, principais problemas pelos quais passam as empresas que se lançam a este desafio e as estratégias que foram adotadas ao longo do processo. No Brasil, as publicações sobre o tema são ainda mais raras.

Com esta pesquisa, seria possível identificar problemas e soluções que são ao menos semelhantes, o que possibilitaria tratá-los com maior pertinência no instante de sua ocorrência nas empresas brasileiras. Para tanto, estes problemas mais comuns deveriam ser identificados de forma que, a partir da verificação de sua potencial ocorrência num processo de implementação em empresas brasileiras, pudessem gerar uma base de conhecimentos que permitisse sua minimização ou eliminação.

A revisão da literatura mostrou que existem fatores críticos no processo de implementação das técnicas JIT, ou seja, fatores importantes para a implementação, que devem ser cuidadosamente considerados neste processo.

\section{2 - Questão de pesquisa}

Existem vantagens, representadas por resultados quantificáveis, que as empresas que operam sob as técnicas da produção JIT podem obter (ver Item 3.2 - Resultados obtidos com 
a implementação de técnicas JIT). Portanto, seria de se esperar que, ao longo do tempo, mais e mais empresas industriais estivessem operando sob o regime da produção JIT. Entretanto, o que se nota empiricamente é que apenas algumas empresas empregam parte das técnicas de produção JIT, o que sugere que a sua implementação tem características próprias e mesmo problemas que precisam ser considerados para facilitar o processo de implementação das mesmas.

Esta pesquisa pretendeu verificar a seguinte questão:

Como foram tratados os Fatores Críticos para a Implementação das técnicas JIT nas empresas pesquisadas?

\section{3 - Definição conceitual e operacional}

Nesta pesquisa, entendeu-se como "processo de implementação" das técnicas JIT a etapa que se inicia com a identificação da necessidade da empresa de aplicar técnicas JIT até que as técnicas implementadas estejam operacionais e produzindo os resultados que delas se espera. Como não se pode definir, de antemão, quais os níveis de resultados que se pode esperar de cada técnica aplicada, durante a segunda fase da pesquisa de campo, uma das preocupações da pesquisa relacionou-se aos resultados obtidos na empresa com a implementação das técnicas, sem, no entanto, ser este o objetivo maior da pesquisa.

O período de tempo tomado como base para a pesquisa (1997 a 2000), foi definido como forma de obter uma maior probabilidade de encontrar as pessoas que trabalham ou trabalharam, de fato, com o processo de implementação das técnicas JIT na empresa, pretendendo-se assim garantir maior confiabilidade e validade para as respostas procuradas.

Entendeu-se como FCI, nesta pesquisa, fatores cuja consideração e tratamento são importantes para permitir que a implementação aconteça de forma que os resultados esperados dela tenham maior probabilidade de ser atingidos e que, por outro lado, quando ausentes ou desconsiderados, podem representar uma falha importante e representativa para o processo de implementação.

Quanto às técnicas JIT, nesta pesquisa analisou-se o processo de implementação das seguintes técnicas integrantes do JIT (enumeradas conforme revisão da literatura inclusa no Capítulo 3 - Fundamentação Teórica), cujas definições são mostradas abaixo: 
a) Redução de set up

Mileham et al (1999) definem set up como as atividades que envolvem a remoção das ferramentas e equipamentos em uso e sua substituição por outras ou ferramentas ou equipamentos para a realização de uma operação diferente, abrangendo todos os ajustes necessários para a nova operação.

Ainda segundo Mileham et al (1999) a redução do set up passa por analisar o uso de materiais, simplificação (reduzir o número de mecanismos), padronização, fixação, localização e ajuste, assim como manuseio.

Zhu e Meredith (1995) enfatizam que a redução do set up é ponto básico para atender ao ideal de produzir lotes unitários, ou ao menos reduzir o tamanho dos lotes processados sem impacto negativo no custo ou tempo de processo.

Leschke (1997) enfatiza que a redução do set up é fundamental para que a empresa atinja as metas de redução de custos, maior flexibilidade e maior velocidade de fluxo. Mostra também a distinção entre set up interno (aquele que demanda a parada do equipamento para que seja realizado) e o externo (que não depende da parada do equipamento para ser completado).

Nesta pesquisa, a redução de set up foi considerada como a busca por troca de ferramental dos equipamentos de forma mais rápida, visando possibilitar redução de lotes de fabricação sem aumento no tempo de máquinas paradas.

b) Kanban

Num sentido amplo, Im (1989) define Kanban como um sistema de controle de produção e estoque que utiliza um sinal visual. O Kanban literalmente significa "cartão", mas na sua aplicação prática pode ser encontrado em forma de contentores ou mesmo como um simples sinal eletrônico. Já Ohno (1988) coloca o Kanban com um dos pilares da produção JIT, e o define como uma etiqueta para o manuseio e garantia da produção JIT.

Nesta pesquisa, Kanban foi considerado como um instrumento de controle visual da produção por meio do uso de cartões ou meio eletrônico que se preste ao mesmo fim.

c) Células de Produção

Zhu e Meredith (1995) definem célula de fabricação como o agrupamento de máquinas que executam diferentes atividades em um local que chamam de "célula de trabalho" de forma que possam executar uma série de atividades reduzindo o volume de 
movimentação de materiais e estoques em processo. Manoochehri (1988) frisa que a formação de uma célula envolve agrupar as peças a serem produzidas numa "família de peças" baseando-se na similaridade das operações requeridas pelo processo. Desta forma, uma célula é um agrupamento de máquinas com diferentes funções voltadas a produzir uma família de peças.

d) Redução de lote de fabricação

Trata da diminuição do lote de fabricação tendo como meta o lote unitário de produção. Segundo Ohno (1988), a redução do lote de fabricação é condição básica para o nivelamento da produção.

e) Melhoria contínua da qualidade (kaizen)

Também originado do japonês, kaizen significa busca constante por melhorias em todas as atividades produtivas. Estas melhorias têm caráter incremental e constante, ou seja, ocorrem gradualmente, ao contrário das inovações, que promovem alterações radicais nos processos. Ohno (1988) faz uma analogia para explicar a melhoria contínua "olhando a linha do tempo" entre a colocação do pedido pelo cliente e o recebimento pelo atendimento a este pedido. Realizar melhoria contínua consiste em reduzir este espaço, eliminando todas as atividades que representem desperdícios.

f) Manutenção preventiva

Raouf (1994) define manutenção preventiva como uma atividade que opera em paralelo com a produção para assegurar que os equipamentos de produção e os itens de apoio estejam em boas condições de uso e segurança para entrar em operação. No caso das técnicas JIT, a manutenção preventiva assume papel especial devido ao fato de os estoques serem reduzidos, fazendo com que qualquer parada de máquina possa ser um problema crítico para o processo como um todo.

g) Solução de problemas

Inclui a formalização de uma equipe para identificação das causas do problema e uso de métodos de solução de problemas. Algumas empresas empregam uma técnica denominada "ci nco por quês".

h) Plano de Produção Nivelado

Estabelecimento de um horizonte de planejamento em que o Plano de Produção deve permanecer estável para que se possa haver o "nivelamento" da produção num determinado 
patamar. Para Ohno (1988), a flutuação nos níveis de quantidade de um processo produtivo são fontes de desperdício, pois o sistema deve sempre estar preparado para atender um "pico" de demanda. Portanto, reduzir desperdício pressupõe minimizar as flutuações de demanda dentro do processo produtivo.

i) Círculos de Controle de Qualidade

Equipes multifuncionais de trabalhadores que se reúnem regularmente para identificar, resolver e, às vezes, implementar soluções de problemas relacionados ao processo produtivo. Conforme Dubrin (1998), um grupo de CCQ envolve de 8 a 10 pessoas, que se encontram uma vez por mês por cerca de uma hora, durante as horas normais de trabalho. No Brasil, os grupos de CCQ receberam ampla atenção na década de 80.

j) Controle estatístico de processo

Uso de conceitos estatísticos para monitoramento do processo produtivo. Está relacionado ao monitoramento da qualidade enquanto o produto está sendo produzido ou o serviço está sendo prestado (Davis, Aquilano e Chase, 2001: 154).

\section{k) Cinco S (housekeeping)}

Importância dos conceitos de organização do local de trabalho. Organizar, limpar, livrar-se do que não tem utilidade, padronizar e manter o local de trabalho.

1) Fornecedores únicos

Desenvolvimento de uma política de relacionamento com fornecedores visando a criação de uma parceria na qual o preço não seja a maior variável considerada para a tomada de decisões, com o estabelecimento de relações de longo prazo baseadas em confiança recíproca. A redução do número de fornecedores tem estrita correlação com a adoção de técnicas de produção que serão analisadas a seguir. Estudos mostram que o desenvolvimento de parcerias com fornecedores traz resultados operacionais expressivos, tal como indicado em um estudo de Arkader (1999), realizado na cadeia produtiva de montadoras de automóveis. Segundo as montadoras, "estaria havendo uma busca de parceria e melhoria de relacionamentos", "áspectos de avanço seriam quanto a atitudes de colaboração e apoio técnico", "busca de solução conjunta de pr oblemas"e "critérios para seleção de fornecedores, que não mais se limitariam a questões de preço”. Estes aspectos melhoram as condições de relacionamento e possibilitam que ambas as partes tenham resultados positivos em seu relacionamento. 


\section{m) Controle Visual (Andon)}

Dispositivo (um display ou lâmpada) que auxilia na identificação e comunicação visual do andamento do processo produtivo. Na Toyota, baseia-se nas cores verde (operação normal), amarela (ajustes no processo) e vermelha (problemas no processo), conforme Ohno (1988).

\section{4 - Objetivos da pesquisa}

Esta pesquisa teve por principal objetivo identificar como foram tratados os Fatores Críticos para a Implementação (FCI) das técnicas JIT e os problemas enfrentados pelas empresas brasileiras pesquisadas, que já implementaram ou estão implementando técnicas de produção JIT. A partir da análise dos FCI e suas inter-relações, foram propostas hipóteses, sugeridas implicações para a prática e temas para estudos posteriores.

\section{5 - Justificativa do estudo}

Supondo que o uso de técnicas JIT possa ser entendido como uma filosofia de manufatura, cabe então aos responsáveis por sua implementação entender a lógica do sistema de produção que lhe serviu de base. Não basta aceitar passivamente aquilo que "deu certo"em outros lugares e em outras circunstâncias, mas entender por que apresentou resultados positivos, quais os princípios e técnicas envolvidas e como poderiam ser utilizados para resolver problemas concretos do sistema produtivo.

As empresas industriais no Brasil ainda representam uma parcela significativa da potencialidade do Produto Interno Bruto, o que significa dizer que as melhorias que forem conquistadas neste segmento terão forte impacto no desenvolvimento do país como um todo.

Portanto a pesquisa justificou-se por pretender contribuir com o melhor entendimento sobre o processo de implementação das técnicas de produção JIT.

No âmbito acadêmico brasileiro foi encontrada apenas uma pesquisa voltada à implementação das técnicas JIT, desenvolvida por Barcellos (1991), que propôs um modelo conceitual para a sua implementação, considerando os seguintes fatores:

a) Gerenciais: envolvendo a Cultura da Empresa, a Motivação dos Funcionários, o Treinamento/Recrutamento e a Política de Implantação;

b) Ambientais: Cultura e Mercado Fornecedor; 
c) Estruturais: o Sistema Técnico, o Sistema de Informação e a Especialização da Fábrica.

Desta forma, esta pesquisa seria uma contribuição adicional ao acervo acadêmico nesta área.

Já no âmbito mundial, foram identificados 125 artigos especificamente voltados à problemática da implementação de técnicas JIT, que serviram de base de comparação com a realidade das empresas a serem pesquisadas.

Estes artigos, cada qual realizado sob condições específicas, ora envolvendo surveys, estudos de caso ou revisões de literatura, chegam a conclusões diversas e até conflitantes entre si, o que não chega a ser um problema, dada a característica contingencial que se constata na implementação de técnicas JIT, mas que suscita a necessidade de o tema ser tratado à luz das condições operacionais e gerenciais a que estão sujeitas as empresas que atuam no Brasil. 


\section{Capítulo 3 - Fundamentação Teórica}

O desenvolvimento da Fundamentação Teórica sobre o tema teve como principal referencial a realização de uma revisão bibliográfica na qual se buscou verificar quais os principais resultados obtidos pelas empresas que implementam técnicas JIT em seus processos produtivos. Alguns desses resultados foram descritos de forma específica e com detalhes de mensuração, entretanto, a maioria deles é apresentada de forma genérica. Apesar deste fato, há fortes indícios de que a implementação de técnicas JIT traz resultados positivos às empresas, muito embora, vários problemas possam ser identificados nos processos de implementação, os quais podem conduzir à expectativa de haver uma série de fatores que poderiam condicionar efetivos resultados da implementação das técnicas JIT, fatores estes que nesta pesquisa foram chamados de Fatores Críticos para a Implementação (FCI) das técnicas JIT.

Foi possível também identificar as técnicas JIT mais aplicadas, com base nos artigos estudados.

A análise da literatura sobre o assunto mostrou que a década de 90 foi a mais profusa na produção de publicações sobre as técnicas JIT. O site <http://www.umi.com>, que contém a base de dados ProQuest, apresenta cerca de 1300 artigos contendo JIT no título (cerca de 400 publicados até 1989, por volta de 900 publicados entre 1990 e 1999 e 46 publicados no ano 2000). Apesar desta quantidade de publicações sobre técnicas JIT, menos de $10 \%$ está voltada a análise de uma importante etapa da adoção das técnicas JIT, a Implementação, que, pela complexidade que representa, mostra-se ainda hoje como um assunto ainda passível de estudos.

Caso o leitor já tenha conhecimentos básicos sobre o tema, poderá abster-se da leitura do sub item 3.1 e partir para o sub item 3.2.

\section{1 - O conceito de JIT}

Aos leitores menos envolvidos com o tema JIT recomenda-se a leitura a seguir que mostra a evolução do conceito ao longo do tempo, desde a sua criação nas empresas da Toyota japonesa até o enfoque mais contemporâneo, assim como a definição de JIT e seu funcionamento, além do seu importante papel como estimulador de mudança na organização. 


\subsection{1 - Evolução da Produção JIT}

A evolução do conceito de produção JIT confunde-se com a própria evolução do Sistema de Produção da Toyota (SPT), fabricante japonesa de automóveis. Na verdade, a Toyota vem desenvolvendo, desde a década de 40, uma série de práticas bem-sucedidas que possibilitaram à empresa destacar-se mundialmente.

Nas palavras do próprio Ohno (1988), o problema principal da Toyota, no pós-guerra, era 'Como cortar custos e, ao mesmo tempo, produzir pequenas quantidades de muitos tipos de carros?". O modelo Fordista de produção não era adequado às condições operacionais do Japão.

Conforme Ohno (1988), o SPT fundamenta-se em dois "pilares principais": o sistema Kanban e a autonomação. É válido ressaltar que outros pontos também são destacados como importantes pelo autor, tais como: a busca incessante pela eliminação de desperdícios, o uso de técnicas de manutenção preventiva, a habilidade individual do trabalhador, o trabalho em equipe, a nivelação da produção, a preparação de máquinas, entre outros.

O desenvolvimento do conceito de autonomação (que significa transferir a inteligência humana para a máquina, ou seja, criar um dispositivo que pare a máquina assim que um problema ocorra, evitando, desta maneira, que produção com defeitos abranja um lote grande de produtos) na Toyota começa em 1945, porém foi desenvolvido com base na experiência de Toyoda Sakichi com a fábrica de teares auto-ativados. Em 1950, um andon (quadro indicador de parada de linha) é instalado na linha de montagem de motores. Em 1955, outro sistema é instalado na linha de montagem da fábrica principal. Em 1961, chega a vez da fábrica de Moromachi. Um ano depois, o sistema baka-yoke (controle autônomo de prevenção de defeitos) é instalado. Em 1963, o sistema é adotado na seleção de peças e em 1966 abrange toda uma linha de montagem na fábrica de Kamigõ. Em 1971 está totalmente implementado.

Já o sistema de Kanban (base do sistema de informação da produção no STP, representado usualmente por um cartão contendo dados sobre o item a ser produzido) começa a ser delineado em 1948 com a idéia de retirada de peças pelo processo subseqüente (contra corrente). Em 1949 são abolidos os depósitos intermediários e em 1953 o sistema de supermercado é implementado para a fábrica principal. Em 1961, o Kanban "caixa" é implementado, mas fracassa e apenas em 1965 o sistema é considerado implementado em toda a empresa, incluindo as afiliadas. 'Embora pareça ser muito tempo, penso que foi natural porque estávamos introduzindo conceitos completamente novos”(Ohno, 1988: 53). 
A partir de então, 1965, sendo copiada por outras empresas japonesas, as técnicas JIT passaram a dominar o interesse das empresas do Ocidente no final da década de 70 e início da década de 80, quando as vantagens competitivas, como menor custo e maior qualidade que o uso de técnicas JIT proporcionavam, começaram a ser sentidas no ambiente internacional.

Ohno (1988), continua mostrando que as técnicas JIT foram tomando as formas atuais gradualmente. Afirmações sobre outras técnicas comprovam: o tempo de set up (preparação de máquina), que, entre 1945 e 1955 era de duas a três horas evolui para três minutos em 1971; a flexibilidade da mão-de-obra (capacidade de um funcionário operar mais de uma máquina), que evolui de duas máquinas em layout tipo 'L" ou em paralelo em 1947, passando pelo layout em "ferradura" ou retangular em 1950, para operações em multiprocesso em células de produção em 1963.

Conforme se pode apreender das declarações do próprio Ohno, a implementação de técnicas JIT não é um processo simples e rápido, a despeito do fato de que as técnicas possam ser consideradas simples. Na maioria dos casos mostrados, o tempo de implementação estende-se por mais de 10 anos, e em algumas situações, por mais de 20 anos.

Entretanto, é importante ressaltar dois aspectos: o primeiro é que a implementação de técnicas JIT na Toyota aconteceu de forma simultânea, algumas levando mais ou menos tempo que outras e o segundo, que existe uma relação de interdependência entre as diversas técnicas que faz com que a implementação se torne mais complexa e gradual.

\subsection{2 - Definição da Produção JIT}

A definição de JIT tem sido um desafio propriamente dito desde sua introdução, e tem recebido as mais diversas abordagens. Ohno (1988: 4) a define como absoluta eliminação de perdas. O primeiro artigo abordando a produção JIT nos EUA, escrito por Sugimori, Kusunoki e Uchikawa (1977), traz a definição do JIT como sendo "um método de organização da produção". Esta definição mostra-se hoje bastante simplista.

Por sua vez, o dicionário da APICS - American Production and Inventory Control Society - define JIT como "uma filosofia de manufatura baseada na planejada eliminação de todas as perdas e na contínua melhoria da produtividade". Esta definição, mais "encorpada", usa o termo filosofia de manufatura, ou seja, uma abordagem quase que utópica. A incorporação da palavra "filosofia", que conforme Aranha e Martins (1983: 72) significa "ámor à verdade", coloca esta definição de forma muito mais abrangente e próxima à realidade da complexidade dos fatos. Também quando analisado o princípio pregado pelo 
próprio Ohno - busca incessante à origem dos problemas - o termo filosofia se adapta como o mais adequado.

Uma análise das definições apresentadas em 21 artigos e livros sobre JIT no período de 1988 a 1999 mostrou que a maioria dos autores (13 deles) inclui o elemento Redução de Perdas em suas definições. Outro elemento que aparece em cinco dos autores é a Melhoria da Qualidade/Produtividade. Os elementos Excelência na Manufatura, Foco na Adição de Valor e Prover Lugar Certo para Materiais e demais Recursos aparecem em quatro dos autores pesquisados.

Os demais elementos presentes nas definições estudadas são: Redução de Custos, Redução de Estoques, Redução de Ineficiência, Redução de Lead time, Aumento de Giro de Estoques, Uso de Células de Produção, Ênfase na Qualidade de Trabalhadores, Materiais e Produtos, Focalização das Atividades da Fábrica, Manutenção Preventiva, Resposta ao Consumidor, Simplificação e Solução de Problemas.

A preocupação com a definição do JIT pode ser analisada também num artigo desenvolvido por Vokurka e Davis (1996), que cita uma série de definições encontradas em artigos publicados entre 1987 e 1994, dentre as quais destacam-se:

- $\quad$ Um método (Sugimori, 1977).

- $\quad$ Um conceito (Schonberger, 1982).

- $\quad$ Uma meta (Hall, 1983).

- $\quad$ Uma crença (Taylor, 1983).

- $\quad$ Uma filosofia (Stasey, 1990).

- $\quad$ Uma estratégia (Robinson, 1990).

- $\quad$ Um programa (Harmon e Peterson, 1990).

- $\quad$ Um processo (Golhar e Stamm, 1991).

- $\quad$ Um estado mental (Krajewsky e Ritzman, 1992).

- $\quad$ Uma abordagem (Giunipero e Law, 1994).

- Um sistema (Gaither, 1994).

O que pode ser percebido é que, ao longo do tempo, a definição de JIT foi ganhando em escopo, passando de um "método" em 1977 para um "sistema” em 1994, transitando por 
"crença" e, finalmente, "filosofia". Quanto à ênfase da definição, evoluiu de uma simples função da manufatura (um método ou meta) para definições que englobam vários setores da manufatura com também de serviços, chegando até aos limites externos da empresa, quando focaliza um sistema envolvendo a relação entre cliente e fornecedor.

As definições mais recentes, mostradas abaixo, confirmam esta percepção.

Toomey (1996: 159) define o JIT como uma "filosofia que busca atender ao máximo o consumidor enquanto melhora a qualidade e a produtividade". Frisa que o JIT pode ser também definido como: manufatura de classe mundial, manufatura de valor agregado, manufatura de melhorias contínuas, simplesmente o extremo uso do bom senso ou manufatura que faz o fornecedor arcar com os custos do estoque. Neste sentido, Arkader (1999), estudando o fornecimento enxuto na indústria automobilística brasileira, constata esta realidade e mostra relatos indicando que o "desenvolvimento de parcerias"é pura retórica.

Ritzman e Krajewski (1998: 735) chamam o sistema de produção JIT pelo nome de Produção Enxuta entre outros nomes.

Já Davis, Aquilano e Chase (2001: 407) fazem a distinção entre JIT e Produção Enxuta chamando esta de "JIT amplo" numa alusão à sua maior abra ngência.

Outro aspecto sobre a definição de JIT que pode ser ressaltado é o fato de que, ao longo do tempo, a definição passa a incorporar a figura do cliente e do resultado para a empresa quando utiliza elementos relacionados ao comportamento do consumidor e termos relativos à produtividade e agregação de valor.

Tomando como base o elemento Redução de perdas, que apareceu na maioria dos artigos consultados, nesta pesquisa foi assumida a definição do termo JIT como sendo "uma filosofia de gestão da produção baseada na Redução de Perdas pela aplicação de técnicas voltadas à Melhoria da Qualidade/Produtividade visando alcançar a Excelência na Manufatura".

\subsection{3 - Como funcionam e onde se aplicam as técnicas JIT}

Uma descrição sumária do funcionamento do JIT (que pode ser de leitura dispensável para aqueles que já dominam os principais conceitos da produção JIT), em seu estágio atual de desenvolvimento, poderia assumir a seguinte forma:

O JIT pressupõe que as máquinas e equipamentos estejam arranjados fisicamente de forma a facilitar ao máximo o fluxo de produção, levando à necessidade de se implementar o 
conceito de células de produção (cabe aqui ressaltar que o uso de células de produção não é aplicável a todos os tipos de processos produtivos). Esta técnica permite que o fluxo produtivo seja mais livre, que a comunicação seja mais fluída e compartilhada, que os lotes de produção sejam reduzidos, e, por conseqüência, que os estoques sejam reduzidos, o que, por sua vez, leva a redução nos custo de manuseio e manutenção de estoques, armazenagem, obsolescência, entre outros. Mas o uso de células de produção não é viável sem a redução do set up, pois sem isto haveria um grande consumo de capacidade instalada para modificar a preparação das máquinas e equipamentos. A redução do set up pode ser obtida por várias formas (alterações em processos, máquinas, ferramentas, projetos e treinamento). Numa célula de produção é normal que os operadores constituam um time ou uma equipe, com funções bem definidas e conhecidas por todos os membros. Na maioria das vezes "todos são capazes de fazer tudo" o que leva a uma necessidade maior de treinamento e melhora o moral da equipe (Helms, 1990).

Portanto, o uso de células de produção pressupõe a existência de multifuncionalidade, ou capacidade demonstrada pelos operadores de trabalhar nos mais variados equipamentos e exercer as mais diferentes funções no processo produtivo, que é resultado de um complexo de ações voltadas ora para a Educação ora para o Treinamento e Capacitação das pessoas. Algumas características do operador multifuncional aparecem quando ele recebe informações sobre a importância do Trabalho em Equipe e os resultados que isto pode trazer para ele próprio, para sua equipe de trabalho e para a empresa como um todo. Daí para a formação dos grupos de funcionários, chamados de Círculos de Controle da Qualidade (CCQ) em muitas empresas, é um passo quase que natural. Nestes grupos de CCQ as pessoas trabalham essencialmente em equipes e estas equipes existem para buscar soluções para problemas comuns encontrados no seu cotidiano no trabalho. A busca de soluções para os problemas fica facilitada na medida em que as pessoas e equipes são iniciadas em técnicas formais de Solução de Problemas, cujo aprimoramento e uso facilitam o surgimento de soluções que a princípio são apresentadas aos grupos e à empresa por meios formais ou informais. À medida que estas sugestões começam a tomar corpo em número e abrangência e que são implementadas e geram os resultados esperados, criam a base para que as Melhorias Contínuas (kaizen) ocorram de forma sistemática. É possível notar que as técnicas citadas estão muito mais voltadas a modificar o comportamento das pessoas em relação ao convívio pessoal no trabalho do que a capacitá-las a executar uma determinada tarefa. 
Mas não basta a mudança de comportamento. É necessário que algumas habilidades técnicas sejam desenvolvidas. Neste sentido aparece o Treinamento e Capacitação em técnicas específicas voltadas para o processo produtivo. A revisão da literatura possibilitou a identificação das principais técnicas, estando a Redução de set up (minimizar o tempo de troca de ferramentas e equipamentos do processo produtivo) entre as mais importantes pela sua interdependência com as demais. $\mathrm{O}$ uso de células de produção, que possibilita que o fluxo de produção seja mais lógico e contínuo denota a preocupação com a racionalização do espaço físico. O controle do fluxo produtivo por intermédio do Kanban possibilita que as informações sejam difundidas em todos os pontos do processo. Como a qualidade assume importância significativa num sistema em que os estoques são reduzidos, torna-se importante o uso do Controle Estatístico de Processo (CEP) visando que não ocorram defeitos ou que na sua incidência, sejam detectados imediatamente e suas causas descobertas e eliminadas. O papel da Manutenção Preventiva fica evidenciado na medida em que o uso das células de produção cria sistemas integrados nos quais o funcionamento efetivo dos equipamentos é importante para que não haja interrupções na produção por quebras nas máquinas e, quando isto ocorrer, que os reparos sejam rápidos e adequados. Como as células de produção representam uma mini fábrica, é importante que o ambiente de trabalho seja limpo, seguro e organizado, além de mantido assim pelos responsáveis por cada célula. Então se percebe a importância dos conceitos de housekeeping ou 5S. Para que o funcionamento da célula de produção seja aprimorado, o uso de ferramentas e processos padronizados é sempre interessante na medida em que facilita o set up, os programas de manutenção preventiva e o próprio treinamento dos operadores. Como o trabalho em células exige maior interação dos operadores com o trabalho, o uso de recursos visuais para a sinalização do trabalho passa a ter importância destacada aparecendo a necessidade de Controles Visuais ${ }^{1}$ para facilitar o monitoramento do processo. Apesar da flexibilidade conseguida com o uso de células de manufatura é importante que haja uma boa definição de Plano de Produção (se possível que sejam estáveis ou nivelados, ao menos dentro de um certo período) para que os resultados obtidos sejam melhores.

O envolvimento dos Fornecedores recebe um grande destaque na implementação de técnicas JIT, pois o relacionamento entre clientes e fornecedores passa a ser mais estreito, ou seja, a empresa deve passar a relacionar-se com um número menor de fornecedores, escolhidos pela sua capacidade em atender às necessidades da empresa em termos de

\footnotetext{
${ }^{1}$ O “andon”é um exemplo de controle visual, conforme Ohno (1988).
} 
qualidade e condições de entregas (lotes e prazos) e não simplesmente pelo preço. A capacidade técnica do fornecedor passa a ser fundamental e se esta capacidade for reconhecida em forma de Certificação, tanto melhor. Este estreitamento de relações possibilita que a busca pela Redução dos Lotes seja facilitada pelo próprio envolvimento que o fornecedor passa a ter com seu cliente.

Quanto à aplicação de técnicas JIT, em síntese, a maioria delas pode ser aplicada em qualquer tipo de sistema produtivo. Davis, Aquilano e Chase (2001: 74) destacam três tipos básicos de processos produtivos (Figura 1: Tipos de processos produtivos):

- $\quad$ Processo de Projeto: um processo orientado para a realização de um único produto. Neste tipo de processo produtivo o volume de produção geralmente é baixo (normalmente trata-se de produtos únicos em lotes de produção unitários). No entanto, a variedade é muito ampla, dado que cada projeto é específico para determinadas aplicações.

- $\quad$ Processo Intermitente: processo que produz produtos em pequenos lotes e uma grande variedade de produtos diferentes. Neste tipo de processo produtivo inclui-se a grande maioria dos produtos produzidos com certo grau de diferenciação, o que reduz a variedade e aumenta o volume de produção quando comparados ao Processo de Projeto.

- $\quad$ Processo de Fluxo em Linha: processo contínuo que produz grandes volumes e produtos altamente padronizados. Neste tipo de processo produtivo é que se encontra a maior parte dos produtos produzidos para o atendimento de demanda elevada.

Figura 1 - Tipos de processos produtivos

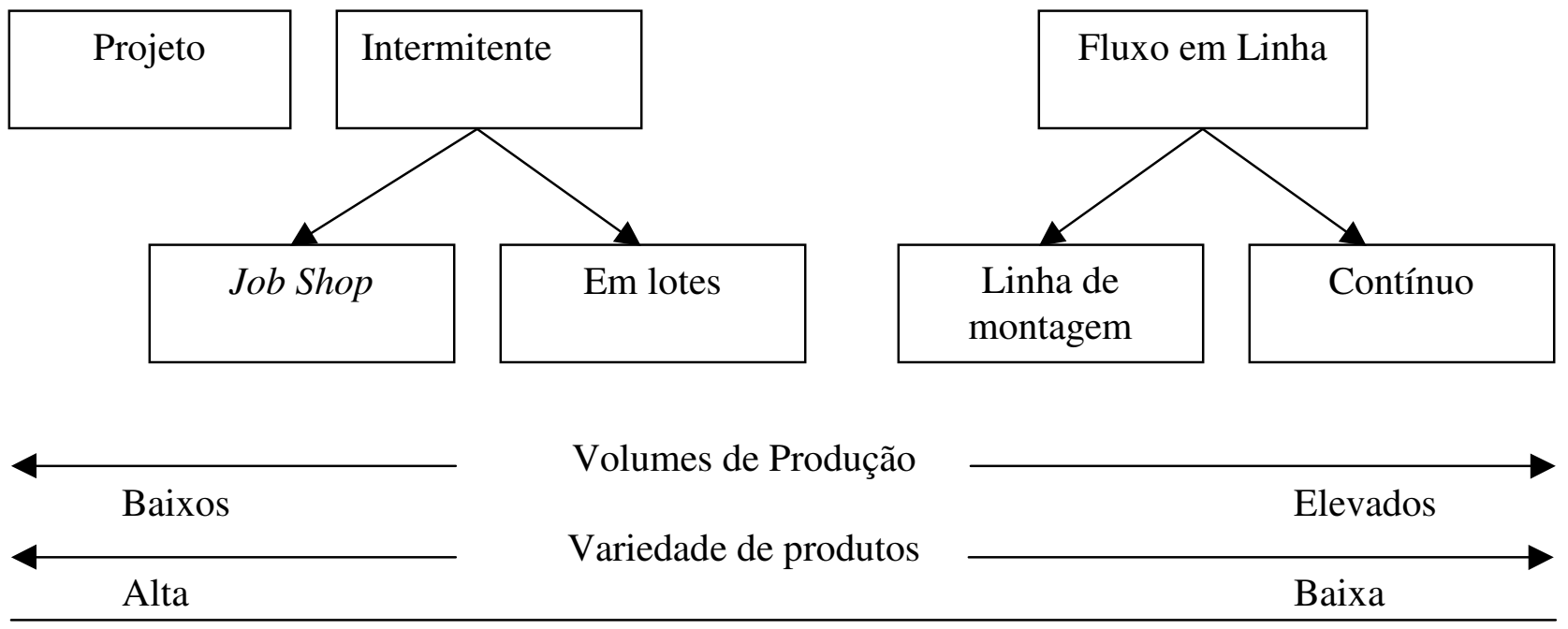


Também segundo Plossl (1987: 101), os benefícios da implementação de técnicas JIT podem ser sentidos em todos estes tipos de processos produtivos, entretanto, é mais comum encontrar as técnicas JIT difundidas em processos de Produção Intermitente (em lotes) e Fluxo em Linha, particularmente em linha de montagem. Esta mesma posição é defendida por Moras e Dieck (1992) que realizaram um amplo estudo sobre os resultados obtidos por empresas que aplicam técnicas JIT entre 1982 e 1990 e comprovaram resultados positivos encontrados nos mais diversos tipos de empresas e processos produtivos. White (1993) realizou um estudo com 1035 empresas americanas objetivando avaliar o uso de várias técnicas JIT e os resultados mostraram que, para os diferentes tipos de processos produtivos (por projeto, intermitente e fluxo em linha), as técnicas mais utilizadas foram sempre as mesmas, ou seja, Controle de Qualidade Total, Redução de set up, funcionários multiespecializados e compras JIT. Outros artigos mostram a aplicação de técnicas JIT na produção aeronáutica, que apresenta muitas das características de Produção de Projeto.

Portanto, as técnicas JIT são de aplicação a todos os tipos de processos produtivos, muito embora, nos processos intermitentes e de fluxo em linha os percentuais de aplicação encontrados sejam mais elevados.

Erroneamente se pensa no uso de técnicas JIT para a redução de estoques, mas isto é resultado de ações conjuntas e não o seu principal objetivo. Caso a redução de estoques não receba uma base de apoio, o serviço ao cliente perderá qualidade. Esta base de apoio vem do aprimoramento na qualidade do produto, do processo e do projeto, facilitado por treinamento e programas de melhorias contínuas.

\subsection{4 - O JIT como gerador de mudança organizacional}

O que pode levar uma empresa a mudar? Segundo Allen (1997) podem ocorrer pressões de competidores (gerando perda de mercado), aumento de custos operacionais ou reduções de margens de lucro. Estes são apenas alguns dos fatores mais comuns. Greiner (1967) já citava a velocidade das mudanças ambientais como condicionantes das necessidades de mudanças nas empresas. Cook (1995), 28 anos mais tarde, lembra que o passo das mudanças na sociedade moderna nunca esteve tão acelerado. A velocidade das mudanças tecnológicas afeta não só a vida cotidiana como também o trabalho. Tratando de implementação de técnicas JIT, Brown (2000) destaca que as mudanças são necessárias tanto no comportamento dos gerentes como no comportamento dos demais colaboradores, com implicações profundas no relacionamento entre fornecedores e clientes. Segundo Malley e Ray (1988), o impacto da implementação de técnicas JIT afeta tanto aspectos organizacionais 
como informacionais. Neste artigo, as alterações fundamentais na manufatura ocorrem em quatro funções básicas:

a) Na fábrica, por exemplo, com alterações de layout e set up, pela necessidade de se operar com lotes de produção menores. O uso de células de produção aumenta a flexibilidade e reduz espaços, mas requer operadores mais hábeis, ou seja, multifuncionais.

b) No controle de estoques, pois a redução do volume de estoques requer sistemas de controle menos sofisticados e torna evidentes os problemas, requerendo um melhor sistema de controle da qualidade e da manutenção preventiva.

c) No controle da qualidade, como o foco é zero defeitos, surge a necessidade de que os problemas sejam solucionados desde o início e que sejam de conhecimento de todos, o que pode ser facilitado pelo uso dos andon.

d) No sistema de suprimentos, na medida em que se pretende obter a quantidade certa no momento certo, os lotes de entregas devem ser reduzidos e a freqüência de entregas aumentada. Como os estoques são mínimos, os fornecedores devem ser confiáveis assim como a qualidade dos produtos adquiridos.

No que tange ao sistema de informações, este deve ser desenvolvido para atender ao projeto do layout da fábrica, calcular o lote ótimo de fabricação para diferentes produtos e processos, avaliar fornecedores e monitorar seu desempenho.

O artigo de Lummus e Duclos-Wilson (1992) confirma as colocações acima acrescentando os aspectos ligados ao sistema de manufatura e de medida de desempenho.

Giunipero e Law (1990), estudando uma centena de empresas industriais americanas de vários setores, também enfocam as principais mudanças organizacionais:

a) no conceito de compras e planejamento;

b) no conceito de administração de materiais;

c) no maior envolvimento do setor de suprimentos com a qualidade e

d) no planejamento de produção e controle de estoques.

Não são afetados apenas os aspectos organizacionais e informacionais, mas também as dimensões comportamentais passam por um processo de mudança profunda, conforme aponta Helms (1990). A implementação de técnicas JIT afeta o comportamento individual na medida em que os colaboradores devem estar aptos a formular questões sobre seu trabalho, receber e 
tratar informações; afeta também o relacionamento interpessoal, quando, ao receber e tratar informações, os colaboradores devem passá-las aos demais membros da equipe e ainda no comportamento do grupo, dado que um grupo de trabalho está envolvido diretamente com outros.

Todo este processo de mudança é complexo e Denton (1996) propõe quatro regras básicas e gerais para liderar um processo de mudança:

a) Saber exatamente o que se quer fazer, para evitar que uma mudança num ponto da organização produza resultados inesperados e negativos em outro ponto. No caso da introdução de técnicas JIT, esta visão de conjunto é fundamental devido à abrangência que as ações empreendidas no processo produtivo têm sobre outras áreas funcionais da empresa, notadamente nas áreas de finanças, contabilidade, marketing, distribuição, recursos humanos, engenharia de métodos e processos, entre outras.

b) Criar um ambiente de confiança e conseguir adesão da alta administração, para que a equipe de trabalho tenha um exemplo forte a seguir. A insegurança num ambiente em mudança é fato normal e aceitável. É importante que os envolvidos na mudança compreendam os motivos que geram as necessidades da mudança e percebam que o processo tem adesão dos principais líderes da empresa. Portanto, envolve aspectos ligados à comunicação.

c) Preparar discípulos e seguidores, como forma de multiplicar os esforços de mudança. A presença de profissionais que possam difundir as ondas da mudança por todos os níveis da organização vai fazer com que as dificuldades e resistências sejam reduzidas. Este ponto já está mais próximo ao treinamento em técnicas JIT.

d) Estabelecer medidas de desempenho para verificar se as mudanças estão ocorrendo, de fato. Estas medidas devem ser claras e objetivas de forma a serem entendidas por todos os envolvidos.

As propostas acima têm o objetivo de se fazer do processo de mudança um movimento da empresa toda e evitar que as mudanças sejam vistas como pequenas ações isoladas lideradas por um grupo de "visionários", na medida em que parte de uma visão geral dos objetivos, passa pela adesão da alta administração, congrega multiplicadores e mostra como os resultados serão medidos. 
Também no sentido de prover uma organização de estratégia para promover mudanças, Allen (1997) propõe que a mudança seja abordada em dois níveis diferentes, cada qual com suas ações específicas:

O primeiro trata da mudança no nível organizacional:

Abrir um canal de comunicação de duas vias (aproximar mais o pessoal de direção daqueles de operação); compartilhar a visão sobre a empresa (deixar mais claros os objetivos da empresa e o que se espera de cada um); considerar o elemento humano (empreender ações que coloquem as pessoas em destaque); desenvolver um processo decisório participativo (valorizar o trabalho em equipe); cuidar do "coração" antes da "mente" (perceber e trabalhar com a ansiedade); minimizar as incertezas (definir horizontes em que as pessoas possam enxergar-se); reestruturar responsabilidades e redefinir tarefas (redesenhar o trabalho com a participação dos envolvidos); simplificar o cotidiano (evitar reuniões desnecessárias); treinar mais intensamente os envolvidos (incluir no cotidiano); desenvolver a paciência (minimizar o imediatismo por resultados); mudar o que é preciso (ter noção clara de prioridades); ser honesto sobre as mudanças e reconhecer as contribuições.

O segundo aborda a mudança no nível pessoal:

Envolve habilidade de comunicação; visão pessoal (enxergar-se e valorizar-se no processo); estar aberto às mudanças, aproveitar as oportunidades; desenvolver senso de humor; tomar a direção; comprometer-se com a carreira; saber o que funciona de fato; ser seu próprio patrão e motivar-se.

As mudanças que devem ocorrer numa empresa, por conta da implementação de técnicas JIT, afetam as formas como as atividades normais da empresa são realizadas, gerando, com isso, a necessidade de que as pessoas estejam abertas a serem capacitadas, ora por treinamento específico, ora por mera exposição à nova realidade de sua empresa. Quanto mais rápida e eficiente for esta adaptação, tanto melhor será o resultado da implementação. Para que os potenciais problemas de uma implementação não causem impacto negativo, alguns Fatores Críticos devem ser conhecidos e administrados, o que pode, em tese, minimizar as dificuldades do processo.

Pela análise dos artigos citados pode-se depreender a complexidade das mudanças potencialmente causadas pela implementação de técnicas JIT (mudanças físicas no ambiente da empresas, mudanças nos sistemas e controles operacionais e mudanças no comportamento das pessoas que a compõe). Todas estas alterações obviamente não são conseguidas "por 
decreto", ou seja, não podem ser simplesmente impostas pela administração da empresa, sob pena de resultados inesperados ou, na melhor das hipóteses, resultados insuficientes.

Como modelo de facilitação do processo de implementação, os artigos concluem que a fixação clara de objetivos e a criação de um ambiente propício, considerando as pessoas envolvidas e suas limitações, técnicas e emocionais, podem conduzir a um nível maior de acertos na implementação das técnicas JIT.

\section{2 - Resultados obtidos com a implementação de técnicas JIT}

No levantamento bibliográfico efetuado (ver Anexo A - Estruturação da Pesquisa Bibliográfica) foram encontrados 55 artigos relatando direta ou indiretamente os resultados ou benefícios obtidos pelas empresas com a implementação de técnicas JIT, envolvendo pesquisas quantitativas e estudos de caso compreendendo o período de 1985 a 1999. A Figura 2, abaixo, ilustra a distribuição do número de artigos pesquisados e o ano de sua publicação.

Figura 2 - Artigos sobre resultados de implementação de técnicas JIT

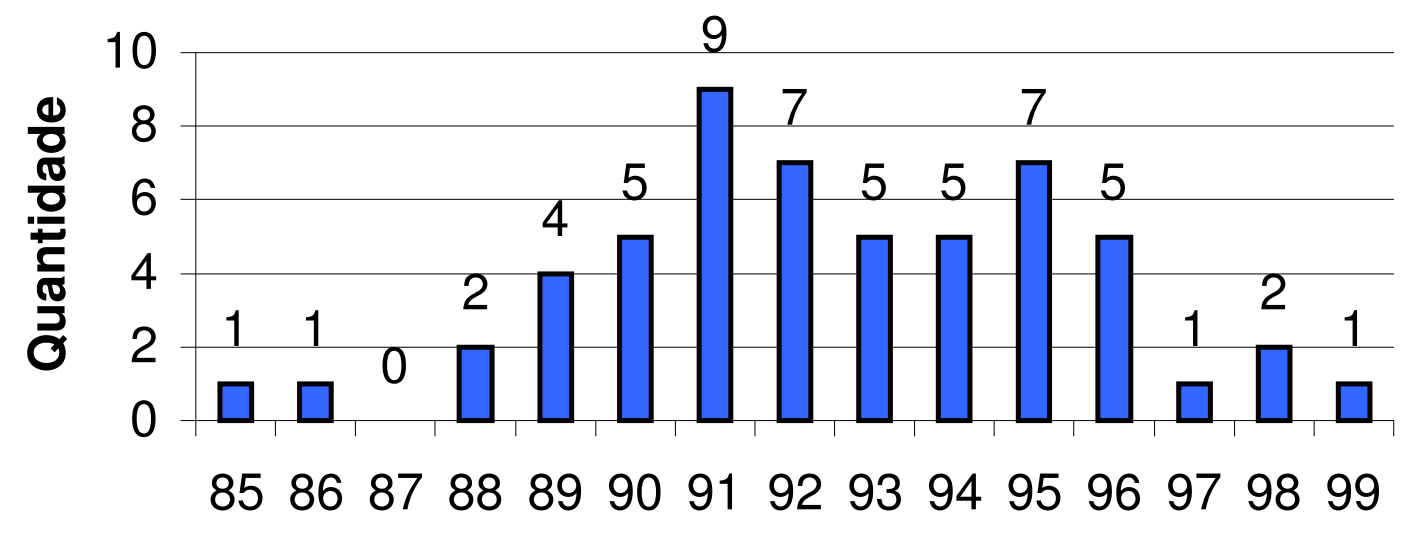

O período de 1989 a 1996 foi o que apresentou o maior número de publicações, dentre os artigos estudados que mostram resultados da implementação de técnicas JIT. A princípio foram relacionados 25 benefícios ou resultados diferentes advindos da implementação de técnicas JIT. Cada artigo apresenta em média cerca de 4 benefícios pela implementação de técnicas JIT, sendo os principais:

- $\quad$ Redução de estoques (e áreas de estocagem)/maior rotação (74,5\% dos artigos)

- $\quad$ Aumento da qualidade $(43,6 \%$ dos artigos) 
- $\quad$ Redução de lead time (41,8\% dos artigos)

- $\quad$ Redução de perdas e retrabalho (34,5\% dos artigos)

Na Tabela 1 - 'Resultados ou benefícios do uso de técnicas JIT', há uma relação dos 9 benefícios ou resultados verificados com mais freqüência após a implementação de técnicas JIT.

Tabela 1 - Resultados ou benefícios do uso de técnicas JIT

\begin{tabular}{l|c|c}
\hline \multicolumn{1}{c|}{ Resultados ou benefícios do JIT } & $\begin{array}{c}\text { Total } \\
\text { de artigos }\end{array}$ & $\begin{array}{c}\% \text { do total } \\
\text { de artigos }\end{array}$ \\
\hline Redução de estoques (e áreas de estocagem)/maior rotação & 41 & $74,5 \%$ \\
\hline Aumento da qualidade & 24 & $43,6 \%$ \\
\hline Redução de lead time (tempo desde a 1ª operação até a última) & 23 & $41,8 \%$ \\
\hline Redução de perdas e retrabalho & 19 & $34,5 \%$ \\
\hline Redução de custos & 16 & $29,1 \%$ \\
\hline Redução de lote de fabricação & 15 & $27,3 \%$ \\
\hline Redução de movimentação de materiais (fluxo) & 14 & $25,5 \%$ \\
\hline Aumento na produtividade & 13 & $23,6 \%$ \\
\hline Redução de paradas de máquinas & 11 & $20,0 \%$ \\
\hline
\end{tabular}

Não foi localizado nenhum artigo que apresentasse uma análise do custo/benefício da implementação das técnicas JIT, porém há uma quantidade de artigos que trazem resultados ou benefícios da implementação, o que poderia sugerir que a adoção de técnicas JIT seria benéfica para as empresas.

Muito embora não tenha sido o objetivo desta pesquisa analisar os resultados da implementação de técnicas JIT torna-se importante, para fins de pesquisas futuras, relacionar as fontes consultadas, detalhando a totalidade dos benefícios ou resultados obtidos dos artigos analisados, suprimindo-se aqueles com 4 ou menos citações visando preservar a demonstração dos artigos que mais se prestaram a mostrar os resultados.

Na Tabela 2 - 'Resultados ou benefícios do uso de técnicas JIT (em curto, médio e longo prazos)", foram separados os resultados considerados de "curto prazo", ou seja, que são mensuráveis e têm sua ocorrência verificada logo após a implementação das técnicas e os resultados de "médio/longo prazo". 
Tabela 2 - Resultados ou benefícios do uso de técnicas JIT (em curto, médio e longo prazos)

\begin{tabular}{|c|c|c|c|c|c|c|c|c|c|c|c|c|c|c|c|c|c|}
\hline Autores dos artigos & $\mathrm{a}$ & $\mathrm{b}$ & $\mathrm{C}$ & $\mathrm{d}$ & $\mathrm{E}$ & $f$ & $\mathrm{~g}$ & $\mathrm{~h}$ & $\mathrm{i}$ & $\mathrm{j}$ & $\mathrm{k}$ & $\mathrm{I}$ & $\mathrm{m}$ & $\mathrm{n}$ & 0 & $p$ & Total \\
\hline \multicolumn{18}{|l|}{$\frac{\text { Resultados ou benefícios do JIT }}{\text { Em curto prazo }}$} \\
\hline $\begin{array}{l}\text { Redução de estoques (e áreas de } \\
\text { estocagem)/maior rotação }\end{array}$ & $\mathrm{X}$ & $\mathrm{X}$ & $\mathrm{X}$ & $\mathrm{X}$ & $\mathrm{X}$ & $\mathrm{x}$ & $\mathrm{X}$ & $\mathrm{X}$ & & $\mathrm{X}$ & $\mathrm{X}$ & $\mathrm{X}$ & $\mathrm{X}$ & $\mathrm{X}$ & $\mathrm{X}$ & $\mathrm{X}$ & 41 \\
\hline Aumento da qualidade & & $\mathrm{X}$ & $\mathrm{X}$ & & $\mathrm{X}$ & $\mathrm{x}$ & $\mathrm{X}$ & $\bar{x}$ & $\mathrm{X}$ & $\mathrm{X}$ & $\mathrm{X}$ & & $\mathrm{X}$ & & & $x$ & 24 \\
\hline Redução de perdas e retrabalho & $\mathrm{X}$ & $\mathrm{X}$ & $\mathrm{X}$ & & $\mathrm{X}$ & $\mathrm{X}$ & & $\mathrm{X}$ & $\mathrm{X}$ & $\mathrm{X}$ & $\mathrm{X}$ & & $\mathrm{X}$ & $\mathrm{X}$ & $\mathrm{X}$ & $\mathrm{X}$ & 19 \\
\hline Redução de lote de fabricação & $\mathrm{X}$ & & & & $\mathrm{X}$ & & $\mathrm{X}$ & & & $\mathrm{X}$ & $\mathrm{X}$ & $\mathrm{X}$ & $\mathrm{X}$ & $\mathrm{X}$ & & & 15 \\
\hline $\begin{array}{l}\text { Redução da movimentação de materiais } \\
\text { (fluxo) }\end{array}$ & & $\mathrm{X}$ & $\mathrm{X}$ & & & $\mathrm{X}$ & & & $\mathrm{X}$ & $\mathrm{X}$ & & $\mathrm{X}$ & & $\mathrm{X}$ & $\mathrm{X}$ & & 14 \\
\hline \multirow[t]{2}{*}{ Redução de paradas de máquinas } & $\mathrm{X}$ & & & $\mathrm{X}$ & & & & $\mathrm{X}$ & $\mathrm{X}$ & & $\mathrm{X}$ & & $\mathrm{X}$ & $\mathrm{X}$ & & & 11 \\
\hline & & & & & & & & & & & & & & & & & \\
\hline \multicolumn{18}{|l|}{ Em médio e longo prazo } \\
\hline $\begin{array}{l}\text { Redução de lead time (tempo desde a } \\
\text { primeira operação até a última) }\end{array}$ & $\mathrm{X}$ & & & & $\mathrm{X}$ & $\mathrm{x}$ & $\mathrm{X}$ & & $\mathrm{X}$ & $\mathrm{X}$ & & $\mathrm{X}$ & $\mathrm{X}$ & $\mathrm{X}$ & $\mathrm{X}$ & $\mathrm{X}$ & 23 \\
\hline Redução de custos & & & $\mathrm{X}$ & $\mathrm{X}$ & & $\mathrm{X}$ & $\mathrm{X}$ & & $\bar{X}$ & & $\mathrm{X}$ & & $\mathrm{X}$ & & $\mathrm{X}$ & & 16 \\
\hline Aumento na produtividade & $\mathrm{X}$ & $\mathrm{X}$ & & $\mathrm{X}$ & & & & & & $\mathrm{X}$ & $\mathrm{X}$ & & $\mathrm{X}$ & & $\mathrm{X}$ & $\mathrm{X}$ & 13 \\
\hline Total de resultados apontados & 6 & 12 & 5 & 6 & 7 & 6 & 6 & 5 & 7 & 7 & 14 & 5 & 16 & 6 & 7 & 8 & \\
\hline
\end{tabular}

Autores dos artigos: a) AGGARWAL, Sumer C (1985); b) MALLEY, John C., RAY Ruthann. (1988); c) MANOOCHEHRI. G. H. (1988); d) INMAN, R. Anthony, MEHRA, Satish. (1989); e) CRAWFORD, Karlene M., COX, James F. (1991); f) INMAN, R. Anthony, MEHRA, Satish. (1991); g) LUMMUS, Rhonda, R., DUCLOS-WILSON, Leslie. (1992); h) INMAN, R. Anthony, BRANDON, Larry D. (1992); i) PAYNE, Terry E. (1993); j) HENDRICKS, James A. (1994); k) NORRIS, Daniel, SWANSON, Robert D., CHU, Yung-Lin. (1994); L) EPPS, Ruth W. (1995); m) HUM, Sin-Hoon, NG, Yong-Tjoon. (1995); n) KARLSSON, Christer, AHLSTROM, Pär. (1996); o) YASIN, Mahmoud M., WAFA, Marwan A. (1996); p) GARG, Dixit, KAUL, O.N., DESHMUKH, S.G. (1998).

Portanto, a interpretação da Tabela 2 permite concluir, por exemplo, que dentre os 55 artigos analisados, 41 deles citaram redução de estoques (e áreas de estocagem)/maior rotação, 24 citaram o aumento da qualidade, 23 a redução de lead time, e assim por diante, compondo os principais benefícios da implementação de técnicas JIT.

Cabe ressaltar que os resultados apresentados nos artigos podem trazer interpretações diversas face à terminologia utilizada em cada estudo, entretanto, quanto aos principais resultados não pairam dúvidas.

Quando se trata da mensuração dos resultados da implementação das técnicas JIT, os artigos localizados somam apenas nove. Hay (1988: 22-23), numa das publicações clássicas sobre técnicas JIT, mostra resultados quantificados (redução do lead time de 83 a 92\%; aumento da produtividade direta do trabalho entre 5 e $50 \%$; redução do custo da qualidade entre 26 e $63 \%$; redução de estoques de produtos comprados entre 35 e $73 \%$, de produtos em processo entre 70 e $89 \%$ e de produtos acabados em até $90 \%$; redução de set up entre 75 e $94 \%$ e redução de espaços entre 39 e 80\%). A Tabela 3 - 'Resultados ou benefícios (mensurados) do uso de técnicas JIT", mostra um resumo dos principais resultados disponibilizados nestes nove artigos. 
Tabela 3 - Resultados ou benefícios (mensurados) do uso de técnicas JIT

\begin{tabular}{|c|c|c|c|c|c|c|c|c|c|}
\hline Autores dos artigos & A & b & C & d & $\mathrm{e}$ & $f$ & g & $\mathrm{h}$ & i \\
\hline \multicolumn{10}{|l|}{$\begin{array}{l}\text { Resultados ou benefícios } \\
\text { do JIT - Mensurados }\end{array}$} \\
\hline & & & & & & & & & \\
\hline Aumento da produção & & & & & & & $\begin{array}{c}\text { de } 30 \text { a } \\
40 \%\end{array}$ & & \\
\hline Aumento da qualidade & & & 75 a $90 \%$ & & & & & & \\
\hline $\begin{array}{l}\text { Redução de estoques (maior } \\
\text { rotação) }\end{array}$ & $60 \%$ & 16 a $45 \%$ & $90 \%$ & $\begin{array}{c}\text { de } 16 \text { para } \\
30 \text { giros }\end{array}$ & $45 \%$ & $8 \%$ & $\begin{array}{c}\text { de } 15 \text { para } \\
31 \text { giros } \\
\end{array}$ & $\begin{array}{c}\text { de } 20 \text { para } \\
57 \text { giros } \\
\end{array}$ & $50 \%$ \\
\hline $\begin{array}{l}\text { Redução de áreas de } \\
\text { estocagem }\end{array}$ & $15 \%$ & & $50 \%$ & & $30 \%$ & & $50 \%$ & & \\
\hline Redução de Obsolescência & $60 \%$ & & & & & & & & \\
\hline \multicolumn{10}{|l|}{$\begin{array}{l}\text { Redução de paradas de } \\
\text { máquinas }\end{array}$} \\
\hline $\begin{array}{l}\text { Redução de perdas e } \\
\text { retrabalho }\end{array}$ & $90 \%$ & & & \begin{tabular}{|c|} 
de $2,5 \%$ \\
para $0,9 \%$ \\
\end{tabular} & & & & & \\
\hline Redução de set up & & & $75 \%$ & \begin{tabular}{|c|} 
de $1 \mathrm{~h}$ para \\
$1 \mathrm{~min}$
\end{tabular} & $90 \%$ & & para 15 min & & \\
\hline Aumento na produtividade & $30 \%$ & 50 a $80 \%$ & & & & & & & $100 \%$ \\
\hline Redução de custos & & & 10 a $30 \%$ & & & & & & \\
\hline $\begin{array}{l}\text { Redução de lead time (tempo } \\
\text { desde a primeira operação até } \\
\text { a última) }\end{array}$ & $\begin{array}{c}40 \text { para } 8 \\
\text { sem }\end{array}$ & 20 a $50 \%$ & $90 \%$ & \begin{tabular}{|c|} 
de 15 para \\
1,5 dias
\end{tabular} & $\begin{array}{c}6 \text { sem para } \\
1 \text { dia }\end{array}$ & & & \begin{tabular}{|c|}
4 sem para \\
1 a 3 dias
\end{tabular} & \\
\hline
\end{tabular}

Fica evidente, pela análise da Tabela 3, que a redução dos estoques é um benefício significativo, tendo sido apontado por $100 \%$ dos autores pesquisados. Nota-se que são benefícios expressivos em alguns casos $(\mathrm{c}, \mathrm{d}, \mathrm{h})$. Como conseqüência direta da redução de estoques, a redução de áreas de estocagem também aparece de forma significativa $(\mathrm{d}, \mathrm{g})$. $\mathrm{O}$ benefício da redução do set up, que por sua vez interfere diretamente na redução do lead time, também é citado pela maioria dos autores pesquisados.

O mais completo artigo sobre resultados obtidos com a implementação de técnicas JIT encontrado foi o artigo escrito por Moras e Dieck (1992), que analisaram 38 artigos sobre resultados de implementação de técnicas JIT publicados entre 1982 e 1990. Os resultados deste artigo são muito semelhantes aos resultados obtidos com a análise dos dados apresentados acima. Dentre os resultados quantificáveis, a redução de estoques também foi a mais freqüente, seguida pela redução de lead time, rotatividade de estoques e melhoria da qualidade.

O outro extremo dentre os artigos pesquisados engloba aqueles cujos resultados ou benefícios foram citados de forma genérica ou abrangente e sem quantificação, aliás, formando o grupo mais extenso de artigos. A despeito das citações serem genéricas, os resultados em geral, confirmam os mostrados na Tabela 1.

Dentre os artigos que apresentaram os resultados de forma genérica, alguns grupos podem ser destacados, pelo enfoque que os originaram: 


\subsection{1 - A aplicação de técnicas JIT em pequenas empresas}

A presença de implementação de técnicas JIT em pequenas empresas é grande e levou ao estudo mais específico, ora buscando os resultados, ora buscando os problemas.

A preocupação com o estudo das técnicas JIT aplicadas às pequenas empresas é expressa pelo artigo de Golhar, Stamm e Smith (1990), que estudaram 20 empresas americanas dos setores automotivo, metalúrgico e de alimentos. Os principais resultados são subdivididos por áreas:

a) Qualidade: 55\% alegam ter observado aumento da qualidade do produto acabado, expressa pela redução do volume de rejeições (tanto no produto acabado como no processo);

b) Estoques: observou-se redução de estoques de matéria-prima (80\% dos casos), de produtos em processo (58\% dos casos) e de produtos acabados (56\% dos casos). Entretanto, apenas $25 \%$ reportaram redução de set up;

c) Participação dos funcionários: 50\% alegaram haver aumento da participação dos funcionários nos vários departamentos funcionais da empresa, 95\% das empresas mostraram aumento no uso de funcionários multifuncionais, $75 \%$ mostrou que os funcionários passam a aceitar mais responsabilidades e $60 \%$ constatou aumento no uso de Círculos de Controle da Qualidade;

d) Relacionamento com fornecedores: 40\% mostraram um aumento da duração do contrato com os fornecedores, $75 \%$ constataram aumento na freqüência das entregas, $40 \%$ constataram melhora da qualidade da matéria prima e mais de 50\% alegaram ter reduzido o número de fornecedores;

e) Serviço ao cliente: $55 \%$ constataram redução no número de reclamações de clientes, $45 \%$ aumentaram a freqüência de entregas, 25\% aumentaram a duração de seus contratos com os clientes.

Os resultados acima são expressivos e importantes medidas de melhorias do desempenho das empresas estudadas, ainda que não mensurados. Mostram significativo número de empresas obtendo melhorias de resultados em áreas importantes ligadas à qualidade, ao volume de estoques, ao envolvimento dos funcionários e ao relacionamento com fornecedores e clientes. 
Sohal e Naylor (1992) estudaram uma pequena empresa australiana, fabricante de aparelhos de controle de temperatura de uso doméstico e industrial. Os resultados mostram que o nível de estoques foi reduzido em até $60 \%$ e foram removidos itens obsoletos ou danificados; reduziu-se o tempo de fluxo de forma que o estoque de matéria prima passou para apenas uma semana; o estoque em processo passou para apenas 40 horas; as horas paradas foram reduzidas e a linha de produção tornou-se mais flexível para atender às flutuações da demanda.

Os artigos acima ratificam melhorias advindas do uso de técnicas JIT, mesmo quando aplicadas em empresas de menor porte.

\subsection{2 - O impacto em Recursos Humanos}

O envolvimento do elemento humano é reconhecido como fundamental para a implementação das técnicas JIT e motivou a elaboração de uma série de artigos, como descrito a seguir:

Inman e Mehra (1989) estudaram os potenciais conflitos sindicais da implementação de técnicas JIT em 41 empresas industriais americanas (o artigo não menciona os ramos das empresas estudadas). A expectativa quanto aos resultados envolve melhoria na qualidade, na manutenção preventiva, na motivação e comprometimento dos funcionários e redução de estoques e set up. Os resultados obtidos confirmaram as expectativas e mostraram aumento no retorno sobre o investimento, redução no custo total, melhoria na qualidade dos serviços, na rotatividade dos estoques, redução na parada de máquinas, com aumento na utilização da mão-de-obra e equipamentos, além de redução do absenteísmo.

Golhar e Deshpande (1993) vinculam a obtenção de benefícios na implementação de técnicas JIT ao cuidado com o desenvolvimento de características muito específicas no pessoal da empresa, tais como a autodisciplina, a multifuncionalidade e o trabalho em equipe. A mesma conclusão é mostrada pelos mesmos autores em seu estudo em empresas canadenses de 1995. Portanto, para os autores, os resultados do uso de técnicas JIT dependem diretamente das ações da empresa no aspecto humano.

Im, Hartman e Bondi (1994) também concluíram que os benefícios do uso de técnicas JIT estão muito ligados a flexibilidade conseguida com equipes multifuncionais e pela redução do número de classificações de cargos.

Mas o uso de técnicas JIT não inclui apenas resultados positivos. Em seu estudo sobre os efeitos indesejáveis do uso de técnicas JIT, Inman e Brandon (1992) mostram alguns 
resultados preocupantes da implementação, atingindo diretamente a força de trabalho. Como exemplo pode ser citado o contínuo aumento do ritmo de trabalho e, como consequiência da redução de estoques, um constante estresse sobre os funcionários. A redução do set up também é fonte de mais estresse, pois a maior parte advém de trabalho em ritmo mais acelerado do que de mudanças nos projetos. Já a multifuncionalidade, alterando as tarefas constantemente, pode aumentar o índice de acidentes de trabalho pela falta de preparação adequada dos operários.

É importante ressaltar que predominam artigos destacando os aspectos positivos da implementação das técnicas JIT em relação aos que tratam dos aspectos negativos. Isto talvez se deva ao fato de que é muito mais fácil e conveniente expor histórias de sucesso do que as de fracasso.

\subsection{3 - O impacto sobre os fornecedores}

Outra grande área de interesse nos artigos sobre o uso de técnicas JIT envolve os fornecedores, aliás, apontados por Hay (1988: 120) como ponto fundamental para o pleno funcionamento das técnicas JIT na empresa.

Os fornecedores têm grande importância quando se trata de aplicação de técnicas JIT pelo fato de que a ocorrência de falhas de fornecimento, seja quanto a atrasos ou não conformidade dos produtos, leva a implicações negativas relevantes sobre a empresa. Por isso é que os fornecedores devem ser escolhidos com cuidadoso critério.

Vickery (1989) estudou as implicações do fornecimento internacional para a manufatura sob o regime de técnicas JIT e constatou que, a despeito da maior distância geográfica, que é notadamente um problema para o fornecimento JIT, a qualidade do fornecimento e a vantagem tecnológica (maior capacitação técnica que fornecedores internacionais podem apresentar) ainda ajudam a obter redução dos estoques. Esta mesma posição é defendida por Freeland (1991), que estudou as práticas de compras JIT nos EUA. Os principais resultados deste artigo mostram que a qualidade do fornecimento era o mais importante critério de escolha do fornecedor e a distância geográfica não era um critério fundamental, mas influía na seleção.

A política de fornecedor único fortalecendo o elo entre cliente e fornecedor também foi destacada por Romero (1991), que constata dificuldades no fornecimento JIT na medida em que os problemas do cliente são simplesmente transferidos para o fornecedor. 


\subsection{4 - O impacto sobre as medidas de desempenho}

Conforme citado anteriormente, os sistemas de medida de desempenho, assim como outros sistemas existentes na empresa, têm papel importante na implementação de técnicas JIT, tal como descrito a seguir:

Green, Amenkhienan e Johnson (1991), Hendricks (1994), Norris, Swanson e Chu (1994) e Upton (1998) estudaram os efeitos da implementação de técnicas JIT sobre as formas de medida de desempenho. Os artigos tratam da medida de desempenho de forma geral, ou seja, como podem ser medidos os resultados pelas diversas áreas da empresa (entrega ao cliente, qualidade, flexibilidade e produtividade) e apresentaram os benefícios esperados pelo uso de técnicas JIT de forma não quantificada, mas destacando a redução dos estoques, do lead time, dos espaços, do refugo e dos custos totais, melhoria da qualidade, da flexibilidade, da utilização de máquinas, da produtividade e da lucratividade, entre outras.

\subsection{5 - A implementação de técnicas JIT em diferentes países}

Foram localizados dez artigos publicados entre 1991 e 1998 que estudaram o uso de técnicas JIT em diversos países e mostraram os resultados encontrados ou esperados também de forma não quantificada.

Billesbach (1991) estudando a implementação em 68 empresas americanas de diversos setores conclui que o treinamento é de grande importância e White (1993) fazendo uma avaliação do uso de técnicas JIT nos EUA, mostra que as técnicas JIT têm sido adotadas por todos os tipos de empresas, embora predominando nas de grande porte e de processo de produção repetitivo; Clode (1993), estudando sistemas de controles de manufatura em empresas inglesas, conclui que as técnicas JIT têm sido usadas mais intensamente a partir de 1987, muito embora em conjunto com outras alternativas de gestão. Oliver, Delbridge e Lowe (1996), estudando 71 fábricas de componentes para a indústria automobilística, envolvendo oito países (França, Alemanha, Itália, Japão, México, Espanha, Inglaterra e Estados Unidos), mostram a franca superioridade japonesa no que tange à maior produtividade, menor taxa de defeitos e volume de estoques, menor taxa de entregas em atraso, maior uso de equipes no trabalho e menor taxa de absenteísmo; Lawrence e Lewis (1993) no México, estudando os obstáculos à implementação de técnicas JIT, citam as melhorias da qualidade, a redução de custos e a responsividade ao cliente como metas principais do uso de técnicas JIT; Sohal e Egglestone (1994) estudando a produção enxuta em 21 das 50 maiores empresas industriais da Austrália, concluem: $70 \%$ das empresas pesquisadas alegaram ter constatado melhoria da qualidade e do processo de produção, cerca de $60 \%$ mostraram resultados expressivos no 
controle de estoques e na satisfação do cliente e cerca de 50\% melhoraram sua posição financeira e aumentaram a fatia de mercado; Mazany (1995), na Nova Zelândia, estudando uma pequena empresa de confecção, mostra a redução do lead time e do estoque em processo como principais resultados; Hum e Ng (1995), em Singapura, estudaram 41 empresas de diversos setores industriais e concluíram que a redução dos estoques (geral e em processo) e do lead time, além da melhoria do controle da fábrica, a redução dos espaços de produção e melhoria da qualidade, foram observados em mais de 50\% das empresas pesquisadas; Kim e Takeda (1996), no Japão, analisaram 81 empresas de vários setores e mostraram uma comparação dos resultados obtidos por empresas usuárias de técnicas JIT, em que se destacam a redução do tamanho do lote de fabricação, do set up, dos estoques e melhorias da qualidade e da produtividade e Garg, Kaul e Deshmukh (1998) conduziram um estudo de caso na Índia, mostrando os seguintes resultados: redução de estoques, movimentação, lead time e espaço e aumento de produção por pessoa.

Os artigos mostrados acima mostram que, em diversos países, os resultados mais tangíveis do uso de técnicas JIT envolvem estoques, lead time, set up, qualidade, respostas aos clientes, chegando até mesmo a indicar melhorias no aspecto financeiro e mercadológico das empresas.

Outros artigos citam, além dos benefícios mais comuns, alguns bastante específicos como o artigo de Walleigh (1986), ressaltando que o uso de técnicas JIT expõe os problemas; Schmenner (1998), chamando a atenção para o fato de o uso de técnicas JIT possibilitar o aumento na velocidade das operações e frisando que o uso de técnicas JIT seria uma boa escolha para a "Política de Manufatura" da empresa; Norris, Swanson e Chu (1994), que destacam os aspectos humanos: o fortalecimento do espírito de equipe, a satisfação no trabalho e a motivação do trabalhador; Sohal (1996), mostrou melhorias no desenvolvimento de produtos; Germain, Dröge e Spears (1996), mostraram que o uso de técnicas JIT está associado com a formalização das medidas de desempenho adotadas pelas empresas e descentraliza as decisões de logística; Upton (1998) constatou que empresas usuárias de técnicas JIT apresentam resultados superiores no que diz respeito a inovações e moral da equipe; Storhagen (1995), ressaltou a melhoria de serviço ao cliente; Wafa e Yasin (1998) relacionam a melhoria da comunicação interna; Mazany (1995) descreve a mudança na forma de trabalho (de individual para em equipe) e nas habilidades individuais.

Todos estes relatos de estudos supra descritos têm o objetivo de deixar evidente a importância da adoção de técnicas JIT. 


\section{3 - Problemas encontrados na implementação de técnicas JIT}

Nesta pesquisa foi definido como um problema para a implementação de técnicas JIT toda situação ou circunstância, constatada por pesquisa empírica (surveys, estudos de caso ou relatos de situações reais), que causa dificuldades ou obstáculos à implementação de alguma técnica JIT.

Numa análise de 25 artigos que citam problemas na implementação de técnicas JIT, no período de 1985 a 1998, constatou-se que foram relatados 23 problemas diferentes, os quais foram classificados em cinco grupos principais, conforme sua pertinência e de acordo como foram expostos nos artigos analisados, por iniciativa deste autor: Falta de Apoio da Alta Administração, Adaptação dos Fornecedores, Fatores Geográficos/Logísticos, Fatores Organizacionais e Preparação dos Recursos Humanos.

A Tabela 4 - 'Principais problemas para a Implementação de técnicas JIT', mostra os principais artigos (aqueles dos quais se pôde extrair o maior número de citações de problemas), o ano da publicação e o total dos artigos que citaram o mesmo tipo de problema. A Falta de Apoio da Alta Administração (apareceu em 9 dos 25 artigos - 36\%), a Falta de Aceitação pelos Funcionários, a Sindicalização dos Trabalhadores, a Qualidade do Fornecimento, a Estrutura de Transporte e a Dispersão Geográfica aparecem com as principais fontes de problemas na implementação.

Tabela 4 - Principais problemas para a Implementação de técnicas JIT

\begin{tabular}{|c|c|c|c|c|c|c|c|c|c|c|}
\hline Autores dos artigos & $\mathbf{a}$ & $\mathbf{b}$ & c & d & $\mathbf{e}$ & 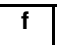 & $\mathbf{g}$ & $\mathbf{h}$ & Total & $\%$ de artigos \\
\hline Principais problemas constatados/ano da publicação do artigo & 85 & 90 & 90 & 93 & 94 & 95 & 98 & 98 & & \\
\hline \multicolumn{11}{|l|}{ Falta de Apoio da Alta Administração } \\
\hline Apoio da alta administração & & & $\mathrm{X}$ & $\mathrm{X}$ & & $\mathrm{X}$ & & & 9 & $36,0 \%$ \\
\hline Comunicação & & $\mathrm{X}$ & & & & & & $\mathrm{X}$ & 3 & $12,0 \%$ \\
\hline \multicolumn{11}{|l|}{ Falta de Preparação dos Recursos Humanos } \\
\hline Aceitação pelos funcionários (falta de informação/medo do desemprego) & $\mathrm{X}$ & $\mathrm{X}$ & & $\mathrm{X}$ & & $\mathrm{X}$ & & $\mathrm{X}$ & 7 & $28,0 \%$ \\
\hline Sindicalização do trabalhador & & & & $\mathrm{X}$ & & & $\mathrm{X}$ & & 7 & $28,0 \%$ \\
\hline \multicolumn{11}{|l|}{ Falta de Adaptação dos Fornecedores } \\
\hline Qualidade do fornecimento & $\mathrm{X}$ & $\mathrm{X}$ & $\mathrm{X}$ & & & $\mathrm{X}$ & & & 5 & $16,0 \%$ \\
\hline Incentivo aos fornecedores para usar técnicas JIT & & $\mathrm{X}$ & & $\mathrm{X}$ & & & & & 3 & $12,0 \%$ \\
\hline Pressão/força dos fornecedores & & $\mathrm{X}$ & $\mathrm{X}$ & & & & & & 3 & $12,0 \%$ \\
\hline Cooperação com empresas externas & & & & & $\mathrm{X}$ & & $\mathrm{X}$ & & 2 & $8,0 \%$ \\
\hline \multicolumn{11}{|l|}{ Problemas Geográficos/Logísticos } \\
\hline Estrutura de transporte ruim (logística) & & & $\mathrm{X}$ & $\mathrm{X}$ & $\mathrm{X}$ & & & $\mathrm{X}$ & 5 & $20,0 \%$ \\
\hline Dispersão geográfica/custos de transporte & $\mathrm{X}$ & & & & $\mathrm{X}$ & & & & 5 & $20,0 \%$ \\
\hline \multicolumn{11}{|l|}{ Problemas Organizacionais } \\
\hline Dificuldades de contabilização JIT & & $\mathrm{X}$ & & & & $\mathrm{X}$ & & & 2 & $8,0 \%$ \\
\hline Pobreza da previsão de demanda & & & & & & $\mathrm{X}$ & $\mathrm{X}$ & & 2 & $8,0 \%$ \\
\hline Alterações no sistema de estoques & & & & & $\mathrm{X}$ & & & & 2 & $8,0 \%$ \\
\hline
\end{tabular}


A seguir, o problema mais recorrente de cada grupo citado nos artigos estudados foi analisado, procurando mostrar a evolução do problema ao longo do tempo, como forma de ressaltar a sua importância.

\subsection{1 - Falta de Apoio da Alta Administração}

De forma geral, deve caber à Alta Administração apoiar as iniciativas de implementação de técnicas JIT não apenas na forma de fornecer os recursos necessários, mas também de integrar-se no trabalho evitando limitar-se à simples nomeação de um JIT Champion. Na verdade os colaboradores querem de fato ver seus superiores envolvidos no processo e a forma como a AA se comunica com seus colaboradores pode ser decisiva, segundo Ansari e Modarress (1990).

A preocupação com a falta de apoio da alta administração foi primeiramente apontada por Walleigh (1986), que enfatizou que uma empresa usuária de técnicas JIT expõe os problemas e que seus administradores devem estar dispostos a resolvê-los definitivamente pela busca e solução das causas destes problemas, sob pena de comprometerem a adequada implementação. Ohno (1988: 49) afirma que "o comprometimento e o forte apoio da gerência são essenciais à aplicação bem-sucedida”. Em 1990, Vora, Saraph e Petersen também mostraram que a falta de apoio da alta administração é problema, pois tira do pessoal de manufatura a sustentação para as ações corretivas que devem ser tomadas, o que é corroborado por Crawford e Cox (1991). Helms (1990), coloca que o apoio serve para dar legitimidade ao programa, ou seja, é através do apoio que a alta administração demonstra o quanto o uso de técnicas JIT é importante para a empresa. Por outro lado, a falta de apoio pode ocorrer por aversão ao risco pela alta administração. Esta é uma das conclusões do artigo de Kim e Schniederjans (1990). Lawrence e Lewis (1993) constataram também, no México, a falta de "int egração administrativa" como um forte obstáculo à implementação bem-sucedida de técnicas JIT (no caso do México, a maioria dos membros da Alta Administração não é nativa e vive no país por apenas alguns anos, chegando, em muitos casos, a falar muito pouco a língua espanhola). Em Singapura, por sua vez, Hum e Ng (1995) constataram que o apoio da alta administração foi um dos problemas mais importantes, segundo o resultado de sua pesquisa que envolveu 41 empresas, predominando as do setor eletro-eletrônico. Yasin e Wafa (1996) citam enfaticamente o problema da falta de apoio da alta administração. Também, em 1998, Yasin e Wafa mostram que a presunção da alta administração em achar que somente eles sabem o que é bom para a empresa enfraquece o comprometimento dos demais colaboradores. $\mathrm{O}$ pobre entendimento da gerência sobre o papel do trabalho em equipe 
foi um problema fundamental encontrado no estudo de caso de Sohal (1996) na Austrália. Para Garg, Kaul e Deshmukh (1998), a falta de comprometimento da média gerência no processo de implementação pode significar um "boicote" ao programa como um todo, conforme concluiu seu artigo sobre implementação de técnicas JIT em indústrias de tratores na Índia.

Pelo número de artigos que enfatizam a importância do apoio da alta administração, fica claro que este aspecto merece maior cuidado. Nota-se que a ênfase na importância do apoio da AA no processo de implementação de técnicas JIT é ratificada ao longo do tempo pelos mais diversos autores nos mais variados lugares do mundo.

\subsection{2 - Falta de Preparação dos Recursos Humanos}

Resistência a mudanças, medo da perda do emprego, falta de cooperação, presença de sindicalização e deficiência de comunicação são os principais problemas constatados nos artigos relacionados ao elemento humano na implementação de técnicas JIT.

Já em 1985, Aggarrwal chamou a atenção sobre o problema da resistência dos colaboradores no processo de implementação de técnicas JIT, apontando este fator como um dos responsáveis pelo fracasso de inúmeros processos. Planejar a transição para o uso de técnicas JIT é, na visão de Helms (1990), um fator importante que passa pela efetiva comunicação dos benefícios da mudança aos colaboradores no intuito de conseguir a sua adesão ao processo. O mesmo cuidado é recomendado por Ansari e Modarress (1990) que relacionam três motivos principais para a falta de cooperação: a) resistência a mudar antigos hábitos; b) medo da perda do emprego e c) aumento da pressão sobre os colaboradores (fazer certo da primeira vez e mais responsabilidade por resolver problemas). Keys (1991) e Lawrence e Lewis (1993) também mostram que o compromisso dos colaboradores é essencial. O problema da resistência parece aumentar na medida em que a idade dos colaboradores aumenta. Esta é a conclusão de Golhar e Deshpande (1993) num estudo de 34 empresas de vários setores industriais americanos. Mais da metade das empresas pesquisadas por Hum e Ng (1995) em Singapura também citaram o mesmo problema de resistência dos colaboradores. Sohal (1996), na Austrália e Garg, Kaul e Deshmukh (1998), na Índia, também constatam o mesmo problema.

Outro problema importante ligado aos Recursos Humanos é a sindicalização. O primeiro artigo localizado relatando o problema do convencimento das entidades sindicais sobre a importância do uso de técnicas JIT para as empresas e para os colaboradores foi o de 
Golhar, Stamm e Smith (1990), que estudaram a implementação de técnicas JIT em 20 pequenas empresas americanas com menos de 500 funcionários. Sevier (1992) ressalta a dificuldade de se promover a multifuncionalidade do pessoal em regimes sindicais muito rígidos quanto a descrição de tarefas dos colaboradores. No México, Lawrence e Lewis (1993) também constataram o forte movimento sindical como fator de dificuldade para a adoção do uso de técnicas JIT. Norris, Swanson e Chu (1994) aconselham que o sindicato dos trabalhadores seja envolvido no processo de implementação de técnicas JIT desde o início, visando prevenir problemas futuros. Esta posição é totalmente aceita por Dahlén, Ericsson e Fujii (1995) que citam a revisão das relações sindicais como o grande trunfo do sucesso do Japão na conversão para o uso de técnicas JIT. Kim e Takeda (1996), entretanto, colocam que a implementação de técnicas JIT pode ser bem-sucedida independentemente do grau de sindicalização de seus colaboradores. Mas esta afirmação só faz sentido se for considerado que a organização sindical japonesa é diferente da ocidental. No Japão os sindicatos são organizados "dentro" das empresas e, por conseqüência, têm menor poder de negociação do que a organização sindical ocidental.

\subsection{3 - Falta de Adaptação dos Fornecedores}

Transformar os fornecedores em parceiros, inseridos na cadeia de fornecimento é o grande desafio mostrado pelos artigos que tratam deste problema. Melhorias na comunicação e no relacionamento com fornecedores mostram-se como vitais para a implementação de técnicas JIT.

Walleigh (1986), estudando os problemas com os fornecedores, declara que na Hewlett-Packard houve um esforço empreendido no sentido de convencer os fornecedores a adotarem as técnicas JIT também para suas próprias fábricas, pela verificação dos resultados obtidos na HP. Helms (1990) desenvolve a idéia da importância da comunicação e os problemas que a falta dela com os fornecedores gera para a empresa que está implementando técnicas JIT. Já Romero (1991) e Wafa e Yasin (1998) enfatizam que a busca de cooperação dos fornecedores evita problemas na cadeia de fornecimento, pela difusão da idéia do "ganhaganha”, sem, no entanto, gerar um clima de pressão para a adoção de técnicas JIT pelos fornecedores. Para Ansari e Modarress (1990), e Muchnik, Shipley e Shane (1990) isto foi entendido como “relacionamento de longo prazo". Um alerta é dado por Shahabuddin (1992) no sentido de não se transferir aos fornecedores todo o ônus da adoção de técnicas JIT, ou seja, exigir como responsabilidade exclusiva do fornecedor a qualidade, quantidade e prazo de entrega. Isto pode se transformar num sério problema na medida em que o fornecedor não 
consiga desenvolver-se por si próprio a ponto de ser um fornecedor JIT. No caso do México, o artigo de Lawrence e Lewis (1993) concluiu que o maior obstáculo ao uso de técnicas JIT está na dependência de fornecedores externos e na fragilidade dos fornecedores locais. Karlsson e Norr (1994), e Epps (1995) mostram que o relacionamento entre fornecedor e cliente num ambiente JIT deve mudar de competição para colaboração.

Parece evidente que a difusão do uso de técnicas JIT entre os fornecedores e na cadeia de suprimento é importante para esclarecer as vantagens de se integrar ao fornecimento JIT, ou seja, que há benefícios para todos, começando pelos benefícios internos e estendendo-se ao longo do tempo pela maior utilização de contratos de longo prazo. Entretanto, a falta de capacitação técnica pode ser um empecilho importante, pois exclui automaticamente um fornecedor da cadeia produtiva.

\subsection{4 - Problemas Geográficos/Logísticos}

A distância física entre fornecedor e cliente já foi destacada por Ohno (1988) em seu relato sobre o Sistema de Produção da Toyota. Ohno mostrou que a implementação de JIT entre a Toyota e seus fornecedores mais distantes, mesmo no Japão, onde quaisquer localidades são relativamente próximas, foi mais demorada pelas incertezas impostas pela distância.

Uma pesquisa feita por Kim e Schniederjans (1990), envolvendo 122 empresas americanas dos ramos de máquinas, elétrico, computadores e transportes foi o primeiro artigo localizado onde se faz alusão ao problema da logística, ainda que de forma pouco conclusiva, simplesmente citando o problema da logística ineficiente. Da mesma forma, Lawrence e Lewis (1993) estudaram os obstáculos ao uso de técnicas JIT no México e concluíram que o item Fornecedores é basicamente importante e diretamente afetado pelo aspecto das distâncias geográficas que precisam ser vencidas pelos fornecedores de empresas mexicanas. A proximidade geográfica é apontada por Karlsson e Norr (1994) como item primordial no ambiente JIT pela sua implicação nos custos devido a redução nos lotes de entrega. Suas conclusões aparecem no estudo feito na Suécia, sobre a efetividade do uso de técnicas JIT. Não obstante o problema, sugerem que uma alternativa seria formar um centro de distribuição que atendesse simultaneamente a várias empresas, reduzindo os custos e tempos de entrega. Garg, Kaul e Deshmukh (1998) citam a falta de confiabilidade no sistema de transportes da Índia como um dos problemas para a implementação de técnicas JIT. 
O problema da distância geográfica acentua-se com a redução dos estoques pelas reduções nos lotes de fabricação e conseqüentemente com maior insegurança no resuprimento dos materiais.

\subsection{5 - Problemas Organizacionais}

Os problemas de ordem organizacional são apontados por Ansari e Modarress (1990), que indicam a dificuldade de se adaptar o sistema de contabilidade ao uso de técnicas JIT, visto que o sistema vigente está preparado para situações da produção em massa. A interface das práticas JIT com o sistema de manufatura vigente foi o principal problema apontado por Hum e Ng (1995) em seu estudo das práticas JIT em Singapura.

Problemas ocorrem também no sistema de informação, dado que uma empresa operando sob técnicas JIT precisa monitorar (e ser monitorada por) empresas externas de forma a sustentar posição conquistada no mercado, conforme Malley e Ray (1988), que afirmam ainda que outros problemas podem ocorrer no que tange ao papel do recurso humano dentro da empresa, pois cada vez mais o trabalho fica enriquecido, mudando as características do setor de 'Recursos Humanos".

Uma particularidade constatada nesta pesquisa foi a presença de problemas de caráter estrutural, ligados a aspectos externos à empresa, relatados por Silva (2001), e que estão mais diretamente ligados ao micro ambiente em que a empresa atua, representado pela oferta e demanda, além do tipo de concorrência predominante neste mercado. Problemas deste tipo não foram aventados nos artigos estudados sobre o processo de implementação.

Na segunda fase desta pesquisa (de estudo multicaso) foi analisada a ocorrência de cada um dos problemas citados, independentemente de sua freqüência de ocorrência, visando maior aprofundamento na questão. Também se buscou verificar a ocorrência de problemas diferentes destes relatados.

\section{4 - Fatores Críticos na Implementação (FCI) das técnicas JIT}

Entendeu-se como FCI, conforme já definido no capítulo 2, fatores cuja consideração e tratamento são importantes para permitir que a implementação aconteça de forma que os resultados esperados dela tenham maior probabilidade de ser atingidos e que, por outro lado, quando ausentes ou desconsiderados, podem representar uma falha importante e representativa para o processo de implementação. 
Nesta pesquisa, os FCI de técnicas JIT foram pesquisados tanto em artigos elaborados por autores considerados especialistas (praticantes), por autores responsáveis por pesquisas (na forma de surveys e cases) bem como em artigos voltados ao desenvolvimento de modelos sobre técnicas JIT.

No levantamento bibliográfico efetuado (ver Anexo A - Estruturação da Pesquisa Bibliográfica) foram encontrados 125 artigos contendo os termos "ímplementação" e " JIT" no título, relatando direta ou indiretamente os FCI. Sabe-se que a implementação de técnicas JIT no Ocidente deu-se mais acentuadamente a partir de fins da década de 70. A distribuição cronológica destes artigos mostra que os anos iniciais da década de 90 foram os de maior intensidade de publicações de artigos relacionados ao tema implementação. A figura 3 ilustra esta afirmação.

Figura 3 - Artigos publicados sobre implementação de técnicas JIT

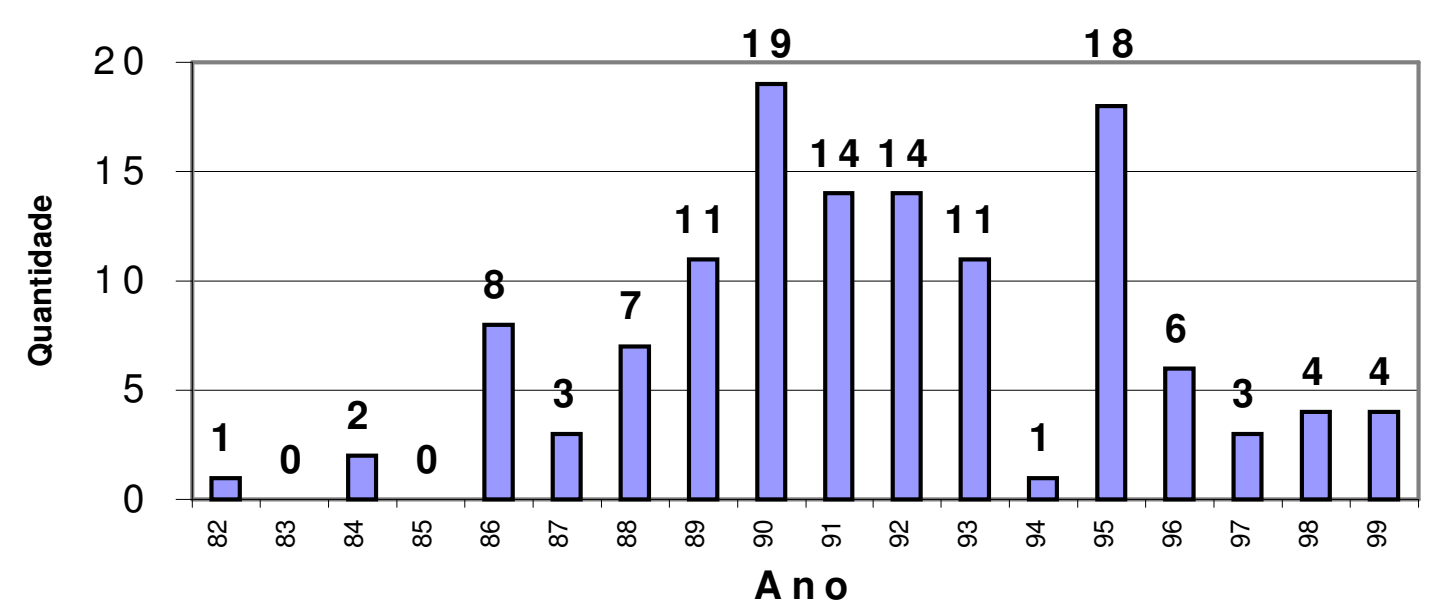

Dentre estes 125 artigos, 4 deles foram considerados seminais sobre o tema pois trataram especificamente sobre a identificação de fatores ou elementos que, quando presentes, tornam-se decisivos para a implementação de técnicas JIT.

O primeiro artigo foi conduzido por Mehra e Inman (1992), que constataram a existência de poucos estudos empíricos sobre FCI de técnicas JIT e realizaram uma pesquisa com 114 empresas americanas tradicionalmente reconhecidas como usuárias de técnicas JIT.

Os critérios usados pelos autores para julgar o nível de sucesso na implementação das técnicas JIT, muito embora sejam passíveis de críticas quanto à definiçãa da palavra sucesso, foram: redução de máquinas paradas, redução de estoques, redução de áreas de trabalho, aumento da qualidade, utilização de horas de trabalho, utilização de equipamentos e aumento 
na rotatividade de estoques. Quanto aos critérios de sucesso já se pode perceber que alguns termos são redundantes (redução de máquinas paradas e utilização dos equipamentos; redução de estoques e aumento da rotatividade de estoques), o que poderia levar a que o sucesso fosse medido por duas variáveis diferentes, entretanto correlacionadas entre si.

Os questionários foram respondidos por pessoas ligadas diretamente à implementação de técnicas JIT em suas empresas, o que permitiu a identificação de 19 elementos, os quais após a aplicação de uma análise fatorial foram reduzidos a quatro grandes fatores: Comprometimento da Alta Administração, Estratégias de Produção, Estratégias de Fornecedores e Estratégias de Educação.

Os resultados encontrados foram os seguintes:

a) Comprometimento da Alta Administração: não foi encontrada correlação entre este fator e o sucesso na implementação de técnicas JIT, o que foi considerado uma surpresa pelos próprios autores dado que inúmeros artigos publicados até então foram contraditos;

b) Estratégias de Produção: constatou-se forte correlação entre este fator e o sucesso na implementação das técnicas JIT;

c) Estratégias de Fornecedores: também mostrou forte correlação, e

d) Estratégias de Educação: surpreendentemente, também este fator não mostrou correlação com o sucesso na implementação das técnicas JIT, contrariando os artigos publicados até então.

Os autores finalizam sua análise mostrando que os fatores ligados à Estratégia de Produção e à Estratégia de Fornecedores são considerados fatores específicos ligados às técnicas JIT e que os fatores Comprometimento da Alta Administração e Educação são fatores mais genéricos, aplicáveis a quaisquer outros processos de implementação, e por isso mesmo, sendo considerados críticos por outros autores.

Pela estruturação da pesquisa no artigo de Mehra e Inman (1992), não foi possível uma análise da evolução da importância dos fatores ao longo do tempo e muito menos identificar o estágio do uso das técnicas JIT nas empresas pesquisadas e sua correlação com o sucesso obtido na implementação.

O artigo de Mehra e Inman (1992) foi utilizado nesta pesquisa como referência para classificar e hierarquizar os fatores depois de analisados os outros três artigos, quais sejam: Zhu e Meredith (1995), Ramarapu, Mehra e Frolick (1995) e Yasin e Wafa (1996). A escolha 
deste artigo se deve ao fato de ser o primeiro e mais completo artigo localizado com o intuito de confirmar empiricamente os elementos críticos para a implementação de técnicas JIT.

A classificação proposta por Mehra e Inman (1992), que engloba os fatores: Comprometimento da Administração, Estratégia de Produção JIT, Estratégia de Fornecedores JIT e Estratégia de Educação JIT, mostra-se bastante consistente com a apresentada por Hay (1988: 12), que buscou separar os elementos das técnicas JIT em elementos aplicáveis ao ocidente e os subdividiu em dois grupos: um grupo focalizado em elementos internos (envolvendo a filosofia JIT em si, a qualidade na fonte, a nivelação da produção, o uso de células de produção, o set up rápido e o Kanban) e o grupo focalizado nos elementos externos, especificamente no fornecimento JIT.

Já em outro artigo, Zhu e Meredith (1995), por seu lado, analisaram a produção de artigos sobre implementação de técnicas JIT publicados entre 1988 e 1992 em 15 journals profissionais, totalizando 42 artigos envolvendo surveys, estudos de caso e artigos puramente teóricos, produzidos por acadêmicos e praticantes. Os resultados permitiram a identificação de 24 elementos importantes na implementação de técnicas JIT, sendo que vários dos elementos listados coincidem com os elementos apontados por Mehra e Inman (1992), cujo artigo foi citado na bibliografia proposta pelos autores. Os principais elementos identificados foram: uso de Círculos de Controle da Qualidade, redução de set up, multifuncionalidade, certificação de fornecedores, uso de tecnologia de grupo, redução de lotes de fabricação e fornecimento, lead time do fornecedor, educação, relações com fornecedores, manutenção preventiva, estabilidade da programação, entre outros.

Constataram-se diferenças relevantes nas conclusões dos vários tipos de artigos estudados (surveys, cases ou discussões) e também entre as conclusões dos diversos tipos de autores (acadêmicos e praticantes) o que permitiu aos autores concluírem que existe uma ampla gama de pontos de vista sobre a implementação de técnicas JIT, o que a torna contingencial por natureza.

As principais contribuições deste artigo estão ligadas a ampliação do escopo proposto por Mehra e Inman, visto que mostram evidências de outros elementos importantes, que vêm a completar o artigo. Dentre estes elementos é possível destacar, no fator Apoio da Alta Administração o elemento comunicação (que apareceu no artigo de Zhu e Meredith entre os dez mais importantes) e a cooperação entre funcionários. Já no fator Fornecedor, o elemento relacionamento com fornecedores (o oitavo mais citado) enfatiza o aspecto comportamental entre fornecedores e clientes. No que tange ao fator Produção, surgem as maiores 
contribuições de aumento de escopo, pois é destacada a importância do nivelamento da produção, a flexibilidade do sistema produtivo e a simplificação da estrutura dos produtos. No aspecto dos fatores Organizacionais surge o incremento das alterações nos sistemas de estoques.

Deve aqui ser ressaltado que os novos elementos foram incorporados aos grupos de fatores já elencados por iniciativa do autor desta pesquisa.

Zhu e Meredith também não analisaram a evolução dos fatores ao longo do tempo.

Já o artigo de Ramarapu, Mehra e Frolick (1995), envolveu uma revisão de literatura abrangendo 105 artigos sobre implementação de técnicas JIT (65 artigos conceituais, 25 empíricos e 15 voltados a construção de modelos de simulação) publicados entre 1980 e 1993. Este artigo enumerou uma série de 28 elementos críticos para a implementação de técnicas JIT e mais uma vez o artigo de Mehra e Inman (1992) foi citado na bibliografia, sendo que houve coincidência da maioria dos elementos citados.

O artigo descreve cinco grandes fatores: eliminação de perdas, estratégia de produção, qualidade e melhorias, compromisso da alta administração e, finalizando, fornecedores. Conclui, pelo volume de vezes que cada elemento de cada fator foi citado na literatura, que os fatores eliminação de perdas e estratégia de produção são os mais importantes.

Este artigo, de Ramarapu, Mehra e Frolick, traz um novo aumento de escopo aos cinco fatores adotados como referência nesta pesquisa. No fator ligado à Educação e Treinamento, aparece o elemento melhoria contínua. Já no fator Fornecedor, surgem as maiores contribuições, pois foram citados elementos ligados à comunicação com fornecedores, 0

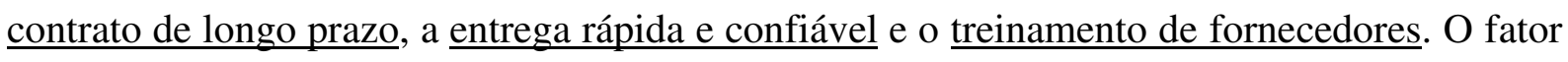
Produção também recebeu vários adendos, destacando-se os elementos ligados à $\underline{\text { automatização, }}, \underline{\mathbf{C E P}}$, qualidade e redução de perdas.

Mais uma vez, a natureza do artigo desenvolvido por Ramarapu, Mehra e Frolick não lhes permitiu analisar a evolução dos elementos ao longo do tempo, limitando-se apenas a registrar seu aparecimento na literatura.

Em 1996, Yasin e Wafa inicialmente visitaram 15 grandes empresas americanas usuárias de técnicas JIT em vários graus de sucesso (a forma de graduação do sucesso não foi definida no artigo). A partir destas visitas e com base na literatura sobre o tema, formularam uma pesquisa respondida por 130 empresas usuárias de técnicas JIT. O artigo identifica 4 fatores: entradas, processo, saídas e gerenciamento. 
No fator entradas, o principal aspecto está ligado à forma de previsão de demanda e concluiu que não apresenta correlação com o sucesso da implementação.

Quanto ao fator Processos, que analisa a extensão e o tipo de processo de automação e as modificações de layout, constatou-se parcial influência no sucesso da implementação de técnicas JIT, o uso de CIM (Computer Integrated Manufactuting) e das modificações de layout.

Já o fator Saídas, que engloba os métodos e sistemas de garantia da qualidade, não apresentou correlação significativa com o sucesso da implementação das técnicas JIT.

Por seu lado, o fator Gerenciamento mostrou forte correlação entre o apoio dos executivos e o sucesso da implementação.

As principais contribuições adicionais deste artigo estão ligadas ao fator Fornecedores, com o elemento planejamento da logística e, no fator Produção, o elemento layout.

Muito embora as referências acima sejam muito expressivas e completas, nesta pesquisa entendeu-se que os Fatores Organizacionais, citados especificamente por Ansari e Modarress (1990), Karlsson e Norr (1994), Hum e Ng (1995) e Wafa e Yasin (1998) como problemas à implementação de técnicas JIT e estruturais, citados por Silva (2001), devem ser analisados também como Fatores Críticos para a Implementação (FCI) pois são de clara implicação nas atividades cotidianas da empresa.

Segue uma análise mais detalhada de cada grupo de fatores.

\subsection{1 - Ligados ao Comprometimento da Administração}

O Comprometimento da Alta Administração pode ser manifestado de forma direta ou indireta. A Tabela 5 - Fatores Ligados ao Comprometimento da Administração, mostra os principais aspectos citados em cada artigo. Mesmo a simples criação de um sistema formal para recebimento e análise de sugestões dos funcionários já foi classificada como um indicador deste comprometimento, que fica mais fortalecido na medida em que o funcionário recebe autoridade para paralisar uma linha de produção ao sinal de algum problema. Já a comunicação, como forma de deixar clara as pretensões da alta administração, toma papel importante na promoção da própria cooperação entre as pessoas. Ao perceber que os funcionários da alta administração também participam dos treinamentos em técnicas JIT, os demais funcionários confirmam o comprometimento direto. 
Tabela 5 - Fatores Ligados ao Comprometimento da Administração

\begin{tabular}{|c|c|c|c|c|c|}
\hline \multirow{2}{*}{\multicolumn{2}{|c|}{ Fatores Críticos para a Implementação (FCI) }} & \multicolumn{4}{|c|}{ Autores e ano da publicação } \\
\hline & & $\mathrm{a}$ & $\mathrm{b}$ & $\mathrm{C}$ & $\mathrm{d}$ \\
\hline & Ligados ao Comprometimento da Administração & 92 & 95 & 95 & 96 \\
\hline 1 & Apoio da alta administração & $\mathrm{X}$ & $\bar{X}$ & $\bar{X}$ & $\mathrm{X}$ \\
\hline 2 & Sistema formal para ouvir sugestões de funcionários & $\mathrm{X}$ & $\mathrm{X}$ & $\mathrm{X}$ & \\
\hline 3 & Autoridade para parar linha de produção & $\mathrm{X}$ & $\mathrm{X}$ & $\mathrm{X}$ & \\
\hline 4 & Comunicação & & $\mathrm{X}$ & & \\
\hline 5 & Treinamento para gerência em técnicas JIT & $\mathrm{X}$ & & & \\
\hline 6 & Cooperação entre funcionários & & $\mathrm{X}$ & & \\
\hline 7 & Investigar e implementar sugestões & $\mathrm{X}$ & & & \\
\hline
\end{tabular}

Autores: a) Mehra e Inman (1992); b) Zhu e Meredith (1995); c) Ramarapu, Mehra e Frolick (1995); d) Yasin e Wafa (1996).

Outros artigos mostram a importância do comprometimento da Alta Administração, tais como Walleigh (1986), que o identifica como importante fator na implementação de técnicas JIT, muito embora o próprio autor afirme que, por si só, o apoio da alta administração não seria suficiente caso o pessoal de staff também não se comprometesse com o projeto, dado que, na maioria das organizações, as pessoas não têm tempo para voltar-se às melhorias, ficando, por demais, presas às atividades cotidianas. Willis e Suter (1989) são enfáticos ao afirmar que se a alta administração não der seu apoio incondicional, o projeto está condenado. Johnston (1989) coloca o apoio da alta administração como sendo um dos cinco pilares de uma implementação bem-sucedida. Por outro lado, Vora, Saraph e Petersen (1990) estudaram 14 empresas do ramo eletrônico buscando verificar a importância do compromisso da alta administração e descobriram que, neste grupo de empresas, a participação da alta administração foi apenas marginal, o que torna o resultado, de certa forma, surpreendente. Para Helms (1990), o compromisso da alta administração serve, antes de tudo, para assegurar o comprometimento dos demais colaboradores. Crawford e Cox (1991) afirmam que o compromisso da alta administração se faz necessário porque as técnicas JIT não são implementadas de um dia para o outro, o que gera a necessidade de um compromisso de longo prazo. Lummus e Duclos-Wilson (1992) afirmam que o JIT não é JIT sem o compromisso da gerência. Lawrence e Lewis (1993) constataram que o baixo compromisso da alta administração no México se deve ao fato de que, em sua maioria, os gerentes e diretores das 18 empresas pesquisadas não passam mais do que três anos no país, o que dificulta a sua demonstração de comprometimento. Sohal e Egglestone (1994) colocam o compromisso num espectro mais amplo, envolvendo não só a alta administração, mas também os demais colaboradores, como fator fundamental de sucesso na implementação de técnicas JIT. Day (1995) também afirma que o sucesso começa pelo compromisso do topo da administração. Markham e McCart (1995) pesquisaram 281 empresas americanas de vários 
setores e constataram que o apoio da alta administração foi o primeiro passo dado pelas empresas que obtiveram o maior grau de sucesso na implementação de técnicas JIT. Num estudo de caso conduzido por Sohal (1996) na Austrália, o sucesso da implementação foi atribuído, entre outros fatores, à equipe de gerentes e seu alto grau de compromisso com o projeto.

\subsection{2 - Ligados à Educação e Treinamento}

Pela mudança de comportamento que a adoção de técnicas JIT causa numa empresa, o papel da Educação e Treinamento toma importância significativa. Aliás, a própria Multifuncionalidade, tão necessária no ambiente JIT, só pode ser conseguida com muito treinamento, o que pode ser facilitado pelo uso de Círculos de Controle da Qualidade (CCQ), ou seja, equipes de funcionários trabalhando para solução de problemas comuns.

Treinamento e educação tratam do processo de preparação da equipe de funcionários para fazer frente aos novos perfis profissionais requeridos no ambiente JIT, e envolvem a preparação para o uso das técnicas JIT no trabalho cotidiano, por meio de estudos dirigidos ou visitas a empresas já usuárias de técnicas JIT. A Tabela 6 - 'Fatores ligados à Educação e Treinamento", indica os principais aspectos citados nos artigos.

Tabela 6 - Fatores ligados à Educação e Treinamento

\begin{tabular}{|c|c|c|c|c|c|}
\hline & & \multicolumn{4}{|c|}{ Autores e ano da publicação } \\
\hline & \multirow{2}{*}{$\begin{array}{c}\text { Fatores Críticos para a Implementação (FCI) } \\
\text { Ligados à Educação e Treinamento }\end{array}$} & 92 & 95 & 95 & 96 \\
\hline & & $\mathrm{a}$ & $\mathrm{b}$ & $\mathrm{C}$ & $\mathrm{d}$ \\
\hline 1 & $\mathbf{C C Q}$ & $\mathrm{X}$ & $\mathrm{X}$ & $\mathrm{X}$ & $\mathrm{X}$ \\
\hline 2 & Educação e Treinamento para JIT & $\mathrm{X}$ & $\mathrm{X}$ & & $\mathrm{X}$ \\
\hline 3 & Multifuncionalidade (cross-training) & $\mathrm{X}$ & $\mathrm{X}$ & $\mathrm{X}$ & \\
\hline 4 & Equipe JIT & $\mathrm{X}$ & $\mathrm{X}$ & $\mathrm{X}$ & \\
\hline 5 & Consultoria externa para implementação & $\mathrm{X}$ & $\mathrm{X}$ & & \\
\hline 6 & JIT Champion & $\mathrm{X}$ & $\mathrm{X}$ & & \\
\hline 7 & Projeto piloto & $\mathrm{X}$ & $\mathrm{X}$ & & \\
\hline 8 & Melhoria contínua & & & $X$ & \\
\hline 9 & Visão de futuro & $\mathrm{X}$ & & & \\
\hline
\end{tabular}

A visão de Walleigh (1986) sobre o treinamento é ampla. O autor propõe que o treinamento seja realizado nos diferentes níveis organizacionais de forma diferente, ou seja, um grupo participando de seminários, outro tendo aulas com especialistas, outro formando grupos de estudos sobre um certo livro ou outro visitando fábricas que já implementaram as técnicas em estudo. Byrd e Carter (1988) indicam que o treinamento deve ser a primeira etapa do processo de implementação e deve concentrar-se em difundir os conceitos básicos da filosofia JIT. O objetivo do treinamento deve ser dar a todos um entendimento geral dos 
conceitos de JIT e promover o apoio "emocional" para o projeto. A mesma proposição é feita por Sohal e Naylor (1992), acrescentando que o treinamento deve evidenciar os benefícios que o uso de técnicas JIT pode trazer ao dia-a-dia do trabalho dos funcionários. Inman e Mehra (1989) colocam que a educação no processo de implementação de técnicas JIT é importante por dois motivos: primeiro para explicar o por quê, como e o quê fazer e segundo para alterar comportamentos, o que efetivamente só ocorre quando os colaboradores entendem profundamente os conceitos. Já Billesbach (1994a) descreve o processo de treinamento adotado pela DuPont, que foi concentrado on-the-job, como uma alternativa. A educação é um investimento e não um custo, conforme Willis e Suter (1989), entretanto, Golhar, Stamm e Smith (1990) colocam que o dispêndio de recursos para treinamento é um problema real para a implementação de técnicas JIT, o que é corroborado também por Kim e Schniederjans (1990), dado que as empresas podem apresentar restrições financeiras para implementar programas de treinamento em técnicas JIT. Treinamento e educação são fundamentais para a implementação de técnicas JIT, segundo Johnston (1989). Orth, Hybil e Korzan (1990) alertam sobre a importância do treinamento da média gerência para convencêla de que a mudança do sistema de "empurrar" a produção para o sistema de "puxar" não vai colocá-la em dificuldades, já que é a responsável operacional pelo sistema. Num estudo envolvendo 14 empresas da indústria eletrônica, Vora, Saraph e Petersen (1990) constataram que todas investiram substancial parcela da implementação em treinamento de operadores, supervisores, média gerência, pessoal de staff e gerentes seniores. Os treinamentos variaram desde seminários internos a cursos externos. Helms (1990) e Yasin e Wafa (1996) corroboram esta afirmação chamando a atenção para as necessidades individuais de treinamento que cada funcionário apresenta. Numa pesquisa realizada por Billesbach (1991) em 68 empresas americanas, 92\% delas afirmaram que a educação e o treinamento são parâmetros fundamentais na implementação de técnicas JIT e mais de $60 \%$ delas acreditam que a duração do treinamento deve ser superior a 21 horas. Keys (1991), Lummus e Duclos-Wilson (1992) e Im, Hartman e Bondi (1994) afirmam que o treinamento é uma forma eficaz de conseguir aumento do comprometimento dos funcionários. Sohal e Egglestone (1994), num estudo realizado na Austrália, constataram que o treinamento tem sido usado para vencer resistências dos funcionários à implementação de técnicas JIT. Chen, Gupta e Chung (1996) pesquisando os elementos que afetam o comprometimento dos funcionários na implementação de sistemas flexíveis de manufatura também concluem que o treinamento e a educação são importantes. Para Romero (1991) e Epps (1995), o estabelecimento de programa de educação personalizado e focalizado em melhorias contínuas é uma das bases da 
implementação de técnicas JIT. Day (1995) descreve um caso real em que o treinamento toma proporções importantes no sucesso da implementação de técnicas JIT. Sevier (1992) liga diretamente o treinamento à multifuncionalidade enfocando os principais tópicos de treinamento que podem ser abordados, tais como matemática, computação e comunicação. Payne (1993) descreve um estudo de caso em que mostra como o treinamento é disseminado pela organização pelo uso de "multiplicadores", ou seja, um grupo inicial é treinado pela equipe de consultoria e fica encarregado de fazer o treinamento dos demais funcionários da empresa. O fator treinamento, particularmente no México, assume um contorno especial, Lawrence e Lewis (1993) o colocam como ponto fundamental para a implementação de técnicas JIT dado que o nível de escolarização dos funcionários quando entram na empresa é muito baixo e há pouca disponibilidade de empresas de consultoria especializada em técnicas JIT. Golhar e Deshpande (1993) constataram que o volume de treinamento aumenta consideravelmente nas empresas usuárias de técnicas JIT (58\% das empresas criaram programas de treinamento e $45 \%$ aumentaram o orçamento de treinamento). Este artigo está baseado em respostas de 34 empresas americanas. Num estudo realizado por Hum e $\mathrm{Ng}$ (1995) em Singapura, o treinamento foi constatado como a segunda prática fundamental para a implementação de técnicas JIT. Spencer e Guide (1995) pesquisaram 101 empresas americanas sobre FCI na implementação de técnicas JIT e mais uma vez a educação e treinamento aparecem entre os elementos mais importantes. Markham (1995) conduziu uma pesquisa com 802 empresas americanas de diferentes setores e portes e também concluiu que educação e treinamento são fundamentais no processo de implementação de técnicas JIT. Zhu e Meredith (1995) afirmam que o treinamento deve concentrar-se não apenas no entendimento dos aspectos técnicos do JIT como também no impacto que sua implementação terá no ambiente operacional da empresa. Karlsson e Ahlström (1995) estudando as mudanças que a empresa deve promover para transformar-se em empresa JIT concluem que, no que tange ao treinamento, deve aumentar o número de horas, de tarefas e áreas funcionais em que os funcionários são treinados. Sohal (1996) enfatiza que o treinamento foi um dos mais sérios problemas durante a implementação de técnicas JIT na Trico Austrália.

De forma geral, o treinamento recomendado está voltado ao desenvolvimento de um entendimento sobre as técnicas JIT e sua aplicabilidade na empresa bem como à preparação do corpo de funcionários para as diversas alterações que se esperam pela adoção das técnicas JIT. Portanto visam aumento da habilidade pessoal e redução das restrições pessoais e resistências pelo desconhecimento das técnicas. 
Já a Multifuncionalidade (cross-training) dos colaboradores refere-se à capacidade da equipe de funcionários para trabalhar em diversos tipos de tarefas diferentes, envolvendo não só atividades operacionais como também atividades de planejamento, e está diretamente ligada à educação e treinamento.

Aggarwal (1985) afirma que esta abordagem pressupõe que os funcionários devem ajudar-se mutuamente e que cada pessoa é capaz de fazer diferentes tarefas, ou seja, são multifuncionais. Isto pode tanto servir de fator motivacional como também aumentar o estresse dos funcionários, conforme lembram Malley e Ray (1988), salientando que o trabalhador não é mais apenas responsável pela tarefa em si, mas também pela qualidade e pelas ações corretivas, o que pode ser visto tanto negativa como positivamente. Como mostram Inman e Brandon (1992), a multifuncionalidade pode ser vista como uma "estrada desconhecida", por onde o colaborador deve conduzir-se com toda a cautela, pois não conhece em detalhes o caminho a seguir. Manoochehri (1988) postula que a multifuncionalidade é fundamental para que se consiga estabilizar o plano de produção, a despeito das variações diárias de mix. Esta potencial mudança de uma área para outra pode ferir os acordos sindicais, gerando conflitos, conforme colocam Inman e Mehra (1989). Orth, Hibyl e Korzan (1990), estudando um caso de implementação, concluem que a multifuncionalidade é um desafio para sindicatos e representantes das empresas. Billesbach e Schniederjans (1989) ressaltam que a multifuncionalidade também é importante quando as técnicas JIT são aplicadas às atividades administrativas e não apenas nas atividades operacionais voltadas à manufatura. Na visão de Willis e Suter (1989) as atividades voltadas à manutenção preventiva, limpeza e organização do local de trabalho também complementam a função operacional do trabalhador e constituem mudança nas suas atividades usuais. Num estudo envolvendo a implementação de técnicas JIT em 14 empresas de vários setores, Vora, Saraph e Petersen (1990) também constataram que a multifuncionalidade é um dos fatores críticos, o que é confirmado por Crawford e Cox (1991); Shahabuddin (1992); e Inman e Mehra (1992). Brown e Mitchell (1991), num artigo comparativo entre o sistema JIT e o sistema de produção em lotes enfatiza ser a multifuncionalidade um dos grandes fatores de diferenciação. Lummus e Duclos-Wilson (1992) interligam o treinamento à multifuncionalidade como forma de uma empresa conquistar o ambiente JIT. Já White (1993) apenas cita a multifuncionalidade como um dos elementos das técnicas JIT enquanto que Golhar e Deshpande (1993) enfatizam que os benefícios do uso das técnicas JIT só podem ser obtidos se o recurso humano das empresas tiver algumas características bem destacadas, entre elas a multifuncionalidade. Im, Hartman e 
Bondi (1994) estudando os efeitos do uso de técnicas JIT sobre o gerenciamento dos recursos humanos, constatou que a multifuncionalidade afeta a descrição dos cargos e o número de classificações dos mesmos. Sohal e Egglestone (1994) colocam a multifuncionalidade num contexto mais amplo ligado à organização baseada em equipe buscando maior flexibilidade e envolvendo maior nível de responsabilidade. Para Groebner e Merz (1994) o uso de técnicas JIT numa empresa significa mudanças radicais em várias áreas funcionais e particularmente no que tange à flexibilidade do trabalho, que é maximizada com o apoio de colaboradores multifuncionais. O sistema de remuneração é um ponto frágil para empresas usuárias de técnicas JIT, na opinião de Karlsson e Ahlström (1995), pois a múltipla habilidade possibilita que múltiplas tarefas sejam desempenhadas e não somente tarefas estritamente operacionais, o que forçaria uma profunda alteração no sistema de remuneração convencional. Epps (1995) argumenta que a multifuncionalidade reduz custos e aumenta a qualidade. Também Day (1995) acredita que as melhorias conseguidas com as pequenas mudanças no processo produtivo são devidas à atuação das equipes multifuncionais. Num estudo realizado em 101 empresas americanas, por Spencer e Guide (1995), a conclusão foi que a multifuncionalidade é o principal fator humano na implementação de técnicas JIT. O mesmo conclui Deshpande e Golhar (1995), estudando as práticas de Recursos Humanos em empresas sindicalizadas e não sindicalizadas. Estabilidade e flexibilidade da equipe de colaboradores são fundamentais para o uso de técnicas JIT na visão de Dahlén, Ericsson e Fujii (1995) após um estudo de 17 empresas no Japão e 4 na Suécia. A multifuncionalidade é um dos 10 principais elementos das técnicas JIT, conforme Vuppalapati, Ahire e Gupta (1995). Mazany (1995) afirma que a multifuncionalidade é uma etapa obrigatória na transição da manufatura tradicional para a baseada em técnicas JIT. Uma revisão bibliográfica realizada por Ramarapu, Mehra e Frolick (1995) constatou que a multifuncionalidade aparece como o quarto elemento mais importante citado pelos 105 artigos sobre implementação publicados entre 1980 e 1993. Novamente Karlsson e Ahlström (1996) postulam que a multifuncionalidade é um fator importante na transição de uma empresa tradicional para uma empresa JIT. Kim e Takeda (1996) afirmam que não apenas as empresas JIT devem fazer uso de colaboradores multifuncionais. Num artigo de Forza (1996), ficou comprovado que empresas JIT fazem mais uso de colaboradores multifuncionais que empresas não JIT. A diferenciação entre empresas JIT e não JIT foi feita com base na experiência do autor. Hancock e Zayko (1998) concluem que, face às diversas funções que um funcionário deve desempenhar num ambiente JIT, é imprescindível que tenha múltiplas habilidades. Imai (1998) e Jusko (1999), considerando o trabalho numa célula de produção, também concluem que a multifuncionalidade é indispensável. 
Tomando por base os diversos artigos citados, pode-se depreender que a multifuncionalidade é básica para o perfil de profissional necessário num ambiente em que técnicas JIT são aplicadas, pois o nível de habilidade pessoal deve ser mais elevado, a compreensão do todo e das origens dos problemas deve ser maior e a capacidade de desenvolver, tanto tarefas operacionais como tarefas de planejamento, deve estar presente.

Equipe JIT e cooperação entre funcionários estão ligados à participação em atividades desenvolvidas coletivamente e que dependem desta ação coletiva para seu sucesso.

Golhar, Stamm e Smith (1990), numa pesquisa envolvendo 32 empresas americanas de variados setores, concluíram que houve aumento da taxa de sugestões e do número de equipes de CCQ (círculos de controle da qualidade), além de aumento na aceitação de novas tarefas e responsabilidades pelos funcionários, evidenciando o aumento da cooperação dos funcionários. A comunicação é a chave para a obtenção da cooperação segundo Helms (1990) e neste ponto é que muitos processos falham em conseguir maior integração. Neste aspecto também concordam Arogyaswamy e Simmons (1991). Já Shahabuddin (1992) entende que a cooperação deve abranger mais que simplesmente funcionários, mas também gerentes, fornecedores e clientes. Em seu artigo "When JIT is not JIT" Lummus e Duclos-Wilson (1992) afirmam que uma equipe de implementação produzirá mais resultados desejados quando contar com a cooperação de todos. Golhar e Deshpande (1993) destacam que as empresas devem preocupar-se também em reter os funcionários com perfil mais adequado para operar em ambiente JIT, e sugerem o uso de programas de incentivo como essenciais para ganhar a cooperação do grupo. Encorajar o senso de responsabilidade compartilhada é a proposta de Sohal e Egglestone (1994) como forma de aumentar a cooperação dos funcionários. O espírito de equipe é visto como o mais importante fator humano num sistema de produção sob regime JIT numa pesquisa realizada por Norris, Swanson e Chu (1994), entre 48 gerentes de empresas americanas dos setores automobilístico, eletrônico e de máquinas. Treinar em princípios de qualidade total e trabalho em equipe é apontado por Mullarkey, Jackson e Parker (1995) como fator fundamental de sucesso antes de implementar redução de estoques e Kanban. Como o uso de técnicas JIT está apoiado na confiança entre as pessoas, a cooperação assume importância fundamental, na visão de Epps (1995). Deshpande e Golhar (1995) citam a orientação para o trabalho em equipe como um dos principais fatores para a obtenção dos potenciais benefícios das técnicas JIT. Karlsson e Ahlström (1996) estudando as mudanças pelas quais uma empresa deve passar para se 
transformar em usuária de técnicas JIT pontuam que deve aumentar o percentual de funcionários trabalhando em equipe.

Os resultados que se pode obter dos programas de treinamento nas empresas estão diretamente ligados à forma como os funcionários estão engajados às metas da empresa e à motivação da equipe para novos desafios.

Conforme Aggarwal (1985) e Sohal e Egglestone (1994), a motivação dos funcionários é a raiz do sistema JIT de produção na medida em que aumenta a responsabilidade e a autoridade. Uma maneira de aumentar a motivação é a demonstração, por parte da gerência, de seu comprometimento, tornando-se mais transparente, expressando seu interesse pelos funcionários, pelos produtos e pela qualidade, afirma Johnston (1989). Ansari e Modarress (1990) acreditam que a falta de motivação ocorre por falha no entendimento dos conceitos das técnicas JIT e o treinamento pode ajudar a minimizar este problema. Keys (1991) coloca a motivação dos funcionários entre as cinco principais barreiras à implementação de técnicas JIT. Instituir programas de envolvimento dos funcionários é, na visão de Bowman (1991) e Clode (1993), um dos principais fatores a ser considerado na implementação de técnicas JIT. Para Inman e Mehra (1991) e Hum e Ng (1995), o uso de técnicas JIT cria oportunidade de aumentar o moral e envolvimento da equipe. Sevier (1992) mostra que o uso de técnicas JIT altera profundamente o processo de tomada de decisão visto que os funcionários passam a participar do processo de "construir a decisão" e não somente obter as "decisões prontas". Esta participação só ocorre efetivamente com funcionários motivados. As conclusões do artigo de Moras e Dieck (1992) sobre as aplicações industriais do uso de técnicas JIT, baseado em 38 artigos publicados entre 1982 e 1990, mostram que o envolvimento dos funcionários e o espírito de equipe são fatores importantes. Lummus e Duclos-Wilson (1992) são enfáticos ao afirmar que uma empresa não é JIT se não tiver a participação dos funcionários, entre outros fatores importantes. Uma particularidade relevante no caso da implementação de técnicas JIT no México foi constatada por Lawrence e Lewis (1993) quanto ao aspecto do envolvimento. No caso do México, a estrutura hierárquica é muito arraigada quanto às linhas de autoridade e responsabilidade, o que faz com que os funcionários julguem que solução de problemas e melhorias contínuas, que dependem de participação voluntária, não são atividades de sua responsabilidade. A maior participação do funcionário na implementação de técnicas JIT pode ser conseguida via treinamento, conforme constataram Im, Hartman e Bondi (1994), e também Day (1995). Dentre vários fatores humanos, a motivação dos funcionários foi o segundo mais importante numa pesquisa 
realizada por Norris, Swanson e Chu (1994) junto a gerentes envolvidos com empresas usuárias de técnicas JIT. Numa pesquisa realizada no Canadá, reunindo 69 empresas industriais (43 sindicalizadas e 25 não sindicalizadas - sic) a participação dos funcionários foi considerada das mais importantes em ambos os casos. Num artigo sobre seleção e implementação de técnicas avançadas de manufatura, Sambasivarao e Deshmukh (1995) separaram atributos tangíveis de atributos intangíveis, quando tratam dos problemas da implementação. Dentre estes atributos estão os fatores humanos, que reúnem a cooperação ou participação dos funcionários e a motivação/moral, sendo ambos considerados relevantes para o êxito da implementação. Já Ramarapu e Frolick (1995), numa revisão bibliográfica sobre a implementação de técnicas JIT acabam por concluir que a participação dos funcionários é um dos cinco grandes fatores críticos para a implementação. Udo e Ehie (1996) também enfatizam a importância do comprometimento e participação para uma implementação de técnicas JIT bem-sucedida, o que é confirmado no artigo de Garg, Kaul e Deshmukh (1998). Forza (1996) analisando as diferenças entre a produção sob o regime JIT e o tradicional, conclui, dentre outros, que os funcionários de empresas usuárias de técnicas JIT são mais comprometidos do que aqueles das empresas tradicionais.

O que se pode notar é que os fatores cooperação, colaboração, participação, integração e trabalho em equipe estão fortemente ligados à motivação do pessoal e que o treinamento e educação em técnicas JIT atuam como catalisadores da adesão dos funcionários na medida em que melhoram seu potencial individual e os capacitam para o trabalho coletivo.

\subsection{3 - Ligados ao Fornecedor}

O estabelecimento de um novo tipo de relação com os fornecedores é ponto fundamental para a implementação de técnicas JIT, visto que, com estoques mais reduzidos, a importância de confiabilidade de fornecimento aumenta. Neste aspecto, a quantidade de fornecedores deve ser reduzida e a forma de contratos deve ser alterada, visando um compromisso mútuo de longo prazo. Com isso, a redução do lead time e dos lotes de compra torna-se possível. O relacionamento com os fornecedores deve migrar para o regime de parcerias, com integração total entre as partes, na forma inclusive de colaboração técnica e financeira, quando for o caso. A Tabela 7 - 'Fatores ligados ao Fornecedor", indica os principais aspectos relacionados nos artigos. 
Tabela 7 - Fatores ligados ao Fornecedor

\begin{tabular}{|c|c|c|c|c|c|}
\hline & & \multicolumn{4}{|c|}{ Autores e ano da publicação } \\
\hline & Fatores Críticos para a Implementação (FCI) & 92 & 95 & 95 & 96 \\
\hline \multicolumn{2}{|r|}{ Ligados ao Fornecedor } & a & $\mathrm{b}$ & $\mathrm{c}$ & d \\
\hline 1 & Fornecedor único & $\mathrm{X}$ & $\mathrm{X}$ & $\mathrm{X}$ & \\
\hline 2 & Redução do Lead time do fornecedor & $\mathrm{X}$ & $\mathrm{X}$ & $\mathrm{X}$ & \\
\hline 3 & Redução do lote de compra & $\mathrm{X}$ & $\mathrm{X}$ & $\mathrm{X}$ & \\
\hline 4 & Certificação de fornecedores & $\bar{X}$ & $\mathrm{X}$ & & \\
\hline 5 & Comunicação com fornecedores & & & $\mathrm{X}$ & \\
\hline 6 & Relacionamento com fornecedores & & $\mathrm{X}$ & & $\bar{X}$ \\
\hline 7 & Contratos de longo prazo & & & $\mathrm{X}$ & \\
\hline 8 & Entrega rápida e confiável & & & $\mathrm{X}$ & \\
\hline 9 & Planejamento da logística & & & & $\mathrm{X}$ \\
\hline 10 & Treinamento de fornecedores & & & $\mathrm{X}$ & \\
\hline
\end{tabular}

O incentivo aos fornecedores para usar técnicas JIT está ligado ao processo pelo qual as empresas voltam-se à obtenção de fornecedores que também estejam interessados em trabalhar sob ambiente JIT.

Walleigh (1986) analisando as principais "desculpas" para uma empresa não ser usuária de técnicas JIT, cita o caso da Hewlett-Packard americana, divisão de sistemas de computadores, que procurou, logo de início, convencer seus principais fornecedores a operar sob o sistema JIT levando-os a conhecer seu processo produtivo e os resultados esperados, chegando até mesmo a promover treinamento de seus fornecedores em técnicas JIT. De certa forma esta necessidade é reconhecida por Bose e Rao (1988) que afirmam que uma empresa usuária de técnicas JIT deve ter fornecedores também usuários de técnicas JIT para que consiga os melhores resultados. É uma visão de que a cadeia de suprimentos deve suportar a iniciativa de implementação das técnicas JIT. Malley e Ray (1988) e Romero (1991) também concordam que as empresas que operam sob o regime JIT devem procurar convencer seus fornecedores sobre os benefícios recíprocos da adoção do sistema. Um empecilho que poderia ser citado pelo fornecedor para não aderir ao sistema JIT poderia ser o tamanho da empresa, mas Manoochehri (1988) é enfático ao afirmar que empresas menores têm, naturalmente, características que facilitam a implementação de técnicas JIT (menor volume de produção, menor divisão de tarefas, trabalhadores menos especializados, equipamentos mais genéricos, menor automação, entre outras). Um fornecedor usuário de técnicas JIT é importante pela maior flexibilidade e capacidade de resposta que passa a possuir, como afirma Vickery (1989) e Crawford e Cox (1991). O relacionamento com o fornecedor sofre alterações importantes, dentre elas a necessidade de redução dos lotes de fabricação e o aumento na frequiência de entregas. Portanto, concluem Willis e Suter (1989), o ideal é que os fornecedores também 
sejam usuários de técnicas JIT. Payne (1993) também enfatiza a criticidade assumida pelas relações entre fornecedor e cliente. Golhar, Stamm e Smith (1990) apregoam uma radical alteração no relacionamento com os fornecedores, principalmente no que tange à vigência do contrato e a quantidade de fornecedores. Kim e Schniederjans (1990) colocam o relacionamento com os fornecedores como um sério problema para a implementação de técnicas JIT, particularmente no que diz respeito à falta de colaboração para entregas no prazo combinado. Mehra e Inman (1992) colocam os aspectos ligados ao fornecedor num prisma mais amplo e comprovam que o convencimento dos fornecedores a adotar técnicas JIT está fortemente relacionado ao sucesso da implementação de técnicas JIT. Shahabuddin (1992) coloca uma observação importante: é comum uma empresa exigir dos fornecedores um comportamento baseado nos conceitos das técnicas JIT (lotes reduzidos, entregas freqüentes e qualidade garantida) gerando, com isso, um desgaste no relacionamento entre fornecedores e empresa, dado que o fornecedor passa a assumir os custos que antes eram de seu cliente. Lummus e Duclos-Wilson (1992) afirmam que uma empresa não é JIT quando o estoque é "transferido" para seus fornecedores sob exigência contratual. Neste aspecto Epps (1995) também afirma que não se pode esperar que o fornecedor assuma todos os riscos e custos do estoque, mas que benefícios recíprocos sejam alcançados. Uma proposta apresentada seria a certificação dos fornecedores. Em outras situações, como mostram Lawrence e Lewis (1993) em seu estudo no México, a participação dos fornecedores é dificultada pelas características técnicas inadequadas, ou ainda, capacidade técnica aquém da desejada. Sohal e Egglestone (1994) chamam a participação dos fornecedores de "relações compartilhadas", lembrando a celebração de alianças. Karlsson e Norr (1994) destacam que a visão tradicional, onde comprador e vendedor encaram-se como oponentes, não é mais possível num ambiente JIT. Já Forza (1996) enfatiza que a participação dos fornecedores aumenta a possibilidade de melhorias na qualidade.

A palavra chave no fornecimento JIT é parceria. Na medida em que a relação entre fornecedor e cliente se altera de forma a celebrarem contratos mais duradouros, incluindo compartilhamento nos riscos do negócio e maior transparência nas negociações, tanto maior mostra-se a oportunidade de resultados positivos para ambas as partes.

\subsection{4 - Ligados à Produção}

A adoção do uso de células de produção não pode ser uma medida isolada, pois envolve muitos outros fatores, ora ligados à produção, ora ligadas aos recursos humanos ou a aspectos técnicos. Primeiramente uma célula de produção pressupõe uma alteração do layout 
da fábrica. Em seguida, pelo fato de uma célula de produção estar ligada à fabricação de uma "família" de produtos, os lotes de fabricação devem ser reduzidos, o que implicará em realizar mais trocas e preparação de ferramentas (set up). Como geralmente as células são únicas e dedicadas, o plano de manutenção preventiva deve estar bem implementado de forma que eventuais problemas no processo não levem a uma paralisação prolongada na fabricação. Como as operações dentro de uma célula de produção estão muito interligadas, deve haver um bom desenvolvimento do Controle Estatístico de Processos, visando prevenir que uma etapa de produção produza material com problemas de qualidade e o disponibilize para a retirada pela etapa seguinte, usando Kanban, o que causaria problemas de paradas de produção. Dentro de uma célula de produção, o conceito do housekeeping - 5S passa a mostrar-se extremamente relevante, visto que a organização do local de trabalho toma grande importância, pois não há sobras de espaço para superprodução ou material fora de lugar e fora do tempo ideal de processamento. A Tabela 8 - "Fatores ligados à Produção", mostra os principais aspectos citados nos artigos.

Tabela 8 - Fatores ligados à Produção

\begin{tabular}{c|c|c|c|c|c}
\hline \multicolumn{1}{c|}{$\begin{array}{c}\text { Fatores Críticos para a Implementação (FCI) } \\
\text { Ligados à Produção }\end{array}$} & \multicolumn{4}{c}{ Autores e ano da publicação } \\
\cline { 3 - 6 } & & 92 & 95 & 95 & 96 \\
\hline 1 & Células de Produção & $\mathrm{X}$ & $\mathrm{b}$ & $\mathrm{C}$ & $\mathrm{d}$ \\
\hline 2 & Redução de set up & $\mathrm{X}$ & $\mathrm{X}$ & $\mathrm{X}$ & \\
\hline 3 & Manutenção preventiva & $\mathrm{X}$ & $\mathrm{X}$ & $\mathrm{X}$ & \\
\hline 4 & Produção nivelada (balanceamento de linha) & & $\mathrm{X}$ & $\mathrm{X}$ & \\
\hline 5 & Redução do lote de fabricação & $\mathrm{X}$ & $\mathrm{X}$ & $\mathrm{X}$ & \\
\hline 6 & Layout & & & & $\mathrm{X}$ \\
\hline 7 & Automatização & & & $\mathrm{X}$ & \\
\hline 8 & CEP & & & $\mathrm{X}$ & \\
\hline 9 & Flexibilidade do sistema produtivo & & $\mathrm{X}$ & & \\
\hline 10 & Qualidade & & & $\mathrm{X}$ & \\
\hline 11 & Redução de perdas & & & $\mathrm{X}$ & \\
\hline 12 & Simplificação na lista de materiais & & $\mathrm{X}$ & & \\
\hline
\end{tabular}

Os principais fatores ligados à produção são:

\section{Células de Produção}

Dentro das perspectivas das técnicas JIT, o termo "células de produção" está ligado à maneira como as máquinas e equipamentos são dispostos dentro do processo produtivo, de forma a melhorar o fluxo da produção. Hay (1988:73) alerta para as falsas células de produção, onde o processamento ainda acontece em lotes e não em peças unitárias e propõe que uma célula de produção só pode ser considerada uma célula de produção quando o produto flui de uma máquina à outra individualmente. 
Segundo Manoochehri (1988), o conceito de célula de produção envolve agrupar as peças a serem produzidas numa "família" de peças com base na similaridade das operações. Esta estratégia aumenta a flexibilidade do sistema produtivo. Billesbach e Schniederjans (1989) destacam a capacidade que o uso das células de produção têm de reduzir o volume de "papel" circulante no controle do processo produtivo. Neste artigo, especificamente, enfocam o uso do conceito na administração. Uma das cinco fases da implementação de técnicas JIT, conforme Willis e Suter (1989), envolve a movimentação de materiais ao longo do processo produtivo e o uso das células de produção assume importância significativa para a simplificação do fluxo, o que também é corroborado por Muchnik, Shipley e Shane (1990). O uso de células de produção, conforme Vora, Saraph e Petersen (1990), é importante porque reduz o número de inspetores do processo produtivo e estimula a participação em equipes de solução de problemas. Em seu artigo sobre a implementação de técnicas JIT em empresas americanas, Billesbach (1991) mostra que 83\% das 68 empresas pesquisadas (26\% do ramo eletrônico, $17 \%$ eletromecânico, $22 \%$ metálico e $36 \%$ de outros ramos) apontam a adoção de células de produção como principal responsável pelo sucesso na implementação de técnicas JIT. Eliminar movimentos desnecessários é básico para o uso de técnicas JIT e a utilização de células de produção ajuda neste intuito, conforme mostram Crawford e Cox (1991). Organizar os colaboradores em torno de células de produção, de forma interdependente é uma característica fundamental do uso de técnicas JIT destacada por Brown e Mitchell (1991). Já Epps (1995) destaca a importância da "visibilidade" do processo produtivo, possibilitada pelo uso das células de produção, visto que a maioria dos colaboradores pode ver a maior parte do processo, se não o seu todo, e compreender melhor a sua participação no mesmo.

Portanto, o uso de células de produção está diretamente relacionado com a melhoria do fluxo do processo produtivo, possibilitando mais flexibilidade e reduzindo a burocracia do controle, pela simplificação destas atividades dentro da célula.

\section{$\underline{\text { Redução de set up }}$}

Hay (1988: 53) coloca a redução do set up como requisito fundamental para a implementação de técnicas JIT, pois servirá de base para que melhorias futuras ocorram ao longo do processo. É enfático ao afirmar que os ganhos de tempo devidos à redução de set up devem ser aplicados em mais redução de set up e não em aumento da produção, pois somente quando o processo de set up está muito desenvolvido é que se pode chegar às melhorias mais significativas como trabalhar em lotes unitários, o que significa maior flexibilidade no processo produtivo. Mostra também que uma equipe de redução de set up não deve ser 
liderada por pessoal de engenharia sob pena de limitar a atuação do pessoal de fábrica. Aliás, a equipe de engenharia deve participar apenas como apoio e para evitar que considerações relativas a segurança não sejam relegadas a segundo plano.

Reduzir o set up significa minimização do tempo envolvido na troca e ajuste de uma ferramenta. Envolve também o tempo de transporte, inspeção e espera pela troca da ferramenta. Hay (1988: 54) propõe que se pergunte: o quê está sendo feito, por quê está sendo feito e quem está fazendo, como regras gerais e iniciais no trabalho de redução do set up.

O trabalho com lotes menores pressupõe que mais preparações de máquinas sejam efetuadas numa freqüência maior. Manoochehri (1988) destaca a redução de set up como a base para alcançar a flexibilidade da manufatura, mostrando que, na fase inicial, os resultados podem ser obtidos com praticamente nenhum investimento adicional. Já Vickery (1989) coloca a redução do set up na base para a redução dos estoques e, conseqüentemente, reduzir lead time e problemas com a qualidade. A conversão para o sistema JIT, segundo Willis e Suter (1989), passa por cinco fases, sendo uma delas ligada ao movimento dos produtos ao longo do processo produtivo. Nesta fase, a redução do set up toma importância significativa. Estudando a implementação de técnicas JIT em pequenas empresas, Golhar, Stamm e Smith (1990) identificam a redução do set up entre os principais fatores. Reduzir estoques e lotes de fabricação só é possível com redução de set up, conforme colocam Muchnik, Shipley e Shane (1990) e Crawford e Cox (1991). Payne (1993) enfoca a redução do lead time, em que a redução do set up ocupa lugar importante. Em sua pesquisa sobre as práticas JIT em Singapura, Hum e Ng (1995) descobriram ser a redução do set up um dos três principais problemas. Spencer e Guide (1995), estudando os componentes das técnicas JIT, também colocam a redução do set up entre as principais "estratégias de produção" JIT. Forza (1996) também cita, entre outras técnicas, a redução de set up como uma prática fundamental do regime JIT. Hancock e Zayko (1998) responsabilizam diretamente a baixa capacidade de set up de um processo pelos altos níveis de estoques e a baixa qualidade. Inman (1999) mostra que, antes da implementação de um sistema de "puxar" a produção, é necessário desenvolver um processo melhorado de set up.

Pelo exposto, reduzir o set up é condição fundamental para implementar as técnicas JIT já que afeta diretamente o funcionamento das células de produção, possibilitando que os lotes sejam reduzidos, aumentando a flexibilidade do processo produtivo. 


\section{$\underline{\text { Manutenção Preventiva }}$}

Envolve a programação de atividades de manutenção preventiva dos equipamentos com base nas condições de uso e nas características de durabilidade dos seus componentes.

Um cuidado especial deve ser tomado quanto à manutenção preventiva no sentido de não colocá-la como uma panacéia dentro dos conceitos JIT, conforme Hay (1988: 148-150). Está claro que a confiabilidade dos equipamentos é necessária num ambiente JIT, pois os estoques são reduzidos, os equipamentos estão agrupados em células de produção e a resposta da produção em relação à demanda deve ser imediata.

Considerações importantes devem ser feitas sobre o envolvimento dos operadores, que passarão a ter rotinas voltadas à manutenção, como atividades de lubrificação e limpeza, bem como tomar parte no processo de decisão sobre seleção ou troca de um equipamento, além de terem desenvolvidas suas habilidades de reparadores imediatos de problemas mais comuns e localizados no equipamentos. Outro aspecto está no processo de seleção dos equipamentos, que não mais deve privilegiar apenas fatores relativos ao custo de aquisição, como também os custos de operação e manutenção. Um papel fundamental do operador na manutenção preventiva é o de coletar dados sobre os problemas que ocorrem durante a utilização dos equipamentos. Estes dados servirão de base para as próximas decisões ligadas ao equipamento.

Tomando parte da função housekeeping, a manutenção preventiva configura-se como importante fator, não só no aspecto operacional, como também no emocional, colocando a pessoa do operador num nível mais elevado de comprometimento, de acordo com Willis e Suter (1989). Para Crowford e Cox (1991) o sentido principal da manutenção preventiva é evitar eventuais atrasos devidos ao mau funcionamento dos equipamentos, antes de tudo. Passar a ter a manutenção preventiva como sua responsabilidade é uma importante alteração na estrutura de relações humanas no trabalho na visão de Im, Hartman e Bondi (1994), que traz consigo profundas mudanças na empresa. Epps (1995) enfatiza a importância da manutenção preventiva passar à responsabilidade do operador no sentido de que o mesmo passa a fazer parte de uma equipe, mais do que ser apenas mais um colaborador. A manutenção preventiva adquire importância estratégica no processo produtivo, na ótica de Spencer e Guide (1995). Isto se confirmou em sua pesquisa envolvendo 101 empresas americanas de vários ramos de atuação. Neste artigo, o programa de manutenção preventiva foi considerado o aspecto físico da empresa mais importante para o sucesso do uso de técnicas JIT. Também Kim e Takeda (1996), estudando a filosofia JIT e a cultura japonesa, colocam 
a manutenção preventiva entre os principais fatores de responsabilidade dos colaboradores numa empresa JIT. Forza (1996), comparando empresas tradicionais com empresas JIT, constata que a manutenção preventiva é um importante fator de diferenciação. Hancock e Zaiko (1998) mostram a ligação da manutenção preventiva com outros elementos do sistema JIT, tais como a multifuncionalidade e o uso de sistemas de alarme (Andon) e destacam o papel da manutenção preventiva para que os equipamentos sejam confiáveis. Imai (1998) é mais enfático, pois afirma que sem um bom programa de manutenção preventiva e gerenciamento da qualidade, o sistema JIT não pode sobreviver.

\subsection{5 - Ligados aos aspectos Organizacionais}

Neste bloco, além dos problemas relacionados às dificuldades de adaptação dos sistemas contábeis e de informação vigentes às novas premissas presentes num processo produtivo controlado por técnicas JIT, foi abordado também o aspecto da conjuntura econômica predominante na empresa e no país à época da adoção das técnicas JIT. A Tabela 9 - 'Fatores ligados aos aspectos Organizacionais", mostra os principais aspectos citados nos artigos.

Tabela 9 - Fatores ligados aos aspectos Organizacionais

\begin{tabular}{|c|c|c|c|c|c|}
\hline & & \multicolumn{4}{|c|}{ Autores e ano da publicação } \\
\hline & \multirow{2}{*}{$\begin{array}{c}\text { Fatores Críticos para a Implementação (FCI) } \\
\text { Ligados aos aspectos Organizacionais }\end{array}$} & 90 & 94 & 95 & 98 \\
\hline & & $\mathrm{a}$ & $\mathrm{b}$ & $\mathrm{C}$ & $\mathrm{d}$ \\
\hline 1 & Dificuldades de contabilização JIT & $\mathrm{X}$ & & $\mathrm{X}$ & \\
\hline 2 & Pobreza da previsão de demanda & & & & $\mathrm{X}$ \\
\hline 3 & Alterações no sistema de estoques & & $\mathrm{X}$ & & \\
\hline
\end{tabular}

Os aspectos estruturais são aqueles ligados ao ambiente externo da empresa (Silva, 2001) aqui caracterizados principalmente pela dinâmica da instalação de novas unidades montadoras de automóveis no Brasil, no período analisado por esta pesquisa.

Nesta pesquisa, na segunda fase, voltada a estudos de caso, foi analisada a forma de tratamento dos principais FCI identificados com a análise da literatura, visando maior aprofundamento na questão.

\section{5 - Técnicas JIT mais utilizadas}

Pela análise da literatura sobre JIT não foi possível fazer uma diferenciação clara e objetiva entre os termos elementos, técnicas ou práticas. Entretanto, um exame mais detalhado dos artigos que descrevem o funcionamento do JIT permitiu que se tenha uma visão mais 
objetiva de quais seriam os elementos, técnicas ou práticas que representam de forma mais significativa uma empresa que opera sob técnicas JIT.

Na descrição da conversão para o JIT, feita por Willis e Suter (1989), aparecem alusões aos problemas da movimentação dos materiais e produtos acabados. São destacados os cuidados com o set up, a simplificação das ferramentas e do layout como suportes à redução dos lotes de fabricação. Para que as melhorias ocorram com mais continuidade, seria ideal que fossem promovidas por aqueles que conhecem mais a fundo o processo, ou seja, os próprios operadores, o que cria as condições para o uso de círculos de controle de qualidade. Para que o ambiente de trabalho fique mais agradável, a aplicação dos conceitos de organização e limpeza mostra-se relevante. Como o estoque é reduzido, os espaços são melhor aproveitados, bem como o tempo, e há o interesse de que não ocorram interrupções no processo de produção, o que demanda operadores capazes de efetuar as correções necessárias nos equipamentos estimulando a necessidade da manutenção preventiva e da multifuncionalidade. $\mathrm{O}$ uso de células de produção reduz as movimentações de materiais, que só devem ser fabricados e movimentados com o uso de Kanbans. A previsibilidade da demanda é importante para manter o plano de produção estável o que significa um melhor relacionamento com os fornecedores, que devem ser em número reduzido e também, assim como as empresas, praticantes de controle estatístico de processo e de técnicas de solução de problemas.

Crawford e Cox (1991) enfatizam a necessidade de sincronismo entre os vários processos, o que é conseguido com a demanda estável e o uso do Kanban, mas que exige um sistema de manutenção preventiva eficiente num layout inteligente e integrado por células de produção operadas por funcionários multiespecializados trabalhando num espaço físico bem organizado (5S ou housekeeping).

Moras e Dieck (1992) estudaram 38 artigos sobre aplicação de técnicas JIT em empresas industriais publicados entre 1982 e 1990 e concluíram que nas empresas que adotam as técnicas JIT, aquelas utilizadas de forma mais freqüente são:
a) reestruturação do layout (27 empresas);
b) uso do Kanban (26 empresas);
c) certificação de fornecedores (18 empresas);
d) $\quad$ redução de set up (13 empresas); 
e) redução do tamanho de lotes (6 empresas) e

f) programas de manutenção preventiva (5 empresas).

Um artigo publicado por Lummus e Duclos-Wilson (1992) afirma que oito áreas principais da empresa são reestruturadas sob o regime JIT:

a) a fábrica, com alterações do layout, com uso de células de produção, redução de set up, alterações no manuseio de materiais, padronização de ferramental, uso de equipamentos dedicados e redução dos estoques;

b) os estoques, com a melhoria contínua da qualidade, a manutenção preventiva das máquinas e a eliminação dos estoques em processo;

c) a qualidade, com a qualidade assegurada e o uso de controle estatístico de processo;

d) o relacionamento com fornecedores, que passam a ser em número menor, mais responsáveis pela qualidade, entregando em menores lotes e mais freqüentemente. São exigidos quanto a melhorias da qualidade e a certificação;

e) os sistemas de controle de estoque passam a usar o Kanban;

f) a engenharia passa a desenvolver produtos simultaneamente com o comprador e com isso a comunicação deve ser aprimorada e

g) nos relacionamentos humanos, surgindo o conceito do trabalho em equipe, da participação nas decisões e as técnicas de solução de problemas.

Shahabuddin (1992) cita 13 elementos chave do sistema JIT em seu artigo sobre a adequação do sistema JIT às empresas americanas enfatizando que a maioria das empresas focaliza-se exclusivamente nas técnicas ou elementos, deixando de lado o aspecto estratégico da implementação. Dentre os elementos principais, destaca a estabilização da demanda, os baixos estoques e lotes de fabricação, o set up, o layout, a manutenção preventiva, a multifuncionalidade dos colaboradores, a qualidade dos produtos, o espírito de colaboração, os fornecedores confiáveis, o sistema Kanban, as técnicas de solução de problemas e as melhorias contínuas.

O sistema JIT pode incluir qualquer número de diferentes práticas de gerenciamento. Isto é postulado por White (1993) que destaca como as práticas mais comuns: a fábrica focalizada, a redução de set up, as células de produção, a manutenção preventiva, a 
multifuncionalidade, as compras JIT, a produção estável, o Kanban, o controle total de qualidade e os círculos de qualidade.

As práticas JIT foram estudadas em Singapura por Hum e Ng (1995) abrangendo 41 empresas de manufatura em diferentes indústrias, sendo 16 americanas, 10 japonesas, 9 de Singapura e 6 de outros países. A maioria das práticas estava no início de sua implementação e o resultado mostrou que a organização e limpeza (5S ou housekeeping) e o treinamento $e$ educação em técnicas JIT foram reconhecidas como as práticas principais, seguidas por redução de lotes, manutenção preventiva, multifuncionalidade, redução de set up, auto correção do trabalho, Kanban e círculos de controle de qualidade. Também neste artigo não foi percebida uma ordem geral de implementação, com os resultados mostrando que empresas da mesma indústria implementaram diferentes práticas JIT em diferentes seqüências.

Segundo Storhagen (1995) estas técnicas representam as mais utilizadas: Uso de Kanban, set up rápido, produção balanceada, lotes pequenos, layout adaptado, fazer certo da primeira vez, controle por horas extras, segurança e limpeza, máquinas pequenas, com boa manutenção e alto nível de automação.

Prasad (1995) cita várias técnicas alternativas às citadas acima, as quais nomeia como táticas: conceito de auto-inspeção, uso de Poka Yoke, simplificação do produto, trabalho multifuncional, uso de Andon e o conceito de zero defeito.

Num artigo propondo-se a analisar as mudanças que devem ocorrer numa empresa para transformar-se em JIT, Karlsson e Ahlström (1996) fazem uma modelagem subdividindo as áreas de impacto do JIT, suas principais determinantes e o que deve ocorrer para que a empresa se torne JIT. A seguir são indicadas as áreas:

a) eliminação de perdas: deve ocorrer redução de estoques em processo, tamanho de lotes, set up, máquinas paradas, movimentação de materiais, perdas com materiais, perdas de tempo e retrabalho;

b) melhoria contínua: deve ocorrer aumento das sugestões apresentadas e implementadas, nos círculos de controle de qualidade, nas equipes multifuncionais e na análise e solução de problemas;

c) zero defeitos: deve aumentar a responsabilidade pela identificação de problemas, a responsabilidade pelo ajuste e correção dos problemas e o controle dentro do processo. Por outro lado deve diminuir o número de pessoas ligadas exclusivamente ao 
controle da qualidade, o número de atividades que não são auto controladas e a área de retrabalho de peças com defeito;

d) processos JIT: devem ser reduzidos os tamanhos de lotes, o estoque em processo, o lead time e devem aumentar as operações JIT;

e) Kanban: deve-se aumentar o uso;

f) equipes multifuncionais: deve aumentar o percentual de pessoas trabalhando em equipe, o número de tarefas executadas por equipes, a rotação de tarefas entre os funcionários, o volume e variedade de treinamento. Deve diminuir o número de classificações de funções.

Pode ser notado que há uma multiplicidade de atividades que são consideradas como técnicas ou elementos ou práticas JIT, dependendo do enfoque usado pelo pesquisador.

Uma análise dos 50 artigos pesquisados que citam elementos, técnicas ou práticas JIT possibilitou a montagem da Tabela 10 - 'Principais Técnicas JIT', a qual relaciona os 20 artigos que citaram mais de quatro técnicas. Na literatura não existe uma diferença explícita entre os termos elementos, técnicas e práticas.

Tabela 10 - Principais Técnicas JIT

\begin{tabular}{|c|c|c|c|c|c|c|c|c|c|c|c|c|c|c|c|c|c|c|c|c|c|c|}
\hline Principais técnicas JIT & $a$ & $\mathrm{~b}$ & $\mathrm{C}$ & $d$ & $E$ & $f$ & $\mathrm{~g}$ & $\mathrm{~h}$ & $\mathrm{i}$ & $j$ & $\mathrm{k}$ & 1 & $\mathrm{M}$ & $\mathrm{n}$ & 0 & $p$ & $\mathrm{q}$ & $r$ & $\mathrm{~s}$ & $\mathrm{t}$ & Total & $\%$ \\
\hline Reducão de set un & $\begin{array}{lllll}\mathrm{y} & & \\
\end{array}$ & $\mathrm{V}$ & $\mathrm{Y}$ & $\mathrm{Y}$ & $\mathrm{y}$ & $\mathrm{Y}$ & $\mathrm{Y}$ & $\begin{array}{llll}y \\
\end{array}$ & $\mathrm{Y}$ & Y & $\mathrm{y}$ & $\mathrm{Y}$ & & & $\begin{array}{llll}y & \end{array}$ & 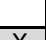 & $\mathrm{Y}$ & $\mathrm{Y}$ & $\mathrm{y}$ & $\begin{array}{llll}y & \end{array}$ & 21 & 1550 \\
\hline Kanban & & $\bar{y}$ & $\bar{y}$ & $\bar{x}$ & & $\mathrm{y}$ & & $\bar{y}$ & $\frac{\hat{v}}{\mathrm{y}}$ & & & $\frac{\mathrm{x}}{\mathrm{x}}$ & $\mathrm{y}$ & & 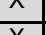 & $\hat{\Lambda}$ & 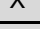 & $\frac{1}{y}$ & & $\frac{\hat{y}}{\mathrm{y}}$ & 24 & $14,5 \%$ \\
\hline Células de Produção & & & & & & & & & & & & & & & A & 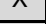 & & & & & & $12,0 \%$ \\
\hline & & $x$ & $x$ & $x$ & & $x$ & & $x$ & $x$ & & & & $x$ & & $x$ & $x$ & $x$ & $x$ & & $x$ & 19 & $11,4 \%$ \\
\hline Redução de lote de fabricação & $\mathrm{X}$ & $\mathrm{X}$ & $\mathrm{X}$ & $\mathrm{x}$ & $\mathrm{X}$ & $\mathrm{X}$ & $\mathrm{X}$ & $\mathrm{x}$ & & $\mathrm{X}$ & $\mathrm{x}$ & $\mathrm{X}$ & $\mathrm{X}$ & $\mathrm{X}$ & & $\mathrm{X}$ & $\mathrm{X}$ & & & & 14 & $8,4 \%$ \\
\hline $\begin{array}{l}\text { Melhoria contínua da } \\
\text { qualidade (kaizen) }\end{array}$ & & $\mathrm{X}$ & & & & & & & & & $\mathrm{x}$ & $\mathrm{X}$ & $\mathrm{X}$ & $x$ & & $\mathrm{x}$ & & & $x$ & & 19 & $11,4 \%$ \\
\hline $\begin{array}{l}\text { Plano de Manutenção } \\
\text { preventiva }\end{array}$ & & & & & & $\mathrm{X}$ & & & $\mathrm{X}$ & $\mathrm{X}$ & $\mathrm{x}$ & $\mathrm{X}$ & $\mathrm{X}$ & & $\mathrm{X}$ & $\mathrm{x}$ & $\mathrm{X}$ & & $\mathrm{X}$ & & 11 & $6,6 \%$ \\
\hline $\begin{array}{l}\text { Técnicas de Solução de } \\
\text { Problemas }\end{array}$ & & $\mathrm{X}$ & & & & $\mathrm{X}$ & & & $\mathrm{X}$ & & $\mathrm{x}$ & $\mathrm{X}$ & $\mathrm{X}$ & $\mathrm{X}$ & & & & & $\bar{x}$ & & 10 & $6,0 \%$ \\
\hline Plano de produção nivelado & $\mathrm{X}$ & $\mathrm{X}$ & & & & $\mathrm{X}$ & & $\mathrm{X}$ & & & $\mathrm{x}$ & & $\mathrm{X}$ & & $\mathrm{X}$ & $\mathrm{X}$ & & & $\mathrm{X}$ & & 10 & $6,0 \%$ \\
\hline$\overline{C C Q}$ & $\mathrm{X}$ & $\mathrm{X}$ & & & & $\mathrm{X}$ & $\mathrm{X}$ & $\mathrm{X}$ & & & & & & & $\mathrm{X}$ & $\mathrm{X}$ & $\mathrm{X}$ & & & & 10 & $6,0 \%$ \\
\hline $\begin{array}{l}\text { Controle estatístico de } \\
\text { processo }\end{array}$ & & & & & & $\mathrm{X}$ & & & & & & & $\mathrm{X}$ & & & & $\mathrm{X}$ & & $\mathrm{X}$ & & 8 & $4,8 \%$ \\
\hline Cinco S (housekeeping) & & & & & & $\mathrm{X}$ & & & & $\mathrm{X}$ & & & & & & $\mathrm{X}$ & & & $\mathrm{X}$ & $\mathrm{X}$ & 6 & $3,6 \%$ \\
\hline Fornecedores único & & $\bar{x}$ & $\mathrm{X}$ & & $\mathrm{X}$ & $\mathrm{X}$ & & & & & & & & $\bar{X}$ & & & & & & & 6 & $3,6 \%$ \\
\hline Controle visual & & & & & & & & & $X$ & & & $\mathrm{X}$ & & & & $x$ & & $x$ & & $\mathrm{X}$ & 5 & $3,0 \%$ \\
\hline $\begin{array}{l}\text { Poka yoke (controle } \\
\text { autônomo) }\end{array}$ & & & & & & & & & & & & & & & & & $\mathrm{X}$ & & & & 1 & $0,6 \%$ \\
\hline Total das técnicas citadas & 4 & 9 & 5 & 4 & 3 & 11 & 4 & 6 & 6 & 4 & 6 & 7 & 8 & 4 & 6 & 10 & 7 & 4 & 7 & 5 & 166 & \\
\hline
\end{tabular}

Autores: a) AGGARWAL, Sumer C. (1985); b) WALLEIGH, Richard C. (1986); c) MALLEY, John C.; RAY Ruthann. (1988); d) MANOOCHEHRI. G. H. (1988); e) VICKERY, Shawnee K. (1989); f) WILLIS, Hillman T.; SUTER, William C. Jr. (1989); g) GOLHAR, Damodar Y.; STAMM, Carol L.; SMITH, Wayland P. (1990); h) BILLESBACH, Thomas J. (1991), i) CRAWFORD, Karlene M.; COX, James F. (1991); j) GREEN, F.B.; AMENKHIENAN, Cma; JOHNSON, George. (1991); k) INMAN, R. Anthony; BRANDON, Larry D. (1992); L) SOHAL, Amrik S.; NAYLOR, Derek. (1992); m) BOER, Harry; KRABBENDAM, Koos. n) GOLHAR, Damodar Y., DESHPANDE, Satish P. (1993); o) HENDRICKS, James A. (1994); p) YASIN, Mahmoud M., WAFA, Marwan A. (1996); q) FORZA, Cipriano. (1996); r) ZAYKO, Matthew J., BROGHMAN, Douglas J., HANCOCK, Walton M. (1997); s) HANKOCK, M Walton e ZAYKO, J Matthew. (1998); t) JUSKO, Jill. (1999). 
Visando definir quais são as empresas usuárias de técnicas JIT, objeto da primeira fase da pesquisa de campo, foi analisada a implementação das seguintes técnicas nas empresas industriais de Sorocaba, sendo estas técnicas as mais comuns encontradas nos artigos analisados:

a) Redução de set up;

b) Kanban;

c) Células de Produção;

d) Redução de lote de fabricação;

e) Melhoria contínua da qualidade (kaizen);

f) Técnicas de Solução de Problemas;

g) Plano de Manutenção Preventiva;

h) Plano de Produção Nivelado;

i) Círculos de Controle de Qualidade;

j) Controle estatístico de processo;

k) $\quad$ Cinco S (housekeeping);

1) Fornecedores únicos;

m) Controle Visual (Andon);

Os detalhes sobre esta fase da pesquisa podem ser verificados no Capítulo 4 Metodologia.

\section{6 - Sinopse}

O conceito de JIT foi considerado nesta pesquisa como sendo uma filosofia de gestão da produção baseada na Redução de Perdas pela aplicação de técnicas voltadas à Melhoria da Qualidade/Produtividade visando alcançar a Excelência na Manufatura.

O JIT fundamenta-se em um conjunto de técnicas inter-relacionadas, dentre as quais incluem-se um arranjo físico (célula de produção), que permite melhor comunicação e fluxo produtivo (controlado por meio do Kanban) e, quando aliado à redução do tempo de set up, permite a diminuição dos lotes de produção e conseqüente queda do nível de estoque e custos a ele associados. Nas células de produção formam-se normalmente equipes, cujos membros são multifuncionais, ou capazes de operar diversas máquinas e equipamentos, o que exige um 
esforço especial de educação e treinamento, ao mesmo tempo em que melhora o moral dos indivíduos. A mudança de comportamento, incluindo a colaboração, apresenta-se como ponto relevante. Constituindo-se em mini-fábricas, estas células de produção devem contar com um ambiente limpo e organizado, enfatizado na prática de housekeeping ou 5S. Os CCQ apresentam-se como meios para que os funcionários busquem soluções para os problemas cotidianos do trabalho, sendo apoiadas pelo treinamento em técnicas de solução de problemas. As sugestões, comunicadas pelos CCQ ou por outros meios formais e informais, apóiam a ocorrência sistemática da Melhoria Contínua (kaizen). A redução de estoque exige um maior destaque para qualidade (com os conceitos de qualidade na fonte e CEP) e manutenção preventiva. O papel dos fornecedores é relevante, criando-se relações de parceria e enfatizando a qualidade, confiabilidade e entregas JIT frente ao preço.

Dentre os principais resultados obtidos com o uso de técnicas JIT destacaram-se a redução de estoques e sua maior rotação, aumento da qualidade, redução de lead time; diminuição das perdas e retrabalho; redução de custos e aumento da produtividade e flexibilidade. Os estudos que indicam estes resultados, creditando-os ao uso de técnicas JIT, porém, não analisam outros programas implementados concomitantemente pelas empresas estudadas, tais como Certificação em Sistemas da Qualidade, que podem afetar os resultados de forma significativa. Mais além, não foram encontradas análises da relação custo benefício relacionada ao uso de técnicas JIT, assim como uma visão do resultado global do uso de técnicas JIT na empresa, incluindo aspectos mercadológicos.

Como principais problemas para a Implementação de técnicas JIT, foram identificados: falta de Apoio da Alta Administração (envolvendo falta de apoio e comunicação); falta de preparação dos recursos humanos (abrangendo aceitação pelos funcionários e sindicalização do trabalhador), falta de adaptação dos fornecedores (qualidade do fornecimento, incentivo aos fornecedores para usar técnicas JIT, pressão/força dos fornecedores, cooperação com empresas externas); problemas geográficos/logísticos (estrutura de transporte ruim, dispersão geográfica/custos de transporte) e problemas organizacionais (dificuldades de contabilização JIT, pobreza da previsão de demanda e alterações no sistema de estoques).

Cinco Fatores Críticos para a Implementação foram identificados: aqueles ligados ao Comprometimento da Administração (apoio da alta administração, sistema formal para ouvir sugestões de funcionários, autoridade para parar a linha de produção, comunicação, treinamento para gerência em técnicas JIT, cooperação entre funcionários e investigar e 
implementar sugestões); Educação e Treinamento (CCQ, Educação e Treinamento para JIT, multifuncionalidade, equipe JIT, consultoria externa para implementação, JIT Champion, projeto piloto, melhoria contínua e visão de futuro); Fornecedores (fornecedor único, redução do lead time do fornecedor, redução do lote de compra, certificação de fornecedores, comunicação com fornecedores, relacionamento com fornecedores, contratos de longo prazo, entrega rápida e confiável, planejamento da logística, treinamento de fornecedores); Produção (células de produção, redução do tempo de set up, manutenção preventiva, produção nivelada (balanceamento da linha), redução do lote de fabricação, layout, automatização, CEP, flexibilidade do sistema produtivo, qualidade, redução de perdas e simplificação na lista de materiais) e Organizacionais (dificuldade de contabilização JIT, pobreza da previsão de demanda, alterações no sistema de estoques). Os artigos que tratam dos FCI os focalizam, porém, de forma isolada, sem, no entanto, analisar o processo de implementação.

Finalmente, como técnicas JIT mais citadas, foram identificadas a redução do tempo de set up, Kanban, células de produção, redução do lote de fabricação, melhoria contínua da qualidade (kaizen), plano de manutenção preventiva, técnicas de solução de problemas, plano de produção nivelado, CCQ, CEP, 5S, fornecedor único, controle visual e poka yoke. 


\section{Capítulo 4 - Metodologia}

A complexidade do tema em estudo, a despeito de trazer uma vasta bibliografia disponível como base de análise, fez com que o aspecto metodológico desta pesquisa merecesse uma atenção redobrada. Assumir uma pesquisa exclusivamente quantitativa poderia levar a resultados muito superficiais, pois como bem coloca Brannen (1992: 4) "o pesquisador quantitativo olha por lentes estreitas". Por outro lado, restringir-se a uma pesquisa qualitativa poderia levar à negligência de empresas importantes para a análise que se pretende fazer da região industrial considerada, dado que seria difícil ter uma idéia mais precisa do universo da pesquisa. A pesquisa qualitativa apresenta vantagens, como colocam Miles e Huberman (1994: 6), "a pesquisa qualitativa tem contato intenso com a situação em estudo e isto produz um maior aprofundamento sobre o problema". Outra defesa irrestrita da pesquisa qualitativa aparece em Silverman (1993: 27) que enfatiza o fato de "a pesquisa qualitativa prover uma versão mais ampla da teoria do que uma simples correlação entre variáveis". Creswel (1994: 145) destaca a importância de uma pesquisa qualitativa mostrando que esta se preocupa mais intensamente com o "processo" do que com os "resultados", ou

seja, busca voltar-se mais para o significado dos fatos do que os próprios fatos em si. Já a coleta de dados envolve mais do que questionários, visto que a interação entre pesquisador e pesquisado é mais próxima e intensa, permitindo que outras observações possam ser realizadas, uma vez que as "co ndições naturais" do pesquisado são reveladas ao pesquisador. Outro aspecto importante é que a pesquisa qualitativa é descritiva e interpreta mais que o significado das palavras e dados, pela ação do pesquisador criando abstrações, conceitos, hipóteses e teorias a partir dos detalhes constatados junto ao pesquisado.

A partir destas considerações, já é claramente perceptível que ambas as abordagens têm suas qualidades e deficiências.

Visando aproveitar ao máximo o potencial de cada uma das técnicas de pesquisa, a opção nesta pesquisa foi por desenvolvê-lo em duas fases distintas adotando o processo proposto por Braneen (1992), em que a fase qualitativa se desenvolve depois da fase quantitativa, pois os dados quantitativos servem de suporte para a amostragem de casos e grupos de comparação que formarão o grupo de estudo qualitativo.

A Tabela 11 - Processo de Construção de Teorias a partir da Pesquisa de Estudos de Caso, mostra, em síntese, cada passo da metodologia adotada e a respectiva adequação à realidade desta pesquisa. 
Tabela 11 - Processo de Construção de Teorias a partir da Pesquisa de Estudos de Caso

\begin{tabular}{|c|c|c|c|}
\hline Passo & Atividade & Motivo & Forma de aplicação nesta pesquisa $(*)$ \\
\hline \multirow[t]{3}{*}{ Início } & Definição da questão de pesquisa & Focaliza os esforços & A partir de revisão de literatura - vide 4.1 \\
\hline & Possivelmente conceitos a priori & $\begin{array}{l}\text { Fornece melhor fundamento das medidas dos } \\
\text { conceitos }\end{array}$ & $\begin{array}{l}\text { Definição de JIT e Fatores Críticos para a } \\
\text { Implementação - vide capítulo } 3\end{array}$ \\
\hline & Ausência de teoria e hipóteses & Retém a flexibilidade teórica & Não há hipótese sobre a questão de pesquisa \\
\hline \multirow[t]{2}{*}{ Seleção de casos } & População especificada & $\begin{array}{l}\text { Limita a variação exógena e aumenta a validade } \\
\text { externa }\end{array}$ & Primeira etapa da pesquisa de campo - vide 4.2 \\
\hline & Amostragem teórica, não aleatória & $\begin{array}{l}\text { Focaliza os esforços em casos teoricamente úteis - p. } \\
\text { ex., aqueles que repetem ou estendem a teoria } \\
\text { cobrindo categorias conceituais }\end{array}$ & $\begin{array}{l}\text { Seleção de empresas que mais usavam técnicas JIT e } \\
\text { inclusão da Empresa E por experiência do orientador - } \\
\text { vide } 4.3 .1\end{array}$ \\
\hline \multirow[t]{3}{*}{$\begin{array}{l}\text { Modelando instrumentos e } \\
\text { protocolo }\end{array}$} & Múltiplos métodos de coleção de dados & $\begin{array}{l}\text { Fortalece a fundamentação da teoria pela triangulação } \\
\text { das evidências }\end{array}$ & Entrevistas pessoais e visitas às instalações - vide 4.3 .2 \\
\hline & Dados qualitativos e quantitativos combinados & Visão sinergística das evidências & $\begin{array}{l}\text { Predominância de informações qualitativas com } \\
\text { algumas quantitativas, especialmente as relativas a } \\
\text { resultados - vide } 4.3 .3\end{array}$ \\
\hline & Múltiplos investigadores & $\begin{array}{l}\text { Incentiva perspectivas divergentes e fortalece a } \\
\text { fundamentação }\end{array}$ & $\begin{array}{l}\text { O pesquisador e um aluno de Iniciação Científica - } \\
\text { vide item 4.3.2 }\end{array}$ \\
\hline \multirow[t]{2}{*}{ Ir a campo } & $\begin{array}{l}\text { Superposição da análise e coleta de dados, incluindo } \\
\text { anotações }\end{array}$ & $\begin{array}{l}\text { Dá velocidade à análise e revela ajustes úteis ao } \\
\text { processo de coleta de dados }\end{array}$ & $\begin{array}{l}\text { Intervalos entre entrevistas para análise de dados - vide } \\
\text { item 4.3.5 }\end{array}$ \\
\hline & $\begin{array}{l}\text { Métodos de coletas de dados flexíveis e adaptados às } \\
\text { oportunidades }\end{array}$ & $\begin{array}{l}\text { Permite aos pesquisadores beneficiar-se dos temas } \\
\text { emergentes e características únicas dos casos }\end{array}$ & Ajustes no roteiro de pesquisa - vide item 4.3.4 \\
\hline \multirow[t]{2}{*}{ Análise dos dados } & Análise dentro dos casos & $\begin{array}{l}\text { Permite o ganho de familiaridade com os dados e } \\
\text { geração preliminar de teoria }\end{array}$ & $\begin{array}{l}\text { Transcrição das entrevistas e observações - vide item - } \\
\text { 4.3.5 }\end{array}$ \\
\hline & $\begin{array}{l}\text { Busca de padrões entre casos usando técnicas } \\
\text { divergentes }\end{array}$ & $\begin{array}{l}\text { Força os pesquisadores a olhar além das impressões } \\
\text { iniciais e ver as evidências através de diversas lentes }\end{array}$ & $\begin{array}{l}\text { Comparação cronológica e por FCI entre os casos - } \\
\text { vide item 4.3.5 }\end{array}$ \\
\hline \multirow[t]{3}{*}{ Formulação de hipóteses } & Tabulação iterativa das evidências para cada conceito & $\begin{array}{l}\text { Torna mais incisiva a definição, validade e } \\
\text { mensurabilidade dos conceitos }\end{array}$ & \multirow{3}{*}{$\begin{array}{l}\text { Hipóteses geradas a partir da análise iterativa dos } \\
\text { resultados cruzados por } \mathbf{F C I} \text { - vide item 4.3.6 e } 5.4\end{array}$} \\
\hline & Replicação, não amostragem, lógica entre os casos & Confirma, estende e torna mais incisiva a teoria & \\
\hline & $\begin{array}{l}\text { Busca de evidências relacionadas ao "por quê" } \\
\text { subjacente às relações }\end{array}$ & Fortalece a validade interna & \\
\hline \multirow[t]{2}{*}{ Abrangendo a literatura } & Comparação com a literatura discrepante & $\begin{array}{l}\text { Constrói validade interna, eleva o nível teórico, e torna } \\
\text { mais incisiva a definição dos conceitos }\end{array}$ & $\begin{array}{l}\text { Breve em função da ausência de estudos sobre o } \\
\text { processo de implementação }\end{array}$ \\
\hline & Comparação com a literatura semelhante & $\begin{array}{l}\text { Incrementa a possibilidade de generalização, melhora } \\
\text { a definição dos conceitos, e eleva o nível teórico }\end{array}$ & $\begin{array}{l}\text { Comparação realizada com a literatura sobre } \mathbf{F C I} \text { - } \\
\text { vide item } 4.3 .7 \text { e } 6.1\end{array}$ \\
\hline Conclusão & Saturação teórica quando possível & $\begin{array}{l}\text { Término do processo quando o progresso marginal } \\
\text { torna-se pequeno }\end{array}$ & \\
\hline
\end{tabular}




\section{1 - Definição da questão de pesquisa}

Segundo Yin (1989), determinar as questões de pesquisa que são mais significativas para um tema e ganhar alguma precisão na formulação destas questões requer preparo. Um importante apoio neste sentido é a revisão de literatura sobre o tema, que não se constitui num fim em si mesma - na resposta às questões - mas em um auxílio na determinação de questões mais incisivas.

Uma revisão de literatura sobre implementação de técnicas JIT permitiu identificar e fundamentar os Fatores Críticos para Implementação cuja forma de tratamento foi analisada nas empresas pesquisadas. É importante destacar que nenhuma hipótese sobre a forma como estes fatores devem ser tratados foi levantada a priori, mantendo coerência com a proposta de Eisenhardt (1989).

\section{2 - Primeira fase da pesquisa de campo}

Partindo da constatação de quais são as principais técnicas JIT usadas nas empresas por meio da revisão bibliográfica (ver 3.5 - Técnicas JIT mais utilizadas) se fez necessário conhecer esta realidade na região de Sorocaba, a região escolhida para a pesquisa de campo.

Para tanto, foi desenvolvida uma pesquisa de caráter exploratório, aproveitando a participação deste autor em uma pesquisa institucional em andamento aplicada às empresas industriais de Sorocaba, intitulada 'Estratégias e Implicações da Reestruturação Industrial em Sorocaba", promovida pelo Núcleo de Pesquisas em Ciências Sociais Aplicadas da Universidade de Sorocaba, contando com a participação deste autor.

Os objetivos da referida pesquisa eram, entre outros, apontar as estratégias adotadas mais freqüentemente pelas empresas industriais de Sorocaba entre 1997 e 2000, para aumentar a produtividade do trabalho, melhorar a qualidade e reduzir custos.

Isto possibilitou que fossem inclusas questões (ver Anexo B - Questionário usado na primeira fase da pesquisa) que puderam verificar o uso de técnicas JIT dentre aquelas identificadas como as mais comuns pela pesquisa bibliográfica, citadas no Capítulo 3.5 Técnicas JIT mais utilizadas.

Desta forma, esta etapa permitiu identificar as empresas que aplicam técnicas JIT em seus processos produtivos, bem como quais técnicas JIT eram mais comuns entre as empresas pesquisadas. 


\subsection{1 - Amostragem}

Tomando por base o relatório do CAGESP - Cadastro Geral das Empresas de São Paulo - ano 2000, constatou-se a existência de cerca de 1600 empresas industriais no município de Sorocaba. Dentre estas, 164 empresas têm 30 funcionários ou mais, as quais formaram o universo da pesquisa, por reunirem, na visão da equipe de pesquisa, as melhores condições para participarem do projeto. Assim, a amostragem atendeu ao critério não probabilístico do tipo "casos críticos" ( critical cases) pelo fato de os participantes terem sido escolhidos em virtude de representarem casos essenciais ou chave para o foco da pesquisa, conforme proposto por Bickman e Rog (1997).

O município de Sorocaba foi escolhido como uma das sedes das empresas pesquisadas por dois motivos fundamentais:

a) A Uniso - Universidade de Sorocaba - tem uma linha de pesquisa voltada à área industrial, que conta com a participação do autor desta pesquisa;

b) $\mathrm{O}$ tema desta pesquisa insere-se adequadamente na linha de pesquisa da Uniso e, portanto, possibilita que o interesse do pesquisador se afine com as necessidades institucionais, criando, assim, melhores condições operacionais de realização da mesma.

A coleta de dados em campo deu-se por meio de um questionário estruturado que foi aplicado a um dos seguintes representantes da empresa: (a) Superintendente Industrial; (b) Gerente de Produção; (c) Chefe de Produção. Ver Anexo B - Questionário usado na primeira fase da pesquisa.

\subsection{2 - Pré-teste da primeira fase da pesquisa de campo}

O pré-teste ocorreu em novembro de 2000, com a aplicação do questionário a um grupo de profissionais participantes do curso de pós-graduação lato sensu em Administração da Produção e Logística da Universidade de Sorocaba, que representam 29 empresas de diversos setores de atuação. O perfil geral do grupo de empresas e seus representantes é mostrado na Tabela 12 - Empresas participantes do pré-teste da primeira fase da pesquisa de campo. 
Tabela 12 - Empresas participantes do pré-teste da primeira fase da pesquisa de campo

\begin{tabular}{|c|c|c|c|}
\hline Empresa & Setor de atuação & $\begin{array}{l}\text { Função do } \\
\text { respondente }\end{array}$ & $\begin{array}{c}\text { Tempo na } \\
\text { empresa }\end{array}$ \\
\hline Agrostahl & Agroindústria, Fertilizantes & Tecnólogo & 2 anos \\
\hline Agrowiggins Ltda. & Agroindústria, Fertilizantes & Analista de sistemas & 20 anos \\
\hline Alcoa Alumínio S A & \begin{tabular}{|l|} 
Metalúrgica, Siderúrgica \\
\end{tabular} & Comprador & 7 anos \\
\hline $\begin{array}{l}\text { CBA - Companhia Brasileira } \\
\text { de Alumínio }\end{array}$ & Metalúrgica, Siderúrgica & Projetista & 11 anos \\
\hline CCE & Eletroeletrônico, Informática & Comprador Internacional & 1,5 anos \\
\hline Cimento Votoran & Construção Civil & Adm. de materiais & 14 anos \\
\hline Cuno Latina Ltda. & Autopeças, Automobilística & Adm. de vendas & 5 meses \\
\hline Dana & Autopeças, Automobilística & Supervisor de PPCM & 11 anos \\
\hline De Villatte & Autopeças, Automobilística & Eng. Metalúrgico & 2 anos \\
\hline Dental Pássaro & Farmacêutica & Comprador & 2 meses \\
\hline Dixie Toga & Plásticos e Borracha & Chefe de manutenção & 12 anos \\
\hline Dragoco & Química e Petroquímica & Eng. Químico & 2 anos \\
\hline Duratex & Papel e Celulose & Supervisor de PCP & 2,5 anos \\
\hline $\begin{array}{l}\text { FBA - Fundição Brasileira de } \\
\text { Alumínio }\end{array}$ & Metalúrgica, Siderúrgica & $\begin{array}{l}\text { Encarregado de Expedição } \\
\text { e Faturamento }\end{array}$ & 1 ano \\
\hline Ferplast & Plásticos e Borracha & Assistente de Vendas & 3 anos \\
\hline GMB & Autopeças, Automobilística & Analista de Processos & 5 anos \\
\hline Heller & Máquinas e Equipamentos & Chefe de Produção & 12 anos \\
\hline INA & Autopeças, Automobilística & Gerente de logística & 15 anos \\
\hline Indústrias Votorantim & Construção Civil & Administrador & 3 anos \\
\hline J. I. Case do Brasil & Autopeças, Automobilística & Supervisor de Produção & 10 anos \\
\hline Linhanyl & $\begin{array}{ll}\begin{array}{l}\text { Têxtil, Lona, } \\
\text { Confecção }\end{array} & \text { Couro, } \\
\end{array}$ & Encarregado de Materiais & 1 ano \\
\hline Luk do Brasil & Autopeças, Automobilística & Chefe de ferramentaria & 26 anos \\
\hline Metalac & Metalúrgica, Siderúrgica & Coord. de Logística & 2 meses \\
\hline NCNB & Agroindústria, Fertilizantes & Eng. Agrônomo & 16 anos \\
\hline Portocruz Ind. e Com. Ltda. & Autopeças, Automobilística & Diretor & 10 anos \\
\hline RCD Faróis & Autopeças, Automobilística & Comprador & 4 anos \\
\hline Thermold S. A. & Metalúrgica, Siderúrgica & Analista de Vendas & 3 anos \\
\hline Unimetal & Metalúrgica, Siderúrgica & Gerente Geral & 11 anos \\
\hline YKK do Brasil & $\begin{array}{l}\begin{array}{l}\text { Têxtil, Lona, } \\
\text { Confecção }\end{array} \\
\end{array}$ & Eng. Processos & 10 anos \\
\hline
\end{tabular}

Nota-se que o parque industrial do grupo de empresas pesquisadas nesta fase é diferenciado, entretanto, predominando as empresas do setor Autopeças/Automobilística (8 empresas) e do setor Metalúrgica/Siderúrgica (7 empresas), que juntas somam mais de 50\% das empresas pesquisadas. Dez dos respondentes do pré-teste estão em funções características de Chefia e o tempo médio de empresa é de 7,5 anos, não tendo sido constatada nenhuma dificuldade em responder ao questionário, mesmo entre os mais "hovos" de casa.

Os resultados do pré-teste indicaram que o formulário utilizado (Anexo B Questionário usado na primeira fase da pesquisa) mostrou-se adequado para identificar as técnicas que vem sendo aplicadas a partir de 1997, bem como as empresas que mais empregam as técnicas JIT. Portanto, nenhuma alteração no questionário foi necessária dado que os termos utilizados foram entendidos na sua essência pelos participantes do pré-teste. 


\subsection{3 - A coleta de dados da primeira fase da pesquisa de campo}

Os questionários de pesquisa (Anexo B - Questionário usado na primeira fase da pesquisa) foram aplicados às empresas por duplas de alunos de graduação em Administração de Empresas supervisionados por professores da disciplina de Métodos e Técnicas de Pesquisa do curso.

\subsection{4 - Resultados da primeira fase da pesquisa de campo}

Foram tabulados com o auxílio do SPSS 7.5 for Windows Student Version.

\section{3 - Segunda fase da pesquisa de campo}

Esta fase da pesquisa constituiu-se de um estudo multicaso, de cunho predominantemente qualitativo, das empresas usuárias das práticas ou técnicas JIT com base nos resultados da primeira fase da pesquisa de campo. Conforme Yin (1989), o estudo de caso pode ser definido como uma pesquisa empírica que investiga um fenômeno contemporâneo dentro de seu contexto na vida real, sendo que os limites entre o fenômeno e o contexto não são claramente evidentes e múltiplas fontes de evidências são utilizadas. Esta estratégia de pesquisa é indicada para responder questões do tipo "como" ou "por quê".

A pesquisa qualitativa tem sido ao longo do tempo, utilizada em ciências sociais clássicas, como História e Antropologia. Recentemente, pesquisadores de outros campos, incluindo a Administração e Negócios, têm usado métodos qualitativos para investigar e entender importantes características de seus respectivos campos (Miles e Huberman, 1994).

Os dados qualitativos são obtidos, costumeiramente, a partir de entrevistas, observações, documentações e vídeos (Strauss e Corbin, 1989) e são organizados de forma a conter ricas descrições de processos que, de outra forma, não poderiam ser obtidas. Dada a escassez de pesquisas sobre implementação de técnicas JIT em empresas brasileiras, a metodologia de estudo de caso se torna a mais adequada (Eisenhardt, 1989) pela sua maior capacidade de responder "o por quê" da ocorrência de um fenômeno.

Deve-se considerar, entretanto, que a aplicação de métodos qualitativos não é simples ou livre de problemas. Tomem-se, por exemplo, as dificuldades de apuração da validade e da confiabilidade dos resultados, apontada por Miles e Huberman (1994). Visto que o volume de dados se torna expressivo, Eisenhardt (1989) aponta para a dificuldade de estabelecer relações na formulação da teoria. Entretanto, a despeito destes problemas, este método mostra-se como uma poderosa ferramenta na análise de uma questão tão complexa como a implementação de técnicas JIT. 


\subsection{1 - Seleção dos casos}

Foram pesquisadas cinco empresas, dentro do intervalo sugerido por Eisenhardt (1989), de 4 a 10 casos. Estes números devem-se ao fato de que, com menos de 4 casos, torna-se difícil gerar teorias complexas e a fundamentação empírica tende a não ser convincente; por outro lado, com mais de 10 casos, existe um grande risco de perder-se na complexidade e volume de dados.

Com base nos resultados da primeira fase da pesquisa, quatro empresas foram escolhidas dentre as empresas que apresentaram maior quantidade de técnicas JIT implementadas ou em fase de implementação. As quatro primeiras, que mais técnicas JIT apontaram, são todas do setor de autopeças. Mais uma empresa, escolhida pela experiência na utilização de técnicas JIT, cuja sede industrial está localizada na cidade de Amparo - SP, completou a amostragem das empresas pesquisadas. Este método de amostragem é descrito por Bickman e Rog (1997) como amostragem de casos típicos. Tal medida, ou seja, inclusão de empresas nesta fase da pesquisa é prática saudável em pesquisas qualitativas baseadas em estudo de caso, também na visão de Eisenhardt (1989), visto que os casos são escolhidos não por fundamentação estatística, mas por experiência do pesquisador, e que aqui se justifica pelo fato de a nova empresa ser usuária de técnicas JIT. Creswel (1994), por sua vez, é mais radical neste aspecto, afirmando que "nenhuma" tentativa de selecionar randomicamente as empresas deve ser feita em estudos qualitativos.

Nesta pesquisa, por iniciativa do autor, as empresas escolhidas foram todas do setor de autopeças, dado que o desenvolvimento inicial do uso de técnicas JIT ocorreu principalmente em empresas deste setor, mais precisamente na montadora Toyota japonesa; foram também todas multinacionais, de forma a minimizar a influência de variáveis exógenas tal como defendido por Eisenhardt (1989).

As empresas foram convidadas a participar da pesquisa através de uma carta endereçada ao Diretor Presidente contendo em detalhes os objetivos da pesquisa e os benefícios que os resultados poderiam trazer para a comunidade empresarial de Sorocaba, a partir dos resultados finais da pesquisa. Esta carta-convite foi encabeçada pelo Diretor do Centro de Ciências Sociais Aplicadas da Universidade de Sorocaba e pelo autor da pesquisa, deixando claro o cuidado e a responsabilidade pelo sigilo das informações coletadas.

A Tabela 13 indica as cinco empresas pesquisadas, destacando as quatro primeiras escolhidas pelo resultado da primeira fase da pesquisa de campo e a última pela reconhecida experiência em aplicação de técnicas JIT. 
Tabela 13 - Empresas pesquisadas na segunda fase da pesquisa de campo

\begin{tabular}{c|l|l}
\hline Empresa & \multicolumn{1}{|c|}{ Principais produtos } & \multicolumn{1}{c}{ Capital } \\
\hline A & Eixos diferenciais leves, componentes para reposição & Americano \\
\hline B & Fabricação de componentes automotivos, rolamentos. & Alemão \\
\hline C & Baterias automotivas & Alemão, Americano e Mexicano \\
\hline D & Embreagens automotivas & Alemão \\
\hline E & Sistemas de exaustão automotivos & Italiano \\
\hline
\end{tabular}

\subsection{2 - Métodos para coleta de informações}

Tal como recomendado por Eisenhardt (1989), múltiplos métodos de coleta de informações devem ser utilizados, de forma a permitir a triangulação de evidências. Nesta pesquisa foram utilizadas a entrevista pessoal e a observação direta na visita às instalações produtivas.

O roteiro (Anexo C - Roteiro usado na Segunda fase da pesquisa de campo) foi utilizado como suporte à coleta de dados por meio de entrevista, citada por Yin (1989) como uma das mais importantes fontes de informação para pesquisas baseadas em estudos de casos.

Alguns cuidados devem ser tomados na formatação do roteiro de pesquisa. Fink (1995) propõe que o roteiro de pesquisa deve usar termos consagrados quanto ao problema da pesquisa, os entrevistados devem ser escolhidos por seu reconhecido envolvimento e conhecimento sobre o assunto e o roteiro de pesquisa deve ser padronizado para grupos homogêneos, ou seja, o mesmo roteiro de pesquisa seria utilizado com todos os informantes entrevistados, entretanto, Eisenhardt (1989) propõe que se os instrumentos de pesquisa sejam adaptados a oportunidades e situações específicas.

Face ao fato de que as técnicas JIT apresentam impacto em várias áreas das empresas, tais como a Alta Administração, a Produção, a Engenharia e Qualidade, a Gestão de Recursos Humanos, Suprimentos e Vendas, o processo de entrevistas foi realizado envolvendo estas seis grandes áreas de cada empresa pesquisada. Portanto, foram entrevistados os Diretores, Gerentes ou Chefes de Produção, de Engenharia/Qualidade, de Recursos Humanos, Suprimentos e de Vendas.

Como os representantes de cada área auxiliaram na elucidação de aspectos específicos, o roteiro de pesquisa foi adaptado para cada área funcional, sendo enviada previamente uma cópia do roteiro como forma de melhorar a qualidade das respostas por possibilitar que o entrevistado prepare dados que completem as informações necessárias. Foi explicitamente facultado ao entrevistado ser acompanhado de terceiros que possam auxiliá-lo no 
esclarecimento dos dados necessários. Conforme Bradburn e Sudman (1980) a presença de terceiros na entrevista não distorce os resultados finais.

Seidman (1991) frisa que o objetivo de uma entrevista não é apenas receber respostas a uma pergunta, nem testar hipóteses. A raiz da entrevista está no entendimento da experiência pela qual outras pessoas passam. Por isso chama a atenção para o cuidado que o entrevistador deve ter em não interferir na resposta. Neste sentido, a cada entrevista foi solicitada autorização do entrevistado para a gravação e/ou filmagem da entrevista, desde que não causassem algum tipo de inibição ao entrevistado, além do convencional uso das "hotas de entrevista".

As questões foram predominantemente de tipo aberta e qualitativa, que segundo Schuman, (1996) forçam o entrevistado a formular um contexto para a resposta, melhorando a qualidade dos dados expostos, embora tenham sido utilizadas também algumas questões de cunho quantitativo, relacionadas principalmente a resultados alcançados (redução de espaço utilizado, tamanho de lotes, etc).

A confiabilidade dos resultados foi buscada pela estruturação do roteiro de pesquisa em face do problema de pesquisa e pela manutenção dos critérios de análise. Para Kirk e Miller (1986) esta providência garante a confiabilidade. Já a validade dos resultados pode ser assegurada, conforme Fowler (1988) pelo uso de mais de uma questão visando esclarecer um mesmo tipo de problema, e também pela formulação de uma mesma questão a mais de um membro da empresa pesquisada, quando se tratar de questão em que o entrevistado está diretamente envolvido e informado. Fowler (1988) ainda sugere que o questionário seja prétestado junto a um grupo de pessoas que representem os entrevistados, o que foi feito em dezembro de 2001, junto a uma empresa fabricante de ferramentas sediada em Sorocaba.

O uso de palavras vagas ou siglas pode levar a respostas enviesadas e a dificuldades de interpretação dos dados. Salant e Dillmann (1996) propõem que as perguntas sejam explicadas ao entrevistado, as palavras mais dúbias sejam esclarecidas e que questões múltiplas sejam formuladas visando um mesmo fim, de forma que as oportunidades de obtenção de respostas sejam aproveitadas ao máximo.

As entrevistas e visitas às instalações foram conduzidas por uma equipe de pesquisa, composta pelo pesquisador e um pesquisador auxiliar, aluno de iniciação científica da Universidade de Sorocaba. O uso desta estratégia prende-se ao fato de que o pesquisador deve mostrar-se atento às explicações do entrevistado, e tomar algumas notas, como forma de 
declarar seu interesse pleno sobre o assunto em questão, mas não deve correr o risco de desviar-se do assunto em demasia. Neste aspecto entra o trabalho do pesquisador auxiliar, que terá como incumbência monitorar o tempo da entrevista, checar se os tópicos em questão estão sendo cobertos e fazer anotações adicionais que serão úteis no processo de análise dos dados, além de agregar potencial criativo e fortalecer a confiança nas conclusões, conforme Eisenhardt (1989).

Segundo Yin (1989), o entrevistador deve tomar especial cuidado em não ficar dependente do "informante", ou seja, para que suas conclusões não sejam baseadas exclusivamente nas informações obtidas nas entrevistas, sugerindo que se observem evidências daquilo que for dito pelos entrevistados. Esta possibilidade de falha na obtenção das informações novamente enfatiza o motivo de se fazer a entrevista, nesta pesquisa, com vários membros da empresa. Como alguns aspectos abordados nas questões permitem análise da confiabilidade da informação mediante uma visita às instalações produtivas da empresa, este procedimento foi realizado.

\subsection{3 - Pré-teste da segunda fase da pesquisa de campo}

O pré-teste foi feito com a participação da equipe de pesquisa (ver Anexo C - Roteiro usado para a segunda fase da pesquisa) entrevistando seis pessoas de uma empresa multinacional fabricante de ferramentas sediada na cidade de Sorocaba, entre os dias 4 e 5 de dezembro de 2001. Os entrevistados foram: o Diretor de Recursos Humanos, o Gerente de Suprimentos, o Gerente de Produção, o Gerente de Qualidade, o Gerente de PCP e a Coordenadora de Vendas.

Durante o desenvolvimento das entrevistas percebeu-se que alguns tópicos deveriam ser adicionados para melhorar o entendimento das respostas, como, por exemplo, incluir nas entrevistas algum representante da área comercial para obter informações sobre a demanda.

Baseado na proposta de Silverman (1993), sobre validade e confiabilidade, tomou-se cuidado adicional no sentido de que a ordem do roteiro de pesquisa fosse mantida para todos os grupos selecionados.

\subsection{4 - Processo de coleta de dados em campo}

Quanto ao processo das entrevistas, alguns cuidados foram tomados conforme orientam Denzin e Lincoln (1994): não se desviar do tema em estudo; evitar interrupções pelo agendamento da entrevista no melhor momento para o entrevistado; não deixar transparecer 
sua opinião pessoal sobre a resposta do entrevistado; não adicionar ou estimular com suas palavras a resposta do entrevistado.

Já Seidman (1991) sugere que se "ouça mais e fale menos", acompanhe cuidadosamente a resposta do entrevistado e faça perguntas adicionais quando não tiver entendimento do conteúdo da resposta, não interrompa o entrevistado no meio de uma resposta. O estímulo a contar uma "história", que é visto como uma estratégia positiva, foi utilizado ao início de cada entrevista sob a forma de estimular o entrevistado a relatar fatores relevantes da implementação do JIT em sua empresa.

Revisar a resposta para confirmar o entendimento é um procedimento importante e recomendável, afirma Burgess (1994). Este procedimento pode alongar um pouco o processo da entrevista, mas garante a confiabilidade dos resultados.

Após cada entrevista, as gravações eram transcritas e analisadas, de forma a possibilitar a visualização da eventual necessidade de ajustes úteis ao processo de coleta de dados. Exemplo disto foi a inclusão de uma entrevista com o Gerente de Marketing/Vendas, não prevista no roteiro inicial, e que foi implementada devido a constatação de sua necessidade já na primeira empresa pesquisada. Outro caso foi a substituição do termo "erro" na implementação, que originou atitudes defensivas, pela perspectiva "do que teria sido feito de forma diferente se a implementação pudesse ser novamente realizada à luz da experiência adquirida no primeiro processo".

As entrevistas foram programadas de forma a possibilitar que a tabulação dos dados (transcrição das entrevistas e geração de relatórios) ocorresse antes da realização da próxima, visando atender ao exposto acima, o que foi conseguido. A Empresa A foi visitada em 05 e 06 de fevereiro, a Empresa B nos dias 20, 22 e 27 de fevereiro, a Empresa C nos dias 19, 20 e 22 de março, a Empresa D nos dias 10 e 22 de abril e a Empresa E no dia 29 de abril de 2002 .

\subsection{5 - Análise dos dados}

$\mathrm{Na}$ maioria dos casos, a análise dos dados em pesquisa qualitativa envolve identificação de conceitos, agrupamento dos conceitos em categorias, codificação dos dados em categorias-chave e desenvolvimento de categorias por meio de análise e comparação entre categorias (Strauss e Corbin, 1989). No caso desta pesquisa, as categorias foram desenvolvidas com base nos Fatores Críticos de Implementação e nos problemas encontrados durante a implementação, descritos no Capitulo 3. 
É recomendável, segundo Eisenhardt (1989), que a coleta de dados e a sua análise ocorram simultaneamente de forma que uma entrevista possa preencher eventuais lacunas observadas em entrevistas anteriores. Desta forma, uma entrevista subseqüente pode enfocar mais especificamente algum aspecto de maior interesse da pesquisa que eventualmente tenha ficado obscuro na entrevista anterior.

Para atender a este objetivo, o calendário de coleta de dados foi intercalado por sessões de análise de dados e a cada sessão de análise de dados, o roteiro foi adaptado visando assegurar maior cobertura do tema sem, no entanto, desviar-se do foco inicial da pesquisa.

$\mathrm{O}$ Anexo $\mathrm{C}$ mostra o roteiro utilizado na segunda etapa da pesquisa.

A análise dos dados foi feita em fidelidade com a proposta de Eisenhardt (1989). Uma primeira etapa analisou os dados dentro dos casos, visando ganhar familiaridade com os dados assim como a geração de algumas hipóteses. Esta análise está disponível em sua forma completa nos Anexos E ao I, que trazem a descrição individual dos casos. A estrutura da análise baseou-se na descrição da empresa, no relato dos entrevistados a partir da transcrição das entrevistas, e nas constatações realizadas durante a visita às instalações. Cada relatório individual gerado suscitou reuniões de análise por parte da equipe de pesquisa e entre este pesquisador e o professor orientador, visando completar as informações pertinentes.

A outra etapa ocorreu pelo cruzamento dos dados obtidos nas entrevistas, sobrepondoos de maneira a obter uma visão geral de como cada um dos FCI se manifestaram nas empresas. Esta análise cruzada dos casos prestou-se a forçar o pesquisador a olhar além de suas impressões iniciais e buscar evidências sob diferentes óticas.

A partir da constatação dos principais eventos relacionados à Implementação de técnicas JIT nas empresas pesquisadas, estes foram organizados cronologicamente para cada empresa e representados de forma gráfica nas figuras 4 a 9. Na Tabela 20, os principais eventos de todas as empresas foram colocados numa mesma base temporal, tomando como "data zero" o marco oficial do JIT em cada empresa e como medida do tempo a razão entre o tempo transcorrido desde o marco oficial até o evento considerado e o tempo transcorrido desde o marco oficial até junho de 2002. Eventos que ocorreram antes do marco oficial localizam-se à esquerda da "data zero". A partir da análise comparativa da cronologia dos eventos, foram identificados alguns padrões. 
Com base predominantemente na transcrição das declarações e nas constatações nas visitas às instalações produtivas, trechos de entrevistas em diferentes empresas que tratavam de aspectos relacionados entre si, independentemente do fator cronológico, foram agrupados em uma matriz. Destes aspectos, alguns eram coincidentes com os identificados na revisão de literatura relacionada aos FCI, enquanto outros se evidenciaram durante a realização da pesquisa de campo. Vale ressaltar que nem todos os aspectos estavam presentes nas cinco empresas pesquisadas.

\subsection{6 - Formulação de hipóteses}

A partir desta etapa buscou-se a geração de hipóteses que são descritas no Capítulo 6 Conclusões e Recomendações. Algumas hipóteses foram geradas pela tentativa de busca de padrões de conduta com base na análise dos principais eventos observados na implementação de técnicas JIT nas empresas pesquisadas (Figuras 4 a 8). Uma análise detalhada destes eventos permitiu a montagem do Tabela 20 - Evolução cronológica dos principais eventos ocorridos nas empresas pesquisadas durante a implementação de técnicas JIT, que também serviu de apoio para a proposição de algumas das hipóteses. A análise cruzada por fator crítico também apoiou a formulação de hipóteses, assim como a experiência deste pesquisador e do orientador.

Não coube no escopo desta pesquisa testar quaisquer das hipóteses geradas. Estas hipóteses são vistas sim como potenciais contribuições à expansão do conhecimento sobre o tema na medida em que podem servir de base para que futuras pesquisas possam ser desenvolvidas.

\subsection{7 - Comparações com a literatura}

A comparação com a literatura, tanto semelhante quanto discrepante, tem por objetivo a construção de validade interna, elevação do nível teórico, melhor definição dos conceitos e incremento na possibilidade de generalização. Considerando que não foram localizados estudos que analisassem o processo de implementação, mas apenas os seus FCI, esta análise restringiu-se a uma comparação entre os fatores críticos que emergiram com destaque no estudo de casos com a literatura sobre FCI descrita na revisão de literatura do Capítulo 3. 


\section{Capítulo 5 - Resultados da pesquisa e formulação de hipóteses}

Neste capítulo são apresentados os resultados da pesquisa em suas duas fases. A primeira fase prestou-se a evidenciar quais eram as principais empresas usuárias das técnicas JIT em estudo nesta pesquisa, o que serviu de base para a seleção das quatro usuárias da maior quantidade de técnicas. A segunda fase indicou os resultados e análise das entrevistas com alguns dirigentes das cinco empresas que estão em processo de implementação das técnicas JIT. A seguir caracterizam-se brevemente as empresas informantes da pesquisa e apresentam-se os principais resultados obtidos.

\section{1 - A primeira fase da pesquisa de campo}

Deve ser enfatizado, novamente, que o objetivo desta fase da pesquisa de campo foi apenas identificar as empresas usuárias de técnicas JIT, descritas como objeto de estudo desta pesquisa e selecionar, dentre as principais usuárias, aquelas que participariam da segunda fase da pesquisa de campo, sem jamais se pretender qualquer tentativa de estabelecer alguma generalização para os resultados.

Os questionários da primeira fase foram aplicados a 164 empresas, obtendo-se 89 respostas $(54,3 \%)$ em condições adequadas para análise, o que permitiu a identificação das empresas usuárias de técnicas JIT.

A maioria das empresas pesquisadas (76\%) era de capital nacional. Ver Tabela 14.

Tabela 14 - Distribuição das empresas por origem do capital

\begin{tabular}{c|c|c|c|c}
\hline & Freqüência & Percentagem & $\begin{array}{c}\text { Percentagem } \\
\text { válida }\end{array}$ & $\begin{array}{c}\text { Percentagem } \\
\text { cumulativa }\end{array}$ \\
\hline Nacional & 68 & 76,4 & 76,4 & 76,4 \\
\hline Estrangeiro & 21 & 23,6 & 23,6 & 100,0 \\
\hline Total & 89 & 100,0 & 100,0 & \\
\hline
\end{tabular}

Quanto ao porte das empresas, por número de funcionários, predominaram aquelas com 50 a 99 funcionários (27\%), conforme Tabela 15.

Tabela 15 - Porte das empresas, por número de Funcionários

\begin{tabular}{c|c|c|c|c}
\hline & Freqüência & Percentagem & $\begin{array}{c}\text { Percentagem } \\
\text { válida }\end{array}$ & $\begin{array}{c}\text { Percentagem } \\
\text { acumulada }\end{array}$ \\
\hline ND & 1 & 1,1 & 1,1 & 1,1 \\
\hline 30 a 49 & 19 & 21,3 & 21,3 & 22,5 \\
\hline 50 a 99 & 24 & 27,0 & 27,0 & 49,4 \\
\hline 100 a 249 & 19 & 21,3 & 21,3 & 70,8 \\
\hline 250 a 499 & 13 & 14,5 & 14,5 & 85,4 \\
\hline 500 a 1000 & 9 & 10,1 & 10,1 & 95,5 \\
\hline >1000 & 4 & 4,5 & 4,5 & 100 \\
\hline Total & 89 & 100,0 & 100,0 & \\
\hline
\end{tabular}


No que se refere ao volume de Vendas, predominaram empresas com vendas inferiores a R\$ 10 milhões anuais $(51,7 \%)$, conforme Tabela 16.

Tabela 16 - Porte das empresas, por volume de Vendas

\begin{tabular}{c|c|c|c|c}
\hline $\begin{array}{c}\text { Volume de } \\
\text { vendas (milhões } \\
\text { de } \mathrm{R} \$ \text { ) }\end{array}$ & Freqüência & Percentagem & $\begin{array}{c}\text { Percentagem } \\
\text { Válida }\end{array}$ & $\begin{array}{c}\text { Percentagem } \\
\text { cumulativa }\end{array}$ \\
\hline ND & 9 & 10,1 & 10,1 & 10,1 \\
\hline$<1$ & 7 & 7,9 & 7,9 & 18,0 \\
\hline 2 a 5 & 23 & 25,8 & 25,8 & 43,8 \\
\hline 6 a 10 & 7 & 7,9 & 7,9 & 51,7 \\
\hline 11 a 50 & 22 & 24,7 & 24,7 & 76,4 \\
\hline 51 a 100 & 13 & 14,6 & 14,6 & 91,0 \\
\hline 101 a 500 & 6 & 6,7 & 6,7 & 97,8 \\
\hline$>501$ & 2 & 2,2 & 2,2 & 100 \\
\hline Total & 89 & 100,0 & 100,0 & \\
\hline
\end{tabular}

Dentre as técnicas objeto de estudo desta pesquisa, todas estavam em uso em pelo menos uma empresa, conforme Tabela 17.

Tabela 17 - Técnicas JIT objeto de estudo em uso nas empresas

\begin{tabular}{l|c}
\hline \multicolumn{1}{c|}{ Técnicas pesquisadas } & $\%$ de uso \\
\hline Plano de Manutenção & $43 \%$ \\
\hline Células de Produção & $37 \%$ \\
\hline Redução de Set up & $36 \%$ \\
\hline Grupos de Melhoria (Kaizen) & $28 \%$ \\
\hline Redução dos Lotes de Fabricação & $26 \%$ \\
\hline Kanban & $21 \%$ \\
\hline
\end{tabular}

Predominaram empresas Metalúrgicas (27) na amostra, seguidas por empresas fabricantes de derivados de Plástico e borracha (12), Autopeças e automobilística, (10) e Confecção (10).

O setor de Autopeças e automobilística foi o que apresentou maior percentagem de empresas usuárias das técnicas JIT em estudo, fator decisivo para que este setor fosse escolhido para ser estudado. 
Tabela 18 - Percentual de uso de técnicas JIT por setor da indústria

\begin{tabular}{|c|c|c|c|c|c|c|c|}
\hline Setor & $\begin{array}{l}\text { Total de } \\
\text { Empresas }\end{array}$ & $\begin{array}{l}\text { Manutenção } \\
\text { Preventiva }\end{array}$ & $\begin{array}{l}\text { Células de } \\
\text { Produção }\end{array}$ & $\begin{array}{l}\text { Redução de } \\
\text { Set up }\end{array}$ & $\begin{array}{l}\text { Uso de } \\
\text { Kaizen }\end{array}$ & \begin{tabular}{|c|} 
Redução de \\
Lote de fabricação
\end{tabular} & $\begin{array}{l}\text { uso de } \\
\text { Kanban }\end{array}$ \\
\hline Alimentícia & 9 & 33,3 & 11,1 & 11,1 & 0,0 & 11,1 & 0,0 \\
\hline $\begin{array}{l}\text { Autopeças e } \\
\text { automobilística }\end{array}$ & 10 & 100,0 & 90,0 & 100,0 & 90,0 & 80,0 & 90,0 \\
\hline Confecção & 10 & 20,0 & 40,0 & 10,0 & 10,0 & 30,0 & 10,0 \\
\hline Construção civil & 8 & 37,5 & 0,0 & 12,5 & 25,0 & 12,5 & 0,0 \\
\hline $\begin{array}{l}\text { Equipamentos } \\
\text { médicos }\end{array}$ & 2 & 50,0 & 50,0 & 50,0 & 0,0 & 50,0 & 0,0 \\
\hline Farmacêutica & 1 & 0,0 & 0,0 & 0,0 & 0,0 & 100,0 & 0,0 \\
\hline Gráfica & 5 & 0,0 & 0,0 & 20,0 & 0,0 & 0,0 & 0,0 \\
\hline $\begin{array}{l}\text { Máquinas e } \\
\text { equipamentos }\end{array}$ & 2 & 50,0 & 0,0 & 50,0 & 0,0 & 0,0 & 0,0 \\
\hline $\begin{array}{l}\text { Metalúrgica, } \\
\text { siderúrgica }\end{array}$ & 27 & 55,6 & 51,9 & 48,1 & 40,7 & 18,5 & 29,6 \\
\hline Outros & 1 & 0,0 & 0,0 & 0,0 & 0,0 & 0,0 & 0,0 \\
\hline Papel e celulose & 12 & 41,7 & 41,7 & 33,3 & 25,0 & 41,7 & 33,3 \\
\hline $\begin{array}{l}\text { Plásticos e } \\
\text { borracha }\end{array}$ & 1 & 0,0 & 0,0 & 0,0 & 0,0 & 0,0 & 0,0 \\
\hline $\begin{array}{l}\text { Química e } \\
\text { petroquímica }\end{array}$ & 1 & 0,0 & 0,0 & 0,0 & 0,0 & 0,0 & 0,0 \\
\hline
\end{tabular}

\section{2 - A segunda fase da pesquisa de campo}

As cinco empresas pesquisadas são fornecedoras da cadeia de suprimentos da indústria automobilística e atendem basicamente às mesmas montadoras. Quatro delas têm sede industrial no município de Sorocaba - SP e uma no município de Amparo - SP.

Em conformidade com os acordos mantidos com as empresas no planejamento das entrevistas, seus nomes, assim como o dos entrevistados não foram revelados, visando preservar a identificação direta das empresas e manter o compromisso de sigilo das informações, dado que os números e fatos relatados nesta pesquisa conservam estreita fidelidade com a realidade.

As entrevistas pessoais e visitas às instalações das empresas ocorreram entre fevereiro e abril de 2002, envolvendo Diretores, Gerentes, Chefes e Supervisores das áreas de Produção, Qualidade, Recursos Humanos e Suprimentos/Logística, que respondem funcionalmente pelas áreas de interesse estudadas nesta pesquisa.

O processo de entrevistas procurou ater-se à experiência dos entrevistados em suas áreas funcionais supondo que as respostas mais adequadas seriam obtidas a partir dos profissionais que tivessem maior e mais prolongada ligação com as atividades da empresa. Dentre os 22 profissionais entrevistados, 10 têm mais de 10 anos de atuação na empresa e outros 5 têm mais de 5 anos. Apenas 7 deles têm entre 3 e 5 anos de experiência na empresa. 
A tabela 19 apresenta mais detalhes sobre as entrevistas.

Tabela 19 - Perfil das entrevistas de campo da segunda etapa da pesquisa

\begin{tabular}{|c|c|c|c|}
\hline \multicolumn{4}{|c|}{ Empresa A } \\
\hline Data & Função exercida pelo entrevistado na empresa & Tempo de empresa & Duração da entrevista \\
\hline $05 / 02$ & Gerente de Melhorias e Manufatura & 15 anos & $1 \mathrm{~h} 40 \mathrm{~min}$ \\
\hline $06 / 02$ & Facilitador de Recursos Humanos & 5 anos & $2 \mathrm{~h} 10 \mathrm{~min}$ \\
\hline \multicolumn{4}{|c|}{ Empresa B } \\
\hline Data & Função exercida pelo entrevistado na empresa & Tempo de empresa & Duração da entrevista \\
\hline $20 / 02$ & Diretor Industrial & 16 anos & $2 \mathrm{~h} 15 \mathrm{~min}$ \\
\hline $20 / 02$ & Diretor Administrativo Financeiro & 25 anos & $55 \mathrm{~min}$ \\
\hline $22 / 02$ & Coordenador de Vendas & 29 anos & $1 \mathrm{~h} 05 \mathrm{~min}$ \\
\hline $22 / 02$ & Gerente de Qualidade Assegurada & 10 anos & $1 \mathrm{~h} 10 \mathrm{~min}$ \\
\hline $27 / 02$ & Chefe de Produção & 27 anos & $2 \mathrm{~h} 00 \mathrm{~min}$ \\
\hline \multicolumn{4}{|c|}{ Empresa C } \\
\hline Data & Função exercida pelo entrevistado na empresa & Tempo de empresa & Duração da entrevista \\
\hline $19 / 03$ & Diretor de Operações Industriais & 3 anos & $55 \mathrm{~min}$ \\
\hline $19 / 03$ & Diretor Comercial & 5 anos & $50 \mathrm{~min}$ \\
\hline $20 / 03$ & Gerente de RH América do Sul & 4 anos & $45 \mathrm{~min}$ \\
\hline $20 / 03$ & Gerente de Garantia da Qualidade e Meio Ambiente & 5 anos & $40 \mathrm{~min}$ \\
\hline $22 / 03$ & Diretor de Logística América do Sul & 5 anos & 1h $20 \mathrm{~min}$ \\
\hline \multicolumn{4}{|c|}{ Empresa D } \\
\hline Data & Função exercida pelo entrevistado na empresa & Tempo de empresa & Duração da entrevista \\
\hline $03 / 04$ & Gerente de Logística & 26 anos & $1 \mathrm{~h} 25 \mathrm{~min}$ \\
\hline $03 / 04$ & Coordenador de Vendas & 6 anos & $45 \mathrm{~min}$ \\
\hline $03 / 04$ & Gerente de Recursos Humanos & 18 anos & $35 \mathrm{~min}$ \\
\hline $03 / 04$ & Gerente de Engenharia da Qualidade & 8 anos & $40 \mathrm{~min}$ \\
\hline $10 / 04$ & Diretor Industrial & 8 anos & $35 \mathrm{~min}$ \\
\hline $10 / 04$ & Gerente de Produção & 5 anos & $1 \mathrm{~h} 20 \mathrm{~min}$ \\
\hline \multicolumn{4}{|c|}{ Empresa E } \\
\hline Data & Função exercida pelo entrevistado na empresa & Tempo de empresa & Duração da entrevista \\
\hline $29 / 04$ & Diretor Industrial & 16 anos & $2 \mathrm{~h} 15 \mathrm{~min}$ \\
\hline $29 / 04$ & Gerente de Recursos Humanos & 6 anos & $55 \mathrm{~min}$ \\
\hline $29 / 04$ & Gerente de Produção & 28 anos & $2 \mathrm{~h} 00 \mathrm{~min}$ \\
\hline $29 / 04$ & Coordenador de Qualidade & 23 anos & $1 \mathrm{~h} 10 \mathrm{~min}$ \\
\hline
\end{tabular}

\section{3 - Perfil das empresas, as entrevistas e uma síntese da implementação}

A seguir são caracterizadas as empresas pesquisadas quanto ao grupo a que pertencem, os principais produtos, o tempo de atuação no Brasil e no mundo, a área construída, a capacidade instalada e o número de funcionários.

A realização das entrevistas, os entrevistados e uma síntese do processo de implementação em cada empresa completam as informações.

\subsection{1 - A Empresa A}

A Empresa A é uma subsidiária de uma Holding norte-americana, do setor de autopeças. As principais linhas de produtos são eixos diferenciais traseiros com caixas diferenciais, seções centrais de eixos traseiros, carcaças e caixas diferenciais de eixos traseiros e conjuntos de engrenagens hipoidais e cônicas.

Sua atuação mundial já ocorre há aproximadamente 97 anos. No Brasil atua há 50 anos. As instalações industriais em Sorocaba - SP encontram-se numa área total de 185.000 
metros quadrados, sendo de 17.000 metros quadrados a área construída. Atualmente a empresa conta com cerca de 200 funcionários diretos e 160 indiretos, que respondem por um faturamento de US\$ 50 milhões (base 2001). A capacidade instalada da fábrica é da ordem de 100.000 eixos anuais. A participação da empresa no mercado brasileiro chega a $70 \%$.

As duas entrevistas foram realizadas nos dias 5 e 6 de fevereiro de 2002, nas dependências da empresa, na cidade de Sorocaba - SP e totalizaram cerca de quatro horas. Foram entrevistados o Chefe de Melhorias Contínuas e Engenharia de Manufatura, que já trabalha na empresas há mais de 15 anos (entre trabalhos como funcionário efetivo e como consultor) e o Facilitador de RH, que embora tenha menos tempo de empresa (cerca de 5 anos), vem participando ativamente do processo de implementação de técnicas JIT desde o lançamento do programa em junho de 2000. A empresa nomeou o Chefe de Melhorias Contínuas e Engenharia de Manufatura como gestor do processo de implementação de técnicas JIT, o que tornou a obtenção das informações mais fácil e objetiva. A partir deste ponto ele será referenciado apenas como Chefe de Melhorias Contínuas.

A oficialização do lançamento do programa de implementação de técnicas JIT na Empresa A aconteceu em junho de 2000, mas antes desta data já havia ocorrido um fato relevante: a chegada do Gerente Geral à unidade de Sorocaba. Este Gerente Geral, contratado pela empresa em 1991, traz consigo uma grande experiência em técnicas JIT e logo após a sua chegada, lança o Programa Kaizen, baseado na realização de sessões chamadas de "sem ana kaizen", com apoio de um consultor, que em junho de 2001, ou seja, um ano depois do lançamento do 'Programa Kaizen", foi contratado como Chefe de Melhorias Contínuas.

Está clara nesta empresa a presença do apoio da Alta Administração, do JIT Champion e o uso de consultoria externa para implementação, conforme proposto por Mehra e Inman (1992) e Zhu e Meredith (1995). O aspecto da ênfase em educação e treinamento também fica evidente pelo aumento das exigências de contratação iniciada a partir de 1998.

A certificação pelas normas ISO 9000 acontece em 1998, portanto, antes do início formal de implementação de técnicas JIT na Empresa A.

Uma visão geral do processo de implementação das técnicas JIT na Empresa A pode ser obtida pela análise da Figura 4. 
Figura 4 - Principais Eventos Empresa A

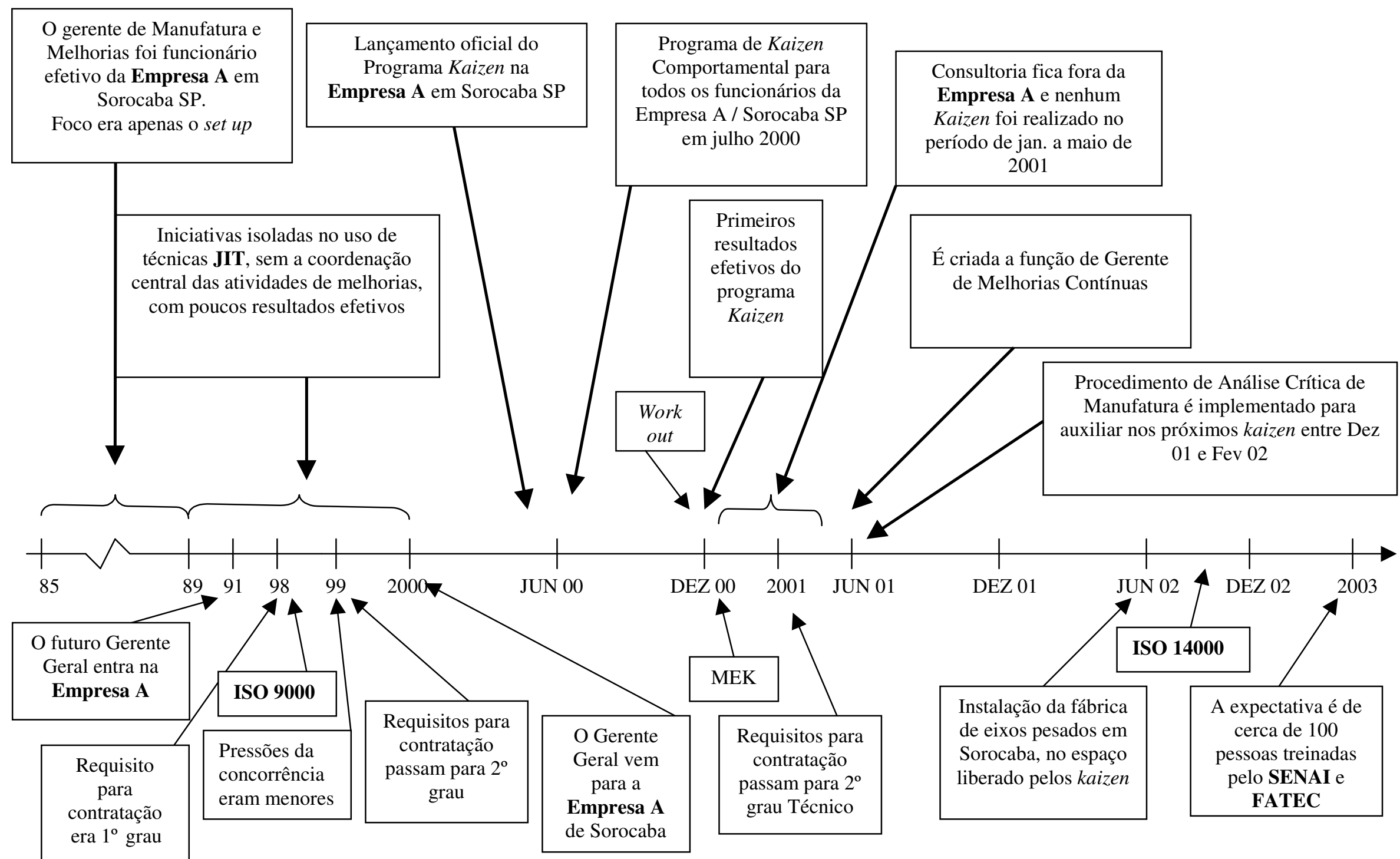




\subsection{2 - A Empresa B}

A Empresa B também é subsidiária de uma Holding, esta de origem alemã, que detém sob seu controle duas empresas fabricantes de rolamentos (uma delas adquirida em 2001) e uma empresa fabricante de embreagens, além de outras atividades de menor expressão no grupo. Trata-se de uma empresa High Tech, cuja tecnologia, bem diversificada, pode ser comparada com empresas de ponta como a alemã Bosch. Os principais produtos são esferas, rolamentos automotivos, agrícolas e especiais além de elementos de motores (tuchos hidráulicos, balancins flutuantes, sistemas tensionadores de correntes, etc).

Em termos mundiais, a Holding já opera há 52 anos. No Brasil, as atividades da subsidiária iniciaram-se em 1958 no bairro de Santo Amaro, em São Paulo - SP. A transferência das instalações para Sorocaba - SP deu-se em 1980 e atualmente todas as atividades industriais da empresa estão sediadas em Sorocaba - SP, numa área de 630.000 metros quadrados sendo 63.700 metros quadrados em área construída.

A Holding emprega cerca de 52 mil funcionários no mundo todo, sendo na fábrica do Brasil empregados cerca de 1700 pessoas (1370 funcionários diretos e 325 funcionários indiretos). Há previsão de contratação de mais 250 funcionários no ano de 2002. O faturamento anual não foi informado. A capacidade instalada da empresa hoje chega a 77 milhões de peças por ano, atendendo a $30 \%$ do mercado nacional de rolamentos.

As cinco entrevistas, realizadas nos dias 20, 22 e 27 de fevereiro de 2002, nas dependências da empresa, na cidade de Sorocaba - SP, totalizaram cerca de 7 horas, sem considerar a visita às instalações produtivas. Dentre os cinco entrevistados, todos têm mais de dez anos de experiência dentro da Empresa B em atividades ligadas diretamente às funções pelas quais são responsáveis. O Diretor Industrial está na empresa há 16 anos e o Diretor Administrativo Financeiro já trabalhou em vários setores ao longo dos 25 anos de atuação na empresa. Já o Coordenador de Vendas tem 29 anos de atividades na empresa; o Gerente de Qualidade Assegurada está na empresa há mais de 10 anos e o Chefe de Produção, há 27 anos.

Em 1997, com o apoio de uma empresa de consultoria, a Empresa B lança seu programa formal de implementação de técnicas JIT, com base em uma metodologia chamada de "semana kaizen". Cria-se, para fomento das atividades da semana kaizen, um escritório kaizen, que tem a responsabilidade de centralizar todas as ações das "semana kaizen", coletar, analisar e divulgar os resultados que são obtidos. 
Neste caso o JIT Champion não está caracterizado, mas há um coordenador de kaizen que tem papel importante de centralização e divulgação das atividades voltadas à implementação das técnicas JIT.

A Empresa B também recebeu certificação ISO 9000 antes de iniciar seu programa de implementação de técnicas JIT.

Os principais eventos do processo de implementação de técnicas JIT na Empresa B podem ser vistos na Figura 5. 
Figura 5 - Principais Eventos Empresa B

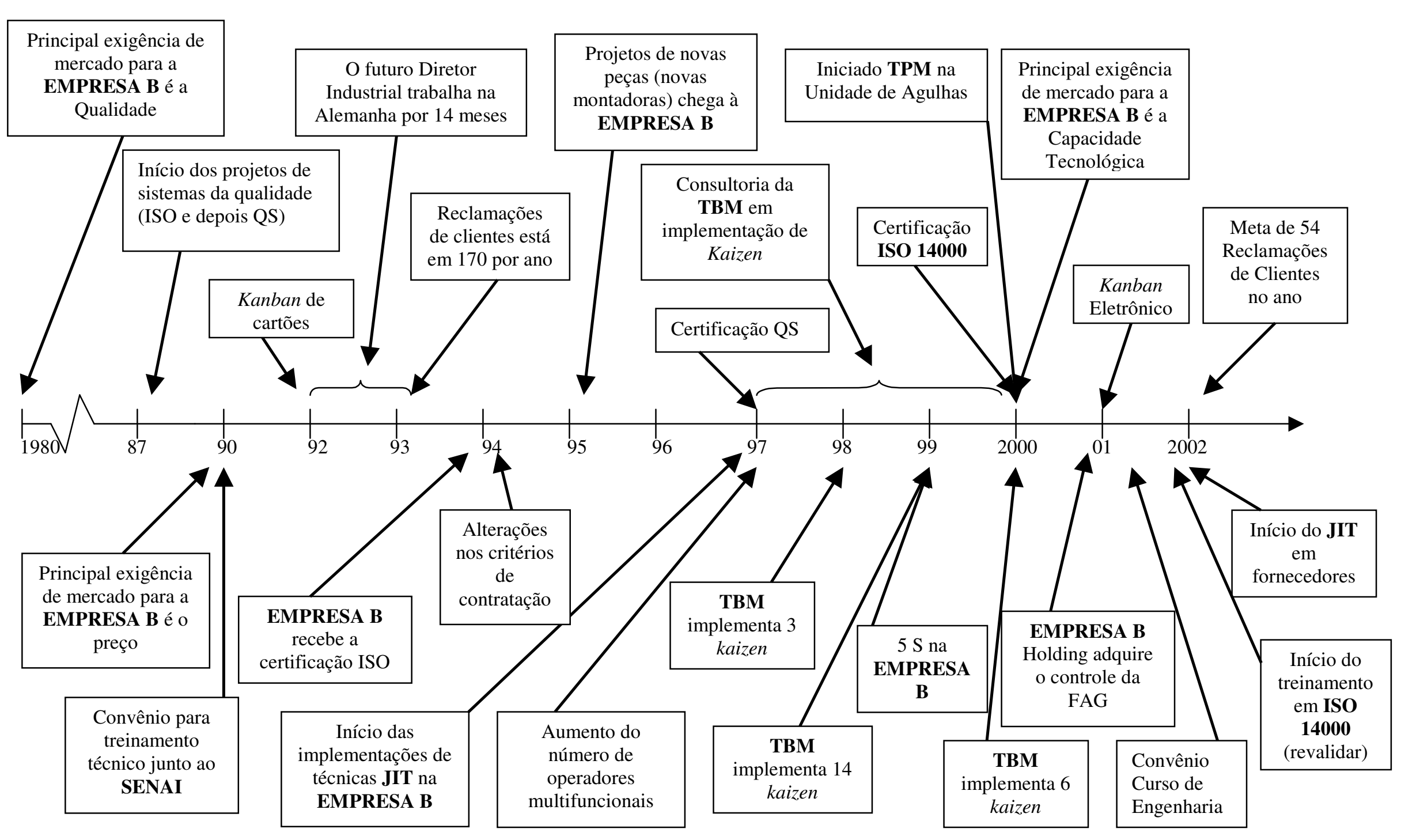




\subsection{3 - A Empresa C}

A Empresa C faz parte de uma aliança global de três grandes fabricantes mundiais de baterias: uma americana (detentora de $25 \%$ do controle da empresa e fundada em 1950), outra alemã (controladora de $25 \%$ da empresa e em operação desde 1930) e outra mexicana (a maior das controladoras, com 50\% e fabricante de baterias desde 1960). A unidade de Sorocaba foi consolidada na joint venture em dezembro de 1998.

Os principais produtos da empresa são baterias de aplicação automotiva de linhas leve, média e pesada. O projeto do produto é alemão, a tecnologia de processo é americana e a administração, mexicana.

A Holding é a maior fabricante de baterias do mundo, quando consideradas as produções agregadas das 10 fábricas americanas (que produzem 40 milhões de baterias anuais), das fábricas instaladas na Alemanha (que produzem em média 20 milhões de baterias anuais) e das fábricas instaladas no México (responsável por mais de 10 milhões de baterias por ano). A Empresa C está instalada numa área total de 650.000 metros quadrados, sendo 35.000 metros quadrados de área construída e emprega cerca de 500 pessoas (277 funcionários diretos e 232 indiretos) com faturamento anual em 2001 chegando a US\$ 90 milhões. A capacidade instalada da Empresa C é de cerca de 4,5 milhões de baterias/ano.

As cinco entrevistas foram realizadas nos dias 19, 20 e 22 de março de 2002, nas dependências da empresa, na cidade de Sorocaba - SP e totalizaram cerca de cinco horas, além da visita ao processo produtivo.

Pelo fato de a empresa ter sido formada em 1998, alguns de seus principais dirigentes estão trabalhando nesta unidade há no máximo cinco anos. Dentre os entrevistados, todos têm entre três e cinco anos de experiência dentro da empresa em atividades ligadas diretamente às funções pelas quais são responsáveis. O Diretor de Operações Industriais está na empresa há 3 anos; o Diretor Comercial, por sua vez, trabalha na empresa há 5 anos. Já o Gerente de RH tem quase 5 anos de atividades na empresa; o Gerente de Garantia da Qualidade e Meio Ambiente está na empresa há mais de 4 anos e o Diretor de Logística, está na empresa há 5 anos.

A Empresa C não tem um programa formal de implementação de técnicas JIT e já havia sido certificada pelas normas ISO 9000 quando as primeiras iniciativas sobre JIT ocorreram na empresa em 1997. 
Mesmo não contando com um programa formal, há evidências de uso de técnicas JIT, ainda que sem a presença de um JIT Champion e sem uma coordenação central.

Uma visão geral do processo de implementação das técnicas JIT na Empresa C pode ser obtida pela análise da Figura 6. 
Figura 6 - Principais Eventos Empresa C

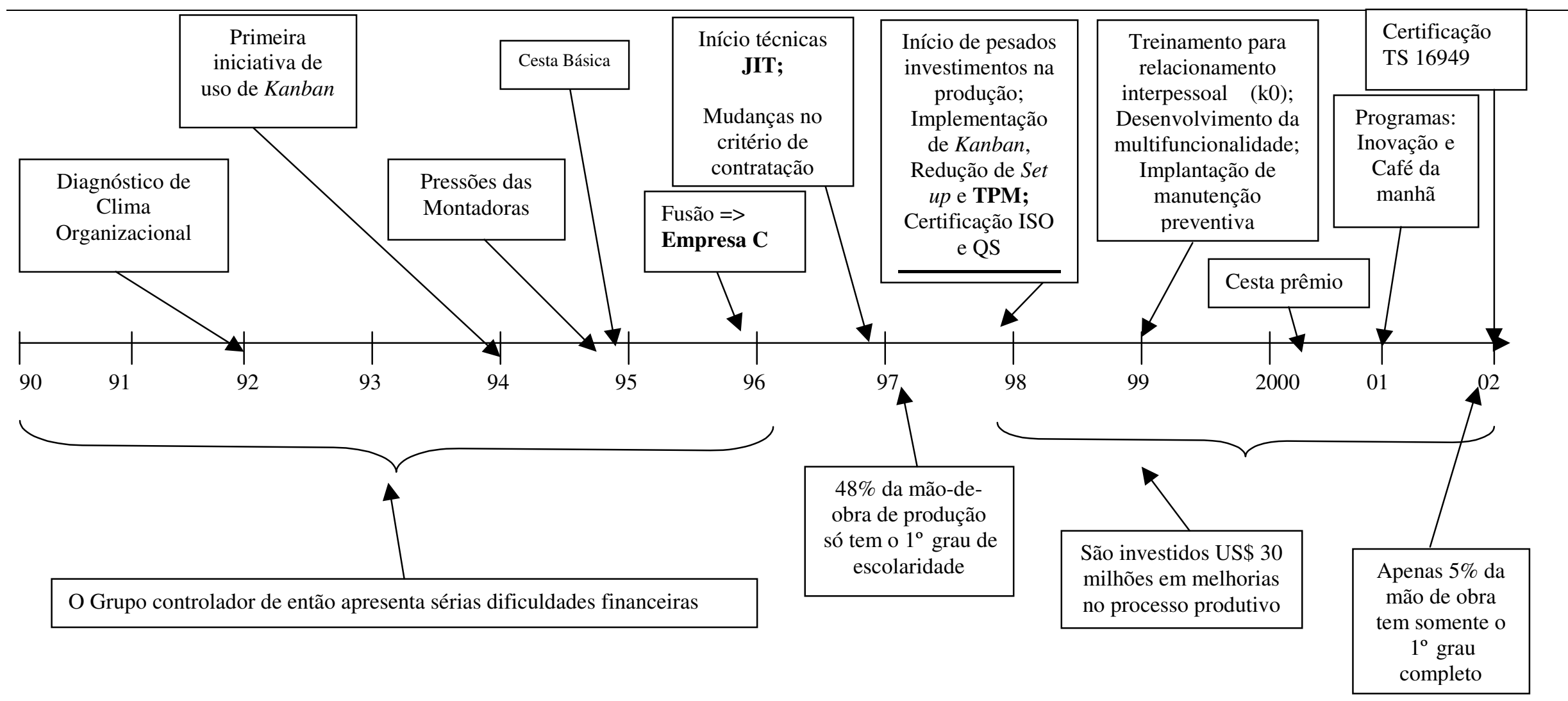




\subsection{4 - A Empresa D}

A Empresa D foi inaugurada na cidade de Sorocaba em 1976, já no atual local, no Distrito Industrial da cidade. A origem do capital controlador da empresa é alemã.

A Empresa D fabrica e fornece, para o mercado automotivo, platôs e discos de embreagem, volantes simples e de dupla massa, fundidos rotacionais (polias, placas de pressão e volantes), sistemas de acionamento, bombas hidráulicas e bombas de vácuo, componentes de conversores de torque e embreagens para conversores. Nos últimos anos, o grande avanço tecnológico desenvolvido pela controladora da Empresa D foi o lançamento dos sistemas de acionamento de embreagens, bombas a vácuo e hidráulicas, platôs SAC (self adjust clutch) que se auto regulam, volantes de dupla massa para amortecimento de vibrações e embreagens eletrônicas, que não necessitam do pedal para realizar o acionamento do conjunto de embreagem.

Em termos mundiais, a empresa já atua há 37 anos e no Brasil, há 26 anos, numa área de 250.000 metros quadrados, sendo a área construída de 30.000 metros quadrados. Hoje opera com 670 funcionários. O faturamento anual não foi informado.

Atualmente a Empresa D detém cerca de 60\% do mercado nacional de embreagens e cerca de $10 \%$ de sua produção destina-se ao mercado externo. As demais empresas do grupo no mundo detém cerca de $50 \%$ do mercado.

As seis entrevistas foram realizadas nos dias 03 e 10 de abril de 2002, nas dependências da empresa, na cidade de Sorocaba - SP e totalizaram cerca de 6 horas.

Dentre os entrevistados, todos têm mais de cinco anos de experiência dentro da empresa em atividades ligadas diretamente às funções pelas quais são responsáveis. $\mathrm{O}$ Gerente de Logística está na empresa há 26 anos; o Coordenador de Vendas, por sua vez, trabalha na empresa há 6,5 anos. Já a Gerente de RH, tem 18 anos de atividades na empresa; o Gerente de Engenharia da Qualidade está na empresa há mais de 8 anos; o Gerente de Produção, trabalha na empresa há 8 anos e o Diretor Industrial, há 5 anos.

Em 1998 ocorrem as primeiras iniciativas de implementação de técnicas JIT na Empresa D, a partir de treinamento ministrado por uma empresa de consultoria. Após a participação de dois de seus gerentes de produção neste treinamento, a Empresa D optou por conduzir o processo de implementação por conta própria, em função dos altos custos cobrados pela empresa de consultoria. 
Não existe uma coordenação central e nem um JIT Champion, o que é visto como uma deficiência.

A certificação pelas normas ISO 9000 ocorreu em 1994, muito antes do início das atividades de implementação de técnicas JIT.

O processo de implementação das técnicas JIT na Empresa D pode ser visualizado pela análise da Figura 7. 
Figura 7 - Principais Eventos Empresa D

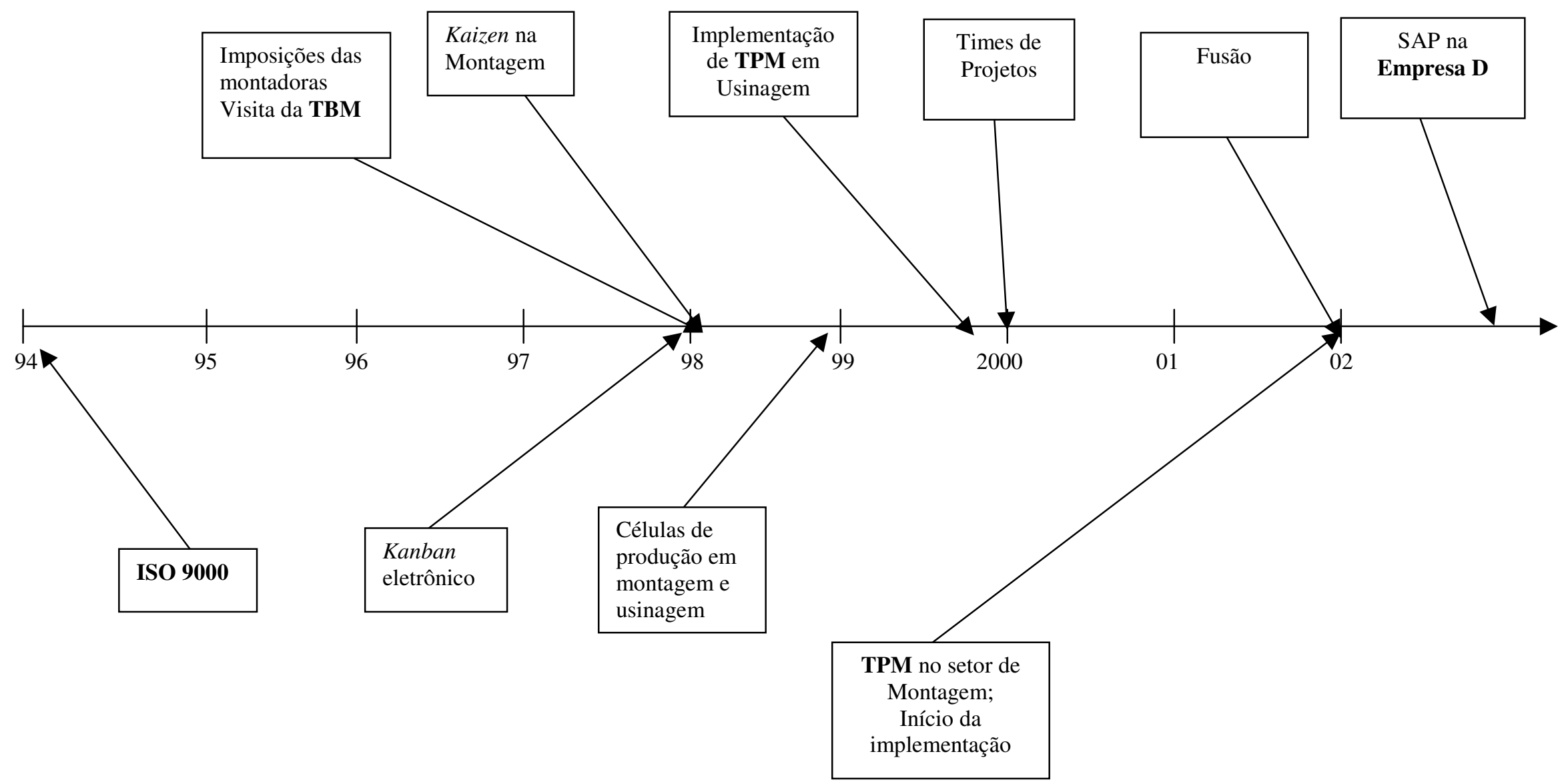




\subsection{5 - A Empresa E}

A Empresa E, localizada na cidade de Amparo - SP, é uma das subsidiárias de uma empresa italiana pertencente ao grupo FIAT, que é segmentado em diversos setores de atuação no ramo automobilístico e inclui dezenas de unidades produtivas e comerciais no mundo todo, nos vários segmentos. Dentre estes segmentos inclui-se a Divisão Escapamentos, a qual pertence à Empresa E. Esta Divisão de Escapamentos tem 9 fábricas em 6 países (três na Itália, uma na Espanha, uma na Polônia, uma na África do Sul, uma na Argentina e duas no Brasil - uma em Contagem- MG e outra em Amparo - SP).

No Brasil, as principais linhas de produtos da empresa são sistemas de exaustão automotivos (escapamentos). A holding atua no mercado mundial há 80 anos e no Brasil a Empresa E está instalada há mais de 37 anos, ocupando atualmente uma área construída de 24.000 metros quadrados dentre os 200.000 metros quadrados disponíveis. A holding emprega mais de 50 mil funcionários no mundo todo, enquanto a Empresa E tem 700 funcionários (550 diretos e 150 indiretos), que foram responsáveis por um faturamento de cerca de US\$ 65 milhões em 2001 e respondem por uma capacidade instalada atual de 600 mil sistemas de exaustão completos por ano, o que possibilita o atendimento de cerca de $45 \%$ do mercado nacional.

As quatro entrevistas foram realizadas no dia 29 abril de 2002, nas dependências da empresa, na cidade de Amparo - SP, e totalizaram cerca de sete horas, além da visita às instalações produtivas.

Foram entrevistados o Diretor Industrial, que trabalha na empresa há 16 anos, o Gerente de Recursos Humanos, com 6 anos de atuação em empresas do mesmo grupo, o Gerente de Produção, funcionário há 23 anos e o Coordenador de Qualidade, que está na empresa há 28 anos.

Nesta empresa as iniciativas de uso de técnicas JIT ocorreram no começo da década de 90, identificando-se claramente a figura do JIT Champion na pessoa do Diretor Industrial. Houve apoio de empresa de consultoria nos treinamentos da fase inicial da implementação e também forte movimento de valorização dos requisitos de contratação de funcionários.

Em 1989 a empresa realizou um amplo processo de terceirização criando, com isso, um grupo de empresas satélites, que ainda hoje têm na Empresa E o seu maior cliente. Esta característica é única dentre as empresas pesquisadas. 
A certificação pelas normas ISO 9000 ocorreu só em 1995, portanto, após a formalização da implementação de técnicas JIT.

Uma visão geral do processo de implementação das técnicas JIT na Empresa E pode ser obtida pela análise da Figura 8. 
Figura 8 - Principais Eventos Empresa E

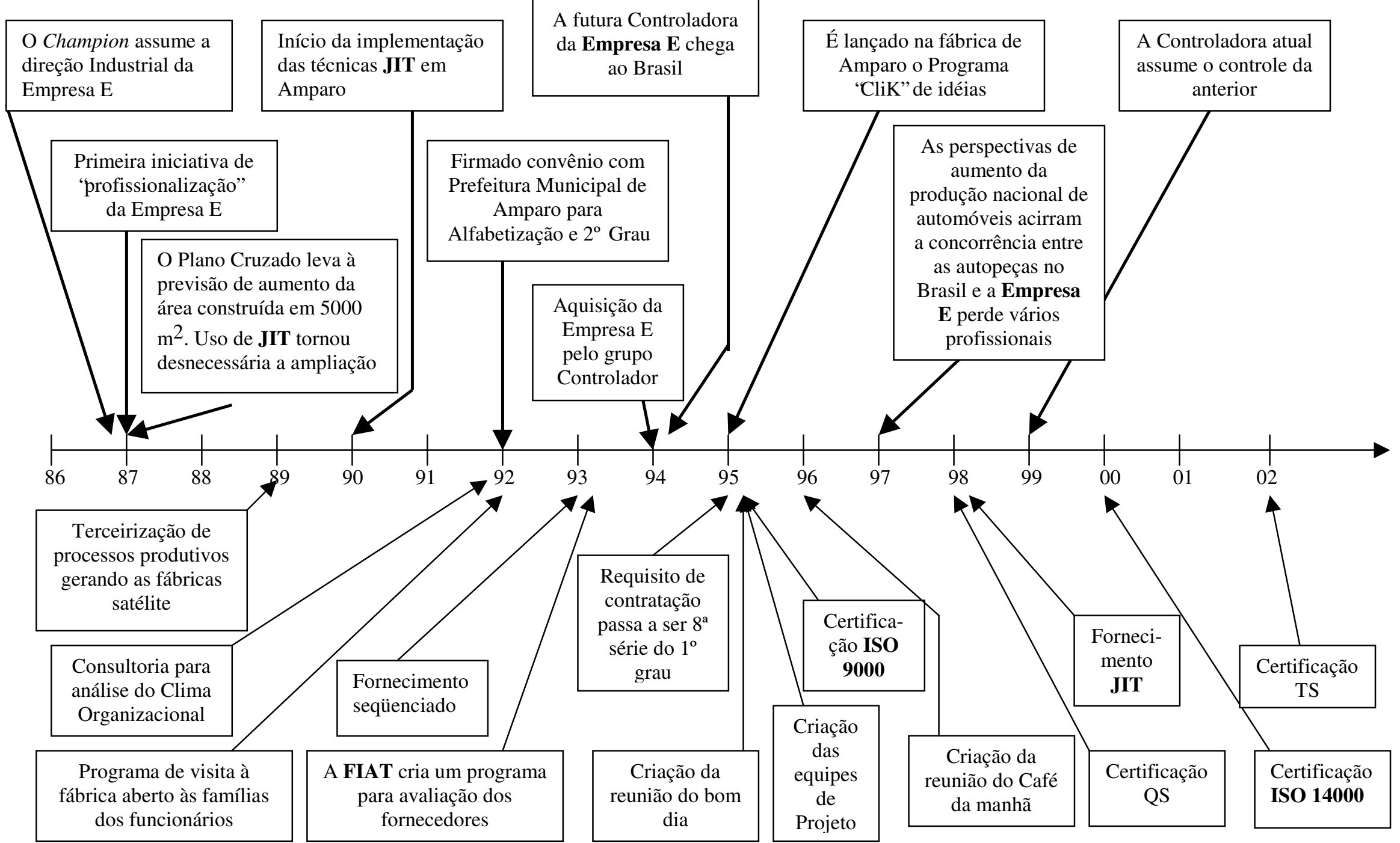




\section{4 - Análise dos resultados da segunda etapa da pesquisa de campo}

A análise dos resultados da segunda etapa da pesquisa de campo foi feita predominantemente com base nas declarações dos entrevistados e nas observações deste pesquisador durante as visitas às instalações físicas das empresas. As declarações foram obtidas junto aos responsáveis pelas áreas funcionais em entrevistas (ver Anexo C - Roteiro usado na segunda fase da pesquisa de campo), gravadas em fita cassete e transcritas. As observações, que, segundo Creswel (1994), são importantes por possibilitar a constatação, pelo entrevistador, das reais condições do entrevistado sobre o tema e também por permitir que algumas informações sejam checadas, aconteceram durante as visitas ao processo produtivo das empresas pesquisadas.

\subsection{1 - Análise cronológica dos principais eventos}

A interpretação da Tabela 20 deve ser feita considerando que os principais eventos de todas as empresas foram colocados numa mesma base temporal, tomando como "data zero" o marco oficial do JIT em cada empresa e como medida do tempo a razão entre o tempo transcorrido desde o marco oficial até o evento considerado e o tempo transcorrido desde o marco oficial até junho de 2002. Eventos que ocorreram antes do marco oficial localizam-se à esquerda da "data zero". Os pontos assinalados mostram a incidência dos eventos nas empresas ao longo do processo de implementação de técnicas JIT. 
Tabela 20 - Evolução cronológica dos principais eventos ocorridos nas empresas pesquisadas durante a implementação de técnicas JIT

\begin{tabular}{|c|c|c|c|c|c|c|c|c|c|c|c|c|c|c|c|c|c|c|c|c|c|c|}
\hline & & \multicolumn{10}{|c|}{$\begin{array}{l}\text { Percentual de tempo em que o evento ocorreu antes da } \\
\text { Implementação de técnicas JIT }\end{array}$} & $\begin{array}{c}\text { Implementação } \\
\text { de JIT }\end{array}$ & \multicolumn{10}{|c|}{$\begin{array}{l}\text { Percentual de tempo em que o evento ocorreu depois da } \\
\text { Implementação de técnicas JIT }\end{array}$} \\
\hline Eventos importantes & Fator & -100 & -90 & -80 & -70 & -60 & -50 & -40 & -30 & -20 & -10 & Data zero & 10 & 20 & 30 & 40 & 50 & 60 & 70 & 80 & 90 & 100 \\
\hline Marco oficial do JIT/primeira iniciativa & Produção & & & & & & & & & & & $\mathrm{ABCDE}$ & & & & & & & & & & \\
\hline Treinamento em aspectos técnicos de JIT & Educação & & & & & & & & & & & $\mathrm{ABDE}$ & & $\mathrm{C}$ & & & & & & & & \\
\hline Treinamento de caráter comportamental & Educação & & & & & & & & & & & A & & $\mathrm{E}$ & & $\mathrm{C}$ & $\mathrm{A}$ & & & & & \\
\hline Alterações em critérios de contratação & Educação & A & & & & $\mathrm{B}$ & $\mathrm{A}$ & & & & & ACD & & $\mathrm{B}$ & & $\mathrm{BE}$ & & & & & & \\
\hline Uso de consultoria & Educação & & & & & & & & & & & $\mathrm{ABD}$ & & $\mathrm{E}$ & & $\mathrm{C}$ & & $\mathrm{B}$ & & & & $\mathrm{C}$ \\
\hline Aplicação da Semana Kaizen & Educação & & & & & & & & & & & $\mathrm{AB}$ & & & & & $\mathrm{D}$ & & & & & \\
\hline Multifuncionalidade & Educação & & & & & & & & & & & $\mathrm{B}$ & & & & $\mathrm{C}$ & $\mathrm{A}$ & & & & & \\
\hline Fusões e Alianças & Conjuntural & & & & & & & & & $\mathrm{C}$ & & & & & $\mathrm{E}$ & & & $\mathrm{B}$ & & $\mathrm{E}$ & & $\mathrm{ABD}$ \\
\hline Pressões (clientes e concorrência) & Conjuntural & & & & & & & & & $\mathrm{C}$ & & $\mathrm{D}$ & & $E$ & & & & $\mathrm{~B}$ & & & & A \\
\hline Certificações de qualidade & Produção & $\mathrm{AD}$ & & & & $\mathrm{B}$ & & & & & & B & & $\mathrm{C}$ & & $\mathrm{E}$ & & $\mathrm{B}$ & $\mathrm{E}$ & $\mathrm{E}$ & & $\mathrm{ACE}$ \\
\hline Uso de técnicas aplicadas específicas & Produção & B & & & & $\mathrm{C}$ & & & & & & $\mathrm{AD}$ & & $\mathrm{C}$ & $\mathrm{DE}$ & $\mathrm{BE}$ & $\mathrm{D}$ & B & & B & & $\mathrm{D}$ \\
\hline
\end{tabular}
Data zero = Formalização da Implementação de Técnicas JIT) e 100 (Ano 2002) em relação ao tempo decorrido desde a formalização da Implementação de Técnicas JIT na Empresa 
Foram destacados na Tabela 20 apenas os eventos considerados importantes e que ocorreram em ao menos três das cinco empresas pesquisadas. Constatou-se que o Treinamento em aspectos técnicos de JIT ocorreu simultaneamente ao lançamento formal dos programas para implementação das técnicas em quatro das empresas pesquisadas (a Empresa C não tem um marco oficial) e todas lançaram mão de Consultorias especializadas, ainda que não apenas para técnicas JIT (as Empresas A, B e D usaram metodologia da 'Semana Kaizen").

Também merece destaque o fato de que as alterações nos critérios de contratação antecederam ou ocorreram simultaneamente às certificações na maioria dos casos estudados. Algumas destas constatações serão novamente lembradas na formulação de Sugestões para estudos posteriores (6.3).

\subsection{2 - Fatores Críticos para a Implementação e os aspectos relacionados: uma visão geral}

A revisão da literatura sobre implementação de técnicas JIT mostrou que alguns Fatores Críticos devem ser considerados na implementação como forma de assegurar os melhores resultados (sucesso) do processo, muito embora esta mesma literatura não tenha definido claramente o que é sucesso na implementação de técnicas JIT. Estes fatores críticos estão ligados ao Comprometimento da Alta Administração, ao processo de Educação e Treinamento, à Produção, aos Fornecedores e aos aspectos Organizacionais e Estruturais, tal como definidos no Capítulo 3.

Não foram encontrados estudos que destaquem a importância relativa entre estes fatores, a despeito da existência de classificação dos fatores proposta por vários autores (Mehra e Inman, 1992; Zhu e Meredith, 1995; Ramarapu, Mehra e Frolick, 1995; Yasin e Wafa, 1996). Entretanto, as constatações obtidas a partir da segunda etapa da pesquisa de campo deste estudo, aliadas às premissas obtidas a partir da revisão da literatura sobre o tema, permitiram que se construísse a Figura 9 - Interdependência entre os FCI, que objetiva mostrar os diferentes Fatores Críticos para a Implementação e os respectivos aspectos que os constituem, visando destacar aqueles mais importantes nesta pesquisa em função das declarações dos entrevistados e das observações das empresas in loco por este pesquisador. Percebeu-se que nem os FCI e nem seus aspectos constituintes são estanques entre si. Existe uma suposta gama de relações causais diretas e indiretas entre os vários fatores críticos e também entre os vários aspectos dentro de cada fator crítico, algumas já relatadas por Ohno (1988) e outras constatadas nesta pesquisa. 
Figura 9 - Interdependência entre os FCI

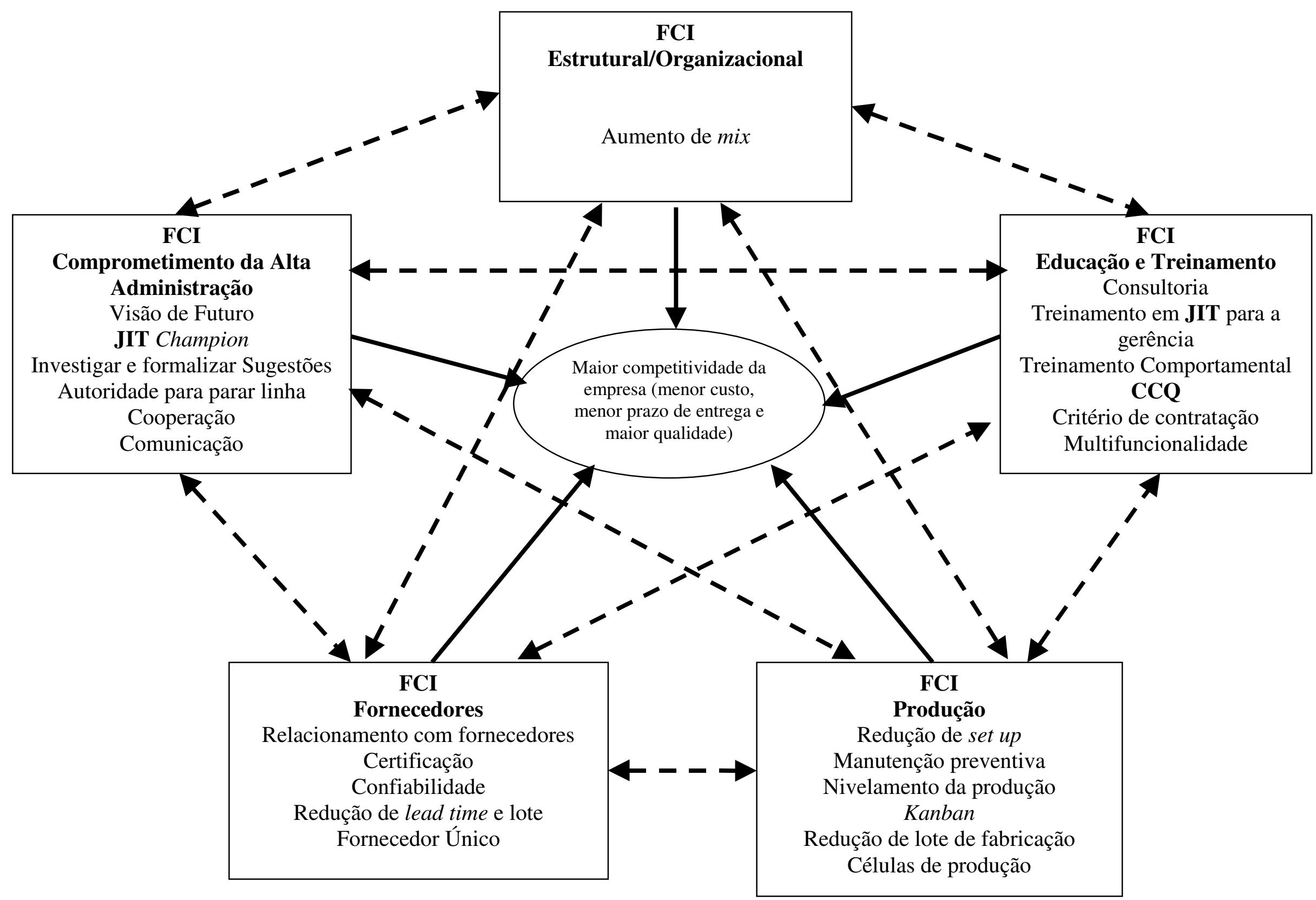


Um breve comentário sobre cada Fator Crítico e seus aspectos é oportuno. O Fator Comprometimento da Alta Administração, por exemplo, congrega os aspectos principais relacionados à forma como a Alta Administração demonstrou seu comprometimento com a causa da implementação de técnicas JIT nas empresas pesquisadas.

Inicialmente existe a manifestação das expectativas da Alta Administração quanto ao futuro da empresa e suas perspectivas, mostrado no aspecto "Visão de Futuro" e na nomeação de um "JIT Champion". Em seguida destacam-se dois aspectos de ordem prática que visam a viabilização de canais formais para "Investigação e formalização de sugestões" e "Autoridade para parar a linha de produção". Estes aspectos são completados pelo aspecto “Cooperação”e todos têm relação com o aspecto "Comunicação", aliás, já aventado como fundamental por Ansari e Modarress (1990), Helms (1990) e Wafa e Yasin (1998).

O Fator Treinamento e Educação é fundamentado principalmente pela adoção de serviços de "Consultoria", que, como já foi visto, presta-se a apoiar o treinamento da Alta Administração e também do pessoal operacional, no que diz respeito aos aspectos de "Tre inamento em JIT para a gerência", "Treinamento Comportamental" e “ CCQ". O aspecto "Critérios de contratação" mostrou-se como importante no apoio ao aspecto 'Multifuncion alidade".

Já o Fator Produção, por sua vez, tem como ponto central o aspecto 'Células de produção", que é apoiado por uma série de aspectos ligados à "Redução de set up" e 'Manute nção", "Nivelamento da produção" e uso de “Kanban". Todos estes aspectos em conjunto possibilitam a "Redução de lotes de fabricação", que no caso das empresas pesquisadas, foi influenciado fortemente pelas pressões do Fator Estrutural que levaram ao "Aumento de mix" em função da instalação de inúmeras novas montadoras de automóveis no período estudado nesta pesquisa.

Finalmente, o Fator Fornecedores apresenta uma série de aspectos ('Confiabilidade", "Certificação", 'Relacionamento" e 'Redução de LT/Lote') que levam ao principal deles que é o aspecto "Fornecedor único", fundamental para reduzir a variabilidade nos padrões de fornecimento, já proposto por Deming (1990).

Todos estes Fatores Críticos e os respectivos aspectos que os constituem, que estão indiretamente correlacionados entre si, contribuem para a melhoria competitividade da empresa no mercado, sob o ponto de vista das operações industriais (menor custo, menor prazo de entrega e maior qualidade). 


\subsection{3 - Análise dos Fatores Críticos para a Implementação}

Como já foi visto, cada Fator Crítico é composto por vários aspectos que lhe dão sustentação. O processo de entrevistas e visitas foi estruturado de forma a verificar como cada um destes aspectos foi tratado nas empresas pesquisadas. A análise das respostas a partir das entrevistas e visitas possibilitou que as empresas fossem estratificadas em uma posição que representasse o quanto de ênfase cada aspecto recebeu durante a implementação na empresa. É importante destacar que nem todos os aspectos citados na literatura serão aqui analisados em função de não terem se apresentado como relevantes nos casos estudados.

Tome-se como exemplo o aspecto 'Investigação e Formalização de Sugestões", um dos aspectos que integram o Fator Comprometimento da Alta Administração. A Tabela 21 mostra como cada empresa foi "classificada".

Tabela 21 - Status das empresas quanto aos aspectos do Fator Crítico Comprometimento da Alta Administração

\begin{tabular}{c|lcc}
\hline Aspectos do Fator Crítico & \multicolumn{3}{|c}{ Status das empresas } \\
\cline { 2 - 4 } Comprometimento da Alta Administração & $(-)$ & $(+-)$ & $(+)$ \\
\hline Investigação de problemas e formalização de sugestões & AD & CB & E \\
\hline
\end{tabular}

A Empresa E foi a que se apresentou "mais desenvolvida" neste aspecto em relação às demais empresas pesquisadas e foi posicionada na extremidade "positiva" da escala. Em seguida aparecem Empresas C e B, posicionadas na escala intermediária. Já as Empresas A e D, posicionadas na extremidade "hegativa" da escala. O posicionamento das empresas em relação aos aspectos analisados está baseado nas declarações dos entrevistados e eventuais observações da equipe de pesquisa.

Desta forma, para cada aspecto constatado como relevante dentro de cada grupo de Fatores Críticos, a mesma análise foi feita e os resultados são mostrados a seguir.

\subsubsection{1 - Comprometimento da Alta Administração}

O Comprometimento da Alta Administração tem recebido destaque como um importante Fator Crítico para a Implementação de técnicas JIT ao longo do tempo. As formas como este apoio pode ser manifestado aparecem nos artigos de Mehra e Inman (1992); Zhu e Meredith (1995) e Ramarapu, Mehra e Frolick (1995) assumindo diferentes significados, que puderam ser comprovados nesta pesquisa.

Nas Empresas A e E, que estão entre aquelas que obtiveram os resultados quantificados em maior volume e maior representatividade, ficou evidente a importância do 
apoio da Alta Administração. Na Empresa A, o Chefe de Melhorias Contínuas afirmou: “o apoio total do Gerente Geral foi irrestrito (foi até ordem!). Mesmo quando envolvia parada de equipamento. Ele conhece as dificuldades”. E ainda ressaltou: “a vontade do líder e seus seguidores é fundamental. Não tem jeito. É muito drástico. É de arrancar o fígado da pessoa. Os operadores falam que estão sentido medo. É preciso ter coragem. Precisa ter decisão forte. Tem de querer fazer a coisa, pois é sofrido!”. Na Empresa E o Diretor Industrial destacou: “o peso que a Alta Administração dá para o processo é muito importante”. Em ambas as empresas observou-se que o Gerente Geral e o Diretor Industrial eram, de fato, os grandes líderes da empresa no que se refere à implementação de técnicas JIT.

As principais manifestações do apoio da Alta Administração, destacados na Figura 9 Interdependência entre os FCI, estiveram presentes nos seguintes aspectos: a visão de futuro que a direção da empresa demonstrou; a existência de um JIT Champion; a existência de sistemas formais para investigação e formalização de sugestões, a cooperação e a comunicação.

A Tabela 22 mostra como as empresas foram classificadas em cada aspecto com base nas declarações dos entrevistados e nas observações in loco das empresas por este pesquisador.

Tabela 22 - Status das empresas quanto aos aspectos do Fator Crítico Comprometimento da Alta Administração

\begin{tabular}{l|lcc}
\hline \multicolumn{1}{c|}{\begin{tabular}{c} 
Aspectos do Fator Crítico \\
\multicolumn{1}{c}{ Comprometimento da Alta Administração }
\end{tabular}} & \multicolumn{3}{c}{ Status das empresas } \\
\cline { 2 - 4 } \multicolumn{1}{c}{$(-)$} & $(+-)$ & $(+)$ \\
\hline Visão de futuro & $\mathrm{BD}$ & $\mathrm{C}$ & $\mathrm{AE}$ \\
\hline JIT Champion & $\mathrm{C}$ & $\mathrm{DB}$ & $\mathrm{AE}$ \\
\hline Investigação de problemas e formalização de sugestões & $\mathrm{AD}$ & $\mathrm{CB}$ & $\mathrm{E}$ \\
\hline Autoridade para parar linha de produção & & $\mathrm{AB}$ & \\
\hline Cooperação & $\mathrm{D}$ & $\mathrm{BC}$ & $\mathrm{AE}$ \\
\hline
\end{tabular}

A Empresa E destacou-se neste Fator Crítico (classificada na melhor posição em 4 dos 5 aspectos), seguida pela Empresa A. As Empresas B e C podem ser consideradas medianamente desenvolvidas neste Fator e a Empresa D foi a que apresentou menor nível de desenvolvimento, com três aspectos classificados entre os menos desenvolvidos em relação às demais empresas pesquisadas

A seguir, analisamos cada um dos aspectos ligados ao Fator Comprometimento da Alta Administração, como forma de justificar as posições apresentadas na Tabela 22: 
Mehra e Inman (1992) trataram da visão de futuro e da existência de um JIT Champion como aspectos importantes na implementação de técnicas JIT ligando-os ao Fator Educação e Treinamento. Nesta pesquisa, entretanto, por iniciativa e julgamento deste pesquisador, estes aspectos foram ligados ao Fator Comprometimento da Alta Administração, já que cabe a ela identificar os caminhos pelos quais a empresa vai trilhar e também cabe a ela definir quem vai conduzir a empresa pelos caminhos traçados.

\section{$\underline{\text { Aspecto visão de futuro }}$}

Nas Empresas A e E, a Visão de Futuro era clara. Em várias declarações, o Chefe de Melhorias Contínuas da Empresa A demonstrou que a empresa estava tomando medidas específicas com clara expectativa quanto aos resultados no futuro. Por exemplo, ao tratar da implementação de técnicas JIT, o Chefe de Melhorias Contínuas afirmou: ‘emos mais um ano e meio pela frente", "hosso foco é a eficiência. É ser competitivo. É ter lucro, é girar estoque”, o que denotou que as ações estavam acontecendo mediante um planejamento que contemplava as relações causais esperadas entre as ações e resultados. Na Empresa E, seu Diretor Industrial foi enfático: "se você olhar no curto prazo, você não faz JIT", "a pressão do tempo para implementar pode prejudicar muito. Não existe resultado imediato”. Em ambos os casos a implementação de técnicas JIT estava colocada num contexto mais amplo do que meras atividades de "chão de fábrica" e por isso foram consideradas como mais desenvolvidas neste aspecto. Eram atividades vistas como vitais para a melhoria do desempenho futuro da empresa.

A Empresa C mostrou alguma preocupação com a Visão de Futuro quando seu Diretor de Operações Industriais declarou que a "p rioridade estratégia foi concentrar as atividades produtivas na fábrica de Sorocaba”. Isto implicava em conseguir viabilizar as atividades na citada região, mas não faz alusão mais direta à implementação de técnicas JIT. Por isso foi classificada na posição intermediária.

Já as Empresas B e D não apresentaram declarações que pudessem ligar a implementação de técnicas JIT a uma visão de futuro e mereceram classificação inferior neste aspecto.

\section{$\underline{\text { Aspecto JIT Champion }}$}

Uma vez que esteja claro para a empresa o porquê de implementar técnicas JIT, seria de se esperar que a responsabilidade pela coordenação mais ampla da tarefa fosse objetivamente designada a um condutor ou um líder, o conhecido JIT Champion apontado 
por Mehra e Inman (1992) e Zhu e Meredith (1995), entre outros. Mas não é o que tem ocorrido. Na Empresa C, não existia nem sequer um programa formal de implementação de técnicas JIT. Na Empresa D, o Gerente de Engenharia da Qualidade afirmou que sentia a falta de um líder, muito embora tenha reconhecido que havia dois gerentes de produção que entendiam muito bem do assunto, mas que eram somente "coordenadores". O Gerente de Engenharia da Qualidade chegou a desabafar: "o gerente de produção pegou os princípios básicos e treinou na sua área alguns auxiliares e liderou estes grupos de trabalho, mas não com todo o rigor que a técnica kaizen manda”. Na Empresa B, a função de liderança do processo de implementação era vista formalmente. O Diretor Industrial diz: "temos um coordenador kaizen”. O Chefe de Produção alegou: ‘há um escritório kaizen”. Percebe-se que a função de liderança ficava restrita a uma posição descrita no organograma da empresa. Nesta empresa, entretanto, observou-se que existia um excelente controle das atividades relacionadas ao JIT, por força da existência do escritório Kaizen.

No caso das Empresas A e E, a presença do JIT Champion era clara. Nas alegações do Chefe de Melhorias Contínuas, da Empresa A, percebia-se a relevância da posição do Gerente geral como o Champion da empresa: "houve necessidade de uma mudança radical, muito forte. A iniciativa partiu do Gerente geral”, "me propus a fazer kaizen em uma linha e ele (o Gerente geral) me empurrou logo dois, já na mesma semana." Neste caso a participação do Gerente geral chegava a parecer de caráter autocrático, mas na verdade era um elemento de apoio às ações do Chefe de Melhorias Contínuas. Já na Empresa E, o Gerente de Produção enfatizou: "toda essa mudança foi com o diretor. Ele é uma pessoa de boa formação. O hobbie dele é ler e estudar. Isto ajudou muito a todos. Aprendi muito com ele". Aqui destaca-se o papel do JIT Champion como um exemplo de comportamento positivo a ser seguido pelos colegas de trabalho. Mais uma vez a predominância de um aspecto do Fator Comprometimento da Alta Administração estava presente nas Empresas A e E.

Duas considerações são importantes por não terem sido abordadas na literatura pesquisada. A primeira diz respeito à origem da idéia de usar técnicas JIT na empresa, ou seja, onde está colocado na hierarquia da empresa o JIT Champion, se é que ele foi identificado como tal. No caso da Empresa A, com o Gerente Geral e da Empresa E, com o Diretor Industrial, ambos eram os membros da organização que ocupavam o maior cargo na hierarquia e tidos como profundos conhecedores do tema, o que se pode notar pelos relatos de funcionários. Na Empresa A, o Chefe de Melhorias Contínuas afirmou: "o Gerente Geral é um profundo conhecedor de plantas industriais...Ele conhece as dificuldades”. E na 
Empresa E, nas palavras do Gerente de Recursos Humanos, "o diretor industrial está diretamente envolvido. É o grande mentor”. Nas Empresas B e D a idéia de usar técnicas JIT nasceu na média gerência, ainda que tenha recebido apoio da Alta Administração.

A segunda está relacionada ao perfil gerencial do JIT Champion. Em ambos os casos foi possível perceber que os líderes tinham perfis bastante semelhantes. Na Empresa A, a liderança forte do Gerente Geral aparecia na declaração do Chefe de Melhorias Contínuas "para fazer JIT tem de ter muita costa quente. Envolve fazer pessoas trabalharem 24 horas seguidas. Quando ele (o Gerente Geral) sente que estou sozinho, ele me apoia”. Também na Empresa E o perfil gerencial do Diretor Industrial era destacado. O Gerente de Recursos Humanos afirmou 'Ele (o Diretor industrial) cobra bastante, sempre se envolve e vai na fábrica ver como a coisa está acontecendo. É um diretor muito ligado à fabrica. Não é um diretor de gabinete”. Estas características nos permitem dizer que o perfil gerencial do JIT Champion também foi relevante no processo de implementação.

Já nas Empresas B, C e D, este apoio ficou menos aparente. Na Empresa B, o presidente, que representa as operações da empresa no Brasil nas reuniões do board na Alemanha, não tinha atuação específica sobre as ações de implementação de técnicas JIT. Na Empresa C "o que interessa para o executivo é a última linha do balanço, ou seja, obter lucro", conforme declarou o Diretor de Logística, denotando um apoio apenas no sentido de que os resultados precisam ser obtidos por pura questão de sobrevivência da empresa. E por último, na Empresa D, o Gerente de Logística mostrou que "a idéia da implementação de JIT não tem um pai”. Nas declarações do Gerente de Engenharia da Qualidade: “a Empresa $\boldsymbol{D}$ não é contra a nada. Basta mostrar que tem retorno que a empresa permite que se faça. Não existe a cultura de fazer na forma de programa, como nas empresas americanas". Percebe-se que o JIT tem sido tratado como uma ferramenta a mais na busca da melhoria de resultados pela empresa.

\section{$\underline{\text { Aspecto investigação de problemas e formalização de sugestões }}$}

Outro aspecto do Fator Comprometimento da Alta Administração é a existência de mecanismos formais de investigação de problemas e formalização de sugestões.

$\mathrm{Na}$ realidade ficou constatado que todas as cinco empresas pesquisadas tinham programas formais de análise de problemas e geração de idéias para solução, cada qual com sua terminologia específica. Na Empresa E, o programa era vinculado ao Plano de Participação em Resultados (PPR), conforme destaca seu Diretor Industrial: "temos o 
programa Clik, inspirado em programa análogo da empresa Arvin americana (fabricante de uma vasta gama de produtos para o mercado automobilístico), que é conceitualmente muito bom, pois aumenta a participação dos funcionários não só com grandes idéias. O objetivo do programa é o comprometimento das pessoas. Faz parte do PPR”. Esta vinculação com o PPR estimulava a participação dos funcionários como alternativa para aumentar a pontuação, levando a um aumento na participação do PPR e possibilitando ganhos financeiros para os funcionários. Havia evidências efetivas da vigência do programa Clik que foram mostradas em relatórios internos da empresa.

Já na Empresa B, segundo seu Diretor Industrial, "o programa de idéias recebeu o nome de programa de sugestões, que é bem simples. É muito rápido. Há prêmios para a pessoa e para o grupo. Os prêmios são pagos rapidamente. Queremos volume de sugestão, se possível, com qualidade". A principal preocupação era quanto ao envolvimento dos funcionários na geração do maior número possível de idéias, antes de tudo. Isto chega a lembrar a técnica de brainstorm, muito usada para geração de idéias para solução de problemas, embora não tenha sido citada nominalmente. Conforme relato do Gerente de Qualidade Assegurada, "há um plano de sugestões em que é calculado o retorno do investimento e o funcionário participa da implementação e não apenas dá a idéia".

Na Empresa C, havia o programa de geração de idéias, ainda em fase inicial, o que a classifica na posição de menor desenvolvimento neste aspecto. Os funcionários davam sugestões e ganhavam pontos, como em sistemas de cartões de crédito. Duas vezes por ano os funcionários trocavam os pontos por prêmios e a área mais pontuada ganhava uma outra premiação. Nesta empresa também existia a vinculação do programa de geração de idéias com o PPR.

Na Empresa D existiam dois programas distintos, mas que objetivam os mesmos resultados: o programa de sugestões e os times de projeto, ambos em fase inicial de implantação. Na Empresa A, conforme declarações do Chefe de Melhorias Contínuas, havia 'kaizen com os operadores, que diria que foi decisivo para a geração de idéias”. Ambas foram classificadas na posição de menor desenvolvimento por estarem em fase inicial de implantação.

\section{$\underline{\text { Aspecto autoridade para parar linha de produção }}$}

As ações voltadas para o aumento da participação dos funcionários podem levar a aumento de autoridade, citado por Mehra e Inman (1992), Zhu e Meredith (1995) e 
Ramarapu, Mehra e Frolick (1995), a ponto de poderem parar uma linha de produção ao constatar um problema, mas apenas nas Empresas A e B ficou patente que existe este comportamento. Na Empresa A, declarou o Chefe de Melhorias Contínuas: "éles ( os operadores) tinham autoridade até para mudar as máquinas de lugar. Poderiam criticar o kaizen anterior”. Outro dado que mostrou o aumento de autoridade dos funcionários apareceu na declaração do Facilitador de Recursos Humanos: "o próprio grupo definiu acabar com uma certa linha de produção". E na Empresa B, nas declarações do Diretor Industrial: "éles podem alterar. Nenhum chefe vai lá e modifica o que eles fazem”. Quanto a este aspecto, acreditamos que a melhor terminologia para refletir o que ocorreu na realidade das empresas pesquisadas seria "aumento da autonomia" para tomada de decisões ao invés de aumento de autoridade, termo este que envolveria inclusive alterações na descrição de cargos e responsabilidades.

Quanto às Empresas C, D e E, não houve relatos e nem observações que pudessem ser vinculadas a este aspecto.

\section{$\underline{\text { Aspecto cooperação }}$}

$\mathrm{O}$ aspecto da cooperação entre as pessoas no trabalho, já destacado por Ansari e Modarress (1990), é mais um dos aspectos colocados entre as responsabilidades da Alta Administração como Fator Crítico para a Implementação de técnicas JIT, ou seja, caberia a esta promover um ambiente de trabalho que induzisse os funcionários a colaborar entre si para a obtenção dos melhores resultados.

As empresas tiveram ações específicas e particularizadas para melhorar a cooperação entre seus funcionários. Inclusive utilizaram técnicas ou estratégias que também se prestaram a outros propósitos, como a já descrita "semana kaizen" (adotada nas Empresas A, B e D), que teve também o objetivo de difundir o treinamento em uso de técnicas JIT, além de mostrar a aplicação prática de conceitos. As reuniões de "café da manhã", adotadas nas Empresas C e E também fazem parte de estratégias que se prestam tanto à melhoria da comunicação como da cooperação. A Empresa E utilizava-se ainda da reunião do "bom dia" também como forma de melhorar tanto a comunicação como a cooperação entre seus funcionários. Estas ações não foram referenciadas na bibliografia pesquisada.

Os relatos de melhorias na cooperação mais enfáticos apareceram na Empresa E, nas declarações do Diretor Industrial, enfatizando que "esta empresa tem um nível de comprometimento muito grande. Facilita o fato de estar numa comunidade pequena. $O$ 
tamanho da cidade não é condição básica, mas facilita. Greves não temos desde 1997. Trazer a família dos funcionários para dentro da empresa (open house) também ajudou muito na cooperação" e do Gerente de Recursos Humanos, quando declarou que "existe comprometimento em todas as empresas do grupo, mas eu sinto que em Amparo o nível de comprometimento é muito grande, tanto é que todo programa que implementamos aqui acaba pegando". É interessante de stacar o ponto levantado pelo Diretor Industrial quando fala da influência do tamanho da comunidade onde está instalada a empresa como um fator que pode ajudar na implementação das técnicas JIT. Esta alusão não foi encontrada nas bibliografias mais recentes, a não ser em Ohno (1988) referindo-se ainda às dificuldades de implementação de JIT nas empresas situadas em locais mais próximos à região metropolitana de Tóquio. O Diretor Industrial da Empresa E frisa que o tamanho da comunidade onde a empresa está instalada não é fator determinante, mas facilita a implementação, com base na experiência pela qual está passando no caso da implementação de técnicas JIT na fábrica de Contagem MG.

Na Empresa A, a partir das considerações feitas pelo Chefe de Melhorias Contínuas, constatou-se que "a cooperação melhorou a partir do momento em que se envolveu os funcionários. Tem funcionário com nível de inteligência maior que dos gerentes". Estas afirmações foram confirmadas pelo Facilitador de Recursos Humanos que diz: “o relacionamento melhorou muito após os kaizen comportamentais. O sentimento de coleguismo ficou maior. Antes as pessoas não se conheciam. Hoje elas conversam, 'batem papo" como amigos. Isto facilitou muito o kaizen técnico". Complementou ainda: "se faltar um operador no meio do processo, todos já sabem que vai atrapalhar o processo. Alguém vai ter que cobrir a falta".

Na Empresa C, pelas declarações do Gerente de Recursos Humanos, o nível de cooperação "Mudou bastante. O aumento de produtividade mostra o elevado grau de compromisso que foi conseguido entre as pessoas na empresa. Isto se nota não só entre o pessoal de produção, mas também entre as áreas de suporte, como manutenção, logística, engenharia, recursos humanos".

Nas Empresas B e D, os informantes também relataram que melhorou o nível de cooperação entre os funcionários, entretanto não existem relatos específicos que possam evidenciar que isto ocorreu de fato. 


\section{$\underline{\text { Aspecto Comunicação }}$}

$\mathrm{O}$ aspecto comunicação, um dos integrantes do Fator Comprometimento da Alta Administração, foi também destacado por Ansari e Modarress (1990), Helms (1990), Zhu e Meredith (1995) e Wafa e Yasin (1998).

A Empresa E declarou, por intermédio de seu Diretor Industrial, que a "reunião do bom dia" e a "reunião do café" (semanal entre gerentes e mensal com a diretoria) com pe ssoal de fábrica eram importantes instrumentos de comunicação. "Você tem de estar preparado para responder o que eles perguntam" destacou ainda o Diretor Industrial.

A partir da análise iterativa dos resultados acima descritos, foram propostas as seguintes hipóteses:

- Existiriam diversas formas de realização de coordenação central, especialmente em aspectos como existência de um JIT Champion, seu nível hierárquico, liderança, controle e existência de um programa formal de JIT.

A Empresa A apresentou como JIT Champion o Gerente Geral, assessorado diretamente pelo Gerente de Melhorias contínuas, caracterizando total apoio da Alta Administração inclusive no aspecto emocional. Na Empresa E, o Diretor Industrial era o próprio JIT Champion, o que confirma também o comprometimento da Alta Administração. Um escritório central Kaizen, de cunho formal, era utilizado na Empresa B, sendo voltado principalmente ao controle. Já nas Empresas C e D não havia coordenação central, nem tampouco um programa formal de JIT, apesar da existência nesta última de dois especialistas “coordenadores". Duas das empresas pesquisadas ( B e D), que não tiveram a coordenação central para a implementação das técnicas JIT, ressentiram-se da falta desta coordenação, julgando que o processo ficou localizado e individualizado.

- A comunicação seria realizada em diferentes formas, incluindo como principais aspectos a transparência na comunicação da gerência, o tipo de informações transmitidas, meios para a comunicação do pessoal operacional e nível de formalidade da comunicação.

As Empresas A e E exerceram a comunicação para o nível operacional de forma explícita e direta indicando as necessidades, objetivos e riscos associados ao JIT. Estas empresas colocaram este fato como o principal "acerto no processo de implementação". A Empresa B apresentou ampla comunicação formal relacionada a aspectos técnicos. Nas Empresas C e D, a comunicação restringiu-se ao aspecto operacional. Todas as empresas 
possuíam algum tipo de grupo de trabalho, conceitualmente semelhante aos CCQ's, MEK na Empresa A; Grupos Kaizen, na Empresa B; Grupos de Idéias, na Empresa C; Grupos de Sugestões, na Empresa D; e Grupos de Projeto na Empresa E. Para a comunicação do pessoal operacional, todas apresentaram programas de coleta de idéias e sugestões (que, nas Empresas A, C, E estavam vinculados ao Programa de Participação em Resultados), e as Empresas A e E utilizavam as informais reuniões do "bom dia" e "do café da manhã", respectivamente. As Empresas A, B e D utilizaram a metodologia formal da Semana Kaizen, como comunicação bidirecional em relação a aspectos técnicos.

Mas o Fator Comprometimento da Alta Administração não pode ser visto isoladamente. O Fator Educação e Treinamento, por exemplo, também depende do Fator Comprometimento da Alta Administração no mínimo para que o treinamento dos funcionários seja financiado.

\subsubsection{2 - Fator Educação e Treinamento}

O Fator Educação e Treinamento apresentou como principais evidências nesta pesquisa os aspectos: uso de "Consultoria", o "Treinamento da Gerência em técnicas JIT", "Treinamento Comportamental", "CCQ" e as "Alterações nos critérios de contratação", sendo que todos estes aspectos possibilitaram o desenvolvimento da 'Multifuncionalidade".

A Tabela 23 mostra como cada empresa foi classificada em cada aspecto com base nas declarações dos entrevistados e nas observações in loco das empresas por este pesquisador.

Tabela 23 - Status das empresas quanto aos aspectos do Fator Crítico Educação e Treinamento

\begin{tabular}{l|lrr}
\multicolumn{1}{c|}{$\begin{array}{c}\text { Aspectos do Fator Crítico } \\
\text { Educação e Treinamento }\end{array}$} & \multicolumn{3}{c}{ Status das empresas } \\
\cline { 2 - 4 } & $(-)$ & $(+-)$ & $(+)$ \\
\hline Consultoria & & & ABCDE \\
\hline Treinamento da Gerência em técnicas JIT & C & ADB & E \\
\hline Treinamento Comportamental & BD & AC & E \\
\hline CCQ & & & ABCDE \\
\hline Alterações em critérios de contratação & C & & ABCDE \\
\hline Multifuncionalidade & & ABE \\
\hline
\end{tabular}

Constata-se, pela análise da Tabela 23, que o uso de serviços de Consultoria, as iniciativas em CCQ e Alterações em critérios de contratação podem ser aspectos considerados básicos no que se refere ao Fator Crítico Educação e Treinamento, dado que todas as empresas pesquisadas os enfatizaram. A Empresa $\mathbf{E}$ destacou-se do grupo pela maior ênfase também nos demais aspectos, seguida pela Empresa A, ainda que de forma mais moderada. 
A seguir, analisamos cada um dos aspectos ligados ao Fator Educação e Treinamento.

\section{$\underline{\text { Aspecto consultoria }}$}

Mehra e Inman (1992) e Zhu e Meredith (1995) apontam o uso de consultoria como um dos aspectos ligados ao Fator Educação e Treinamento. Lawrence e Lewis (1993) também destacaram a importância do uso de consultoria para a implementação.

O uso de "Consultoria" especializada em implementação de técnicas JIT foi constatado em três das empresas pesquisadas (A, B e D) e as três usaram a mesma metodologia, ou seja, a "semana kaizen", já comentada anteriormente. Mesmo aquelas que não se utilizaram desta metodologia, fizeram uso de apoio de consultoria na implementação de técnicas específicas, como Kanban e K zero - treinamento comportamental (na Empresa C), e diagnóstico de clima organizacional (na Empresa E).

A metodologia da "semana kaizen" é comercializada pela empresa de consultoria TBM Consulting Group e mostra-se como uma ferramenta para catalisar o processo de implementação de técnicas JIT. Foi aplicada nas Empresas A, B e D exatamente com a mesma formatação, apesar de apenas a Empresa B ter contratado formalmente os serviços da consultoria enquanto a Empresa A usou um consultor independente, que também aplicou a mesma metodologia, e a Empresa D usou dois gerentes que conheceram a metodologia justamente em contato técnico sobre JIT na Empresa B.

Esta metodologia de implementação não foi referenciada na bibliografia pesquisada e, por isso, configura-se como uma característica particular da abordagem do processo de implementação de técnicas JIT constatada nesta pesquisa.

Na Empresa A, o Chefe de Melhorias Contínuas, que já havia sido funcionário efetivo da Empresa A em 1985 e consultor em 2000, declarou: “como consultor participei de 3 ou 4 kaizen. Quando me afastei da empresa não fizeram mais nenhum kaizen”. Este consultor foi contratado novamente como funcionário efetivo da Empresa A a partir de junho de 2001 para dar continuidade ao processo de implementação, que ficou descontinuado quando a empresa de consultoria afastou-se da Empresa A. A contratação definitiva do Chefe de Melhorias Contínuas aconteceu por iniciativa do Gerente Geral e mentor da aplicação de técnicas JIT na empresa, conforme declaração do próprio Chefe de Melhorias Contínuas.

Tanto na Empresa B como na Empresa D, o consultor era visto como extremamente necessário. Nas declarações do Diretor Industrial da Empresa B, ficou clara a importância da consultoria: "O papel é fundamental, principalmente para a média e alta gerência, que acham 
que sabem tudo. O consultor pode falar o que é necessário. É fundamental um consultor porque ele é neutro, ele pode falar o que quiser para quem quiser". Já o Gerente de Engenharia da Qualidade da Empresa D considerou que fez falta a presença de empresa de consultoria: "o processo que usamos foi amador, apesar de ter dado resultado. Na minha opinião, se tivéssemos o apoio de consultoria (específica para JIT), os resultados seriam melhores. Fizemos o arroz com feijão, as coisas mais simples, urgentes e fáceis. Não fomos mais a fundo para fazer mais coisas aqui dentro. Foi uma iniciativa individual e localizada. Não foi implantado na forma de programa. Só na usinagem e montagem”. Ficou evidente que a implementação estava ocorrendo, mas com deficiências. O Gerente de Engenharia da Qualidade continuou defendendo e argumentando a favor do uso de consultoria: "o legal da metodologia da "semana kaizen” é que faz marketing da implementação. Aqui a gente faz. muito, mas não contabilizamos ... é legal porque registra tudo. Filma antes, filma depois e fica tudo contabilizado. O ponto negativo é que tem que criar um escritório kaizen, que tem a missão de administrar tudo que é kaizen. Criaram um departamento específico para isso". E finalizou num desabafo: "aqui não se faz programa, como nas empresas americanas ... com o programa kaizen, o processo fica disseminado. Aqui, não está disseminado". Nos três casos ficou patente a importância da consultoria para a implementação de técnicas JIT.

No caso da Empresa E, apesar de não ter feito uso de uma metodologia do tipo "s emana kaizen", também utilizou serviços da consultoria brasileira IMAM - Instituto de Movimentação e Armazenagem de Materiais - na década de 90 como precursor de treinamentos internos, conforme informou seu Diretor Industrial: "alguns cursos isolados foram feitos com o IMAM'. Estas informações foram confirmadas pelo Gerente de Recursos Humanos: "a fase inicial foi com consultoria, depois com multiplicadores internos, porém, variando muito de acordo com o tipo de curso".

Também para analisar e entender o clima organizacional da empresa no início dos anos 90, portanto antes da implementação de técnicas JIT, a Empresa E contratou os serviços de uma consultoria especializada e obteve a seguinte conclusão, nas palavras de seu Diretor Industrial: "diagnóstico de clima de fábrica: baixa escolaridade dos chefes, encarregados e gerentes. Eram tipicamente capatazes".

Até mesmo na Empresa C, ainda que em menor intensidade, a consultoria foi utilizada, conforme declarações do Diretor de Operações Industriais: "usamos o IMAM para cursos e palestras" e do Diretor de Logística: "usamos consultoria para implementação da teoria das restrições". 
É claro o valor da participação de empresas de consultoria no processo de implementação de técnicas JIT entre as empresas pesquisadas, seja pela autonomia que representam em relação às pressões inevitáveis da hierarquia, ou seja pela rapidez de respostas que podem conseguir pelo domínio que detém da metodologia que utilizam para implementar as técnicas.

$\mathrm{O}$ trabalho das consultorias foi fundamental para que as empresas pesquisadas fizessem o treinamento em técnicas JIT e aprimorassem o trabalho em equipe, manifestado de forma intensa em termos de equipes de geração de idéias e assemelhados, conforme já comentado anteriormente.

\section{Aspecto treinamento da gerência em técnicas JIT}

O aspecto "Treinamento da Gerência em técnicas JIT" foi citado por Mehra e Inman (1992) como um dos Fatores Críticos para a Implementação. Apenas na Empresa C não ficou evidente a existência deste tipo de treinamento, talvez devido ao fato de não haver uma formalização clara de um programa JIT, a despeito de haver uso de algumas técnicas no processo de produção da empresa. Na Empresa E, o treinamento inicial para a gerência e supervisão foi feito com apoio de consultoria e depois estes funcionários ficaram encarregados de "mu ltiplicar" o treinamento para os demais. Esta estratégia tem dois pontos positivos: reduz custos e aumenta a legitimidade, na medida em que o funcionário vê o envolvimento da gerência no processo. Mas, naturalmente pode ter consequiências negativas, tal como a deficiência na multiplicação por falta de habilidade do funcionário "multiplicador", muito embora este problema não tenha sido citado.

Já nas Empresas A, B e D, o treinamento para a gerência em técnicas JIT foi feito nos eventos "semana kaizen". Estes eventos estão relacionados a uma metodologia de implementação de técnicas JIT aplicada pela TBM Consulting Group e consiste em uma série de reuniões, que acontecem ao longo de uma semana, com a seguinte estrutura, conforme descrição do Chefe de Melhorias Contínuas da Empresa A: "As reuniões da "semana kaizen" envolvem um determinado tema ou objetivo, constatado por uma equipe, por um gerente ou mesmo por algum funcionário. A partir disso são desenvolvidas reuniões em cinco dias".

\section{Aspecto treinamento comportamental}

Três Empresas (A, C e E) tiveram a preocupação de tratar do aspecto comportamental além do aspecto técnico no que diz respeito ao treinamento em técnicas JIT. Isto está ligado ao aspecto chamado de mudança cultural por Ramarapu, Mehra e Frolick (1995). Na 
Empresa A, "foi instituído o kaizen comportamental para melhorar o relacionamento das pessoas nas equipes, estimular a confiança mútua e esclarecer o que é o kaizen e qual é o propósito da empresa ao usá-lo", conforme declarações do Chefe de Melhorias Contínuas. Na Empresa $\mathbf{C}$ houve um treinamento ministrado pela Wilson Cerqueira Consultoria, que funcionou para ajudar nas mudanças culturais. $\mathrm{O}$ foco foi a conscientização das pessoas quanto à importância da qualidade e do relacionamento pessoal. Na Empresa E, em 1992, foi contratado um consultor de Recursos Humanos para fazer um diagnóstico de "clima de fábrica", objetivando conhecer as limitações a que a fábrica estava sujeita, fato este que culminou com o início do processo de terceirização na empresa. Por seu lado, nas Empresas B e D, ambas com origem de capital Alemã, não houve relatos de iniciativas voltadas à melhoria das relações pessoais no trabalho. Aliás, nestas empresas, o processo de implementação tinha uma "aura" mais formal do que nas Empresas A e E, na visão deste pesquisador.

\section{$\underline{\text { Aspecto CCQ }}$}

Os CCQ (Círculos de Controle da Qualidade), um dos aspectos citados nos trabalhos de Mehra e Inman (1992); Zhu e Meredith (1995); Ramarapu, Mehra e Frolick (1995); Yasin e Wafa (1996), estão ligados ao Fator Treinamento e Educação. Muito embora com terminologia diferente, o CCQ apareceu em todas as empresas. Na Empresa A foi chamado de MEK (melhoria kaizen); na Empresa B são os grupos kaizen; na Empresa C são os grupos de idéias; na Empresa D, os grupos de sugestões e na Empresa E os grupos de projeto. O termo CCQ pareceu estar fora de uso nas empresas pesquisadas.

\section{Aspecto alterações nos critérios de contratação}

Aliado à estratégia de uso de empresas de consultoria para fazer o treinamento e educação para as técnicas JIT, todas as empresas pesquisadas alteraram radicalmente suas posturas quanto ao aspecto "Critérios de contratação", passando a ser mais exigentes no momento da contratação, muito embora este fato não seja devido exclusivamente ao uso de técnicas JIT.

Na Empresa A, declarou o Facilitador de Recursos Humanos: "até 98 era exigido apenas primeiro grau; após 98, segundo grau e a partir de 2001, só segundo grau técnico". $\mathrm{Na}$ Empresa B, conforme seu Diretor Industrial, "os critérios de contratação estão muito mais rigorosos depois do JIT. O nível de exigência da empresa para contratar pessoas é 
muito maior que a média do estado de São Paulo. Existem vagas que não são preenchidas por falta de pessoal técnico".

$\mathrm{Na}$ Empresa C, que passou por grandes alterações e melhorias no processo de produção, o Gerente de Recursos Humanos afirmou "mudamos os equipamentos e layout. As pessoas precisam ter o mínimo de conhecimento para trabalhar aqui", "Até 1996 a contratação era baseada simplesmente em critérios de capacidade física. O supervisor era o “apataz” e ao funcionário cabia cumprir as ordens. Era "proibido pensar”. No início de 1997, 48\% das pessoas não tinham o primeiro grau completo. Hoje este número mudou completamente (5\% das pessoas ainda não têm o primeiro grau completo). Antes as pessoas só vinham trabalhar aqui em último caso. Hoje é exigido pelo menos o primeiro grau completo, ideal estar cursando o segundo grau. Isto se deve ao fato da radical mudança na tecnologia de produção empregada atualmente. Muitos dos novos equipamentos têm comando numérico, que exige um mínimo de proximidade com a informatização. É claro que ainda existem muitas tarefa manuais, mas já foram muito reduzidas".

Também na Empresa D: “quanto aos critérios de contratação observados após 1998, está evidenciado que se tornaram muito mais seletivos, exigindo-se ensino básico e fundamental completo nas áreas de produção e ainda assim, aplicando-se testes de admissão buscando proficiência mínima em matemática e Língua Portuguesa. Periodicamente, há um novo treinamento sempre que um novo produto ou nova tecnologia é introduzida à linha de produção" conforme a Gerente de Recursos Humanos.

Na Empresa E, conforme o Gerente de Recursos Humanos, “A partir do diagnóstico de RH, os funcionários de fábrica só seriam contratados se tivessem ao menos a $8^{a}$ série do ensino médio. A notícia espalhou-se rapidamente pela cidade (que é pequena, com cerca de 60 mil habitantes, e favorece a isto)".

A brusca alteração nos critérios de contratação de funcionários para trabalhar nas empresas que implementam técnicas JIT não aconteceu por puro acaso ou simplesmente por um desequilíbrio nas condições de oferta de empregos, o que favoreceria às empresas terem posturas mais rígidas no processo de contratação. Isto também ocorreu porque existia a necessidade de funcionários com perfil profissional diferenciado, ou seja, capazes de compreender o processo produtivo com mais abrangência e perceber a real importância de cada um neste processo. 


\section{$\underline{\text { Aspecto multifuncionalidade }}$}

Particularmente, acreditamos que as ações que levam à melhoria da comunicação (a investigação e solução de problemas, o treinamento em técnicas JIT e treinamentos comportamentais), o uso de consultoria, buscando catalisar o entendimento dos conceitos e sua disseminação, favorecendo o trabalho em equipe e o maior rigor nos processos de contratação de funcionários, complementam as condições ideais para que outro aspecto importante seja desenvolvido: a multifuncionalidade, muito destacada na literatura especializada, conforme Aggarwal (1985), Malley e Ray (1988), Manoochehri (1988), Orth, Hibyl e Korzan (1990), Billesbach e Schniederjans (1989), Vora, Saraph e Petersen (1990), Inman e Brandon (1992), Mehra e Inman (1992), Sevier (1992), Golhar e Deshpande (1993), Lawrence e Lewis (1993), Zhu e Meredith (1995), Ramarapu, Mehra e Frolick (1995), Vokurka e Davis (1996), Hancock e Zayko (1998) e Jusko (1999) entre inúmeros outros.

Na Empresa E, a maior parte das células de produção era composta por dois ou três funcionários. Algumas tinham apenas um único funcionário operando três ou quatro máquinas diferentes. Na Empresa B, conforme as declarações de seu Diretor Industrial: "aqui chamamos de polivalência. Há quadros mostrando o que o funcionário faz, o que ele sabe fazer além daquilo e no que ele está em treinamento. Isto implica alterações nos níveis salariais. Hoje quem não sabe várias tarefas é um nulo", do Gerente de Qualidade Assegurada: há quadros de polivalência destacando as habilidade dos funcionários" e do Chefe de Produção: “os funcionários decidem entre si o que fazer na célula”. Foram as evidências do estágio de desenvolvimento deste aspecto na empresa.

Também na Empresa A era evidente a presença da multifuncionalidade, conforme declarações do Chefe de Melhorias Contínuas: "não é a maioria, mas vem crescendo, até por necessidade, pois a cada setor que a gente vai arrumando, vai sobrando gente e já vemos que começa a faltar nos outros setores ... já tem áreas que têm multifuncionalidade entre setores. Já tem gente na montagem que é multifuncional com a usinagem" e do Facilitador de Recursos Humanos: "temos três níveis de operadores em função da quantidade de máquinas que operam e fazem set up ... Na usinagem já está bem claro isso. Na montagem os operadores escolhem onde querem trabalhar".

A partir da análise iterativa dos resultados acima descritos, foram formuladas as seguintes hipóteses: 
- A educação dos funcionários seria aprimorada com alterações nos critérios de contratação e incentivos a continuidade dos estudos, o que não necessariamente se deveria ao JIT.

Todas as empresas alteraram seus critérios de contratação no período analisado. Incentivaram também a elevação do grau de escolaridade dos funcionários; a Empresa $\mathbf{E}$ firmou convênio com a prefeitura municipal e as Empresas A, B e D subvencionavam o estudo de seus funcionários. Tal fato, porém, não se deve exclusivamente ao JIT, mas a diversos fatores como a aplicação de sistemas da qualidade e alterações tecnológicas do processo produtivo. Tal independência é reforçada pelo fato de que as Empresas A e B elevaram os critérios de contratação antes mesmo da implementação do JIT (vide Tabela 20).

- O treinamento técnico seria realizado por consultoria, o que teria fomentado o desenvolvimento deste tipo de negócio.

Todas as empresas utilizaram a consultoria, no momento inicial para treinamento (vide Tabela 20), que posteriormente prosseguiu por meio de multiplicadores; três delas (A, B e D) utilizaram para este fim a metodologia da semana Kaizen e também firmaram parcerias com instituições de ensino técnico como o SENAI, SESI e CIESP; a Empresa E lançou mão da consultoria do IMAM e a Empresa C do treinamento comportamental K zero de Wilson Cerqueira e técnico do IMAM.

- Seriam utilizados treinamentos específicos voltados ao aspecto comportamental.

Três das cinco empresas pesquisadas (A, C e $\mathbf{E})$ desenvolveram treinamentos específicos visando melhorias comportamentais de seus funcionários, seja na forma de relacionamentos pessoais, seja na forma de posicionamento em relação aos problemas que encontram no dia-a-dia do trabalho. A relação mais direta entre o treinamento comportamental e JIT é sugerida pelo fato de as três empresas o terem utilizado após a data zero do JIT (vide Tabela 20).

- No que se refere à gerência, sua resistência à mudança seria tratada, em parte, pela influência de consultoria externa.

As Empresas B e D apresentaram problemas de resistência à mudança da gerência. A Empresa B cita o relevante papel da consultoria para quebrar essa resistência.

- A organização sindical não exigiria nenhum tratamento específico. 
A organização sindical não tem sido fator de preocupação para as empresas pesquisadas no que tange à implementação das técnicas JIT. Em todas elas havia a presença de líderes sindicais entre os trabalhadores. Isto, provavelmente, se devia às condições de oferta e demanda em relação ao emprego formal. Em condições de mercado aquecido e com maior oferta de emprego, as organizações sindicais teriam maior poder de barganha e colocariam mais exigências para as empresas, o que não tem sido o caso, pelo menos neste setor da indústria.

\subsubsection{3 - Fator Produção}

Retomando novamente a Figura 9 - Interdependência entre os FCI, tratamos agora do Fator Produção. Uma das principais características de um processo produtivo em regime JIT é a existência de células de produção em operação, segundo Ohno (1988). Mas as células de produção não poderão ser implementadas a contento se não houverem cuidados específicos com alguns pontos básicos, segundo Lummus e Duclos-Wilson (1992): a redução de set up, um plano de manutenção preventiva, a prática de redução da base de fornecedores, o nivelamento da produção, a redução de perdas e a multifuncionalidade. Caso seja possível e viável, a adoção de controle de fluxo de produção via Kanban também possibilita um diferencial importante dada a facilidade de controle que promove no local de trabalho.

A Tabela 24 mostra como cada empresa foi classificada em cada aspecto com base nas declarações dos entrevistados e nas observações in loco das empresas por este pesquisador.

Tabela 24 - Status das empresas quanto aos aspectos do Fator Crítico Produção

\begin{tabular}{l|ccc}
\multicolumn{1}{c|}{$\begin{array}{c}\text { Aspectos do Fator Crítico } \\
\text { Produção }\end{array}$} & \multicolumn{3}{c}{ Status das empresas } \\
\cline { 2 - 4 } & $(-)$ & $(+-)$ & $(+)$ \\
\hline Nivelamento da Produção & ABCDE & & \\
\hline Redução de set up & $\mathrm{C}$ & $\mathrm{B}$ & $\mathrm{ADE}$ \\
\hline Manutenção preventiva & & $\mathrm{ABC}$ & $\mathrm{DE}$ \\
\hline Kanban & $\mathrm{D}$ & $\mathrm{CA}$ & $\mathrm{BE}$ \\
\hline Redução de lotes de fabricação & $\mathrm{C}$ & $\mathrm{DBA}$ & $\mathrm{E}$ \\
\hline Células de Produção & $\mathrm{C}$ & $\mathrm{BDA}$ & $\mathrm{E}$ \\
\hline
\end{tabular}

Mais uma vez apareceu a Empresa E em destaque também neste Fator Crítico (cinco vezes na melhor posição). Em situação intermediária ficaram as Empresas A, B e D. A Empresa C, que não apresentava programa formal em JIT, apareceu na posição de menor ênfase em aspectos do Fator Crítico Produção.

A seguir, analisamos cada um dos aspectos ligados ao Fator Produção: 


\section{$\underline{\text { Aspecto nivelamento da produção }}$}

Em todas as empresas pesquisadas não houve destaque no atendimento deste aspecto voltado especificamente à implementação de técnicas JIT, muito embora existissem iniciativas de nivelamento da produção em algumas delas. Na Empresa B, por exemplo, o Diretor Industrial simplesmente declarou: "este é um problema"; na Empresa D, o Gerente de Logística destacou: "nós sugerimos os pedidos aos clientes, pela média de consumo" e na Empresa E, o Diretor Industrial afirmou: "a demanda é definida pelo mercado". Fica evidente a dificuldade de se promover o nivelamento da produção nas condições em que operam as empresas pesquisadas. Não se observou ação efetiva de nivelamento da produção para auxiliar na implementação de técnicas JIT em nenhuma das empresas pesquisadas.

\section{$\underline{\text { Aspecto redução de set up }}$}

A redução do set up é mais uma forma de suporte à implementação de células de produção, conforme Zhu e Meredith (1995). Quanto menor for o set up, mais a célula de produção vai conseguir trabalhar em lotes mais reduzidos sem que o impacto nos custos seja significativo. A redução de set up ocorreu em todas as empresas, com menos ênfase na Empresa C que não usa o conceito de células de produção, mas que também desenvolveu alternativas para reduzir os tempos de set up dos equipamentos em geral.

Nos casos das Empresas A e B, foram realizadas "semana kaizen" específicas para tratar do set up de determinadas células. Nestas empresas predominavam as atividades de set up realizadas pelo próprio operador $(70 \%)$ em relação às atividades desenvolvidas por preparadores especializados (30\%).

Na Empresa D, os tempos de set up foram reduzidos graças ao trabalho de duas equipes especialistas em preparação externa dos equipamentos.

No caso da Empresa E, o início dos trabalhos deu-se com os operadores ajudando os ajustadores no processo de preparação das máquinas. O Gerente de Produção declarou: “os operadores se sentiam impotentes. Nem limpavam as máquinas. Devagar foi evoluindo para os operadores fazerem a preparação". A princípio, somente os ajustadores faziam a preparação, mas ao longo do tempo, os próprios operadores perceberam que poderiam ajudar na preparação, fazendo as atividades mais simples enquanto aguardavam pela chegada dos ajustadores, sempre muito ocupados atendendo a outras preparações. Com o tempo, mais e mais atividades de preparação passaram a ser feitas pelos operadores até que a maior parte da preparação externa passou a ser feita pelos próprios operadores. 


\section{Aspecto manutenção preventiva}

A importância da manutenção preventiva é ressaltada por Hay (1988). No caso da Empresa E, o programa de manutenção preventiva iniciou-se pela base, logo no início da implementação de técnicas JIT, conforme declarações do Gerente de Produção: "precisa que o operador de máquina esteja consciente de que deve colaborar. A limpeza da máquina é o básico para que a manutenção funcione".

Na Empresa D, estava bem desenvolvida, como alegou o Gerente de Logística: "tem todo um planejamento, check list. Está bem desenvolvido".

Nas Empresas A, B e C estava ainda em fase inicial, conforme declararam: o Chefe de Melhorias Contínuas da Empresa A, “começou junto com o 5S, mas não é o TPM moderno. Foram os primeiros passos. Educação na direção de manter o equipamento"; o Gerente de Qualidade Assegurada da Empresa B, “iniciado em 2000 na unidade de agulhas. Estamos ainda no primeiro nível" e o Diretor de Logística, da Empresa C, "Há manutenção mecânica, eletrônica (que são basicamente corretivas) e a preventiva, coordenada por uma equipe independente". Existia ainda pouco desenvolvimento de programas de manutenção preventiva, estando mais desenvolvidos nas Empresas E e D.

\section{Aspecto Kanban}

O uso de Kanban estava ocorrendo na maioria das empresas pesquisadas (exceto na Empresa D), mas com mais evidência na Empresa E. Seu Diretor Industrial destacou: "dentro da fábrica funciona tudo com Kanban. Retiramos material dos fornecedores com Kanban”. Isso foi constatado pela visita à fábrica, quando foi possível presenciar a entrega de tubos de aço em forma de matéria-prima, oriundos do fornecedor, acionado por Kanban. Mas o Gerente de Produção alertou: "precisa ter operadores treinados para reduzir o tempo da troca. Tem de ter refugo pequeno e fornecedores confiáveis em qualidade e prazo. É simples mas deve ter um conjunto de coisas para funcionar". Ele estava justamente chamando a atenção para a interdependência que se observa no uso das várias técnicas JIT.

Na Empresa B também o uso do Kanban estava bem disseminado, conforme as declarações do Diretor Industrial: "temos o Kanban eletrônico e com cartão. Há unidades que trabalham só com Kanban”, do Gerente de Qualidade Assegurada: “há Kanban em várias áreas"e do Chefe de Produção: "temos Kanban de superfície, sem cartão".

A Empresa A, por seu lado, estava ainda preparando a implementação de Kanban de superfície, conforme descreveu o Chefe de Melhorias Contínuas: "o mini mercado é que é o 
Kanban. Vamos marcar no piso a quantidade de caixas que devem existir e caberá ao processo anterior preencher o espaço".

Já a Empresa C, embora use Kanban há 7 anos, o fazia apenas em um setor específico (o Diretor de Operações Industriais destaca "a programação da máquina COS para a fábrica de plásticos é com Kanban"), pois nos demais setores era inviável. Na Empresa D não era usado, conforme comprovou o Gerente de Logística: "não usamos Kanban na fábrica".

\section{$\underline{\text { Aspecto redução de lotes de fabricação }}$}

$\mathrm{Na}$ Empresa E, "o tamanho dos lotes de fabricação passou de cerca de 1000 peças para múltiplos de 40 peças" conforme declarou seu Diretor Industrial. Já na Empresa A, o Chefe de Melhorias Contínuas afirmou que "as linhas estão tão enxutas, que em algumas linhas as entregas são feitas uma a uma".

Na Empresa B, a redução de lotes de fabricação era menos evidente, muito embora tenha ocorrido, conforme declarações do Gerente de Qualidade Assegurada: "é reduzido até o ponto que seja viável de produzir, ou seja, o lote econômico".

A Empresa D tinha dificuldades de mensuração sobre a redução de lotes de fabricação, mas, pelas afirmações de seu Gerente de Logística: "teve redução de lotes, seguramente. Eu sinto na fábrica uma reclamação dos mestres, que estamos programando lotes muito pequenos". Foi possível constatar que houve redução de lotes de fabricação.

Já a Empresa C não apresentou declarações que permitam concluir que houve redução de lotes de fabricação.

\section{$\underline{\text { Aspecto células de produção }}$}

Na Empresa E está disseminada por toda a fábrica que é uma "grande montadora de sistemas de exaustão", nas palavras de seu Diretor Industrial. Já na Empresa A, conforme relatos de seu Gerente de Melhorias Contínuas: "já fazíamos células de produção naquela época (há 15 anos). Hoje, cerca de 60\% das máquinas já estão operando em células".

As Empresas B e D também tinham células de produção em operação, entretanto, em menor escala. Na Empresa C não havia células de produção em operação.

A partir da análise iterativa dos resultados acima descritos, foram formuladas as seguintes hipóteses:

- O uso das técnicas JIT estaria limitado por características do processo produtivo. 
Constatou-se que, apesar de as técnicas JIT serem recomendadas para uso universal, existem limitações de processo produtivo que inviabilizam a adoção de algumas das técnicas estudadas nesta pesquisa, conforme foi destacado pela Empresa C, que trabalha num processo produtivo específico, representando praticamente uma grande linha de produção, que inviabiliza, por exemplo, a adoção dos conceitos de células de produção. Também vale ressaltar que operações de montagem mostraram-se mais propícias à aplicação de técnicas JIT do que as operações de produção. A Empresa E, por exemplo, é predominantemente montadora, enquanto que as demais estão em situação intermediária.

- Os resultados obtidos com a implementação de técnicas JIT estariam vinculados a outros fatores tais como Sistemas da Qualidade e avanços tecnológicos, que nem sempre poderiam ser isolados.

Todas as empresas pesquisadas certificaram-se em Sistemas de Qualidade logo após (E e C) ou até antes do início da implementação do JIT (A, B e D - vide Tabela 20), o que provavelmente afetou os resultados, especialmente no que se refere à qualidade do processo. Inovações tecnológicas ocorreram em todas as empresas, também afetando possivelmente os resultados, porém sem qualquer vínculo com o JIT.

\subsubsection{4 - Fator Fornecedores}

Outro aspecto importante no suporte da implementação de células de produção é referente ao Fator Fornecedores e está ligado à redução da base de fornecedores objetivando fornecimento oriundo de uma única fonte. Colocado como importante por Malley e Ray (1988), Vickery (1989), Willis e Suter (1989) e Lawrence e Lewis (1993), no caso das empresas pesquisadas não tem sido possível adotar a recomendação, ainda que reconhecida como muito importante.

Entendemos que a redução de lead time e da base de fornecedores, culminando com fornecedores únicos é um processo gradual que depende de outros fatores que lhe dão sustentação. Existem relatos claros de que foi necessária uma evolução no relacionamento entre a empresa e seus fornecedores. Esta evolução passou por uma melhoria no processo de comunicação envolvendo até a participação do cliente, oferecendo treinamento específico em técnicas JIT para o fornecedor. Outro aspecto que se apresentou como significativo neste Fator Fornecedor foi o advento das certificações de sistemas da qualidade, que levou ao aumento da confiabilidade dos fornecedores, ainda que haja relatos de que a realidade não era exatamente esta. 
A Tabela 25 mostra como cada empresa foi classificada em cada aspecto com base nas declarações dos entrevistados e nas observações in loco das empresas por este pesquisador.

Tabela 25 - Status das empresas quanto aos aspectos do Fator Crítico Fornecedores

\begin{tabular}{l|ccc}
\hline \multicolumn{1}{c|}{$\begin{array}{c}\text { Aspectos do Fator Crítico } \\
\text { Fornecedores }\end{array}$} & \multicolumn{3}{c}{ Status das empresas } \\
\cline { 2 - 4 } & $(-)$ & $(+-)$ & $(+)$ \\
\hline Fornecedor Único & $\mathrm{ABD}$ & $\mathrm{C}$ & $\mathrm{E}$ \\
\hline Redução do Lead time/Lote de fornecimento & $\mathrm{ABCD}$ & & $\mathrm{E}$ \\
\hline Relacionamento com fornecedores & $\mathrm{AC}$ & $\mathrm{DB}$ & $\mathrm{E}$ \\
\hline Certificação & $\mathrm{BD}$ & $\mathrm{C}$ & $\mathrm{AE}$ \\
\hline Confiabilidade & $\mathrm{B}$ & $\mathrm{DC}$ & $\mathrm{E}$ \\
\hline
\end{tabular}

Mais uma vez a Empresa E destacou-se das demais, mostrando-se como a mais desenvolvida nos aspectos relacionados ao Fator Crítico Fornecedores, quando comparada com as demais empresas pesquisadas. A Empresa C apresentou-se na posição intermediária principalmente em função de que seus principais insumos eram adquiridos de forma corporativa.

A seguir, analisamos cada um dos aspectos ligados ao Fator Fornecedor:

Aspecto fornecedor único

Apenas a Empresa E tinha práticas mais efetivas. O Coordenador da Qualidade afirmou: "hoje temos no máximo dois fornecedores e a tendência é diminuir para um".

Na Empresa A, declarou o Chefe de Melhorias Contínuas: "nosso JIT é interno. A redução da base de fornecedores ocorreu por decorrências de negócio e não por força do JIT'. Portanto, não havia cuidado ainda com redução da base de fornecedores. Ainda havia forte insegurança quanto à fonte de fornecimento. Isto ficou evidente pela declaração do Gerente de Logística da Empresa D: "é um grande perigo reduzir fornecedores. Você fica na mão deles. Exemplo disso nós temos em aço. Quando o pessoal percebe que está sozinho, infelizmente a coisa fica difícil. Na cultura brasileira não tem parceria. Nem sei se lá fora tem. Mesmo na matriz na Alemanha, não tem".

Também na Empresa B os problemas com fornecedores inibiam a busca por fornecedores únicos, conforme relato do Diretor Industrial: 'há grandes fornecedores, acostumados com JIT, e pequenos, que não querem nem ouvir falar de JIT', o que levava a uma diversidade de modos de fornecimento. Já o Diretor Industrial destacou: "a regra da indústria automobilística é clara: você tem de avisar quando quiser trocar de fornecedor. Quem não fizer isso está com problemas. Vai pagar toda a conta". Isto mostra a dificuldade 
de relacionamento entre a empresa e seu cliente. Se não bastasse isso, o Gerente de Qualidade Assegurada lembrou "há um abismo entre nós e os fornecedores. Um fornecedor de aço nos faz engolir material quando não precisamos de tanto".

Finalmente a Empresa C recebia 95\% de seus materiais de três fornecedores, que são fornecedores de todas as empresas do grupo no mundo e entregam materiais em regime de consignação, o que a levava a não ter maiores preocupações com redução da base de fornecedores. Notou-se que ainda há grande insegurança nas empresas para a adoção de fornecedor único.

\section{$\underline{\text { Aspecto redução do lead time/lote de fornecimento }}$}

Como conseqüência direta do baixo desenvolvimento de relações JIT com os fornecedores, a redução do lead time de fornecimento foi praticamente imperceptível. Apenas na Empresa E constatou-se afirmação de que houve redução, a partir das palavras do Coordenador da Qualidade: "o lead time diminuiu, pois o fornecedor sabe a nossa condição de estoques" e completou “o lote de compra também se reduziu ".

Na Empresa B, o Coordenador de Vendas afirmou que "o ônus da redução de lote ainda está sobrando para os transformadores de matéria prima”. Nas Empresas A, C e D não houve declarações ou observações que permitissem identificar a redução de lead time.

\section{$\underline{\text { Aspecto relacionamento com fornecedores }}$}

A evolução da melhoria de relacionamento entre cliente e fornecedor ainda aparece de maneira muito tênue. A Empresa $\mathbf{E}$ mostrou que está encaminhada neste sentido, conforme seu Coordenador da Qualidade: “desenvolvemos o fornecedor, o ajudamos na certificação. Ajudamos o fornecedor a fazer o PPAP (Processo de Aprovação de Amostras e Projeto) exigido pelas montadoras". Esta iniciativa denota claramente uma busca de relacionamento diferenciado com os fornecedores. Acrescentou ainda o Coordenador da Qualidade: "estamos fazendo um trabalho para desenvolver os fornecedores. Certificamos os processos deles. Os fornecedores devem ser parceiros, de fato".

Na Empresa D apareceu iniciativa semelhante, conforme destacou o Gerente de Logística: "temos projetos em conjunto com fornecedores".

Já na Empresa $\mathbf{B}$ apareceu um relato que mostra que as relações ainda precisam de muito aprimoramento, conforme disse o Diretor Industrial: "o relacionamento com alguns fornecedores é GA ("goela abaixo”) mesmo, fazemos kaizen nos nossos fornecedores 
também, mas nem todos permitem. Ficam desconfiados". Este relato torna evidente que uma relação de parceria aos moldes do que é proposto na literatura ainda era utópico, nas empresas pesquisadas, dada a desconfiança que ainda paira no ambiente das relações comerciais entre as empresas. Como alternativa, o próprio Diretor Industrial mostrou uma saída: "tentamos trabalhar com fornecedores locais que tenham matriz no exterior, para facilitar o processo, assim como as montadoras fazem conosco".

Nas Empresas A e C ainda não existia iniciativa JIT junto a fornecedores.

Estas relações ficam ainda mais frágeis na medida em que não são regidas por contratos de fornecimento. "No Brasil não se faz contrato de fornecimento. É bem informal. $O$ que você dá para ele é uma “carta de intenção”. Nenhum fornecedor aceita amarrar preço em função da quantidade" afirmou o Diretor Industrial da Empresa B.

\section{$\underline{\text { Aspecto certificação }}$}

A despeito das constatações anteriores, a certificação dos fornecedores era privilegiada. Na Empresa E, o Coordenador da Qualidade afirmou que o fornecedor "tem de ser pelo menos certificado ISO. Com fornecedores antigos não certificados, não desenvolvemos novos produtos. Hoje a grande maioria é certificada ... monitoramos o PPM e exigimos que eles também busquem a certificação".

O mesmo se constatou na Empresa A, no relato do Chefe de Melhorias Contínuas: "sempre houve exigência pelas montadoras para que nossos fornecedores fossem certificados. Privilegiamos fornecedores certificados". Aqui ficou evidente que existe pressão clara das montadoras pela elevação da qualidade de seus fornecedores e a estratégia que vinha sendo utilizada para garantir isso era a certificação, muito embora a Empresa D tenha demonstrado que existiam problemas, pelas afirmações de seu Gerente de Logística, mesmo com fornecedores certificados: "o primeiro critério é o técnico, depois compras escolhe o melhor preço. A certificação não faz grande diferença. Tenho fornecedor QS que você não acredita. Ele atrasa, não entrega, não responde. Não adianta. Não adianta fazer tanta pressão. Nós aumentamos o estoque de segurança. Esta é a realidade”. Esta afirmação adquiriu até uma conotação de desabafo. Naquele instante o entrevistado fez questão de mostrar um "processo" no qual a Empresa D pediu explicações sobre um problema de fornecimento a um fornecedor devidamente certificado, sem obter êxito. Vale ressaltar aqui que se tratava de uma grande aciaria e não um pequeno fornecedor sem maior expressão. Isto serve para mostrar que havia, de fato, problemas nas relações com os fornecedores, 
principalmente quando se trata de um grande fornecedor de um cliente que não lhe é tão significativo em termos de volume de negócios, como já foi colocado.

Na Empresa C, os fornecedores dos principais insumos eram escolhidos pela Holding, para todo o grupo e na Empresa B, até mesmo fornecedores certificados tinham apresentado problemas. Constatou-se que a preocupação com fornecedores nesta empresa era pequena, dada a forma como os principais insumos eram adquiridos.

\section{$\underline{\text { Aspecto confiabilidade }}$}

A instabilidade das relações com fornecedores fica evidenciada quando se constata que a inspeção sistemática de lotes no recebimento ainda era prática corrente. A Empresa $\mathbf{E}$ estava em condição mais desenvolvida, como assegurou o Coordenador da Qualidade: “Ainda temos inspeção de recebimento, com base no desempenho histórico do fornecedor. $O$ fornecedor pode chegar à condição de qualidade assegurada, ocasião em que entrega seus produtos direto na linha de montagem".

Já na Empresa D, o Gerente de Logística afirmou que "a confiabilidade melhorou de 98 para cá, mas continua havendo inspeção de recebimento, de forma amostral".

Os depoimentos verificados na Empresa B deram a exata dimensão do que tem ocorrido: o Diretor Industrial desabafou "somos obrigados a inspecionar e encontramos problemas. Os fornecedores não querem assumir responsabilidades", já o Coordenador de Vendas colocou um problema importante: "os fornecedores não têm a mesma velocidade que precisamos ter em relação aos nossos clientes". Ainda havia extremas dificuldades técnicas e operacionais na base de fornecedores o que foi confirmado pelas declarações do Gerente de Qualidade Assegurada: “os fornecedores ainda têm problemas. Há um abismo enorme entre nós e nossos fornecedores. Estamos no meio de uma guerra. As montadoras nos espremendo por um lado e os fornecedores não tendo condições de nos acompanhar, por outro". Alguns autores já chamaram a atenção para este importante elo, como Hay (1988), Vickery (1989), Freeland (1991) e Romero (1991) que apontou como problema a transferência de responsabilidades do cliente para os fornecedores.

No desenvolvimento das entrevistas, aliás, como sugere Eisenhardt (1989), foi necessário entender como estava posicionada cada uma das empresas em relação aos seus principais fornecedores no que se refere à importância no volume de negócios. A constatação foi interessante, pois no caso da Empresa E, sem dúvida a que mais conseguiu desenvolverse neste Fator Fornecedores, constatou-se que a empresa era cliente importante, no relato do 
Coordenador da Qualidade: “dos fornecedores satélites somos os maiores, da CSN somos o maior e puxamos com Kanban". A Empresa E construiu quase um "keiretsu" 2 próprio na medida em que criou os fornecedores satélites a partir da terceirização que empreendeu em fins dos anos 80. "Hoje a Empresa $\boldsymbol{E}$ é praticamente uma montadora de escapamentos, recebendo inúmeros subconjuntos prontos de terceiros" conforme seu Diretor Industrial. Já na Empresa A, declarou o Chefe de Melhorias Contínuas: "somos um cliente qualquer. Ainda não temos compra corporativa. Somos muito individualistas". Fica patente aqui a possibilidade de que esta empresa venha a desenvolver futuramente estratégias que englobem o Fator Fornecedores como alternativa de melhorar a sua competitividade. Na Empresa D, o Gerente de Logística foi objetivo: "para alguns, nós não representamos nada (as aciarias)".

De maneira geral, fornecedores monopolistas não discutem condições de entrega e isso inviabiliza implementação de técnicas JIT junto aos fornecedores, o que limita em muito a implementação e os potenciais resultados esperados, conforme foi destacado pelas informações obtidas na Empresa D. Os artigos analisados não colocam a discussão deste aspecto sob este prisma, limitando-se apenas a recomendar a redução da base de fornecedores, como se tal ação sempre fosse possível.

A partir da análise iterativa dos resultados acima descritos, foram formuladas as seguintes hipóteses:

- No que se refere aos fornecedores, haveria melhorias na confiabilidade, não necessariamente devidas ao JIT.

Todas as empresas relataram melhorias na confiabilidade dos fornecedores, muito embora este fato não se deva exclusivamente ao JIT, mas também ao processo de certificação em Sistemas da Qualidade. Este aumento da confiabilidade não se mostrou muito significativo, tanto é que as empresas não aplicavam a política de fornecedor único; as Empresas B e D tinham uma visão extremamente negativa do fornecedor único e ressaltavam inclusive a debilidade técnica de alguns de seus fornecedores. Em algumas ocasiões estes não tinham capacidade instalada para atendimento das autopeças, que se viam obrigadas a ter vários fornecedores diferentes para suprir suas linhas de produção, aumentando, assim, a variabilidade de seus processos e dificultando o atendimento das exigências cada vez mais restritivas das montadoras.

\footnotetext{
${ }^{2}$ Segundo Ohno (1988:19) uma reunião de pequenos fornecedores que fabricavam submontagens ou prestavam serviços, na maioria das vezes a um único cliente maior.
} 
- O nível de relacionamento com os fornecedores dependeria de vários fatores tais como a importância do cliente para o fornecedor e posicionamento na cadeia produtiva, sendo raras as parcerias.

A utilização de contratos de fornecimento não foi citada por nenhuma das empresas, que trabalham simplesmente contra pedidos. Quanto aos grandes fornecedores, especialmente as aciarias, todas as empresas, exceto a Empresa $\mathbf{E}$ que utilizava uma matéria prima muito específica em grande volume, não possuíam qualquer poder de barganha para exigir entregas JIT. Por outro lado, com os fornecedores menores, algumas empresas apresentavam parcerias, incluindo treinamento em técnicas JIT (Empresa E) e desenvolvimento conjunto de processos (B, D e E). A Empresa $\mathbf{E}$ representa um caso aparte, tem desenvolvimento conjunto de projetos e processos, assim como recebimento JIT de seus principais fornecedores, que constituíam um pequeno "keiretsu" formado na medida em que terceirizou muitas das atividades de produção que passaram a ser realizadas em pequenas empresassatélite criadas, em grande parte, por ex-funcionários.

\subsubsection{5 - Fatores Organizacionais e Estruturais}

A implementação de técnicas JIT pode trazer implicações organizacionais conforme Malley e Ray (1988) e Hum e Ng (1995). Os resultados desta pesquisa mostraram que ainda não ocorreram problemas organizacionais significativos nas empresas pesquisadas, nem mesmo quando estimuladas a tratar de problemas relacionados ao sistema de controle de estoques, de previsão de demanda e contabilização.

Importante foi a brusca alteração nas condições de demanda verificada no mercado brasileiro a partir de 1996. Silva (2001), caracteriza este tipo de ocorrência como problemas de caráter estrutural, que são ligados a aspectos externos à empresa. De fato, conforme se constata no Anexo J - Cronologia da Instalação (e desativação) das Fábricas de Automóveis,

Comerciais Leves, Caminhões e Ônibus no Brasil entre 1957 e 2002, houve um boom de novas montadoras no Brasil a partir de 1996. Isto levou a um aumento significativo no mix de produtos consumidos pelas montadoras, que passaram a produzir quantidades cada vez maiores de produtos em versões diversas, sem que houvesse elevação da produção agregada, como pode ser constatado no Anexo L - Produção Nacional, Importações e Exportações de autoveículos (Automóveis, Comerciais leves, Caminhões e ônibus), onde se vê que no período de 1996 a 2001, a produção nacional de autoveículos oscilou entre 1,6 a 1,8 milhões de unidades. Naturalmente que este fenômeno pressionou os lotes de fabricação das autopeças para baixo. Na Empresa D, o Gerente de Logística declarou: "teve redução de lotes, 
seguramente. Eu sinto na fábrica uma reclamação dos mestres, que estamos programando lotes muito pequenos". Também na Empresa A, o Chefe de Melhorias Contínuas afirmou: "as linhas estão tão enxutas, que em algumas linhas as entregas são feitas uma a uma".

Todo o esforço por usar técnicas JIT está relacionado ao aumento da competitividade. A Empresa E, no destaque de seu Diretor Industrial mostrou que "as montadoras começaram a pressionar para redução de estoque, entrega diária, em janelas, JIT e seqüenciada". E a empresa teve de se adaptar a todas estas exigências. "A adoção de técnicas JIT foi inevitável", complementou.

Nas Empresas B, D e E foi citado o problema da acumulação de faturamentos para o mercado de peças de reposição nos últimos dias do mês por motivos tributários, o que foi chamado de "síndrome do final do mês".

A partir da análise iterativa dos resultados acima descritos, foi formulada a seguinte hipótese:

- Mudanças nas características das exigências do cliente e na estrutura da indústria afetariam significativamente a pressão para a implementação de técnicas JIT, enquanto que peculiaridades do sistema tributário nacional e a composição da carteira de clientes das empresas condicionariam adaptações na utilização do JIT.

Houve uma expressiva mudança nas exigências dos clientes das autopeças (quanto a prazo de entrega e qualidade) e também quanto à estrutura da indústria, que passou a ter um número maior de montadoras a partir de 1996. Isso levou a um aumento das pressões do mercado comprador de autopeças, manifestadas pelo interesse das montadoras em receber produtos das autopeças em regime JIT. O mercado de reposição, por outro lado, apresentou características distintas, sofrendo da "síndrome do final do mês", ou seja, concentrando suas compras nos últimos dias de cada mês para obter vantagens fiscais. Quanto maior for a participação do mercado de reposição no montante de negócios da empresa de autopeças, mais estas têm tido que manter estoques de produtos acabados ou de estoque em processo próximo à etapa final de fabricação (Empresa $\mathbf{C}$, que possui $85 \%$ dos clientes no mercado de reposição) para fazer frente à este pico mensal de demanda.

Todas as hipóteses formuladas demonstram diferentes padrões de atuação das empresas pesquisadas no processo de implementação das técnicas JIT, o que também pode ser constatado nas figuras 4 a 8 no Capítulo 5 - Resultados da Pesquisa, o que suscita a hipótese da contingencialidade: 
- Existiria, nos casos pesquisados, contingencialidade no processo de implementação.

\subsection{4 - Visão geral}

A Tabela 26: Visão geral do status das empresas em relação aos aspectos de cada Fator Crítico para a Implementação, mostra em resumo, a posição relativa de cada empresa constatada por esta pesquisa para cada um dos aspectos de cada Fator Crítico para a Implementação.

Tabela 26 - Visão geral do status das empresas em relação aos aspectos de cada Fator Crítico para a Implementação

\begin{tabular}{l|c|c|c|c|c}
\hline \multicolumn{1}{c|}{ Fatores e aspectos } & \multicolumn{3}{c}{ Empresas pesquisadas } \\
\hline Fator Comprometimento da Alta Administração & $\mathrm{E}$ & $\mathrm{A}$ & $\mathrm{B}$ & $\mathrm{D}$ & $\mathrm{C}$ \\
\hline Visão de futuro & $* * * * *$ & $* * * * *$ & $*$ & $*$ & $* *$ \\
\hline JIT Champion & $* * * * *$ & $* * * * *$ & $* *$ & $* *$ & $*$ \\
\hline Investigação de problemas e formalização de sugestões & $* * * * *$ & $*$ & $* *$ & $*$ & $* *$ \\
\hline Autoridade para parar linha de produção & $\mathrm{ND}$ & $* *$ & $* *$ & $\mathrm{ND}$ & $\mathrm{ND}$ \\
\hline Cooperação & $* * * * *$ & $* * * * *$ & $* *$ & $*$ & $* *$ \\
\hline Fator Educação e Treinamento & & & & & \\
\hline Consultoria & $* * * * *$ & $* * * * *$ & $* * * * *$ & $* * * * *$ & $* * * * *$ \\
\hline Treinamento da Gerência em técnicas JIT & $* * * * *$ & $* *$ & $* *$ & $* *$ & $*$ \\
\hline Treinamento Comportamental & $* * * * *$ & $* *$ & $*$ & $*$ & $* *$ \\
\hline CCQ & $* * * * *$ & $* * * * *$ & $* * * * *$ & $* * * * *$ & $* * * * *$ \\
\hline Critérios de contratação & $* * * * *$ & $* * * * *$ & $* * * * *$ & $* * * * *$ & $* * * * *$ \\
\hline Multifuncionalidade & $* * * * *$ & $* * * * *$ & $* * * * *$ & $\mathrm{ND}$ & $*$ \\
\hline Fator Produção & & & & & \\
\hline Nivelamento da Produção & $*$ & $*$ & $*$ & $*$ & $*$ \\
\hline Redução de set up & $* * * * *$ & $* * * * *$ & $* *$ & $* * * * *$ & $*$ \\
\hline Manutenção preventiva & $* * * * *$ & $* *$ & $* *$ & $* * * * *$ & $* *$ \\
\hline Kanban & $* * * * *$ & $* *$ & $* * * * *$ & $*$ & $* *$ \\
\hline Redução de lotes de fabricação & $* * * * *$ & $* *$ & $* *$ & $* *$ & $*$ \\
\hline Células de Produção & $* * * * *$ & $* *$ & $* *$ & $* *$ & $*$ \\
\hline Fator Fornecedores & & & & & \\
\hline Fornecedor Único & $* * * * *$ & $*$ & $*$ & $*$ & $* * *$ \\
\hline Redução do Lead time/Lote de fornecimento & $* * * * *$ & $*$ & $*$ & $*$ & $*$ \\
\hline Relacionamento com fornecedores & $* * * * *$ & $*$ & $* *$ & $* *$ & $*$ \\
\hline Certificação & $* * * * *$ & $* * * * *$ & $*$ & $*$ & $* *$ \\
\hline Confiabilidade & $* * * * *$ & $\mathrm{ND}$ & $*$ & $* *$ & $* *$ \\
\hline & & & & \\
\hline
\end{tabular}

$* * * * *$ = Aspectos nos quais a empresa mereceu a melhor classificação.

** Aspectos nos quais a empresa mereceu classificação intermediária.

* Aspectos nos quais a empresa mereceu a pior classificação.

ND = Não há dados que permitam a classificação.

A Tabela 26 mostra as empresas e seus respectivos posicionamentos em relação aos principais aspectos dentro de cada Fator Crítico. Propositadamente as empresas foram ordenadas em função da quantidade de aspectos que apresentaram maior desenvolvimento relativo. A conclusão é que a Empresa $\mathbf{E}$ foi a que apresentou-se mais desenvolvida quanto à 
observância dos diversos aspectos, seguida pelas Empresas A, B, D e C. Isto despertou o interesse deste pesquisador em verificar se existe "correlação" direta entre a observância dos Fatores Críticos para a Implementação e os resultados obtidos pelas empresas com a implementação das técnicas JIT, muito embora não tenha sido este o objetivo desta pesquisa. Aliás, esta situação é prevista e bem-vinda por Eisenhardt (1989) quando enfatiza que a construção de teoria pode emanar de hipóteses surgidas ao longo da pesquisa, ainda que desconectas do objetivo principal. Isto ensejou a compilação da Tabela 27 - Evidências de resultados da implementação de técnicas JIT por empresa.

Tabela 27 - Evidências de resultados da implementação de técnicas JIT por empresa

\begin{tabular}{|c|c|c|c|c|c|}
\hline \multirow{3}{*}{$\begin{array}{c}\text { Evidências de resultados } \\
\text { da implementação }\end{array}$} & \multicolumn{5}{|c|}{ Empresas pesquisadas (ver legenda) } \\
\hline & \multirow{2}{*}{$\frac{\text { Grupo 1 }}{\text { E }}$} & \multicolumn{3}{|c|}{ Grupo 2} & \multirow{2}{*}{$\begin{array}{c}\text { Grupo 3 } \\
\text { C }\end{array}$} \\
\hline & & A & $\mathbf{B}$ & D & \\
\hline Número de níveis hierárquicos & $\begin{array}{l}\text { Redução de } 6 \\
\text { para } 3 \text { níveis }\end{array}$ & $\mathrm{ND} / \mathrm{C}$ & $\mathrm{ND} / \mathrm{C}$ & $\mathrm{ND} / \mathrm{C}$ & $\mathrm{ND} / \mathrm{C}$ \\
\hline Níveis de estoques & $\begin{array}{l}\text { Redução de } 6 \\
\text { para } 1 \text { mês }\end{array}$ & $\begin{array}{l}\text { Redução de } 90 \% \\
\text { nos estoques em } \\
\text { processo }\end{array}$ & $\begin{array}{l}\text { Redução de } 30 \text { a } \\
50 \% \text { nos } \\
\text { estoques em } \\
\text { processo }\end{array}$ & $\begin{array}{l}\text { Redução da } \\
\text { cobertura de } \\
\text { estoques de } 120 \\
\text { para } 40 \text { dias } \\
\end{array}$ & $\mathrm{ND} / \mathrm{C}$ \\
\hline Produção/produtividade & $\begin{array}{l}\text { Aumento de } \\
\text { cerca de } 285 \% \\
(*)\end{array}$ & $\begin{array}{l}\text { Aumento de } \\
\text { cerca de } 40 \%\end{array}$ & $\mathrm{ND} / \mathrm{C}$ & $\mathrm{ND} / \mathrm{C}$ & $\begin{array}{l}\text { Aumento de } 1,7 \\
\text { para } 6 \text { peças por } \\
\text { hora/pessoa/ mês }\end{array}$ \\
\hline Área ocupada & $\begin{array}{l}\text { Redução } 21 \% \\
(5000 \mathrm{~m} 2)\end{array}$ & \begin{tabular}{|l|} 
Redução $18 \%$ \\
$(2500 \mathrm{~m} 2)$ \\
\end{tabular} & $\begin{array}{l}\text { Redução 18\% } \\
(12000 \mathrm{~m} 2)\end{array}$ & $\mathrm{ND} / \mathrm{C}$ & $\mathrm{ND} / \mathrm{C}$ \\
\hline Lote de produção & $\begin{array}{l}\text { Redução de } 1000 \\
\text { para } 40 \text { peças }\end{array}$ & $\mathrm{ND} / \mathrm{C}$ & $\mathrm{ND} / \mathrm{C}$ & $\mathrm{ND} / \mathrm{C}$ & $\mathrm{ND} / \mathrm{C}$ \\
\hline Geração de idéias por funcionário & 21 idéias & $\mathrm{ND} / \mathrm{C}$ & $\mathrm{ND} / \mathrm{C}$ & $\mathrm{ND} / \mathrm{C}$ & $\mathrm{ND} / \mathrm{C}$ \\
\hline Índice de defeitos internos & $\begin{array}{l}\text { Redução de } 4000 \\
\text { para } 23 \text { ppm }\end{array}$ & $\mathrm{ND} / \mathrm{C}$ & $\mathrm{ND} / \mathrm{C}$ & $\mathrm{ND} / \mathrm{C}$ & $\begin{array}{l}\text { Redução de } 4 \% \\
\text { para } 0,5 \%\end{array}$ \\
\hline Índice de defeitos dos fornecedores & $\begin{array}{l}\text { Redução de } 1500 \\
\text { para } 600 \mathrm{ppm}\end{array}$ & $\mathrm{ND} / \mathrm{C}$ & $\mathrm{ND} / \mathrm{C}$ & $\mathrm{ND} / \mathrm{C}$ & $\mathrm{ND} / \mathrm{C}$ \\
\hline Fornecedores certificados & A maioria & $\mathrm{ND} / \mathrm{C}$ & $\mathrm{ND} / \mathrm{C}$ & A maioria & $\mathrm{ND} / \mathrm{C}$ \\
\hline Uso de células de produção & $\begin{array}{l}\text { Em todas as } \\
\text { áreas }\end{array}$ & $\begin{array}{l}\text { Em algumas } \\
\text { áreas } \\
\end{array}$ & $\mathrm{ND} / \mathrm{C}$ & $\begin{array}{l}\text { Restrita a } \\
\text { algumas áreas }\end{array}$ & Não aplicável \\
\hline Uso de Kanban & $\begin{array}{l}\text { Em todas as } \\
\text { áreas }\end{array}$ & Em implantação & $\begin{array}{l}\text { Só do tipo } \\
\text { eletrônico }\end{array}$ & Ainda não usa & $\begin{array}{l}\text { Restrito a uma } \\
\text { única área }\end{array}$ \\
\hline Manutenção preventiva & Implementada & $\mathrm{ND} / \mathrm{C}$ & Em implantação & Implementada & $\mathrm{ND} / \mathrm{C}$ \\
\hline Operadores multifuncionais & $\begin{array}{l}\text { Presentes em } \\
\text { células }\end{array}$ & $\begin{array}{l}\text { Presença de } \\
\text { quadros de } \\
\text { habilidades }\end{array}$ & $\begin{array}{l}\text { Presença de } \\
\text { quadros de } \\
\text { habilidades }\end{array}$ & $\mathrm{ND} / \mathrm{C}$ & $\mathrm{ND} / \mathrm{C}$ \\
\hline
\end{tabular}

Legenda:

Grupo 1: empresa cujos resultados quantificados ligados diretamente à implementação de técnicas JIT foram citados em maior volume e maior representatividade e também aquela na qual mais evidências de implementação de técnicas JIT foram constatadas quando da realização da visita às instalações físicas.

Grupo 2: empresas em situação intermediária quanto aos resultados e constatações.

Grupo 3: empresa que não declarou resultados ligados diretamente à implementação de técnicas JIT e que apresentou menos evidências de implementação de técnicas JIT.

ND/C: Resultados não declarados pelos entrevistados e não constatados pelo pesquisador.

(*): Valor calculado tomando como base a declaração de que a produção era $70 \%$ da atual e feita pelo dobro de pessoas. 
Nota-se que a "quantidade" de resultados obtidos pela implementação de técnicas JIT mostrados pelas empresas colocam a Empresa E (grupo 1) na melhor posição em relação às demais empresas, culminando com a Empresa C (grupo 3) tendo alegado a menor "quantidade" de resultados. É importante frisar que nesta busca de "correlacionar" Fatores Críticos com "resultados obtidos pela implementação", algumas variáveis apresentam-se com o viés da autocorrelação, pois são ao mesmo tempo apresentadas como aspecto de um Fator Crítico e como variável de resultados de implementação.

A despeito disso, poderíamos sugerir a seguinte hipótese:

- A observância dos Fatores Críticos para a Implementação de técnicas JIT elencados nesta pesquisa conduziria à obtenção de resultados com esta implementação.

A literatura pesquisada que tratou deste problema é controversa e o próprio artigo de Mehra e Inman (1992) reforça esta controvérsia. 


\section{Capítulo 6 - Conclusões e Sugestões}

Esta pesquisa foi conduzida por meio de um estudo multicaso de cinco empresas industriais da cadeia produtiva da fabricação de automóveis e teve como principal referencial metodológico a proposta de Eisenhardt (1989), que enfatiza a construção de teorias a partir de estudos de caso.

As empresas foram selecionadas a partir da constatação de que estavam em processo de implementação de técnicas JIT, obtida pela primeira etapa da pesquisa. Isto possibilitou que o instrumento de coleta de dados (um roteiro de pesquisa) fosse aplicado diretamente às pessoas envolvidas no processo de implementação. As entrevistas, conduzidas por este pesquisador e um pesquisador auxiliar, foram seguidas de visita às fábricas o que possibilitou que muitos dados fossem complementados. As análises entre os casos e dentro de cada caso culminaram com a formulação de hipóteses e comparação com a literatura sobre o tema.

As conclusões e sugestões são apresentadas em seções que mostram as contribuições relevantes sobre do processo de implementação de técnicas JIT em empresas em relação à proposta da literatura (confirmando, refutando ou apresentando pontos ainda não abordados) e em relação às empresas pesquisadas em operação no Brasil, destacando as peculiaridades locais; apresentam as contribuições à metodologia, face ao pioneirismo da aplicação desta metodologia em estudos sobre implementação de técnicas JIT; formulam sugestões para estudos posteriores; analisam as implicações para a prática da implementação de técnicas JIT e tecem as considerações finais.

\section{1 - Contribuições relevantes}

As contribuições que esta pesquisa trouxe aos conhecimentos relativos à implementação de técnicas JIT foram divididas em quatro partes: aquelas que confirmam a proposta da literatura pesquisada, aquelas que divergem da mesma literatura, aquelas que não foram cobertas pela literatura e aquelas que representam peculiaridades das empresas brasileiras pesquisadas.

\subsection{1 - Contribuições que são confirmadas pela literatura pesquisada}

A revisão de literatura (ver Capítulo 3 - Fundamentação Teórica) constatou os seguintes pontos, entre outros:

- A coordenação central constitui-se em Fator Crítico para a implementação de técnicas JIT. 
Duas das cinco empresas pesquisadas (B e $\mathbf{D})$, que não tiveram a coordenação central para a implementação das técnicas JIT ressentiram-se da falta desta coordenação. Julgam que o processo ficou localizado e individualizado. Por outro lado, as Empresas A e E, que tiveram esta coordenação central, a colocam como fundamental.

- A transparência da Alta Administração é importante.

Duas das cinco empresas pesquisadas (E e A) colocaram a transparência da Alta Administração, na forma de informações claras e objetivas sobre as reais necessidades da empresa quanto a utilização das técnicas JIT, como principal "acerto" praticado no proce sso de implementação.

- O processo de implementação envolve apoio às mudanças comportamentais.

Três das cinco empresas pesquisadas (A, C e E) desenvolveram treinamentos específicos visando melhorias comportamentais de seus funcionários, seja na forma de relacionamentos pessoais, seja na forma de posicionamento em relação aos problemas que encontram no dia-a-dia do trabalho.

- A confiabilidade dos fornecedores aumentou.

A confiabilidade, de forma geral, aumentou após a implementação das técnicas JIT, mas mesmo assim ainda persistem as inspeções de recebimento, realizadas amostralmente.

- Existiu, nos casos pesquisados, contingencialidade no processo de implementação.

A julgar pelo fato de todas as empresas pesquisadas terem alcançado resultados positivos com seus processos de implementação e que estes processos foram desenvolvidos considerando alguns eventos semelhantes, ainda que em tempos diferentes, é verdadeira a afirmação encontrada na literatura acerca da contingencialidade do processo de implementação de técnicas JIT, o que pode ser constatado nas Figuras 4 a 8 no Capítulo 5 Resultados da Pesquisa. Entretanto, a mesma literatura pesquisada não apresentou um trabalho que reúna um grupo representativo de empresas e teste a existência de um modelo de implementação.

- Alterações nas exigências dos clientes e na estrutura da indústria.

Houve uma expressiva mudança nas exigências dos clientes das autopeças (quanto a prazo de entrega e qualidade) e também quanto à estrutura da indústria, que passou a ter um número maior de montadoras a partir de 1996. 
Isso levou a um aumento das pressões do mercado comprador de autopeças, manifestadas pelo interesse das montadoras em receber produtos das autopeças em regime JIT. Dessa forma, quanto maior a participação das montadoras no montante de negócios da empresa de autopeças, mais fortemente as pressões foram sentidas.

\subsection{2 - Contribuições discrepantes em relação à literatura pesquisada}

Os resultados desta pesquisa não confirmaram o que propõe a literatura pesquisada (ver Capítulo 3 - Fundamentação Teórica) nos seguintes pontos:

- Empecilho representado pela organização sindical.

A organização sindical não tem sido fator de preocupação para as empresas pesquisadas no que tange à implementação das técnicas JIT. Em todas elas havia a presença de líderes sindicais entre os trabalhadores. A literatura tem mostrado que a presença de sindicatos organizados pode significar dificuldades para a implementação de técnicas JIT, conforme Lawrence e Lewis (1993) e Wafa e Yasin (1998). Nestes artigos não há alusão às condições econômicas das empresas e nem mesmo dos países onde elas operam. Provavelmente estas pressões seriam sentidas com mais evidência caso as condições de oferta de emprego fossem mais favoráveis.

- A existência de contratos de fornecimento de longo prazo.

Não foram identificados contratos formais de fornecimento entre as indústrias de autopeças e seus fornecedores e entre autopeças e seus clientes, apregoados por Ansari e Modarress (1990), e Muchnik, Shipley e Shane (1990). Quando muito havia um "acordo" de fornecimento, que nem chega a ser escrito. Ainda existia uma grande dicotomia nos fornecedores das empresas de autopeças pesquisadas, variando de grandes fornecedores a fornecedores muito pequenos. A constante instabilidade da economia brasileira pode ser a causa do receio de se firmar contratos de fornecimento escrito e de longo prazo.

- Fornecedores únicos.

A prática de "fornecedores únicos" chega a ser vista como um empecilho, conforme afirmações de informantes das Empresas B e D. Chega mesmo a ser uma imposição das montadoras às autopeças na medida em que estas são obrigadas a trabalhar com os fornecedores definidos nos projetos oriundos das áreas de engenharia das montadoras. A troca de fornecedor é difícil e extremamente burocratizada, mesmo quando totalmente justificada. Mesmo assim, algumas das empresas de autopeças pesquisadas mostravam-se relutantes em 
firmar posição com fornecedores únicos, provavelmente em função das limitações técnicas e operacionais apresentadas por alguns fornecedores.

Apenas a Empresa E tinha recebimento JIT de seus principais fornecedores e assim mesmo por ter praticamente desenvolvido um pequeno "keiretsu" na medida em que terceirizou muitas das atividades de produção que antes eram realizadas internamente. É claro que as demais poderiam ter lançado mão do mesmo expediente em suas fábricas, mas o fato é que apenas uma conseguiu criar esta situação, o que lhe foi muito favorável.

\subsection{3 - Pontos não abordados na literatura pesquisada}

A revisão de literatura (ver Capítulo 3 - Fundamentação Teórica) não fez menção aos seguintes pontos:

- O uso da metodologia "Semana Kaizen" para a implementação.

Esteve difundida em três das cinco empresas pesquisadas uma metodologia aplicada para a implementação de técnicas JIT, comercializada pela TBM Consulting Group, uma empresa de consultoria especializada que tem filiais em quatro países, além da matriz americana. Esta metodologia, que é chamada de "Semana Kaizen" e foi apontada como muito eficiente pelas empresas pesquisadas, está sendo aplicada no Brasil há sete anos e nos EUA há doze anos, baseando-se no tradicional e conhecido Sistema Toyota de Produção, conforme informações da Gerência de Atendimento ao Cliente.

- Posição hierárquica e perfil gerencial do JIT Champion.

A literatura é profícua em recomendar que o processo de implementação de técnicas JIT seja liderado por um JIT Champion, entretanto, não foi constatado nenhum trabalho que tratasse de forma mais específica sobre o JIT Champion em si. Os dois pontos levantados (a posição hierárquica do JIT Champion na estrutura da empresa e as características de seu perfil gerencial) podem ser fatores determinantes na implementação, como foi constatado nas Empresas A e E, que possuíam claramente a função do JIT Champion desempenhadas pelo Gerente Geral e pelo Diretor Industrial, respectivamente.

- Posição da empresa na cadeia produtiva.

A posição das empresas de autopeças na cadeia produtiva das indústrias automobilísticas no Brasil pode ser considerada frágil. Constatou-se que as empresas de autopeças, independentemente de seu porte, fornecem a grandes montadoras que têm grande poder de pressão por condições especiais de recebimento de seus pedidos, que incluem 
tamanho de lotes reduzidos, entregas freqüentes e exigências explícitas quanto a qualidade. $\mathrm{Na}$ outra extremidade da cadeia produtiva estão dois tipos básicos de fornecedores: o primeiro grupo, composto por grandes fornecedores monopolistas, que ditam as normas de fornecimento (prazos de entrega e o tamanho do lote, etc), mesmo para aqueles clientes mais expressivos. Às empresas de autopeças não resta outra alternativa senão acatar estas "forças do mercado". O segundo grupo de fornecedores é composto por uma miríade de pequenos fornecedores que pecam por vários motivos. Em algumas ocasiões não têm capacidade instalada para atendimento das autopeças, que se vêm obrigadas a ter vários fornecedores diferentes para suprir suas linhas de produção, aumentando, assim, a variabilidade de seus processos e dificultando o atendimento das exigências cada vez mais restritivas das montadoras e em outras ocasiões, os fornecedores não têm capacidade técnica de suprimento em conformidade com as exigências das autopeças. Pior ainda se torna a situação quando os fornecedores disponíveis apresentam os dois problemas conjugados, ou seja, falta de capacidade instalada e falta de capacidade técnica, aliás, fato este constatado como bastante freqüente conforme destacado pelas Empresas B e D.

Porter (1986) mostra a influência do poder dos compradores e fornecedores, entretanto sem relacionar seu estudo às técnicas JIT.

- Limitações representadas pelo processo produtivo

Ficou patente que, apesar de as técnicas JIT serem recomendadas para uso universal, existem limitações de processo produtivo que inviabilizam a adoção de algumas das técnicas estudadas nesta pesquisa, conforme foi destacado pela Empresa C, que trabalhava num processo produtivo específico, representando praticamente uma grande linha de produção, que inviabiliza, por exemplo, a adoção dos conceitos de células de produção. Também vale ressaltar que operações de montagem mostraram-se mais propícias à aplicação de técnicas JIT do que as operações de produção. A Empresa E, por exemplo, era predominantemente montadora, enquanto que as demais estavam em situação intermediária.

- A vinculação dos programas de geração de idéias aos Planos de Participação em Resultados (PPR).

Em três das empresas pesquisadas (A, C e E) os programas de geração de idéias estavam vinculados formalmente aos Planos de Participação em Resultados como forma de estímulo à participação dos funcionários. 


\subsection{4 - Peculiaridades verificadas nas empresas pesquisadas no contexto brasileiro}

Os pontos a seguir não foram diretamente abordados na literatura pesquisada e, portanto, podem constituir características peculiares das empresas pesquisadas.

- A "síndrome do final do mês"

A inexistência de interesse por parte das empresas revendedoras de peças e componentes do mercado de reposição em formalizar programações de entregas para as empresas fornecedoras de autopeças. Desta forma, estas revendedoras adiam ao máximo a colocação dos pedidos, que são feitos na maioria das vezes ao final do mês (dois ou três dias antes do final do mês fiscal), com prazos de entrega praticamente imediatos. Resumindo, querem receber em regime JIT, mas não se comprometem ao menos a prever sua demanda futura. Em alguns casos, como no da Empresa D, a empresa tem sido obrigada a tomar para si a responsabilidade da programação de seus clientes. Este comportamento tem sido chamado pelas empresas de autopeças como "síndrome do final do mês". A conseqüência imediata tem sido a formação inevitável de estoques reguladores nas próprias empresas de autopeças. Quanto maior for a importância do cliente no montante de negócios da empresa de autopeças, maiores as suas dificuldades de implementar efetivamente as técnicas JIT, muito embora seja certo que a implementação de técnicas JIT amplie a flexibilidade do processo de produção.

- $\quad$ O aumento do mix de produtos requeridos pelas montadoras.

O abrupto aumento da entrada em operação de novas empresas montadoras no Brasil a partir de 1996, principalmente, levou a um aumento do mix de produtos requeridos por estas montadoras. Como a expansão da produção para atendimento da demanda não foi expressiva (Anexo L - Produção Nacional, Importações e exportações de Autoveículos: Automóveis, Comerciais leves, Caminhões e ônibus), os lotes de produção também sofreram reduções, pressionando ainda mais as empresas a perseguirem melhorias em seus processos produtivos.

- As deficiências da formação escolar dos funcionários.

As parcerias para desenvolver e capacitar os funcionários também se fizeram presentes na maioria das empresas pesquisadas. Algumas destas parcerias foram voltadas a desenvolver aspectos básicos da formação escolar dos funcionários, como foi o caso da Empresa E que fez convênio com a Prefeitura Municipal de Amparo-SP para a promoção cursos internos de formação fundamental. Já outras empresas firmaram convênios mais voltados a desenvolver habilidades específicas, como foi o caso das Empresas A, B e D, que estruturaram treinamentos com o SESI, SENAI, CIESP e até mesmo com uma faculdade de engenharia. 
- O uso de técnicas JIT não gerou demissões de funcionários.

A implementação de técnicas JIT nas empresas pesquisadas não gerou demissões de funcionários. Houve uma real expansão na demanda de automóveis no mercado brasileiro, muito embora não tenha sido um crescimento que chegasse a ser significativo (Anexo L Produção Nacional, Importações e exportações de Autoveículos: Automóveis, Comerciais leves, Caminhões e ônibus). Aliás, uma das empresas pesquisadas (a Empresa B) alegou que a chegada das montadoras em meados da década de 90 trazia expectativas de demanda que foram frustradas em mais de $70 \%$. Isto causou problemas às autopeças, que investiram em aumento de capacidade de suas fábricas e não tiveram a demanda que esperavam.

\section{2 - Contribuições metodológicas}

Cinco artigos específicos sobre casos de implementação de técnicas JIT foram localizados na revisão da literatura - Payne (1993), Spencer e Guide (1995), Garg, Kaul e Deshmukh (1998), Mazany (1995) e Sohal (1996). Entretanto, em nenhum deles se pode analisar o processo de implementação, pois todos tratam do processo de forma estática, ou

seja, não fazem qualquer alusão ao seu desenvolvimento ao longo do tempo e tampouco tecem considerações sobre os acontecimentos aos quais as empresas estiveram sujeitas ao longo do processo.

Nesta pesquisa, a metodologia adotada permitiu que se pudesse analisar a implementação de técnicas JIT constatando os principais eventos que ocorreram, fossem estes eventos diretamente relacionados às técnicas JIT ou não, como foram os casos de fusões ocorridas nas Empresas B, C, D e E ou mesmo o movimento das certificações da qualidade, presente em todas elas.

A análise do processo de implementação de técnicas JIT, desde o lançamento formal do programa (quando ocorreu) até junho de 2002, procurou evidenciar a presença ou ausência dos principais aspectos componentes dos fatores críticos propostos a partir da pesquisa bibliográfica e como foram tratados nas empresas pesquisadas.

Esta pesquisa foi pioneira ao basear-se na metodologia proposta de Eisenhardt (1989) e aplicá-la para estudar a implementação de técnicas JIT, o que permitiu que diversas hipóteses e sugestões de pesquisa para estudos posteriores fossem levantadas, abrindo espaço para futuros estudos envolvendo o tema JIT. 


\section{3 - Sugestões para estudos posteriores}

Ao longo da realização da pesquisa de campo e análise de dados, alguns pontos se destacaram pelo seu potencial como tema de futuras pesquisas na área e, pelo fato de não estarem enquadrados diretamente no objetivo principal desta pesquisa, não foram explorados com maior detalhe. Entretanto, podem servir de base para futuras pesquisas que em muito poderão aumentar o arcabouço de conhecimento sobre o processo de implementação de técnicas JIT. Alguns destes pontos surgiram em função dos resultados obtidos com as entrevistas e um, especificamente, surgiu a partir das contribuições dos professores no instante da qualificação.

Sugestões de estudos posteriores a partir de constatações nos estudos de caso:

- Para a implementação de técnicas JIT não basta apenas treinamento em aspectos técnicos, mas também é necessário treinamento em aspectos comportamentais e/ou motivacionais (vide Tabela 20). Hipótese: o treinamento técnico deveria ser complementado por treinamento em aspectos comportamentais e/ou motivacionais. Sugere-se estratificar empresas usuárias de técnicas JIT e verificar se as mesmas realizaram treinamentos de caráter comportamental/motivacional concomitantemente aos treinamentos técnicos em JIT.

- Empresas de origem Alemã são menos sensíveis à necessidade de treinamentos motivacionais e/ou comportamentais (vide Tabela 20). Hipótese: a cultura predominante afetaria a utilização de treinamentos motivacionais e/ou comportamentais. Sugere-se reunir amostra de empresas de várias origens de capital, usuárias de técnicas JIT, e verificar se existe diferença significativa no uso de treinamentos motivacionais/comportamentais em função desta variável.

- A multifuncionalidade é resultado de investimentos em treinamento e educação além de um refinamento nos critérios de contratação (vide Tabela 20). Hipótese: a multifuncionalidade seria função de refinamento nos critérios de contratação e de investimentos em treinamento e educação. Sugere-se estratificar as empresas usuárias de JIT em dois grupos. O primeiro com empresas em que a multifuncionalidade está predominante e o segundo onde ainda não existe o conceito efetivamente aplicado e verificar como se deu a evolução dos critérios de contratação ao longo do tempo.

- O uso de uma metodologia aplicada de implementação de técnicas JIT (Semana Kaizen) com apoio de consultoria especializada é fator catalisador do processo de implementação (vide Tabela 20). Hipótese: o uso da metodologia 'Semana Kaizen" catalisaria 
o processo de implementação. Sugere-se estratificar um grupo de empresas usuárias da metodologia "Semana Kaizen" e comparar com um grupo não usuário da metodologia quanto ao tempo efetivo para a implementação de técnicas JIT.

- As pressões externas (concorrência e clientes) forçam as empresas a buscarem certificações de qualidade e uso de técnicas JIT (vide Tabela 20). Hipótese: o uso de técnicas JIT e certificação de qualidade seriam decorrentes de pressões da concorrência e de clientes. Sugere-se analisar os fatores de motivação para a certificação de sistemas da qualidade e uso de técnicas JIT.

- A adesão dos funcionários ao projeto de implementação de técnicas JIT é tanto maior quanto mais alta na hierarquia da empresa for a geração da idéia do projeto e depende também do perfil gerencial do gerador da idéia. Hipótese: a posição do Champion na hierarquia afetaria o nível de adesão dos funcionários ao projeto. Sugere-se estratificar dois grupos de empresas: o primeiro composto por empresas em que a idéia de implementação de técnicas JIT ocorreu a partir da Alta Administração e o segundo composto por empresas onde a idéia da implementação de técnicas JIT tenha surgido a partir da média gerência. Analisar, por meio de entrevista estruturada, o nível de adesão dos funcionários.

- A posição da empresa na cadeia produtiva influencia a implementação de técnicas JIT na medida em que favorece ou não o poder de barganha da empresa com seus fornecedores e clientes. Hipótese: empresas com maior poder de demanda por insumos teriam maior facilidade de implementar técnicas ligadas aos fornecedores. Sugere-se estratificar as empresas em função de sua posição na cadeia produtiva. O primeiro grupo de empresas formado por fornecedores de empresas fabricantes de autopeças. O segundo grupo formado por empresas fabricantes de autopeças e o terceiro grupo formado por montadoras de automóveis. Elencar algumas técnicas JIT como variáveis de controle e comparar o uso efetivo destas técnicas em cada grupo.

- Quanto maior a predominância de operações de montagem no processo produtivo da empresa, maior a adequação do uso de técnicas JIT. Hipótese: existiriam técnicas JIT mais adequadas a processos produtivos específicos. Sugere-se estratificar um grupo de empresas onde predominam operações de montagem (empresas pouco verticalizadas) e outro grupo com empresas com processo produtivo mais verticalizado, ou seja, fabricantes de vários de seus sub conjuntos, e verificar a predominância do uso de técnicas JIT em cada grupo. 
- Como as empresas pesquisadas iniciaram seus processos de implementação das técnicas JIT em datas diferentes (A (2000) = 3 anos; B (1997) = 6 anos; C (1997) = 6 anos; D $(1998)=5$ anos e $E(1990)=13$ anos), uma questão natural seria imaginar que quanto mais tempo de experiência a empresa tiver, maiores seriam os resultados obtidos a partir da implementação das técnicas JIT. A literatura pesquisada não faz alusão ao timing de obtenção de resultados a partir da implementação de técnicas JIT, limitando-se a apresentar os resultados numa forma estática, apenas quantificando, quando muito, os resultados obtidos. A Tabela 27 mostra alguns dos resultados obtidos pelas empresas a partir da implementação de técnicas JIT. Como se poder notar, a Empresa A, a despeito de ser a "mais nova" em termos de formalização da implementação de técnicas JIT, já apresentava mais resultados que as empresas B, C e D. Hipótese: Maiores períodos de aplicação das técnicas JIT estariam relacionados a melhores resultados. Sugere-se estratificar empresas quanto ao tempo de uso de técnicas JIT, analisar os resultados obtidos e correlaciona-los com o tempo de uso.

Sugestão de estudos posteriores quanto à metodologia:

- A partir da sugestão dos professores durante a qualificação, percebeu-se a possibilidade de se estudar a implementação de técnicas JIT a partir do acompanhamento das etapas de implementação ao longo do tempo, destacando os principais eventos envolvidos, procurando verificar a existência de um padrão de ações comuns no processo. Hipótese: existiria um "processo geral" de implementação de técnicas JIT. Sugere-se levantar bibliografias sobre implementação e identificar as principais etapas do processo e depois verificar, mediante estudos de caso, a ocorrência dos padrões.

\section{4 - Implicações para a prática}

Mais uma vez ressalta-se que a implementação de técnicas JIT é de caráter contingencial, fazendo com que a proposta de cuidados para a implementação de técnicas JIT mostrada a seguir sirva mais como um alerta aos praticantes do que como uma "receita" para a implementação.

A revisão da literatura sobre implementação de técnicas JIT realizada para o desenvolvimento desta pesquisa propõe que a empresa considere um grupo de cinco abrangentes fatores críticos, cada qual composto de uma variedade de aspectos relacionados a estes grupos, e esta pesquisa mostrou que além dos fatores elencados, outras considerações também são importantes. 
Inicialmente tratando de aspectos gerais não vinculados aos cinco fatores críticos, a empresa deveria considerar se a implementação de técnicas JIT em seu processo produtivo lhe traria melhoria de competitividade imediatamente ou no futuro, considerando a sua posição na cadeia produtiva de seus principais clientes. A razão primeira desta consideração seria buscar analisar o quanto seus clientes valorizam e cobram de seus fornecedores entregas JIT e quanto investimento seria necessário para se atingir esta meta caso ela fosse julgada importante. Esta análise surgiu a partir da constatação de que existem situações em que não há uma exigência explícita dos clientes predominantes por receber entregas JIT, como foi constatado na Empresa C.

Outra consideração importante é relativa ao tipo de processo produtivo dominante na empresa. Muito embora a implementação de técnicas JIT seja considerada de âmbito universal, existem processos produtivos, tais como linha de montagem e produção em lotes, que são notadamente mais adequados ao uso destas técnicas. Isto também foi constatado claramente na análise da Empresa C, que apresenta um processo produtivo com características mais ligadas ao processo contínuo.

Passando agora para cada um dos cinco fatores críticos, verificamos que no que tange ao Fator Comprometimento da Alta Administração, a transparência mostrada pela direção da empresa é de fundamental importância. Os funcionários de todos os escalões devem ser informados detalhadamente da real situação que leva à necessidade da empresa de empreender modificações profundas em seus processos. Esta transparência conduz ao envolvimento, que ficará bem mais evidente na medida em que os líderes participem ativamente das iniciativas de monitoramento do programa ao longo de sua execução. A figura do JIT Champion é um forte elo de ligação entre a Alta Administração e as ações que ocorrem no dia-a-dia. A criação de um programa de sugestões estreita o canal de comunicação formal entre a área operacional e a direção da empresa, criando a base para sustentar o aumento de autoridade que se faz necessário no ambiente JIT, para dar suporte a maior responsabilidade que todos têm de assumir. Consequientemente, torna-se necessária uma contínua preocupação em acompanhar o desenvolvimento da carreira dos funcionários, cuidando do crescimento de cada um ainda que estejam atuando numa empresa em que os níveis hierárquicos tenham sido reduzidos.

Quanto ao Fator Educação e Treinamento, foi o que mais destaque apresentou em todas as empresas pesquisadas. Prevaleceu o uso da metodologia da "Semana Kaizen" como forma de promover o treinamento técnico, mas houve também ações de melhorias nas 
condições de educação básica dos funcionários, a partir de convênios da empresa com instituições externas e treinamentos técnicos dos mais diversos em áreas diferentes das áreas ligadas exclusivamente às técnicas JIT. Portanto, deve ficar ressaltado que a abrangência deste fator é grande. O uso da metodologia da "Semana Kaizen" é um catalisador da implementação no aspecto técnico. Recomenda-se também, em paralelo, que os critérios de contratação sejam elevados às reais necessidades da empresa, sem que isso gere situações de trauma para a empresa, mas que consiga elevar o perfil de habilidades dos funcionários de forma a atingir as condições de multifuncionalidade mais rapidamente.

O Fator Fornecedores ainda está por se desenvolver, mas uma alternativa interessante foi encontrada pela Empresa E, que criou um "keiretsu" a partir do programa de te rceirização que começou no final da década de 80 . O pleno conhecimento da cadeia produtiva da empresa é importante para se vislumbrar, de antemão, onde estarão as dificuldades. Os grandes fornecedores ainda não estão conscientes das necessidades de seus clientes e não têm ações que possam levar a prever que estarão em condições de fornecimento JIT a curto prazo. Não existe poder de barganha e nem mesmo poder de pressão neste sentido. Já os pequenos fornecedores, que poderiam sofrer as mesmas pressões de seus clientes para fornecimento em regime JIT, não são confiáveis, em aspectos técnicos e operacionais, a ponto de que a empresa possa operar em regime JIT sem que corra enormes riscos. Recomenda-se que se recorra a fornecedores certificados, embora isso não tenha sido garantia de eliminação dos problemas de fornecimento.

Já no Fator Produção, o caminho recomendado é instituir um efetivo programa de manutenção preventiva e de estudo e redução de set up, seguido pela implementação de Kanban e células de produção. Estas ações conjugadas com um programa de Qualidade Total proverão a empresa das condições mínimas adequadas à melhoria dos resultados operacionais do processo produtivo. Não há como exercer influência sobre a demanda. Por isso é que o processo produtivo deve ser o mais flexível possível.

O Fator Estrutural é sistêmico. Estar atento às mudanças que ocorrem na economia como um todo ajuda na adaptação da empresa. A dificuldade está em perceber estas mudanças ao longo do tempo. Este é um desafio importante e específico da Alta Administração. Já o Fator Organizacional apresentou menos problemas, pois a adaptação requer, na maioria das vezes, apenas ações internas.

Passados mais 30 anos do movimento JIT no Japão e pelo menos 20 anos do mesmo movimento nos EUA e Europa, acreditamos que as empresas pesquisadas ainda estão na fase 
inicial do processo. Exceção feita à Empresa E, que se apresentou mais desenvolvida, as demais ainda têm um árduo caminho a percorrer. Estamos certos de que a competitividade da indústria nacional teria muito a ganhar se houvesse uma mobilização geral de toda a indústria no sentido de trabalhar efetivamente sob regime JIT de produção. Os benefícios disto seriam sentidos em todos os aspectos da economia do país.

\section{5 - Considerações finais}

Como bem destacado em Womack (1992), na frase do professor José Roberto Ferro, "á difusão da produção enxuta no Brasil é possível, necessária e fundamental para superar o atraso e a estagnação". Continuamos a acreditar nisso, dez anos depois, muito embora não se tenha constatado avanço expressivo neste sentido, pelo que foi observado nas empresas pesquisadas.

Acreditamos também que três grandes grupos de interesse têm papel importante na difusão da implementação das técnicas JIT no Brasil: as associações de classe empresariais, as instituições acadêmicas e as instituições governamentais, cabendo a cada uma a sua parcela de responsabilidades e seu espectro de ação. As associações de classe empresariais poderiam organizar um pool de empresas interessadas na implementação das técnicas JIT e promover ações em conjunto integrando a cadeia produtiva de sua indústria, reduzindo custos e promovendo um processo de implementação em conjunto, minimizando as dificuldades para todos. O meio acadêmico poderia estimular o desenvolvimento de pesquisas que pudessem estratificar as empresas em função do porte (por faturamento, número de funcionários empregados, etc), em função do tipo de processo produtivo predominante, do grau de desenvolvimento tecnológico dos produtos produzidos ou de outras variáveis que sejam consideradas importantes e prestar-se a desenvolver modelos de implementação que melhorassem o desempenho de cada grupo e, finalmente, as instituições governamentais poderiam lançar programas oficiais de apoio à implementação de técnicas JIT, nos moldes do Prêmio Nacional da Qualidade, envolvendo inclusive o financiamento da implementação.

Todas essas instâncias passam a ter expressiva responsabilidade no fomento do desenvolvimento das estratégias de gestão das empresas industriais brasileiras, dada a amplitude da importância que o tema assume quando se enfoca o aspecto da competitividade num mundo irreversivelmente globalizado. 


\section{Anexos}

\section{Anexo A - Estruturação da pesquisa bibliográfica}

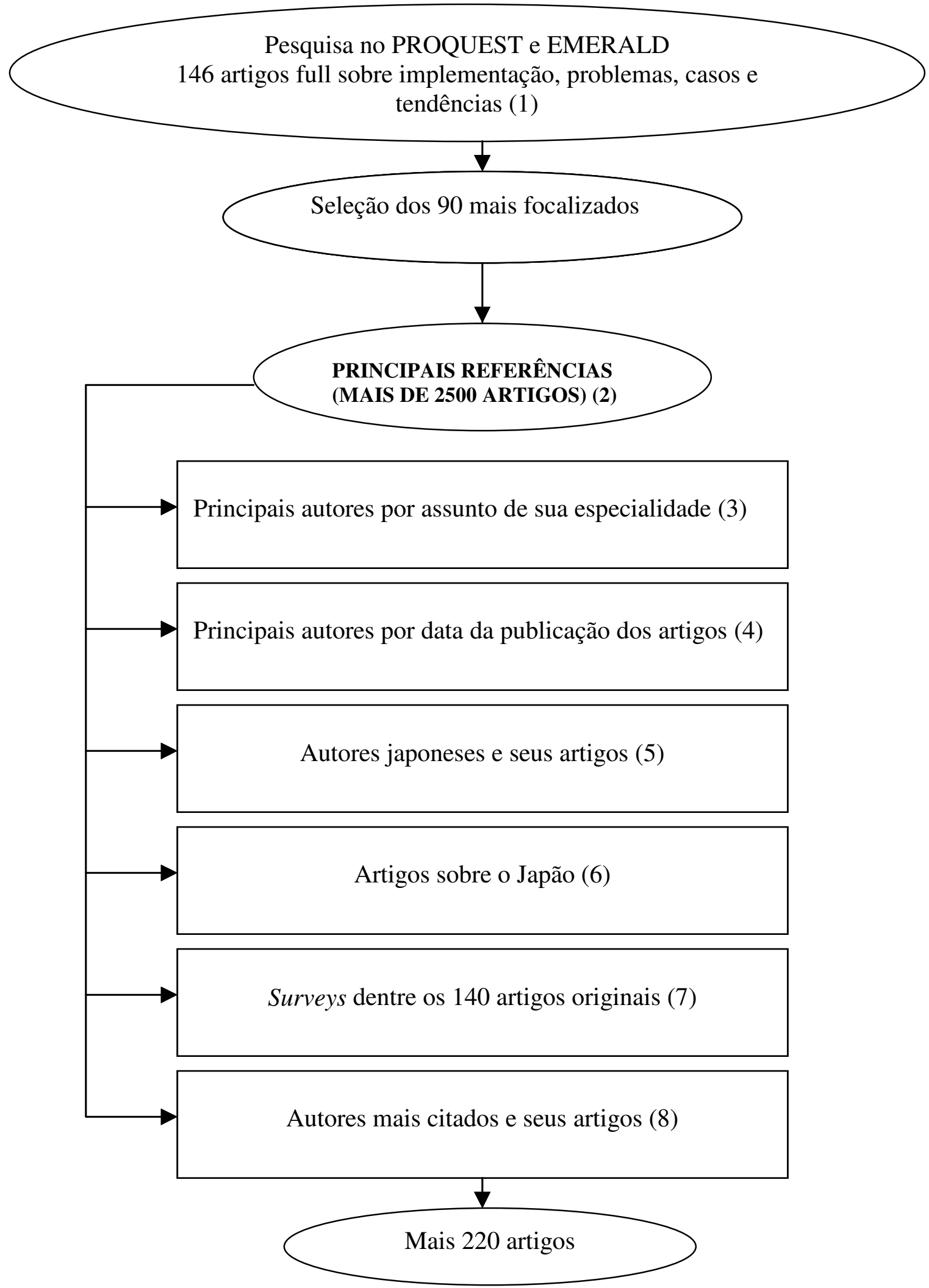




\section{Anexo B - Questionário usado na primeira fase da pesquisa de campo}

\section{BLOCO 1: INFORMAÇÕES GERAIS DA EMPRESA}

1.1 Razão Social

1.2 Principais Produtos

1.3 Origem do Capital

( ) Nacional

( ) Estrangeiro

País(es) de Origem

( ) Sociedade Anônima

1.4 Natureza Jurídica: $\quad$ （ ） Sociedade Limitada $\quad$ ( ) Sociedade Anônima
Outra

1.5 Número de Empregados:

( ) menos de 30

( ) 100 a 249

( ) mais de 1000

(pessoas ocupadas)

( ) 30 a 49

( ) 250 a 499

( ) 50 a 99

( ) 500 a 1000

1.6 Vendas Anuais, em , R \$:

( ) menos de 1.000 .000

( ) de 10.000 .001 a 50.000 .000

(ano de 1999)

( ) de 1.000 .000 a 5.000 .000

( ) de 50.000 .001 a 100.000 .000

( ) de 5.000 .001 a 10.000 .000

( ) 100.000 .001 a 500.000 .000

( ) mais de 500.000 .000

Responsável pelas Informações: Nome

Cargo

Tel. E-mail

\section{BLOCO 2: ESTRATÉGIAS DE GESTÃO DA PRODUÇÃO}

Responda de acordo com a seguinte escala:

$$
\begin{array}{ll}
1 \text { - Sim } & 3 \text { - Sem informação } \\
2 \text { - Não } & 4 \text { - Não se aplica }
\end{array}
$$

A partir de 1997 ocorreu a adoção de novos métodos de trabalho ou produção:

( ) Gestão da Qualidade Total.

( ) Controle Estatístico de Processo.

( ) Grupos de Melhoria (kaizen).

( ) Células de Produção.

( ) Engenharia simultânea.

( ) Redução de set up.

( ) Círculos de Controle da Qualidade.

( ) Kanban.
( ) Redução de Lotes de Fabricação.

( ) Técnicas de Solução de Problemas.

( ) Plano de Manutenção preventiva.

( ) Plano de Produção Nivelado.

( ) Housekeeping (5S).

( ) Fornecedor Único.

( ) Controle Visual (Andon).

( ) Outros. 


\section{Anexo C - Roteiro usado na segunda fase da pesquisa de campo}

Perfil dos entrevistados:

Foram entrevistados até 6 membros de cada empresa: um Diretor, um Gerente de Produção, de Engenharia/Qualidade, de Recursos Humanos e de Suprimentos e de Vendas. Pretende-se, com os depoimentos deste grupo, verificar os FCI tanto sob a ótica estratégica quanto operacional.

Equipe de entrevista:

Rogério Augusto Profeta (pesquisador) e um aluno de graduação em Administração de Empresas - Iniciação Científica da Uniso (pesquisador auxiliar).

Introdução:

a) Breve apresentação da pesquisa e dos objetivos pretendidos (tese de doutorado em Administração visando estudar os Fatores Críticos de Sucesso para a Implementação de técnicas JIT tomando por base empresas industriais de Sorocaba).

b) Mostrar aos entrevistados como e porquê sua empresa foi escolhida para participar da pesquisa e a importância de suas contribuições.

c) Evidenciar o objetivo de se propor um modelo conceitual para implementação de técnicas JIT considerando as características apresentadas pelas empresas pesquisadas.

d) Apresentar a equipe de pesquisa.

Definições conceituais:

Apresentação das definições conceituais de cada um dos termos que representam as técnicas JIT a serem estudadas, com base no Capítulo 2 - 2.3 - Definição conceitual e operacional.

Cuidados tomados na elaboração do roteiro: 
As questões e os entrevistados foram escolhidos de acordo com a pertinência entre ambos, para evitar que o entrevistado responda a questões que não sejam de seu domínio técnico e operacional. 


\section{Informações gerais}

Panorama geral do JIT na empresa (descrição dos principais eventos

ligados ao JIT em sua empresa)

Tempo de empresa

Tempo na função

Iniciativas anteriores, quando?

Motivos para uso do JIT

De quem partiu a idéia de usar JIT

Principais dificuldades e soluções

$\mathrm{O}$ que você mudaria no processo

Maiores acertos

Principais resultados objetivos do

JIT em sua empresa

\section{Fatores Organizacionais}

Em que período ocorreram as implementações

Influência da conjuntura econômica

Pressões da concorrência

Pressões dos clientes

Pressões da matriz

O JIT no Plano Estratégico

Vendas e Marketing

Sistemas de controle de Marketing e Vendas

O perfil do cliente

Como o cliente percebe a empresa após as técnicas

JIT

Mudança na estratégia de vendas

Mudanças significativas de mix de produtos

Alteração real de custo e preço de venda do produto

Influência das técnicas JIT no aspecto mercadológico

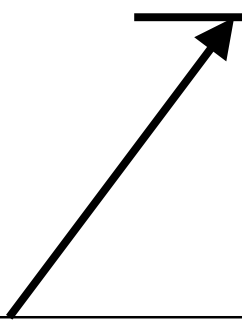

\section{Fator Apoio da Alta} Administração

Principais eventos que mostram o apoio Como o funcionário informa melhorias Como o JIT foi comunicado às pessoas Cooperação entre as pessoas Autoridade do pessoal operacional Classificação de cargos

Paradoxo: Redução de estoque e eficiência

\section{Fator Educação e Treinamento}

Principais eventos relacionados à educação e treinamento

Grupos de trabalho (equipes) e atividades desenvolvidas

Treinamento em técnicas JIT

Participação de consultoria externa

Coordenação geral e equipe

Integração entre as partes da empresa

Uso de área piloto

Multifuncionalidade e exemplos reais

Alterações em critérios de contratação

Melhorias (metas e formalização)

Qualidade (evolução do comportamento do pessoal)

Participação do sindicato

\section{Fator Produção}

Células de Produção

Tempos de set up

Manutenção Preventiva

Balanceamento das linhas

Local de trabalho (limpeza, organização, etc)

Evolução da qualidade

Alterações tecnológicas importantes

Sistemas de controle de produção e

estoques

Alterações na forma de previsão de

demanda

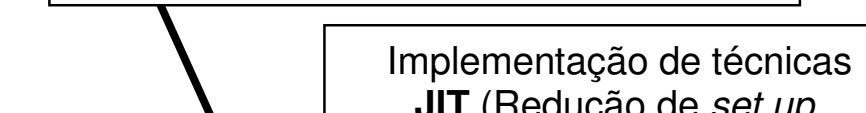

JIT (Redução de set up,

Kanban, Células de Produção,

Redução de Lote de

Fabricação, Melhoria Contínua,

Manutenção Preventiva) em

empresas industriais

\section{Fator Fornecedores}

Principais eventos relacionados aos fornecedores Importância desta empresa para fornecedores de componentes tecnológicos

Como são escolhidos

Houve redução de lead time e lotes

Participação de fornecedores certificados

Redução de base de fornecedores

Evolução das relações com os fornecedores (contatos,

parcerias, contratos, treinamento, etc)

Evolução da confiabilidade dos fornecedores

Inspeção de recebimento

Fornecedores operando entregas JIT para esta

empresa

Os sistemas de controle de suprimentos foram afetados 


\section{Anexo D - Modelo de Pesquisa}

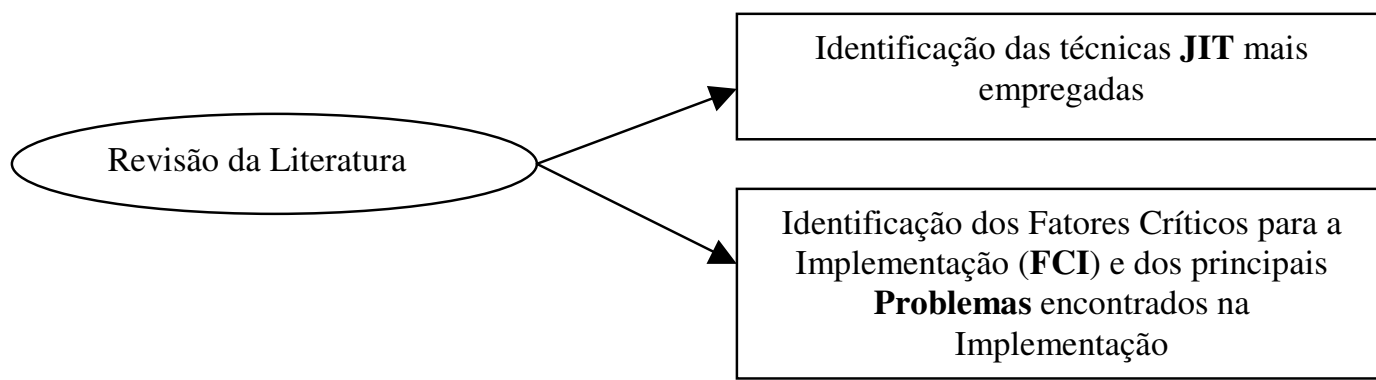

Comparação entre os FCI e Problemas encontrados na revisão de literatura e os resultados da pesquisa empírica

Contribuições: hipóteses desenvolvidas ao longo do estudo, sugestões para estudos posteriores e implicações para a prática 


\section{Anexo E - Descrição do caso da Empresa A}

A Empresa A é uma subsidiária de uma Holding Norte-americana, do setor de autopeças. As principais linhas de produtos são eixos diferenciais traseiros com caixas diferenciais, seções centrais de eixos traseiros, carcaças e caixas diferenciais de eixos traseiros e conjuntos de engrenagens hipoidais e cônicas.

Sua atuação em nível mundial já ocorre há 97 anos. No Brasil atua há 50 anos. As instalações industriais em Sorocaba - SP encontram-se numa área total de 185.000 metros quadrados, sendo de 17.000 metros quadrados a área construída. Atualmente a empresa conta com cerca de 200 funcionários diretos e 160 indiretos, que respondem por um faturamento de US\$ 50 milhões (base 2001). A capacidade instalada da fábrica é da ordem de 100.000 eixos anuais. A fatia de mercado da empresa no Brasil chega a $70 \%$.

As duas entrevistas foram realizadas nos dias 5 e 6 de fevereiro de 2002, nas dependências da empresa, na cidade de Sorocaba - SP e totalizaram cerca de quatro horas. Foram entrevistados o Chefe de Melhorias Contínuas e Engenharia de Manufatura, que já trabalha na empresa há mais de 15 anos (entre trabalhos como funcionário efetivo e como consultor) e o Facilitador de RH, que embora tenha menos tempo de empresa (cerca de 5 anos), vem participando ativamente do processo de implementação de técnicas JIT desde o lançamento do programa em junho de 2000. A empresa nomeou o Chefe de Melhorias Contínuas e Engenharia de Manufatura como gestor do processo de implementação de técnicas JIT, o que tornou a obtenção das informações mais fácil e objetiva. A partir deste ponto ele será referenciado apenas como Chefe de Melhorias Contínuas.

Os principais eventos ligados às técnicas JIT na Empresa A são recentes (junho de 2000), muito embora tenha havido iniciativas anteriores que datam de meados da década de 80, ainda que abandonadas ao longo do tempo. Justificou-se este abandono pela clara falta de coordenação da aplicação das várias técnicas, conforme relatou o Chefe de Melhorias Contínuas, que trabalhou na empresa na época. Segundo suas informações, havia uma série de técnicas lançadas de forma independente e sem coordenação efetiva. Até mesmo a bibliografia técnica utilizada na ocasião era carente da visão sistêmica do processo de implementação. Com estas falhas, ao longo do tempo o processo esmoreceu e caiu em desuso na empresa.

O “tiro de partida" para o uso de técnicas JIT na Empresa A foi efetivamente dado na última semana de junho de 2000, com o lançamento da 'Semana Kaizen" em duas das mais 
importantes linhas de produção da empresa (as linhas de Carcaças e a de Semi eixos). Nas palavras do Chefe de Melhorias Contínuas, "a princípio estaríamos trabalhando uma única linha, mas o Gerente Geral me empurrou para fazer nas duas". A chamada 'Semana Kaizen"é constituída de uma grande reunião de pessoas, dos mais diversos níveis técnicos e hierárquicos, com o objetivo de analisar um determinado processo e viabilizar a sua radical alteração visando transformá-lo em uma célula de produção.

Esta "Semana Kaizen" acontece de forma ininterrupta, seguindo uma programação bastante específica:

No primeiro dia são desenvolvidos e disseminados os conceitos da metodologia Kaizen (melhorias contínuas) e as diversas medições que se deve tomar do processo (capacidade das máquinas, demanda atual, equipamentos disponíveis, etc.) a todos os membros da equipe kaizen; neste instante é praxe do Chefe de Melhorias Contínuas justificar o por quê das alterações que estão por ser processadas. Há um "franco" esclarecimento sobre as pressões que a empresa sofre tanto de clientes como de concorrentes e acionistas para que se torne mais produtiva. $\mathrm{O}$ esclarecimento chega mesmo a mostrar que as melhorias poderão fazer com que algumas pessoas fiquem "sobrando", uma vez que os resultados tenham sido alcançados. Desta forma, todos os funcionários são claramente informados quanto a em que estarão trabalhando.

O segundo dia é reservado ao planejamento e projeto da melhoria, quando são discutidos os detalhes operacionais das mudanças, tais como as diversas propostas que o novo leiaute pode adquirir e a possível sobra de equipamento ou espaço físico.

O terceiro e quarto dias são dedicados às alterações físicas em si. No caso do kaizen que marcou o lançamento do programa, estas alterações perduraram por cerca de três dias e três noites consecutivas, resultando, ao final do período, na alteração de leiaute de cerca de 50 máquinas (somente duas não foram instaladas totalmente), ainda que algumas delas chegassem a pesar várias toneladas e fossem alimentadas além da energia elétrica, também por circuitos pneumáticos e hidráulicos.

O quinto dia é reservado aos ajustes finais do processo para que esteja totalmente operacional já para a semana seguinte.

Na Empresa A, todas as iniciativas JIT levam o nome de kaizen, ou seja, existem vários tipos de kaizen: há o kaizen técnico (que se presta a explicar os conceitos de melhoria contínua), há o kaizen voltado ao leiaute, o kaizen de manutenção entre outros. 
No que tange às técnicas JIT objeto de estudo desta pesquisa, a empresa tem trabalhado efetivamente com redução de set up, células de produção, redução de lotes de fabricação e manutenção (destacando que ainda limita-se a um programa de manutenção corretiva). O Kanban está em fase de projeto ainda, pois depende de liberação de um espaço físico nas linhas de montagem, o que deveria ocorrer ainda no mês de fevereiro. A peculiaridade é que o Kanban da Empresa A não deverá usar os típicos cartões, mas estará condicionado a marcas no solo das linhas de montagem, que servirão de orientação aos setores de abastecimento.

O movimento JIT na Empresa A tem fontes bem definidas no âmbito externo (as pressões de clientes - em sua maioria grandes montadoras - e da concorrência) que se tornaram mais evidentes nos últimos anos e outra fonte no âmbito interno, expressa pela obstinação da Gerência Geral, que lidera pessoalmente o processo e concede pleno apoio às equipes de kaizen, segundo relata o Chefe de Melhorias Contínuas.

Não há dúvida de que a idéia de transformar a empresa tem origem certa. Ambos os entrevistados são taxativos em afirmar que a liderança do Gerente Geral, um profundo conhecedor de processos de manufatura, é inequívoca.

A implementação das técnicas JIT na Empresa A está tendo que superar as dificuldades mais comuns possíveis, tais como: estrutura organizacional muito inchada, tempo de set up elevado, excessivo manuseio de materiais, receio produzir sem estoque, insegurança do pessoal de PCP, muitas esperas, elevado nível de não conformidades, fábrica sem espaços livres, dificuldade de visualizar desperdícios, confusões e certos conflitos com clientes.

A resistência das pessoas, um forte empecilho constatado em diversas literaturas sobre este tema, fica mais evidente na medida em que estes não são envolvidos, conforme comenta o Chefe de Melhorias Contínuas. Aliás, este tem sido o aspecto mais importante no sucesso que a empresa vem conseguindo até o momento: as pessoas estão sendo fortemente envolvidas não só no aspecto técnico, mas também no emocional. O relato do Chefe de Melhorias Contínuas deixa claro que o processo gera perplexidade e até mesmo medo no início, pois as pessoas são literalmente informadas da profundidade e da abrangência do trabalho que precisam fazer. Mas os resultados que se obtém são significativos, como se vê a seguir.

No caso da Empresa A, o resultado mais expressivo aparece na forma de liberação de espaço físico e de imobilização de equipamentos. A liberação de espaço físico já chegou à 
casa de 2500 metros quadrados, o que possibilitou que uma nova unidade industrial fosse instalada na planta de Sorocaba, em detrimento da unidade de Curitiba. A direção americana da empresa resolveu transferir a unidade de Eixos pesados da Argentina para o Brasil e o local de instalação poderia ser tanto Curitiba como Sorocaba. Se optassem por Curitiba, o investimento na construção de um galpão industrial consumiria US\$ 2 milhões, mas em Sorocaba esta área estaria livre com poucos investimentos, e ainda possibilitaria que a nova unidade utilizasse toda a infra-estrutura de apoio já implantada (serviço de alimentação, limpeza, segurança e medicina do trabalho, transporte e armazenagem, além de mão-de-obra especializada já preparada para operar as modernas máquinas em questão).

Este fato tem sido o grande mote dos novos kaizen que a empresa vem promovendo, ressaltado ainda pelo fato de que nenhum funcionário foi desligado por motivo das melhorias de qualquer kaizen anterior, muito embora tenham ocorrido realocações de funções para outras áreas da empresa.

O Chefe de Melhorias Contínuas é enfático ao afirmar que os resultados são obtidos na base de $50 \%$, ou seja, utiliza-se $50 \%$ menos espaço, $50 \%$ menos equipamentos, $50 \%$ menos estoques, $50 \%$ de aumento na velocidade do fluxo da produção, etc. Força de expressão ou não, os espaços estão disponíveis para a instalação de outra fábrica de forma inquestionável.

Passando agora para uma análise detalhada dos grupos de fatores críticos para a implementação apontados pela bibliografia, podemos concluir:

Quanto ao apoio da Alta Administração, na Empresa A, tem sido irrestrito. A presença do Gerente Geral é citada enfaticamente pelos dois entrevistados. Na verdade a Empresa A já aplica técnicas JIT em outras unidades subsidiárias no Brasil. Dentre os principais aspectos que denotam o apoio da Alta Administração conforme literatura técnica sobre implementação de técnicas JIT, constata-se que a Empresa A está atenta a todos eles. Conforme relata o Chefe de Melhorias Contínuas, "para fazer kaizen tem de ter muita costa quente", ou seja, tem de haver franco apoio da Alta Administração, aqui representada pelo Eng. ${ }^{\circ}$ Gerente Geral, mesmo em situações em que a empresa tenha perda de rendimento (ou mesmo aumento claro de custos), como é o caso da fase inicial da implementação.

Está em operação na empresa uma sistemática de busca pelas idéias dos funcionários, o programa Pró-idéias, um programa formal, disseminado pela rede interna de computadores em que o funcionário registra tudo que lhe ocorra que possa vir a produzir melhorias na empresa, seja em atividades de sua responsabilidade ou não. Este programa é complementado 
ou apoiado pelos grupos de trabalho intitulados MEK's, que são grupos semi-autônomos de trabalho, nos moldes dos conhecidos Círculos de Controle de Qualidade (CCQ) muito difundidos no Brasil na década de 80. Estes grupos de trabalho receberam o nome de MEK para que ficassem vinculados ao kaizen (equipes de melhoria kaizen). Outra iniciativa que se coloca em prol da busca e disseminação das idéias dos funcionários são os grupos de "work out", que também são semi-autônomos e se prestam a desenvolver projetos de maior amplitude, tendo como principal característica o fato de poderem isolar-se das atividades normais da empresa enquanto estão trabalhando num projeto.

A autoridade formal para o funcionário parar uma linha de produção é clara nas ocasiões em que está trabalhando em algum kaizen específico, situação em que pode até mesmo envolver uma área onde já tenha sido realizado algum kaizen anterior. Nestas situações o processo produtivo envolvido passa por uma severa crítica pelos funcionários do setor que envolve, inclusive a necessidade de mudança dos equipamentos de lugar, o que implicitamente significa parada de máquinas.

Para que a disseminação da metodologia kaizen seja efetiva, conforme relata o Chefe de Melhorias Contínuas 'há um treinamento montado, no qual eu sou instrutor, e pretendo formar multiplicadores. Há uma agenda, um check list, tudo pronto, basta arrumar a sala de aulas". 'Repassar a teoria é fácil (existem mais dificuldades na hora de responder perguntas dos operários), mas as pessoas precisam treinar em muitos kaizen para poder liderar". Percebe-se claramente a posição do gestor e sua busca pela disseminação da metodologia. Na medida em que notaram problemas de envolvimento dos funcionários, passaram a realizar os kaizen comportamentais. Isto ocorreu um mês após o projeto piloto (julho de 2000) e foi visto como decisivo na implementação. Este treinamento é relativamente rápido e envolve diretamente todas as pessoas das áreas nas quais vai acontecer alguma mudança mais significativa.

O aspecto da cooperação entre os funcionários é um ponto alto da Empresa A na visão do Chefe de Melhorias Contínuas. E tem se tornado muito mais evidente ao longo do tempo. Após os kaizen comportamentais, a cooperação melhorou muito, conforme afirma o Facilitador de RH: "As pessoas conviviam, mas não tinham um relacionamento mais estreito". Depois, realizar os kaizen técnicos, em que a área de trabalho deles foi alterada, ficou mais fácil. O kaizen comportamental foi montado por meio de parcerias com SENAI (Serviço Nacional de Aprendizagem Industrial) e FATEC (Faculdade de Tecnologia) e 95\% da fábrica foi treinada, incluindo a Alta Administração (exceto alguns em viagens e férias). 
Foram desenvolvidas várias atividades em que as pessoas dependiam umas das outras para obter resultados. Dependiam do grupo, tinham que desenvolver confiança no grupo. Foi a única atividade de treinamento feita em paralelo com o kaizen técnico. A própria configuração do leiaute celular torna evidente quando um funcionário tem baixo rendimento ou mesmo quando há faltas ou atrasos no setor, pois imediatamente é necessário um arranjo entre as pessoas da célula. Deve ser ressaltado que a empresa não faz mais controle de ponto dos funcionários desde junho de 2000.

Quanto ao mito do emprego vitalício, presente em algumas literaturas sobre a aplicação do JIT no Japão, não houve, por parte da Empresa A, nenhum compromisso no que se refere à garantia de qualquer posto de trabalho. Muito pelo contrário, a cada sessão de treinamento para o kaizen, o treinador deixava claro que as mudanças iriam provocar melhorias de produtividade nas áreas envolvidas e que isso poderia gerar a demissão de algumas pessoas. A empresa “joga muito aberto com os funcionários”, segundo o Chefe de Melhorias Contínuas. Houve, sim, situações em que funcionários foram realocados para outras áreas por força do kaizen, mas não houve demissões por motivo do kaizen.

Na medida em que os funcionários evoluem em suas habilidades ocorrem as alterações nos cargos e salários. Existe um plano de carreira associado às habilidades, divulgado de forma clara e objetiva, com quadros de salários expostos na fábrica. Aos funcionários, basta qualificar-se, com apoio da empresa, e acompanhar as tabelas.

Pelo exposto, as principais premissas ligadas ao apoio da Alta Administração estão sendo observadas na Empresa A, o que pode representar um importante diferencial para justificar os resultados que estão sendo obtidos pela empresa.

O fator Educação também se mostra como um ponto de destaque na Empresa A. Existem os MEK’s em pleno funcionamento. Há cerca de sessenta grupos de melhorias. A cada kaizen executado surgem inúmeros MEK's que complementam as melhorias. São orientados a tratar dos trabalhos da maneira mais informal possível ("não desenhem nada! Façam o que tem de ser feito sem burocracia", é a orientação salientada pelo Chefe de Melhorias Contínuas). As reuniões são semanais e realizadas em horários de trabalho. Outra atividade interessante é o "work out”, já citados, que ocorrem esporadicamente. São grupos de pessoas de áreas diferentes, que identificam uma oportunidade de fazer um projeto e montam uma equipe com as pessoas que julgam necessárias. Levam o projeto à diretoria, que após análise e aprovação, liberam a equipe para estudar o projeto em local externo à empresa (num hotel ou sala cedida pelo CIESP Regional Sorocaba - Centro das Indústrias do Estado de São 
Paulo). Ao término dos estudos, retornam e apresentam os resultados do projeto. Um exemplo é um estudo feito em uma linha de produção exclusiva para um certo produto, com demanda sazonal, que teve como resultado a eliminação da linha. O produto passou a ser produzido em outra linha, que foi equipada para tal.

O cuidado com o treinamento é explícito pelos kaizen técnicos, comportamentais, MEK e work out já citados. Mas também a educação tem seu destaque. Houve uma maior ênfase em educação (é subvencionado pela empresa todo estudo dos funcionários em até 80\% do valor). Foi montada uma sala de aula em convênio com a FATEC e SENAI onde são ministradas aulas de mecatrônica e metalurgia. Até 2003 estarão formados mais de 100 técnicos. Há também projeto de um curso de pós-graduação voltado à manufatura para qualificar o pessoal administrativo. Até o final de 2003, o objetivo é ter $80 \%$ do pessoal de fábrica com nível técnico.

A multifuncionalidade é uma realidade em algumas áreas da empresa. Em uma unidade mais desenvolvida, já se pode notar a multifuncionalidade não só dentro do setor, mas entre setores. Já existem funcionários do setor de montagem que são polivalentes com pessoal do setor de usinagem. Entretanto, esta característica ainda não se estende à maioria dos funcionários, muito embora venha crescendo, por contingência das necessidades. A cada setor em que se realiza o kaizen, pode haver sobra de pessoal, que é realocado para outras funções. Este processo coloca a multifuncionalidade como uma alternativa importante para o funcionário não se tornar desnecessário para a empresa.

Como consequiência destas alterações surge a necessidade de melhoria do perfil de escolaridade dos colaboradores. Hoje, os requisitos de contratação estão mais apurados. Até 1998 o requisito era apenas o primeiro grau. A partir de 1999 passou-se a exigir $2^{\text {o }}$ grau (básico) para os trabalhadores da fábrica e curso superior para os administrativos. A partir de 2001, o segundo grau deve ser técnico para os funcionários de fábrica.

Quanto ao apoio de consultoria externa, na fase inicial (junho de 2000), o próprio Chefe de Melhorias Contínuas era o consultor responsável pelos kaizen que foram realizados nas linhas de Carcaças e Semi eixos. Num período posterior, o consultor, que já fora funcionário efetivo anteriormente (entre 1985 e 1989, nesta mesma fábrica de Sorocaba), passou a ser novamente funcionário contratado (em junho de 2001). Durante o período em que o consultor ficou "fora" da empresa, não houve nenhum outro kaizen. A partir do retorno do consultor, agora como funcionário, é que o processo foi retomado. 
Neste aspecto fica evidente o uso da figura do JIT Champion, pois esta função foi claramente assumida pelo Chefe de Melhorias Contínuas, encarregado de coordenar todas as iniciativas voltadas ao uso de técnicas JIT na empresa.

Foi desenvolvido um projeto piloto: as linhas eram a de Carcaça e a de Semi Eixos. As duas linhas foram incluídas ao mesmo tempo já no primeiro kaizen, numa mesma semana. Este kaizen envolvia o deslocamento de cerca de 40 a 50 máquinas, que tinham que ser mudadas radicalmente de lugar. 'O pessoal ficou assustado. Eu também fiquei assustado. Jamais havia passado por aquilo em tamanha dimensão", "olhamos aquilo e um encorajou ao outro", "o objetivo era mudar em um dia. Ficamos três dias e três noites na empresa para mudar as máquinas", relata o Chefe de Melhorias Contínuas. A cada mês foram feitos dois kaizen, um voltado às mudanças no setor e outro voltado aos operadores (focalizados em questões específicas, para resolver problemas operacionais, envolvendo pequenas alterações nos locais de trabalho).

O sindicato dos trabalhadores não teve influência. Há um funcionário que é líder sindical e acompanha os trabalhos de kaizen. O cuidado com o "jogo aberto"é fundamental.

O aspecto da mudança cultural que envolve o JIT está sendo tratado pelo kaizen comportamental, instituído para melhorar o relacionamento das pessoas nas equipes e estimular a confiança mútua. Esclarecer o que é o kaizen e qual é o propósito da empresa ao usá-lo também tem facilitado a implementação na opinião dos entrevistados.

A expectativa é que a disseminação do JIT na Empresa A pela fábrica toda ainda levará mais um ano e meio. Há um evento chamado de "análise crítica da manufatura" ocasião em que se analisam todos os gargalos, índices de sucata e down time de todas as linhas. Analisa-se a capacidade, a demanda, os custos de cada linha e identificam-se os focos de trabalho. Neste ponto descobre-se que tipo de kaizen deve ser feito em cada local (set up, qualidade, sistemas, comportamental, etc.). 'Estamos enxergando uma fábrica para dois, três ou quatro anos à frente", destaca o Facilitador de Recursos Humanos.

É possível se perceber que os principais aspectos relacionados à educação e treinamento estão sendo considerados e devidamente tratados na Empresa A, o que pode ser um reforço às expectativas de uma implementação bem-sucedida.

Já o fator Fornecedor é o menos enfatizado na Empresa A. Ainda não há nenhum desenvolvimento de JIT junto aos fornecedores. A empresa não é cliente significativo de 
nenhum de seus fornecedores. As compras não são feitas de maneira corporativa, o que diminui ainda mais as perspectivas de mudanças neste quadro no curto prazo.

Por seu lado, o fator Produção apresenta muito bem desenvolvido o uso de células de produção, em uso desde a implementação do primeiro kaizen de leiaute nas linhas de Carcaças e Semi eixos em junho de 2000 . Hoje, cerca de $60 \%$ da empresa já trabalha sob o conceito de células e há projetos de expansão para as demais linhas de produção da empresa. Durante visita à fábrica foram visualizadas duas células compartilhando uma máquina única no processo de ambas (um forno), o que evidencia a abrangência que o processo está tomando.

A partir do momento em que o arranjo físico tem sido alterado para células de produção, tem crescido a necessidade de se trabalhar mais efetivamente o set up. Há registros de kaizen específico para tratar de problemas de set up e há um programa anual já montado para kaizen exclusivos para set up. Em junho de 2001, o primeiro kaizen realizado no retorno do Chefe de Melhorias Contínuas como funcionário da empresas foi voltado a set up e, neste ano, todos os kaizen programados são ligados a set up. Há set ups com realização dos próprios operadores e outros realizados por preparadores.

Quanto à manutenção, ainda está restrita ao aspecto da correção mais que da prevenção.

Só ocorreram alterações tecnológicas que estavam programadas por motivos técnicos, mas não devido ao uso de JIT. Exemplo é o caso das cortadoras Gleason a seco, top de linha no mercado atual.

Fica bastante evidente que a ação da empresa nos aspectos ligados à produção está ainda restrita ao uso de conceitos de redução de set up e de células de produção.

Finalizando, a análise do fator Organizacional mostra que a influência da conjuntura econômica é indireta via efeito que produz nas grandes montadoras de automóveis e caminhões, os principais clientes da empresa, que por sua vez, exercem clara pressão.

Há contratos de fornecimento que prevêem redução de custos por conta de melhorias. Além disso há o controle efetivo das peças defeituosas. A meta é 100 PPM (peças por milhão). Índices acima destes já começam a causar deméritos para a empresa, que corre o risco de ser excluída da lista de fornecedores.

Hoje, a Empresa A está privilegiando o contato com o cliente. Há na empresa salas especiais para atendimento personalizado aos principais clientes da empresa. Hoje já é 
possível adquirir toda a linha da Empresa A em contato com um único vendedor, o que era impossível no passado.

A influência da matriz na implementação não é notada já que a iniciativa é totalmente local. Aliás, a Empresa A é vista como "benchmarking" entre as empresas do grupo no uso de células de produção, tendo sido objeto de visitas de clientes (inclusive da Toyota japonesa) e mesmo de membros da matriz.

Ainda persistem dificuldades de contabilizar os resultados da implementação das técnicas JIT, muito embora esteja bem evidente que há um movimento de aumento dos custos na fase inicial, quando é exigido algum investimento, mas após o primeiro período, que gira em média em torno de seis meses, os custos caem significativamente.

Os problemas relacionados à previsão de demanda não foram enfatizados talvez pelo fato de a empresa já estar operando com células de produção nas principais linhas, células estas que estão entregando $100 \%$ dos pedidos dentro dos prazos.

A presença do JIT no plano estratégico é evidente, pois inclui-se no planejamento de todos os escalões da empresa, fluindo de cima para baixo. É peça chave, pois afeta aspectos físicos da empresa, que influenciam seus números mais importantes, o retorno sobre o investimento e o retorno sobre o ativo. O JIT possibilita significativas melhorias nestes valores.

Estão evidentes um forte apoio da Alta Administração, um cuidadoso trabalho voltado à educação e treinamento dos funcionários e uma meticulosa e sistemática implementação de células de produção. Não há sinais de problemas ligados ao fator Organizacional e o fator Fornecedor ainda não foi abordado.

São dignos de destaque como elementos importantes a presença efetiva da Alta Administração no apoio às iniciativas e também a figura do gestor do processo na pessoa Chefe de Melhorias Contínuas, além do forte envolvimento das pessoas por meio do trabalho em equipe em vários níveis. $\mathrm{O}$ amadurecimento do conhecimento sobre técnicas JIT e a "coragem" para fazer a implementação em curtíssimo espaço de tempo são fatores de destaque, ressaltados pelo Chefe de Melhorias Contínuas.

Os resultados que se tem obtido, a despeito da abrangência estritamente interna do JIT, já são expressivos e têm sido utilizados como elementos de motivação para novas empreitadas. 


\section{Anexo F - Descrição do caso da Empresa B}

A Empresa B também é uma subsidiária de uma Holding, esta de origem alemã, que detém sob seu controle duas empresas fabricantes de rolamentos (uma delas adquirida no ano passado) e uma empresa fabricante de embreagens, além de outras atividades de menor expressão no grupo. A Empresa B detém uma tecnologia bem diversificada. É uma empresa High Tech, cuja tecnologia pode ser comparada com empresas de ponta como a alemã Bosch. Os principais produtos são esferas, rolamentos automotivos, agrícolas e especiais além de elementos de motores (tuchos hidráulicos, balancins flutuantes, sistemas tensionadores de correntes, etc).

Em termos mundiais, a Holding já opera há 52 anos. No Brasil as atividades da subsidiária iniciaram-se em 1958 no bairro de Santo Amaro, em São Paulo - SP. A transferência das instalações para Sorocaba - SP deu-se em 1980 e atualmente todas as atividades industriais da empresa estão sediadas em Sorocaba - SP, numa área de 630.000 metros quadrados, sendo 63.700 metros quadrados em área construída.

A Holding emprega cerca de 52 mil funcionários no mundo todo, sendo na fábrica do Brasil empregados cerca de 1700 pessoas (1370 funcionários diretos e 325 funcionários indiretos). Há previsão de contratação de mais 250 funcionários no ano de 2002. O faturamento anual não foi informado. A capacidade instalada da empresa hoje chega a 77 milhões de peças por ano, atendendo a $30 \%$ do mercado nacional de rolamentos.

As cinco entrevistas, realizadas nos dias 20, 22 e 27 de fevereiro de 2002, nas dependências da empresa, na cidade de Sorocaba - SP, totalizaram cerca de 7 horas, sem considerar a visita ao processo produtivo. Dentre os cinco entrevistados, todos têm mais de dez anos de experiência dentro da Empresa $\mathbf{B}$ em atividades ligadas diretamente às funções pelas quais são responsáveis. O Diretor Industrial está na empresa há 16 anos; o Diretor Administrativo Financeiro já trabalhou em vários setores ao longo dos 25 anos de atuação na empresa. Já o Coordenador de Vendas, tem 29 anos de atividades na empresa; o Gerente de Qualidade Assegurada está na empresa há mais de 10 anos e o Chefe de Produção, está na empresa há 27 anos.

As iniciativas relacionadas ao uso das técnicas JIT em estudo nesta pesquisa ocorreram em 1998 e foram facilitadas pelo fato de a empresa ser certificada pela ISO 9001 desde 1994. A idéia da implementação foi notadamente proposta e facilitada pela alta administração da empresa, muito embora o apelo para reduzir lead time, set up, espaços, 
consumo de materiais entre outros, sempre tenha sido "palavra de ordem" na Empresa B, conforme relata o Diretor Industrial. Mas reduzir estoques não era algo usual na empresa até o advento da implementação de técnicas JIT. Com a abertura do mercado nacional à concorrência mundial no início década de 90, durante o governo Collor, a Empresa B teve a exata noção de que não poderia continuar a operar no Brasil caso não obtivesse imediatamente condições objetivas de competitividade, ligadas diretamente ao atendimento do mercado em que atua, condições estas marcadas por flexibilidade do processo produtivo, rapidez e confiabilidade das entregas, lotes reduzidos e entregues diretamente nas linhas de montagem com garantia de qualidade de forma a não necessitar de inspeção pelo cliente. Estes eram os padrões de satisfação expressos pelo cliente e que foram buscados de forma incisiva pela empresa desde 1998.

Houve vultosos investimentos nos processos produtivos da empresa nos últimos 4 anos, chegando a cerca $\mathrm{R} \$ 30$ milhões ao ano, conforme palavras do Diretor Industrial. Entretanto, não há uma clara definição sobre quanto deste investimento foi feito por conta da implementação de técnicas JIT. Não se pode afirmar então, no caso da Empresa B, que os investimentos tenham sido algum empecilho à implementação das técnicas, mas certamente a mudança do paradigma de manutenção de estoques foi um obstáculo, pois a empresa jamais havia trabalhado com tanta ênfase sobre este aspecto.

A Empresa B aplica uma metodologia denominada "semana kaizen" para a implementação de técnicas JIT em sua planta em Sorocaba. A "semana kaizen" é uma metodologia de aplicação de técnicas JIT patenteada e comercializada por uma empresa de consultoria com sede nos Estados Unidos (TBM Consulting Group - especializada em implementação de técnicas JIT), que tem como uma de suas características a aplicação de kaizen em um processo de cinco dias.

Neste caso a semana kaizen é configurada de forma bem simples e objetiva. Equipes kaizen são compostas por um mínimo 12 funcionários, pessoas estas oriundas das mais diversas áreas da empresa. Na segunda-feira o grupo de kaizen entra em contato com o "padrinho" do grupo (normalmente um membro da alta administração), que define as metas da semana, anteriormente acertadas com o chefe (ou chefes) da área envolvida. Há cerca de 2 horas de teoria e depois todos os membros partem para a aplicação propriamente dita. $\mathrm{Na}$ terça-feira ocorre o mapeamento da área que foi o objetivo do kaizen. Na quarta-feira acontece a composição da proposta de trabalho da equipe kaizen. Na quinta-feira ocorre a execução da proposta e na sexta feira há uma apresentação do que foi alcançado. Neste 
período o funcionário não tem hora para sair da empresa, enfatiza o Diretor Industrial. Entre 11 horas e meio-dia da sexta-feira acontece a apresentação dos resultados, depois há um churrasco e os funcionários são dispensados para casa, dado que permanecem em atividades por um grande número horas consecutivas durante a semana.

Com a implementação das células de produção, principal atividade desenvolvida pelos kaizen da Empresa B, deixou-se de construir uma ala de 12 mil metros quadrados graças aos espaços liberados pelas melhorias de leiaute obtidas. $\mathrm{O}$ estoque em processo caiu entre $30 \mathrm{e}$ $50 \%$ e houve melhoria da taxa de utilização de máquinas por conta da aplicação da manutenção preventiva.

A despeito dos bons resultados obtidos pela empresa por ocasião da implementação das técnicas JIT, dois pontos foram indicados como importantes caso a implementação pudesse ser "refeita" considerando-se a experiência adquirida neste processo: primeiramente deveria haver a indicação clara de um "gestor" ou "gerente de melhoria contínua" do processo de implementação com total autonomia e responsabilidade. Nas palavras do Diretor Industrial, tal medida evitaria que o processo ficasse "solto" entre as diversas áreas da empresa. O outro ponto, levantado pelo Gerente de Qualidade Assegurada, está relacionado à preparação de variáveis consideradas importantes com antecipação antes de se lançar à implementação propriamente dita. Esta preparação deveria envolver "condições de infra-e strutura" tais como manutenção dos equipamentos, considerada deficiente à época da implementação dos primeiros kaizen de redução de espaço e lotes de matéria-prima, excessivamente elevados.

O controle dos resultados obtidos com a aplicação das técnicas JIT na Empresa B é efetivo. Há um grande quadro, atualizado, detalhando o ocorrido nas "semanas kaizen" desde 1998 até janeiro de 2002, descrevendo minuciosamente os resultados, dentre os quais podem ser destacados: postos de trabalho, espaço físico das áreas produtivas, set up, produtividade, entre outros, sempre mostrando comparativamente o "antes e depois" do kaizen. O quadro destaca cerca de uma centena de kaizen. Este controle estende sua abrangência inclusive aos resultados financeiros de cada kaizen.

Segue uma análise detalhada dos grupos de fatores críticos para a implementação apontados pela bibliografia:

Quanto ao apoio da Alta Administração, na Empresa B tem sido irrestrito mesmo em situações em que a adaptação do processo não ocorre de imediato, levando a reduções de 
produtividade nos instantes iniciais da implementação de um determinado kaizen, segundo declarado pelo Diretor Industrial e confirmado pelo Gerente de Qualidade Assegurada.

A presença do presidente da Empresa B para a América do Sul na fábrica de Sorocaba é um fator importante de apoio às ações de implementação de técnicas JIT.

A Empresa B tem um sistema formalizado e desburocratizado para tratar das sugestões dos funcionários. Basta que o funcionário ou grupo de funcionários formalize suas idéias num impresso próprio e o entregue ao superior imediato. Caso haja viabilidade, o próprio superior avaliza o projeto e autoriza implementação imediata, o que pode resultar em prêmios na forma de "vale supermercado". A Empresa B optou por instituir um sistema simples e objetivo de coleta de sugestões dos funcionários. Está embasado de forma a fomentar a quantidade das idéias antes de focalizar a abrangência das mesmas. Conforme destaca o Diretor Industrial "ho que diz respeito às idéias, queremos antes de tudo, volume".

Está evidente que ao operador é concedida a autoridade para interromper a operação ou mesmo mudar uma máquina de posição quando isto se fizer necessário, muito embora exista sempre a presença de um coordenador para cada equipe kaizen.

A formação destas equipes claramente fortaleceu as relações pessoais entre os funcionários conforme destaca o Gerente de Qualidade Assegurada: "Aumentou, naturalmente, a tensão com a redução dos estoques, mas estamos conseguindo revertê-la mostrando que é melhor ter menos estoque para alcançar maior percentual de PLR (Participação em Lucros e Resultados) ao final do ano. Há claramente um nível maior de cooperação entre os funcionários". Esta afi rmação é confirmada pelo Diretor Industrial que relata 'h oje o pessoal que trabalha em células se sente dono do negócio, pois quem montou as células foram eles. Participaram do kaizen. A cooperação entre os funcionários também pode ser constatada pelos dados que mostram as áreas que já passaram por algum tipo de kaizen e o número de funcionários participantes. Existem áreas em que mais de 90\% dos funcionários já participaram de kaizen. No começo da implementação acontecia a participação "pró forma", mas "depois de conhecidos alguns resultados, os índices de participação aumentaram muito", acrescenta o Chefe de Produção.

A despeito das equipes de kaizen estarem funcionando efetivamente, o processo de comunicação aos funcionários, tido como essencial pela literatura especializada, é simples: baseia-se na estrutura da já citada "semana kaizen". Entretanto, apesar da simplicidade, é efetivo, pois envolveu, até hoje, a maioria das pessoas ligadas diretamente ao processo 
produtivo, ao ponto em que algumas tenham se envolvido em mais de dez kaizen diferentes, conforme destacou o Chefe de Produção. Cabe ainda destacar que muita coisa tem sido feita na empresa mais "por puro ímpeto do que por outro motivo" nas palavras do Diretor Industrial. Há 69 eventos de semana kaizen programados para 2002 (61 internos e 8 em fornecedores). Desde 1998 foram realizados 184 eventos kaizen, totalizando cerca de 1680 pessoas treinadas na metodologia (algumas fizeram até dez kaizen).

Os tipos de kaizen realizados foram:

\begin{tabular}{l|c}
\hline \multicolumn{1}{c|}{ Tipo de kaizen } & quantidade \\
\hline Housekeeping $\mathbf{5 S})$ & 39 \\
\hline Processo & 34 \\
\hline Set up & 31 \\
\hline Qualidade & 21 \\
\hline Kanban & 17 \\
\hline Montagem & 13 \\
\hline Administrativo & 9 \\
\hline Ergonomia e 5S & 9 \\
\hline Ergonomia & 5 \\
\hline Preparação do processo de produção & 3 \\
\hline Manutenção & 3 \\
\hline
\end{tabular}

Segundo a filosofia da Empresa B, o funcionário deve participar do maior número de kaizen possível para garantir a mudança de comportamento. Até maio de 2002, 934 funcionários participaram de ao menos um evento kaizen.

A estrutura de treinamento é simples e também é baseada na metodologia da "semana kaizen". Destacam-se as facilidades de realização de intercâmbio internacional entre a Empresa B do Brasil e as outras unidades da empresa, principalmente na Europa. Conforme declarou o Diretor Industrial: “A Empresa B é uma empresa muito interessante, pois oferece muita oportunidade de treinamento no exterior. E quem tiver vocação para estudar a língua alemã, vai ter muito mais chance".

Apesar de todo o aparato de treinamento e educação dos funcionários, ainda não houve criação de novos cargos por conta da elevação da capacidade e da habilidade dos funcionários, muito embora exista uma clara e objetiva informação sobre os salários de cada faixa de operadores divulgada publicamente aos interessados.

O fator Educação e Treinamento é, sem sombra de dúvida, ponto de relevante destaque na Empresa B.

A Empresa B tem um centro próprio de treinamento (uma ala da empresa só para treinamento). Há parceria com o SENAI que engloba cursos com duração de três a quatro 
anos. Há laboratórios de pneumática, de micro informática e de idiomas. No que tange a treinamento externo, os funcionários podem fazer MBA/especialização/idiomas por conta da empresa (o funcionário paga metade e a empresa paga a outra metade e no semestre seguinte, são reembolsados integralmente pelo que pagaram).

A Empresa B lidera o pool de empresas que criou em 2001 o curso de Engenharia Mecânica em parceria com uma faculdade de Sorocaba.

Os grupos de trabalho são representados pelas equipes kaizen (cada setor deve apresentar no mínimo 12 funcionários para os grupos kaizen). Estes grupos têm pessoas das mais diversas áreas da empresa.

A educação e o treinamento são focalizados nas necessidades dos grupos. Não houve e não há um treinamento específico para técnicas JIT, mas sim uma série de treinamentos que ajudam no que se relaciona a estas. Os funcionários precisam ser treinados para operar máquinas, inspecionar produtos e planejar a fábrica em geral. O plano de treinamento é anterior a 1994 e é responsabilidade dos chefes de setor definir em que atividade cada funcionário deve ser treinado de forma a atingir os resultados.

São definidos os treinamentos básicos (mostrados em uma tabela em azul) e outros níveis. A carga de treinamento tem aumentado continuamente desde 1994. Hoje o foco é o treinamento para ISO 14000. Na Empresa B o treinamento sempre foi muito enfatizado.

A partir de 1997 constata-se grande aumento no número de operadores multifuncionais, chamados de polivalentes. Há quadros na fábrica mostrando quais tarefas um determinado funcionário executa, para quais está apto e para quais está em treinamento .

Hoje a escolaridade mínima na produção é o ensino médio. Há vários alunos cursando tecnologia em nível superior. Desta forma, a exigência para a contratação tornou-se muito mais rigorosa, situando-se muito acima da média do estado de São Paulo. De cada dez candidatos, apenas dois são selecionados, existindo várias vagas abertas que não são preenchidas por inadequação do perfil.

No início dos kaizen houve a participação de consultoria externa, cujo 'papel mais importante é convencer a média e alta gerência que acham que sabem tudo", segundo o Diretor Industrial. A consultoria não depende de hierarquia. Quando ocorrem divergências, a consultoria é independente. É fundamental um consultor. Não tanto pelo aspecto técnico, mas pela administração dos conflitos, complementa o Diretor Industrial. Os kaizen foram 
monitorados pela consultoria na fase inicial (1998 - 3 kaizen, 1999 - 14 kaizen e 2000 - 6 kaizen).

Houve iniciativas anteriores no uso de técnicas JIT, entretanto de modo isolado e sem contar com uma metodologia de implementação, o que comprometeu os resultados, como frisou o Chefe de Produção.

A figura do JIT Champion, ou gestor centralizado para a implementação de JIT, não existe na Empresa B, o que e é visto como uma das grandes falhas na implementação pelo impacto que causa na integração e coordenação das atividades entre as diversas partes da empresa.

As mudanças sempre foram realizadas usando áreas piloto, ou seja, áreas em que a implementação de técnicas JIT foi acompanhada em separado das demais atividades de produção da empresa.

Um aspecto cultural interessante é o fato de que "o alemão tem mais preocupação com aspectos técnicos do que com a redução de estoques", nas palavras do Diretor Industrial, confirmadas pelo Chefe da Produção. Este é um traço cultural forte. Por exemplo, antes da fusão da holding, a justificativa para a compra de um novo equipamento poderia resumir-se a redução do tempo de fabricação ou do lote. Hoje se deve mostrar qual é o retorno do investimento, em quanto tempo será amortizado, que impacto trará sobre os estoques e níveis de atendimento ao cliente. Ainda há o enfoque técnico, mas também o financeiro.

'Sempre tivemos bom relacionamento com o sindicato", destaca o Gerente da Qualidade Assegurada. A multifuncionalidade tem sido vista como benéfica para o funcionário, tanto dentro como fora da empresa. Hoje há na Empresa B quatro dirigentes sindicais. $O$ sindicato sabe que a multifuncionalidade não prejudica o trabalhador. Atualmente, uma pessoa que entra na empresa para realizar uma única função será um profissional "nulo" no futuro. Não houve demissões por conta das técnicas JIT. "Desde o início sabíamos que haveria sobra de pessoal. Mas o slogan era: "ninguém vai ser demitido", 'Sabíamos que tínhamos outras linhas nas quais aproveitar o pessoal excedente por conta dos kaizen", acrescenta o Gerente da Qual idade Assegurada.

Constatou-se que os principais elementos do fator Educação estão sendo cuidadosamente tratados na Empresa B e isso pode ser decisivo para uma implementação bem sucedida, conforme relatado na bibliografia especializada. 
Quanto ao fator Fornecedores, a Empresa B apresenta-se com certo desenvolvimento em alguns elementos. Pode-se afirmar que a Empresa B é um fornecedor JIT de seus clientes mais por força da pressão desses clientes do que por própria vocação neste momento.

Por outro lado, quanto aos seus fornecedores, a Empresa B ainda não trabalhou a cadeia de fornecimento de forma que possa considerar que recebe entregas JIT, muito embora seja um cliente expressivo para a maioria de seus fornecedores.

É importante destacar que maioria dos fornecedores pequenos tem dificuldades em atender a Empresa B, tanto no sentido qualitativo, como no aspecto da quantidade, ou seja, há um "descompasso tecnológico entre a Empresa B e alguns de seus fornecedores".

Em virtude de trabalhar com fornecimento para exportações, a Empresa B procura praticar programa firme com seus fornecedores, muito embora isso praticamente não exista em relação aos seus principais clientes. Na Empresa B entende-se por programa firme a manutenção da programação por um determinado período de tempo sem que se processem alterações. O período de "firmeza" do plano é variável em função das condições de mercado para a empresa.

O elemento voltado ao fornecedor único é presente, mas não por uma ideologia da empresa. Os fabricantes de produtos para empresas automobilísticas normalmente ficam "ha mão" de um único fornecedor, devido ao processo de aprovação de produtos na montadora, que predefine o fornecedor da matéria-prima que vai ser usada. Há um processo que homologa as amostras entregues em lote piloto. Se a Empresa B quiser mudar de fornecedores, tem que se submeter à apreciação da montadora. Praticamente não existe a possibilidade de fazer escolha do fornecedor. O fornecedor já é pré-selecionado em função do aspecto técnico.

Ainda persistem as dificuldades em reduzir lotes de compra de materiais e, consequientemente, lead time. Existem fornecedores nacionais de grande porte, como a Villares, a Mannesmann, a Norek, a Brasmetal, a Armico, que são empresas que também fornecem ao mercado das montadoras. Estes fornecedores entendem as necessidades da Empresa B porque também passam pelo mesmo problema. Porém há uma infinidade de pequenos fornecedores, que ainda querem trabalhar baseados na política industrial dos anos 80.

A Empresa B procura trabalhar com fornecedores locais que possuam matriz no exterior e forneçam para outras empresas do grupo em algum outro lugar do mundo. Há o 
objetivo trabalhar com qualidade assegurada. Para isso o fornecedor tem que ser auditado pela Empresa B, possuir certificado de sistema de qualidade e apresentar processos de fabricação formalizados.

A confiabilidade dos fornecedores ainda é uma questão preocupante, já que há inspeção de recebimento e ocorrem muitos problemas. A maioria dos fornecedores não assina sequer o “Acordo de Qualidade Assegurada”. Quem assina está privilegiado. Há um abismo tecnológico enorme que separa as empresas fornecedoras e a Empresa B. Os fornecedores não têm como acompanhar a Empresa B tecnológica ou financeiramente. Por outro lado, "estão as montadoras "hos espremendo" para reduzir custo e melhorar a qualidade.. Estamos numa guerra", relata o Gerente de Qualidade Assegurada.

A indústria automobilística brasileira "quase" não faz desenvolvimento, como regra. Apenas transfere projetos para cá. No máximo faz alguma ‘tropicalização”, relata o Diretor Industrial, muito embora haja um trabalho dentro da planta do fornecedor, realizando auditoria e treinamento, caso o fornecedor desejar.

Quanto ao elemento ligado aos contratos de longo prazo, o Diretor Industrial é enfático: "ho Brasil não se faz contrato de fornecimento. Isto é comum na Europa. Aqui não há formalização, nem pelo lado do fornecedor e nem pelo lado do cliente. Tudo é bem informal. O que ele recebe é uma "carta de intenção". Não há garantia de preços nem do produto que será entregue amanhã!".

Há um apoio técnico aos fornecedores. Há compartilhamento de custos com fornecedores (os ferramentais são sempre por conta da Empresa B). 'Nós ajudamos muito os fornecedores. Temos um sistema de kaizen interno, semana sim, semana não. Convidamos fornecedores a fazer estágio conosco para que vejam como funciona. E fazemos kaizen também nos fornecedores, muito embora nem todos os fornecedores permitam (alguns acham que vamos espionar o processo, melhorar os custos e depois pleitear redução de preços, o que é uma ilusão, pois as pessoas que fazem o kaizen nem sabem os preços dos produtos)" destaca o Diretor Industrial. Um exemplo, colocado pelo Chefe de Produção mostra que em um dia foram mudadas seis prensas de 250 toneladas em quatro horas. A intervenção junto ao fornecedor é muito delicada. Depende de como se faz a abordagem. No caso da Empresa B, foi mostrada a gama de melhorias que o fornecedor pode ter em seu processo pela adoção das técnicas JIT, melhorias estas que terão impacto direto na redução dos custos de produção dos produtos fornecidos a todos os clientes. 
A aplicação da metodologia da "Semana Kaizen" pela Empresa B em seus fornecedores é praticada e prevista no contrato firmado com a empresa proprietária dos direitos autorais da metodologia, segundo frisou o Chefe de Produção.

O fator Fornecedor mostra-se como um elo fraco da implementação das técnicas JIT na Empresa B.

Um fator importante na Empresa B é a Produção. Há franco uso de células de produção nas principais linhas de montagem da empresa. As células são predominantemente do tipo 'U”' sem presença de esteiras entre os postos de trabalho, sem estoques intermediários, objetivando o fluxo de uma peça. Nas palavras do Diretor Industrial, "Hoje só queremos trabalhar com células. Diria que em nossas linhas de montagens, $90 \%$ operam com células, a maioria montada com os kaizen semanais. Há casos de compartilhamento de uma máquina por mais de uma célula e casos de duas linhas de produtos que funcionam dentro de uma única célula, variando as máquinas que são utilizadas. Até que todas as mudanças fossem feitas levou cerca de três anos, porém, algumas linhas automáticas, vindas da Alemanha, ainda não foram alteradas".

A presença de Kanban é clara. Há Kanban eletrônico, de cartões e "de superfície" (áreas demarcadas no chão da fábrica, que devem ser preenchidas pelos processos anteriores assim que fiquem vazios). Há unidades que trabalham 100\% com Kanban.

Os kaizen começaram em 98. No ano de 99 foi realizado o maior número de kaizen de set up. No início foram reduções de 20 a 30\%, havendo casos de redução de $70 \%$ nos tempos. A cada ano a redução é de cerca de $5 \%$. O set up é realizado pelo próprio operador ou por ele e um “ajustador volante”, um técnico em preparação.

Como o processo produtivo é longo, a metodologia da "semana kaizen" é aplicada, a princípio, no final do processo, ou seja, na linha de montagem, e depois vai evoluindo para abranger as etapas iniciais do processo. Isto faz com que a percepção da redução do lead time não seja tão grande nas fases iniciais, muito embora seja visível a flexibilidade alcançada nas linhas de montagem, conforme destaca o Chefe de Produção. Como exemplo cita o caso de um produto, que levava 24 horas para "sair" da montagem e hoje leva 7 minutos. Não há mais lotes de montagem. Trabalha-se no conceito de one piece flow, ou seja, poucas peças percorrendo o processo de montagem todo, que é alterado para outra peça tão logo seja necessário. Em suma, com relação à montagem, a redução chega a 95\%, mas no lead time total atinge $50 \%$. 
Para trabalhar o elemento ligado à Manutenção Preventiva, foi contratada uma consultoria especializada. A Manutenção Preventiva começou a ser implementada em 2000, e está concentrada na linha de agulhas, exportadas para os EUA. Já foi sentida uma mudança na rentabilidade das máquinas, com reduções nas paradas.

O nivelamento da produção é praticado no desenvolvimento do kaizen de células, ou seja, na montagem das células. Neste momento é calculado o "tempo de ciclo" para dimensionar quantas peças devem ser feitas por minuto em função da demanda do mercado. $\mathrm{O}$ balanceamento é conseguido alterando as pessoas de lugar.

A automatização é elemento muito presente na Empresa B, a tecnologia é fundamental. Entretanto, não tem nada a ver com as técnicas JIT.

Há kaizen de 5S, que normalmente não demora mais que dois dias. É chamado de “kaizen Blits". Há auditorias periódicas de 5S, que está implantado desde 99, sendo que cada seção tem um líder.

Não houve alteração de máquinas por conta da implementação das técnicas JIT, muito embora tenham sido substituídas muitas máquinas (cerca de 70\%) nos últimos 4 anos, entretanto, sem influências das técnicas JIT.

É possível se perceber que o fator Produção encontra-se bem desenvolvido, ainda que de forma muito concentrada em células de produção.

Já o fator Organizacional, para finalizar a análise, mostra que a conjuntura econômica não tem sido danosa para a empresa. A Empresa B é uma empresa que tem crescido na média de 10 a $15 \%$ ao ano nos últimos anos aqui no Brasil. A abertura do mercado brasileiro na década de 90 forçou a Empresa $\mathbf{B}$ a posicionar-se quanto às pressões da concorrência externa.

Os produtos da Empresa B vão direto para a linha de montagem, sem passar por inspeção nas montadoras. Há um processo de aprovação monitorado pelas montadoras, ocasião em que é produzida uma amostra que é submetida à aprovação (teste ou inspeção). Depois de aprovadas, passam a entrar direto na linha. Para vários clientes e linhas de produtos, a Empresa B é o único fornecedor. "A Empresa B não deixa parar uma linha do cliente. Há mais de 40 anos fornecemos às montadoras sem uma única ocorrência", enfatiza o Coordenador de Vendas.

Os clientes obrigam a Empresa B a trabalhar no regime JIT. Cliente nenhum quer estoques, da mesma forma que a Empresa B também não quer estoques. O segmento da 
Empresa B é 50\% dirigido ao mercado de automóveis (fornece para todas as montadoras), $15 \%$ para reposição (ainda no mercado automotivo), 15\% para indústria de máquinas e tratores e $20 \%$ para exportação (também para mercado automotivo). A pressão do cliente é muito clara: "entregar com hora marcada". O cliente "é rei". Máximo de atraso que podemos ter é 3\% do faturamento. A Empresa B trabalha hoje abaixo de 1\%, índice melhor que da própria Alemanha.

No dia a dia, há uma insegurança muito grande quanto à demanda, pois há muita flutuação, mas no final do período funciona bem. A cadeia de fornecedores, por sua vez, é muito lenta para reagir às mudanças impostas pelos clientes. Com a chegada das novas montadoras, como a Renault, por exemplo, o volume aumentou muito na previsão, mas em números reais apenas cerca de 1/3 se confirmou, e "hós ficamos com a capacidade instalada e com materiais em estoque e em processo" frisa o Coordenador de Vendas. No mercado de reposição, praticamente nada mudou. As compras acontecem ao final do mês.

A concorrência nacional não tem sido relevante. Praticamente não interfere, pois tem reduzido a importância ao longo do tempo. A Empresa B é fornecedor único para a maioria das montadoras.

Na matriz, o kaizen está começando e está menos desenvolvido que no Brasil. Portanto, não houve pressão direta da matriz para a implementação das técnicas JIT. Na fábrica de Sorocaba, que é a maior, está localizada a presidência da Empresa B na América do Sul. Há uma pequena fábrica na Argentina. Nos outros países da América do Sul existem escritórios de engenharia e centros de distribuição, mas todos comandados por esta unidade do Brasil. Sorocaba é benchmarking. O mercado é setorizado por regiões, ou seja, uma subsidiária não concorre com a outra. Atualmente, a produtividade da Empresa B do Brasil está no mesmo nível das européias ou asiáticas.

Foram necessários ajustes em procedimentos contábeis, mas sem alterações significativas. Nos índices de PLR inclui-se o volume de estoques como um fator importante para melhorar os resultados, principalmente para forçar a redução dos estoques. Na verdade, o que ocorreu foi uma adaptação dos sistemas contábeis em uso às necessidades decorrentes da aplicação das técnicas JIT.

A postura dos clientes da Empresa B é ditatorial. Querem entregas JIT e não abrem possibilidade de discussão. As montadoras trabalham no sistema de janelas no qual a Empresa B tem que entregar de acordo com as programações. O controle é feito todo 
eletronicamente pelo setor de administração de vendas, que faz a interface com a área de compras das montadoras, ajustando os programas diariamente. Todas estas alterações fazem com que algumas vezes, embora muito raramente, ocorram problemas de entrega, o que causa a necessidade de enviar peças até mesmo por helicóptero diretamente na linha de montagem do cliente. "hós não paramos a linha do cliente em hipótese alguma", afirma o Diretor Industrial. A forma de previsão de demanda alterou-se, mas não por influência das técnicas JIT, mas sim devido mais à globalização do que por qualquer outra influência.

Houve alterações de mix, mas não por influências das técnicas JIT e talvez seja devido a que o mercado aumentou em complexidade com a chegada de novas montadoras.

As alterações dos padrões de custo da Empresa B fazem com que a empresa trabalhe hoje num patamar de preços internacionais, competindo com fornecedores externos em igualdade.

Há evidências claras de apoio incondicional da Alta Administração, muito embora haja resistências de algumas pessoas da média gerência. O fator Produção está bem desenvolvido, embora focalizado ainda nas células de produção e $\mathbf{5 S}$.

Notou-se a falta de um membro centralizador das ações de melhorias (um JIT Champion), preconizado pela literatura.

Destaca-se nesta empresa a utilização de uma metodologia voltada a implementar "kaizen de uma semana", que segundo o relato do Chefe de Produção "é bom porque não deixa ninguém inventar nada que gaste dinheiro para implementar". O uso desta metodologia em si é uma novidade em termos de procedimentos para a implementação de técnicas JIT.

O uso das técnicas JIT na Empresa B foi fator preponderante para aprimoramentos nas competências da empresa em seu processo produtivo de forma que pudesse aumentar sua linha de produtos e seu volume de vendas.

A maioria dos problemas ligados à implementação é de ordem cultural e não técnica. Neste caso houve um forte trabalho visando a mudança de comportamento, principalmente daqueles membros da média gerência, centro das maiores restrições às mudanças. A resistência, no caso da Empresa B, ocorreu por falta de convencimento destas pessoas e este convencimento foi e está sendo conseguido por intermédio da participação destas pessoas nas "sem anas kaizen". A partir desta participação e dos resultados imediatos que são conseguidos, a adesão apresenta melhoras sensíveis. 
Um problema típico constatado foi a "síndrome do final do mês" que afeta frontalmente a previsão de demanda e que continua sem solução definitiva. 


\section{Anexo G - Descrição do caso da Empresa C}

A Empresa $\mathbf{C}$ faz parte de uma aliança global de três grandes fabricantes mundiais de baterias: uma americana (detentora de $25 \%$ do controle da empresa e fundada em 1950), outra alemã (controladora de $25 \%$ da empresa e em operação desde 1930) e outra mexicana (a maior das controladoras, com 50\% e fabricante de baterias desde 1960). A unidade de Sorocaba foi consolidada na joint venture em dezembro de 1998.

Os principais produtos da empresa são baterias de aplicação automotiva de linhas leve, média e pesada. O projeto do produto é alemão, a tecnologia de processo é americana e a administração é mexicana.

A Holding é a maior fabricante de baterias do mundo, quando consideradas as produções agregadas das 10 fábricas americanas (que produzem 40 milhões de baterias anuais), das fábricas instaladas na Alemanha (que produzem em média 20 milhões de baterias anuais) e das fábricas instaladas no México (que por sua vez produzem mais de 10 milhões de baterias por ano). A Empresa C está instalada numa área total de 650.000 metros quadrados, sendo 35.000 metros quadrados de área construída e emprega cerca de 500 pessoas (277 funcionários diretor e 232 indiretos) com faturamento anual em 2001 chegando a US\$ 90 milhões. A capacidade instalada da Empresa C é de cerca de 4,5 milhões de baterias anualmente.

As cinco entrevistas foram realizadas nos dias 19, 20 e 22 de março de 2002, nas dependências da empresa, na cidade de Sorocaba - SP e totalizaram cerca de cinco horas, além da visita ao processo produtivo.

Uma breve descrição do processo produtivo pode ser feita em cinco etapas: inicia-se pela produção de placas (compostas de dióxido de chumbo e da grelha), a montagem da bateria, a carga (alimentação da energia elétrica) e o acabamento (lavagem, secagem, colocação das etiquetas, enfim, a parte "decorativa" do produto). O quinto elemento do processo aparece como um fornecedor interno, o setor de plásticos, que fornece todas as peças plásticas (caixa, tampa, rolha, alça, etc.). A fábrica é programada com base na Teoria das Restrições, com apoio de um software chamado Drummer. O recurso restritivo é a montagem, onde existe uma máquina (COS - cast on strep) que faz a união das placas que compõem a bateria, através de uma fundição de chumbo. Esta peça é chamada strep.

Uma tendência que se observa na produção de baterias é isolar o setor de carga e acabamento da fábrica convencional mencionada acima, ou seja, a bateria é transportada 
"bra nca" (sem carga) até os centros de distribuição, que ficarão encarregados de carregar e acabar as baterias para entrega ao cliente final. Este procedimento visa reduzir o tempo de fluxo dos produtos pela fábrica.

O investimento em melhorias, na visão da Empresa $\mathbf{C}$, deve ser feito exclusivamente no gargalo da produção e só depois de otimizado o gargalo é que outras áreas devem ser trabalhadas, mantendo-se fiel à Teoria das Restrições.

As iniciativas relacionadas ao uso das técnicas JIT em estudo nesta pesquisa ocorreram a partir de 1997 e foram facilitadas pelo fato de a empresa estar em um processo de fusão com outras grandes fabricantes mundiais de baterias. A idéia da implementação foi notadamente proposta pelo então Gerente Industrial (atual Diretor de Logística), motivado pela pressão exercida pelas montadoras de automóveis. A partir de então, as técnicas de Kanban, manutenção preventiva e redução de set up foram as mais intensamente utilizadas na Empresa $\mathbf{C}$ e seu uso foi também motivado pela eminente necessidade de melhoria da competitividade da empresa, que havia estado fortemente abalada financeiramente antes da citada fusão.

Houve vultosos investimentos nos processos produtivos da empresa nos últimos 4 anos, chegando a cerca R $\$ 30$ milhões desde 1998, conforme palavras do Diretor de Logística. Entretanto, não há uma clara definição sobre quanto deste investimento foi feito por conta da implementação de técnicas JIT.

As principais dificuldades enfrentadas pela Empresa $\mathbf{C}$ estão ligadas diretamente à resistência da média gerência e supervisão em aceitar as novas metodologias de trabalho. A incerteza quanto a mudança, no que diz respeito a sobra de efetivo, foi um problema real. A solução foi um treinamento de conscientização, mostrando como as funções seriam modificadas e não eliminadas. A flexibilidade da mão-de-obra é ponto chave no processo, como enfatizado pelo Diretor de Logística. No aspecto mais prático a principal dificuldade é a programação antecipada. Tomando como exemplo a montadora da Toyota, a programação da coleta da peças pela empresa envolve relacionamento muito estreito entre o setor de planejamento da Empresa C e da Toyota.

Um aspecto interessante ocorreu na Empresa C, ressaltado como destaque: o comprometimento dos funcionários. "Ocorreu uma cobrança de baixo para cima buscando conhecer os objetivos da empresa, para que todos pudessem ajudar", destacou o Gerente de Recursos Humanos, apesar da clara resistência da média gerência e supervisão, também 
destacada. Esta cobrança ocorreu porque houve todo um processo de conscientização das pessoas sobre a necessidade da empresa ser mais competitiva no mercado, como forma de manter-se em operação.

Os principais resultados não podem ser, de forma alguma, creditados exclusivamente às técnicas JIT empregadas, muito embora seja inegável a melhoria obtida no processo de produção. A produtividade era de três baterias por homem x hora, enquanto hoje chega a sete. A fábrica contava com 1000 pessoas em 1997 e hoje tem cerca de 600. Eram produzidas 250 mil baterias por mês e hoje são 400 mil (num período de 8 meses, a produção de 2,5 milhões de baterias por ano foi aumentada para 4,5 milhões). Os índices de rejeição interna passaram de $4 \%$ para menos de $0,5 \%$, número comparável às melhores do mundo. Estes resultados foram conseguidos por uso de treinamento, tecnologia, processos, equipamentos novos, etc.

Segue uma análise detalhada dos grupos de fatores críticos para a implementação apontados pela bibliografia em comparação aos fatos constatados na Empresa C:

Quanto ao apoio da Alta Administração na Empresa C mostra-se mais com o aspecto de uma determinação superior do que na verdade um apoio. Nas palavras do Gerente de Recursos Humanos "a Alta Administração participou efetivamente cobrando das áreas envolvidas que se fizesse o treinamento necessário para o uso das técnicas JIT na Empresa C. Apesar da cobrança ter um "ar" um tanto "ditatorial", as mínimas condições materiais foram oferecidas dado que o treinamento foi realizado em horários normais de trabalho. Paralelamente, em 2001, instituiu-se o evento “café da manhã com o presidente", ocasião em que alguns funcionários reúnem-se mensalmente com presidente da empresa para tratar de problemas (e soluções) para as atividades mais comuns. Outra manifestação do apoio foi a criação do Programa de Incentivos via cesta básica em 1995 (atualmente chamado de "cesta prêmio"), criado e monitorado pelo setor de Recursos Humanos, com amplo apoio e participação das demais gerências. Há cinco níveis ou tipos de cestas prêmio que os funcionários podem receber: o básico, com 40 quilos, que é fornecido a todos os funcionários; o kit 1, com produtos de limpeza, o kit 2, matinal, o kit 3, com produtos de toalete e o kit 4, com produtos para crianças. O recebimento dos kits 1 ao 4 depende da participação dos funcionários em atividades de melhorias no processo produtivo da empresa. $\mathrm{Na}$ medida em que participa dos programas de treinamento ou de sugestões, acumula pontos, aos moldes dos programas de milhagem de cartões de crédito, e os troca, duas vezes por ano, por prêmios. Este programa, idealizado pelo Gerente de $\mathrm{RH}$, tem claramente a finalidade de buscar o 
comprometimento dos funcionários para com as metas da empresa mediante um "prêmio" que o beneficia indiretamente, mas que se torna muito significativo para sua família.

Estas ações melhoraram o nível de cooperação dos funcionários, que 'Mudou bastante. $\mathrm{O}$ aumento de produtividade mostra o elevado grau de compromisso que foi conseguido entre as pessoas na Empresa C. Isto se nota não só entre o pessoal de produção, mas também entre as áreas de suporte, como manutenção, logística, engenharia, recursos humanos. Quando o trabalho foi iniciado em 1997, a empresa era completamente diferente do que é hoje. Até 1996 era de um grupo controlador, embora de controle de capital por família alemã, era gerida por brasileiros. Foi um amplo processo de mudança cultural, neste caso abrangendo três culturas diferentes, além da brasileira (mexicana, americana e alemã). A filosofia de administração era diferente. Havia pouco investimento na produção. No período de 1990 a 1996 esse grupo passou por sérias dificuldades financeiras, tanto é que a empresa controladora do negócio na época estava vendendo sua parte no negócio. Neste período não houve investimentos em manutenção, segurança do trabalho, tecnologia, etc. A fábrica passou por um período muito ruim. $\mathrm{O}$ pessoal contratado era escolhido basicamente pela capacidade física que apresentava para suportar as dificuldades do processo de produção", frisou o Gerente de Recursos Humanos.

Com relação aos cargos ocorreram alterações, pois na medida em que os funcionários adquiriram maior conhecimento e passaram a exercer novas funções, houve um enriquecimento das tarefas, e estas pessoas tiveram a oportunidade de crescer dentro da empresa.

O fator Educação e Treinamento foi tratado de forma criteriosa. O primeiro passo dado pela Empresa C quanto ao treinamento para uso de técnicas JIT foi um levantamento das necessidades de treinamento (tipo, pessoas, locais e temas). Este trabalho foi desenvolvido junto à supervisão e gerências das áreas envolvidas, principalmente a área de produção, logística, expedição, entre outras. Isto gerou a criação de um programa de capacitação de pessoal adequado às necessidades da implementação destas técnicas. $\mathrm{O}$ treinamento envolveu cerca de 70 a 80 pessoas das áreas citadas, com cerca de 4 horas de treinamento por funcionário.

O treinamento técnico, por exemplo para a COS (uma máquina de fundição de chumbo), abrangendo qualidade, segurança, produtividade, controle ambiental e manutenção, foi e ainda é conduzido pelo próprio pessoal da produção que orienta os mais novos. Já o treinamento mais genérico, como o Telecurso segundo grau, os cursos de hidráulica, elétrica, 
pneumática, comandos elétricos, qualidade total, segurança do trabalho, entre outros, são conduzidos por parcerias da Empresa C com outras empresas.

Os critérios de contratação foram realmente afetados. Até 1996 a contratação era baseada simplesmente em critérios de capacidade física. O supervisor era o "capataz" e ao funcionário cabia cumprir as ordens: “proibido pensar”. No início de 1997, 48\% das pessoas não tinham o primeiro grau completo. Hoje este número mudou completamente (apenas 5\% das pessoas ainda não têm o primeiro grau completo). "Antes as pessoas só vinham trabalhar aqui em último caso" reforça o Gerente de Recursos Humanos.

Atualmente exige-se ao menos o primeiro grau completo para novas contratações na fábrica (o ideal é estar cursando o segundo grau). Este fato deve-se à radical mudança na tecnologia de produção empregada. Muitos dos novos equipamentos têm comando numérico, o que exige um mínimo de proximidade com a informatização. É claro que ainda existem muitas tarefa manuais, mas já foram reduzidas de forma significativa.

A presença de grupos de trabalho é clara. São montados grupos para projetos específicos. A produção, por exemplo, tem linhas de produção que formam uma grande equipe de trabalho, envolvendo os três turnos, visando integrar o trabalho de todos os turnos. Em 1999 foi desenvolvido um treinamento voltado ao relacionamento interpessoal dos funcionários, que envolveu todo o pessoal da empresa, desde os terceirizados até a diretoria. O treinamento durou cerca de quatro horas e buscou transmitir os conceitos de empatia, transparência, pensar positivo (ver o bom antes do ruim), buscando melhorar o relacionamento entre funcionários e chefia e vice-versa, com resultados excelentes na opinião do Gerente de RH. A condução ficou a cargo de uma empresa de consultoria.

O desenvolvimento da multifuncionalidade foi iniciado há cerca de três anos. Procurou-se estimular a multifuncionalidade com um "cardápio de treinamento", ou seja, é oferecido um pacote de treinamento aos operadores, que devem candidatar-se àqueles que se relacionarem mais estreitamente ao seu trabalho. Com isso monta-se um quadro de habilidades disponível em cada área, que é usado quando há falta de um funcionário. A participação nestes treinamentos é facultativa na maioria dos casos e "vale" pontos para o sistema de incentivos por meio dos brindes.

A presença de consultoria externa é inegável. No caso do Kanban, foi conduzido pelo IMAM - Instituto de Movimentação e Armazenagem de Materiais (uma empresa de consultoria brasileira, com sede em São Paulo, especializada em consultoria industrial). Já no 
caso do treinamento em relacionamento pessoal, a participação mais efetiva de consultoria foi da Wilson Cerqueira, que desenvolveu um projeto intitulado K zero (nome dado pela própria consultoria) que culminou com um teatro conduzido pelos próprios funcionários, mostrando o "antes” e o "depois" das relações pessoais na Empresa C. Depois disso é que surgiu a carta de "valores" e a "missão" da empresa. O treinamento foi realizado com $100 \%$ dos funcionários, para passar exatamente a idéia de que na Empresa $\mathbf{C}$ todos são fabricantes de baterias. Houve também palestras de conscientização e palestras técnicas sobre o uso do software de gestão da produção com base na teoria das restrições, conduzida por consultores contratados.

Por outro lado, nas atividades ligadas à qualidade não houve participação de consultoria externa. Há desenvolvimento de treinamento em técnicas de qualidade conduzidos pelos próprios funcionários da empresa, por decisão do Gerente de Qualidade e Meio Ambiente.

Não houve e não há perspectivas de concentrar as atividades voltadas ao JIT em um JIT Champion. Isto talvez se deva ao fato de não ter havido um plano específico para a implementação de técnica JIT nesta empresa.

Quanto à presença do sindicato dos empregados não se registraram problemas quanto às técnicas JIT. O relacionamento melhorou significativamente ao longo do tempo. Em 1997 as condições de trabalho presentes na fábrica causavam muitos problemas na relação com o sindicato, que, segundo o próprio gerente de $\mathrm{RH}$, tinha certa razão na postura crítica que adotava contra a Empresa C. A estratégia foi melhorar minimamente as condições de trabalho dos funcionários. Na medida em que estes pontos foram resolvidos, ou minimizados, as relações com o sindicato melhoraram. No que tange ao JIT com relação ao sindicato, não há o que se destacar. Hoje a Empresa C é indicada como modelo pelo sindicato no que diz respeito ao PLR (participação em Lucros e Resultados). O diálogo é aberto com o sindicato, mesmo quando ocorrem problemas de mercado que demandem redução de pessoal, como é o caso da atual crise da Argentina.

Constatou-se que os principais elementos do fator Educação estão sendo cuidadosamente tratados na Empresa C.

Quanto ao fator Fornecedores, a Empresa C apresenta-se como restrito. A maioria de seus componentes não é entregue em regime JIT, muito embora alguns tenham recebimento "coordenado" pelo estoque mínimo. Dentro do processo produtivo há o exemplo do estoque 
de chumbo, com apenas três dias de cobertura e responsabilidade de ressuprimento pelo fornecedor.

A Empresa C compra de poucos fornecedores. Os principais produtos são Chumbo, do qual é um grande cliente (da China, Peru, Argentina); o Polipropileno, do qual é um cliente médio (do Brasil, da Colômbia e de outros países sul americanos); o Ácido Sulfúrico (oriundo das Usinas de álcool) e separadores (dos EUA). Há três ou quatro fornecedores que representam $90 \%$ do custo dos produtos comprados pela Empresa C. Estes fornecedores são globais, ou seja, fornecem para todas as empresas do grupo em preços iguais, naturalmente dolarizados.

Os estoques de chumbo e separadores não são de responsabilidade da Empresa C. Ficam sob responsabilidade dos fornecedores, que os mantêm em estoque no porto. A Empresa C só paga quando retira e não precisa sequer programar a compra. No porto são mantidos 40 a 50 dias da demanda média em estoque. Não há necessidade de preocupação com redução de lotes de compra, os quais, face ao elevado consumo, possuem elevadas quantidades.

Existe uma determinação da ISO TS que força os fornecedores a possuir ISO implementada, o que faz com que a inspeção de recebimento, embora ainda mantida, seja basicamente amostral.

Há apoio técnico para auxiliar os fornecedores a obterem certificação. Os principais fornecedores passaram por um treinamento por força da homologação de fornecedores para certificação da Empresa C.

O fator Fornecedor demonstra-se como um fator ainda por desenvolver-se na Empresa C, talvez por haver pouca pressão pelo controle de estoques.

Quanto ao fator Produção, na Empresa C verifica-se situação bastante peculiar. Não se usa o conceito de Células de Produção devido às particularidades do processo produtivo. As máquinas são caras e de alta taxa de produção. Apenas na montagem há algumas características de célula.

O Kanban foi implantado em 1998 na configuração atual, na fábrica de plástico. Usase um rack metálico que define as quantidades a serem produzidas (100 peças para caixas, 400 peças para tampas, etc.). Em fábricas de baterias, mesmo no Japão, o Kanban é usado apenas em áreas onde a demanda é razoavelmente previsível, como no caso da produção de caixas e outros componentes plásticos, pelo que informou o Diretor Comercial, que esteve em 
visita nas principais fábricas de baterias japonesas. Mesmo assim os lotes são grandes devido aos custos de set up.

Os tempos de set up são elevados em função do processo produtivo, o que condiciona a fabricação de grandes lotes, independentemente do padrão da demanda. O set up da COS (máquina de fundição de chumbo) leva 5 horas, o que inviabiliza o trabalho em lotes pequenos (o menor lote é 3000 baterias, independentemente da demanda). O mix de produção chega a 180 diferentes tipos de baterias, o que agrega mais complexidade ao processo produtivo. O set up em fundição é um processo crítico por natureza. Há problemas com o cadinho de fundição, com a limpeza de moldes, etc. Esta complexidade faz com que nos EUA, por exemplo, existam fábricas dedicadas à produção de um único tipo de bateria, visando ganhar com a escala de produção. Uma fábrica de baterias não é flexível. 'O sistema de produção de baterias é bem rígido", conforme ressalta o Diretor de Operações.

Há aplicação do conceito de manutenção preventiva na fábrica toda, tendo sido implementada há cerca de três anos. Por exemplo, na montagem há um turno por mês de manutenção preventiva por linha de produção (no total são 5 linhas). Toda semana há uma ou duas linhas paradas durante um turno de 8 horas para manutenção. Há manutenção mecânica, elétrica/eletrônica (que são basicamente corretivas) e a preventiva, coordenada por uma equipe independente. O tempo médio entre falhas é um fator considerado para operar a manutenção preventiva.

O nivelamento da produção é feito exclusivamente por intermédio de estoques reguladores que somam 20 dias de demanda, em média (baterias 'brancas", ou seja, sem carga, com $70 \%$ de estoque - 14 dias - e baterias acabadas, com $30 \%$ de estoque -6 dias).

As principais etapas do processo de produção são contínuas e em grandes lotes de fabricação. O lead time total de produção de um lote é sete dias. Em função da COS, o lote mínimo de fabricação é de 3000 peças.

A Empresa C implantou um inovador processo de carga de baterias em bancada de água, que reduz o tempo de carga de 25 para 8 horas. Houve um investimento de US\$ 8 milhões no sistema de carga das baterias. Esta foi uma importante inovação tecnológica, entretanto, sem nenhuma motivação pelo uso de técnicas JIT.

Por conta da alteração do sistema de carga, o lote de produção foi reduzido em cerca de 30\%, porém sem influência das técnicas JIT adotadas. O processo tem várias etapas de "cura" que não podem ser eliminados pela adoção de técnicas JIT. 
Não houve modificações importantes no leiaute devido à rigidez imposta pelo processo produtivo de baterias, que é muito semelhante em todo o mundo. Na Empresa C, apesar de ter havido significativas alterações no processo produtivo, o leiaute da fábrica permaneceu o mesmo. O housekeeping é usado como programa de incentivo aos funcionários.

A principal vantagem competitiva da empresa é a qualidade, superior à da concorrência. É ponto de referência dos produtos da Empresa C, que é certificada pela ISO 9001 e QS 9000 (exigência das montadoras) desde 1998, o que levou a exigência de outros requisitos como, por exemplo, a análise do sistema de medição, que anteriormente era só voltada à calibração. Passou-se e exigir uma análise da capacidade dos equipamentos de medição (repetitibilidade, estabilidade, linearidade) que afetaram os índices devidos às especificações mais estreitas. Hoje também está certificada pela norma TS 16949 (que engloba a ISO e a QS), a partir de dezembro de 2001.

Apesar da rigidez imposta pelo tipo de processo produtivo, é possível se perceber que o fator Produção encontra-se em desenvolvimento, ainda que de forma muito tímida. $\mathrm{O}$ fato de a empresa atender em apenas $15 \%$ de suas vendas às montadoras também pode estar contribuindo para este fato.

Para finalizar a análise, um Fator Estrutural mostra que a atual situação econômica da América Latina tem sido danosa para a empresa. Particularmente a crise Argentina e a desvalorização da moeda venezuelana estão afetando fortemente a demanda, mas não são propulsores de maiores mudanças voltadas às técnicas JIT. A realidade da competitividade necessária à Empresa $\mathbf{C}$ na América do Sul é diferente das demais empresas do grupo, que trabalham em mercados muito mais estáveis. Por exemplo, a Empresa C México tem $85 \%$ do mercado, com 14 milhões de baterias por ano. A Empresa C Brasil tem cerca de $26 \%$ de market share, e apesar deste número ser pequeno, é líder de mercado (o segundo maior fabricante ocupa $17 \%$ do share). O mercado da Empresa C compõe-se de $15 \%$ de montadoras e $85 \%$ de reposição. Há uma enorme pulverização do mercado brasileiro de produção de baterias. Mesmo assim a Empresa $\mathbf{C}$ tem crescido cerca de 2 pontos percentuais ao ano desde 1998. Isto se deve à qualidade do produto e às estratégias de distribuição.

As montadoras pedem entregas JIT com coleta diária e hora marcada. Já a maior parte dos clientes de reposição não quer receber em lotes menores. Se os clientes de reposição mudassem de política abruptamente, o primeiro impacto seria uma quebra de vendas da ordem de um a um mês e meio. Portanto, não há interesse em mudar a forma de entregas adotada atualmente. 
Os preços de baterias no Brasil são reduzidos pela existência de concorrência de segunda linha, que produz e vende produtos sem notas fiscais. Com isso o preço das baterias no Brasil atinge a metade do que se pratica no resto do mundo. De fora do Brasil o principal concorrente é a Delphy e no Brasil a Moura, Ajax, Reifor, Tudor, que não têm a mesma tecnologia da Empresa C.

Existe pressão da matriz para aumentos de produtividade, muito embora seja de conhecimento geral que as condições de operação da fábrica do Brasil são mais complexas. No Brasil são fabricadas baterias de automóveis a caminhões, para montadoras e mercado de reposição, o que dificulta muito o processo pela extrema variação de mix que isto representa.

A fábrica está sob forte sazonalidade (no inverno as vendas sobem cerca de $30 \%$ ), o que fez que se optasse por administrar o processo produtivo pela Teoria das Restrições. O gargalo é a montagem por encontrar-se lá a maior concentração de investimentos em equipamentos.

No Brasil, pelas características da planta e do mercado, o mix é muito diversificado se comparado com as fábricas dos EUA que, em sua maioria, são quase que dedicadas a certos modelos. No caso da Empresa C a variação de mix não força a adoção de técnicas JIT. Procurou-se reduzir o número de baterias antes da carga e aumentar o número de marcas. Portanto aumentou a quantidade em termos de baterias acabadas e diminuiu em termos de baterias antes da formação. Com isso, uma bateria pode ter vários tipos de destino final.

Não houve alteração da rotatividade de pessoal em função do uso das técnicas JIT, muito embora haja um trabalho direcionado para a redução dos índices. Hoje está em nível de 0,4\% (este número não considera as faltas amparadas por lei).

Esta empresa representa um caso sui generis: não existe a pressão do mercado para redução no lead time de entrega dos produtos (só $15 \%$ da demanda é oriunda de montadoras) e o processo produtivo, conforme descrito pelo Diretor de Operações, é "uma grande linha de produção com 500 metros de comprimento. É uma grande esteira”.

Estas duas características são fatores fortemente determinantes do estágio de desenvolvimento e uso de técnicas JIT observado na Empresa C. 


\section{Anexo H - Descrição do caso da Empresa D}

A Empresa D foi inaugurada na cidade de Sorocaba em 1976, já no atual local, no Distrito Industrial da cidade. A origem do capital controlador da empresa é alemã.

A Empresa D fabrica e fornece, para o mercado automotivo, platôs e discos de embreagem, volantes simples e de dupla massa, fundidos rotacionais (polias, placas de pressão e volantes), sistemas de acionamento, bombas hidráulicas e bombas de vácuo, componentes de conversores de torque e embreagens para conversores. Nos últimos anos, o grande avanço tecnológico desenvolvido pela controladora da Empresa D foi o lançamento dos sistemas de acionamento de embreagens, bombas à vácuo e hidráulicas, platôs SAC (self adjust clutch) que se auto regulam, volantes de dupla massa para amortecimento de vibrações e embreagens eletrônicas, que não necessitam do pedal da embreagem para realizar o acionamento do conjunto de embreagem.

Em termos mundiais, a empresa já atua há 37 anos e no Brasil, há 26 anos, numa área que tem 250.000 metros quadrados, tendo a área construída um total de 30.000 metros quadrados. Hoje opera com 670 funcionários. O faturamento anual não foi informado.

Atualmente a Empresa D detém cerca de $60 \%$ do mercado nacional de embreagens e cerca de $10 \%$ de sua produção destina-se ao mercado externo. As demais empresas do grupo no mundo detém cerca de $50 \%$ do mercado.

As seis entrevistas foram realizadas nos dias 03 e 10 de abril de 2002, nas dependências da empresa, na cidade de Sorocaba - SP e totalizaram cerca de 6 horas.

De acordo com a descrição do Gerente de Logística, existem montadoras, tais como a Toyota e a Ford, que fazem retiradas de produtos com data e hora marcadas (dentro de ‘janelas” de programação por elas estabelec idas, no sistema chamado de milk run) e há outras montadoras que recebem os materiais transportados pela própria Empresa D, também com data marcada, mas sem a rigidez do horário de entrega, entretanto com quantidades específicas. Já as montadoras de tratores, que também trabalham com uma programação, têm periodicidade semanal. O mercado de reposição, na Empresa D chamado de "comércio", que representa cerca de 50\% do volume de atividades da empresa, "é bastante ingrato para a programação", porque, por questões fiscais, principalmente, as compras são realizadas somente nos dois ou três últimos dias do mês. Visando minimizar este problema, a Empresa D já tentou fornecer descontos a estes clientes de forma a estimulá-los a programar entregas ao longo do mês, sem sucesso. 
Portanto, para o mercado de "comércio", a Empresa D produz para estoque. Numa negociação com este mercado, a Empresa D assumiu a responsabilidade de fazer estoque para os clientes, ou seja, estimula seus clientes a não terem estoque e a própria Empresa D programa as entregas para eles, bastando para isso que confirmem os pedidos gerados pela própria Empresa D em nome deles. No caso das grandes redes de revendedoras de peças, há uma rede de comunicação via internet que as conecta diretamente aos estoques da Empresa D, visando criar facilidades e vantagens para que o cliente deixe a programação de entregas por conta da Empresa D. Mesmo com este tratamento do problema da demanda, os pedidos são sempre deixados para a última hora o que faz com que a Empresa $\mathbf{D}$ tenha que trabalhar com um nível de estoques maior que o desejado.

No caso das exportações, que representam cerca de $10 \%$ das vendas da Empresa D, é ainda mais crítica a situação de fazer entregas JIT pois no Brasil ainda persistem as dificuldades com o desembaraço de mercadorias nos portos e estações aduaneiras, aliado às dificuldades com rotas e linhas.

Em síntese, entregas JIT somente acontecem para cerca de $40 \%$ dos produtos comercializados pela Empresa D. Nos demais casos, a produção é feita para estoque.

As iniciativas relacionadas ao uso das técnicas JIT em estudo nesta pesquisa ocorreram a partir de 1998, como uma resposta às necessidades e imposições das montadoras. O marco inicial foi a visita da empresa de consultoria TBM, que fez um levantamento do potencial para a implementação de técnicas JIT na Empresa D, em 1998. Anteriormente não houve outras iniciativas ligadas a produção JIT (não com este nome, ao menos). Na Empresa D não se tem o hábito de "batizar" programas com nomes especiais, como é o costume americano. Portanto, é claro que iniciativas de melhorias sempre existiram, mas não com nome JIT, o que talvez se deva à cultura alemã. Por outro lado, se um programa não é feito na matriz, fica mais difícil implementar nas filiais, como destacou o Gerente da Qualidade.

Tradicionalmente a Empresa D sempre produziu por lotes e não peça a peça. A base é o lote econômico de fabricação. O processo produtivo é departamentalizado (por exemplo, estamparia, tratamento térmico, montagem, etc.). É uma filosofia do grupo da Empresa D mundial trabalhar desta forma. São doze fábricas, todas elas trabalhando com base no lote econômico de produção.

Um evento marcou o início do uso formal de técnicas JIT na Empresa D. Ocorreu no setor Montagem, pela própria necessidade de espaço físico no local. E os resultados foram 
muito positivos (ainda que não definidos em números), pois tornou desnecessária a construção de outra área para a Montagem. Em outros setores, como a Têmpera e a Usinagem, também foram aplicados kaizen voltados ao layout. Em outras áreas menos favoráveis como a Estamparia, por exemplo, não estão previstas alterações importantes de layout, devido às dificuldades técnicas de se mudar prensas de grande porte, já ajustadas para o trabalho naquela área, com alimentação de materiais e escoamento de resíduos feitos de maneira automática.

As principais dificuldades enfrentadas pela Empresa D estão ligadas diretamente à inexistência de um "escritório de kaizen" exclusivo ou um responsável específico por melhorias, muito embora este ponto já tenha sido discutido em várias ocasiões até mesmo no nível da Diretoria Industrial. Outro ponto é o "paternalismo" da empresa no trato com as mudanças que representam a adoção das técnicas JIT, ou seja, as resistências não são "atacadas" de frente. Desta forma o "lado humano" é outro grande problema. No aspecto externo, uma dificuldade que se destaca é a extrema burocracia enfrentada pela empresa nos desembaraços alfandegários.

O Gerente de Qualidade destaca a dificuldade relativa ao fato de o processo de produção estar totalmente departamentalizado, ou seja, fortemente organizado por processos, além da presença de setores, como os de Prensa e Tratamento Térmico, que têm características muito específicas que dificultam a formação de células de produção. Por exemplo, o setor de Prensas requer uma preparação especial do solo para receber os equipamentos. Já o setor de Tratamento Térmico, que por si só já é extremamente agressivo ao ambiente no qual se instala, tem o agravante de ter de trabalhar necessariamente em lotes.

Já o Gerente de Produção aponta como uma grande dificuldade a separação dos conceitos meramente acadêmicos daqueles que podem ser efetivamente implementados nas condições presentes na empresa. Reforça que as técnicas são fortemente interligadas e que o fundamental é a mudança na forma de agir, o que está sendo alcançado por meio de treinamento do pessoal, que passou a ver o uso das técnicas como um "presente", pelas evidências de melhorias que apresenta.

A previsão de demanda também é uma grande dificuldade para a Empresa D. Pelo fato de as empresas revendedoras ("comércio") terem muitas restrições a trabalharem com programação, é utilizada uma sistemática particular para prever a demanda futura, por intermédio da análise estatística da demanda passada. O objetivo é "ábrandar" as variações da demanda visando que a produção trabalhe com pequenas alterações de volumes dos lotes de 
produção. Esta análise também possibilita à programação saber se o produto apresenta uma demanda normal (dentro de padrões esperados) ou se está com variações, que podem ser positivas no caso de demanda em elevação, ou negativas, nos casos de descontinuidade planejada do produto.

O Gerente de Qualidade aponta como grande dificuldade a inexistência de um programa formal de disseminação do Kaizen pela empresa. Afirma ainda que, "se você andar pela fábrica e perguntar o que é kaizen, muita gente não sabe responder". Isto poderia ser resolvido pela consolidação de um programa formal, com responsáveis formais e ações coordenadas. Relata ainda o Gerente da Qualidade, que o sistema de implementação adotado pela Empresa D perde oportunidades de fazer "marketing" do programa, principalmente pela falta de um escritório central. Na verdade, a Empresa D aplica diversas iniciativas, entretanto, não as contabiliza formalmente. Se é positivo por ser mais 'barato", é ruim por não se poder usar como referência para processos futuros.

O Supervisor de Vendas destaca a elevada freqüência de entregas objetivada pela filosofia JIT como uma dificuldade tanto para quem entrega como para quem recebe, pois gera a produção diária em lotes menores ou gera a formação de estoques para aproveitamento do lote econômico para quem produz e gera custos adicionais de frete e recebimento para quem recebe, dependendo das condições contratuais de fornecimento. O problema fica ainda mais crítico quando o cliente trabalha com as "janelas" (horários rígidos) de entregas. As montadoras têm tentado trabalhar neste esquema de entregas mais freqüentes, mas outras estão retornando ao sistema anterior, ou seja, recebendo uma vez por semana. O motivo da reversão em algumas montadoras pode estar ligado às dificuldades de planejamento e controle e a inviabilidade financeira de se pagar pelos transportes mais freqüentes. Na sua visão, a proximidade geográfica e o volume de produção são dois importantes fatores críticos de sucesso na implementação do JIT.

Os principais resultados obtidos na Empresa D com o uso das técnicas JIT estão ligados à redução dos níveis de estoques, que passaram de cerca de 120 dias em 1998 para cerca de 42 dias atualmente. Um fator que afeta diretamente o tamanho do estoque é a estratégia da Empresa D em trabalhar com lote econômico. Há componentes que têm lead time de fabricação de até duas semanas, o que também pressiona para cima o volume de estoques.

A agilidade e a confiabilidade dos produtos e das entregas da Empresa D fez com que a fatia de mercado ocupada pela empresa venha crescendo continuamente. Na Volks, em que 
a Empresa D tinha 40\% das vendas em 1998, hoje tem 65\%, na GM , em que tinha 20\%, hoje detém $80 \%$.

Segue uma análise detalhada dos grupos de fatores críticos para a implementação apontados pela bibliografia em comparação com os fatos constatados na Empresa D.

Quanto ao apoio da Alta Administração na Empresa D, é manifestado na forma convencional, ou seja, há disponibilização de investimentos em treinamento de pessoal, geridos pelas próprias áreas de produção em função das necessidades de cada setor e também um sistema de coleta e premiação de sugestões dos funcionários. Na cultura da Empresa D, as iniciativas são sempre apoiadas. "A Empresa D não é contra nada!", enfatiza o Gerente da Qualidade. Portanto, sempre há apoio para a inovação e melhoria, mas não existe a cultura de 'Programa", ao estilo dos realizados em empresas americanas, que fazem muito bem o "marketing" do programa.

O fator Educação e Treinamento é tratado na Empresa D por setor específico somente para efeito de controles internos e voltados às documentações formais da ISO. Na verdade a Gerente de Recursos Humanos não estava diretamente envolvida nos treinamentos específicos sobre JIT. Entretanto, é importante que se destaque que há um cronograma geral de treinamento na empresa formulado por Gerentes e Supervisores com horizonte de dois anos, que prevê o treinamento a ser realizado em todos os níveis na empresa. Os treinamentos específicos são coordenados e organizados pelas próprias áreas, cabendo ao setor de RH somente o registro das atividades.

Em termos numéricos, o volume de treinamento em 2001 atingiu 18 mil horas (ainda que não sejam computadas as horas de treinamento em cursos de Língua Inglesa e Alemã).

Existem formalmente os "times de projeto", que são formados pela reun ião de vários membros de diversos setores para a solução de um problema comum a todos os envolvidos, o que dá ênfase ao trabalho em equipe, muito embora não sejam vistos como uma iniciativa ligada ao JIT.

Quanto aos critérios de contratação observados após 1998, está evidenciado que se tornaram muito mais seletivos, exigindo-se primeiro grau completo nas áreas de produção e ainda assim, aplicando-se testes de admissão buscando proficiência mínima em Matemática e Língua Portuguesa. Uma vez contratado, o funcionário passa inicialmente por um treinamento de apresentação da empresa e seus colaboradores, chamado de Integração. Depois, 
periodicamente, tem um novo treinamento sempre que um novo produto ou nova tecnologia são introduzidos à linha de produção.

A classificação de cargos sofreu alterações nos últimos anos, mas não em decorrência do uso de técnicas JIT.

Não se pode creditar ao uso de técnicas JIT eventuais alterações em níveis de absenteísmo, rotatividade ou índices de acidente de trabalho.

Não houve a participação de consultoria externa para a implementação de qualquer técnica JIT, particularmente pelo elevado preço cobrado pelas consultorias analisadas.

Existe um programa formal de sugestões que concede prêmios automáticos de R $\$$ 40,00 às sugestões mais simples de implementação imediata e sem custos, até as premiações maiores para as sugestões que envolvem análise de custo/benefício mais aprimorada. A meta é alcançar duas sugestões por funcionário por ano, em média.

Não houve e não há perspectivas de concentrar as atividades voltadas ao JIT em um JIT Champion. Na Empresa D há uma equipe ligadas às iniciativas JIT, mas não necessariamente com a nomeação de um responsável específico.

Quanto à presença do sindicato não se constatou qualquer empecilho, havendo inclusive membros do sindicato no quadro de pessoal de fábrica.

Houve, no início em 1998, a oferta de serviços de uma empresa de consultoria chamada TBM, para a implementação de Programa de Melhoria Contínua, mas os preços cobrados foram considerados muito elevados pela diretoria. Concomitantemente, outra empresa, que hoje é parte do mesmo grupo controlador da Empresa D, estava contratando os trabalhos desta consultoria e a Empresa D participou dos treinamentos realizados nesta empresa, com a participação de dois membros da Empresa D (o Gerente e o Diretor da produção).

Após esta participação da Empresa D neste workshop, os dois membros da Empresa D treinaram multiplicadores internamente (mostrando os princípios básicos), sempre sob a direção do Gerente da Montagem, que é o elemento mais ligado ao assunto na Empresa D.

Apesar do grande esforço empreendido pelo Gerente de Montagem, a despeito dos bons resultados obtidos nas áreas onde o kaizen foi implementado, o Gerente de Qualidade é enfático em afirmar que o kaizen ainda não está fortemente implementado na Empresa D. Fizemos o "arroz com feijão", destaca, finalizando. 
Constatou-se que os principais elementos do fator Educação estão a cargo das áreas produtivas, cabendo ao setor de RH (aliás, bastante reduzido, contando com apenas cinco funcionários) apenas as atividades legais quanto ao pessoal empregado.

Quanto ao fator Fornecedores, a Empresa D compra de cerca de 120 diferentes fornecedores; dez deles representam $75 \%$ do valor total de compra; enquanto 19 já respondem por $90 \%$ do valor de compras; logo, 101 fornecedores representam apenas $10 \%$ do valor das compras, ou seja, há um grande número de pequenos fornecedores. Há grande concentração de compras nos grandes fornecedores de aço e arames. Por exemplo, no caso da CSN, a Empresa D é um pequeno cliente, o que dificulta as transações, pois a aciaria produz os diversos tipos de aço de acordo com sua melhor conveniência e a Empresa D tem de enquadrar-se ao programa do fornecedor tendo como única opção alternativa o mercado paralelo, que cobra preços até $40 \%$ maiores.

O desenvolvimento de projetos em conjunto com fornecedores existe e há exemplos em que a Empresa $\mathbf{D}$ foi fundamental para o desenvolvimento do fornecedor.

A Empresa D não conseguiu reduzir a base de fornecedores. Houve tentativa de se fazer isto com fornecedores de aço, mas ocorreram problemas. Tão logo o fornecedor percebeu que estava ficando com a maior parte dos pedidos, os problemas com preço e prazos começaram. 'Não existe parceria com fornecedores no Brasil, e acredito que mesmo lá fora não ocorrem como se vê descrito na literatura, pelo menos não com a Empresa D, ainda que pensando na Empresa D da Alemanha”, destaca o Gerente de Logística.

A inspeção de recebimento é presente, embora seja reduzida gradualmente em função da confiabilidade apresentada pelo fornecedor ao longo do tempo. Os fornecedores são "e scolhidos" basicamente pela capacidade técnica e pela capacidade de fornecer com preços e prazos mais satisfatórios.

A presença de certificação nos fornecedores não é indicador de idoneidade, segundo o Gerente de Logística: 'Temos fornecedores com QS, ISO e outras certificações, que atrasam, não se justificam, não respondem". A Empresa D teve de se ajustar a fornecedores que não cumprem $100 \%$ dos compromissos sob pena de ter de trocar de fornecedor. 'Não adianta fazer tanta pressão se compensa aumentar o estoque de segurança", enfatiza o Gerente de Logística. No exemplo colocado pela Empresa D, um grande fornecedor foi mostrado como exemplo de um caso típico de descaso no fornecimento. 
A despeito destes casos, a confiabilidade dos fornecedores está em alta e vem melhorando continuamente, como afirma o Gerente de Logística.

Quanto ao fator Produção, fica evidente que houve avanço quanto à redução de lotes de fabricação, dado o aumento de mix de produtos e redução de estoques. Entretanto, conforme declarações do Gerente de Logística, não há um acompanhamento da evolução histórica dos índices, pois isto demandaria a necessidade de se ter pessoas específicas para obter, processar e divulgar as informações, o que é visto como um custo desnecessário pela empresa.

Na Empresa D, o sistema de produção é uma mescla do sistema Japonês (com base na Toyota) e do sistema Alemão (usado na Porsche). Aliás, um meio de facilitação da adesão da cúpula, conforme relato do Gerente de Produção, é citar a Porsche como referência para a implementação de algo diferente.

O Kanban não foi implantado ainda na forma convencional (com cartões) e nem o será pois já existe uma variante do Kanban, mas em meio eletrônico. Optou-se por esta forma devido ao grande mix de produtos fabricados em cada mês e às constantes alterações de lotes de fabricação.

As células de produção estão em várias áreas, predominando nos setores de Montagem e na Usinagem. Já no setor de Prensas, dadas as características dos equipamentos e das instalações, ainda não estão em uso e não há previsão de implementação.

Os tempos de set up foram reduzidos graças ao trabalho de duas equipes especialistas em preparação externa dos equipamentos.

Há aplicação do conceito de manutenção preditiva e preventiva bem desenvolvida. Na visão do Gerente de Produção, a manutenção preditiva é preferida e chega a citar a manutenção preventiva como uma "manutenção mal feita". Está implementada no setor de Usinagem desde 2000 e está em fase de implementação no setor de Montagem.

O nivelamento da produção é feito com base na determinação de lotes econômicos de fabricação, que são automaticamente reavaliados por software específico a cada mudança nas variáveis que o compõem.

Houve modificações importantes no leiaute por conta da implementação de células de produção, porém apenas em setores específicos como Montagem e Usinagem. 
Já o fator Organizacional praticamente não apresentou alterações significativas. Na produção, por exemplo, a não ser o uso de Kanban eletrônico ao invés do Kanban por cartões, não houve alterações. No âmbito comercial, a estratégia de vendas atual é manter a Empresa D em primeiro lugar entre as montadoras calcando-se principalmente na vantagem tecnológica apresentada pelos produtos da Empresa D. Ocorreram significativas alterações nos custos dos produtos, entretanto, principalmente devidas a alterações tecnológicas e não ao JIT.

A concorrência aparece como um forte apelo ao uso de técnicas JIT toda vez que as montadoras, principalmente, buscam redução de custos, muito embora a maior fatia do mercado de embreagens para montadoras no Brasil seja da Empresa D (para veículos, entre 60 a $65 \%$ do mercado; para caminhões e ônibus, entre 35 e $40 \%$; para tratores, cerca de $95 \%$ e pick ups, 85\%). Em alguns segmentos a Empresa D não atua, por preferência específica das montadoras, como é o caso de algumas linhas da Ford e da GM.

O planejamento de produção é descentralizado, com um grupo de oito disponentes ou programadores de produção, responsáveis pelos contatos diretos com os clientes após o produto estar totalmente desenvolvido técnica e comercialmente.

Esta forma de trabalho é adotada em todas as unidades da Empresa D pelo mundo.

Atualmente há um mix de 890 produtos ativos diferentes na linha da Empresa D (eram cerca de 450 em 1998). Estes produtos são processados em oito diferentes linhas de montagem, o que significa mais de cem produtos para cada linha, em média. Por exemplo, no mês de março de 2002 foram produzidos 714 tipos diferentes de produtos, ou seja, quase cem produtos diferentes por linha. Isto só foi possível pelo avanço conseguido em termos de preparação de máquinas, manutenção e padronização no uso de materiais e componentes.

Este aumento de mix está relacionado ao aumento do mix de modelos e motorizações das linhas de automóveis disponíveis hoje no Brasil, segundo relata o Supervisor de Vendas da Empresa D. O que no passado era padronizado, hoje é customizado.

Os sistemas de controle também foram alterados a partir de 1998. Os contatos de clientes são feitos diretamente com os setores de produção responsáveis, sem passar pelo departamento de compras.

Uma mudança que se faria no processo de implementação seria, segundo o Gerente de Logística, um maior esforço no convencimento da equipe. Quanto aos clientes e grandes fornecedores (aspectos externos da empresa) não há no que gastar energia. Outra mudança 
seria a adequação tecnológica dos equipamentos, ou seja, utilização de equipamentos mais adaptados à realidade atual do mercado consumidor e fornecedor. Há na Empresa D muitas máquinas que estão defasadas tecnologicamente, ainda que estejam funcionando perfeitamente. Logo, a melhoria deveria ocorrer também nos aspectos da tecnologia e não apenas nos processos de produção. $\mathrm{O}$ desenvolvimento de parcerias com fornecedores deveria ser fomentado de forma prática. A contratação de pessoal técnico, engenheiros em especial, para atuar no setor de Compras, seria um fator importante para ajudar os fornecedores a se desenvolver na velocidade que a Empresa D precisa. Mais de cem fornecedores são pequenos, ainda que forneçam produtos em grande volume. 


\section{Anexo I - Descrição do caso da Empresa E}

A Empresa E está localizada na cidade de Amparo - SP e é uma das subsidiárias de uma empresa italiana pertencente ao grupo FIAT, que é segmentado em diversos setores de atuação no ramo automobilístico, incluindo dezenas de unidades produtivas e comerciais no mundo todo, nos vários segmentos. Dentre estes segmentos está a Divisão Escapamentos, à qual pertence à Empresa $\mathbf{E}$ e que possui 9 fábricas em 6 países (três na Itália, uma na Espanha, uma na Polônia, uma na África do Sul, uma na Argentina e duas no Brasil - uma em Contagem- MG e outra em Amparo - SP).

No Brasil, as principais linhas de produtos da empresa são sistemas de exaustão automotivos (escapamentos). A holding atua no mercado mundial há 80 anos e no Brasil a Empresa E está instalada há 37 anos, ocupando atualmente área construída de 24.000 metros quadrados dentre os 200.000 metros quadrados disponíveis. A holding emprega mais de 50 mil funcionários no mundo todo, enquanto a Empresa E tem 700 funcionários (550 diretos e 150 indiretos), que foram responsáveis por um faturamento de cerca de US\$ 65 milhões em 2001 e respondem por uma capacidade instalada atual de 600 mil sistemas de exaustão completos por ano o que possibilita o atendimento de cerca de $45 \%$ do mercado nacional.

As quatro entrevistas foram realizadas no dia 29 abril de 2002, nas dependências da empresa, na cidade de Amparo - SP, e totalizaram cerca de sete horas, além da visita às instalações produtivas.

Foram entrevistados o Diretor Industrial, que trabalha na empresa há 16 anos, o Gerente de Recursos Humanos, com 6 anos de atuação em empresas do mesmo grupo, o Gerente de Produção, funcionário há 23 anos e o Coordenador de Qualidade, que está na empresa há 28 anos.

A Empresa E iniciou seus trabalhos visando a implementação das técnicas JIT em sua fábrica nos anos 90 e jamais havia tido qualquer tipo de iniciativa no uso de técnicas JIT anteriormente. Desde o início o JIT foi visto como uma estratégia para aumentar a produtividade da empresa. Houve a necessidade de usar o JIT para atender às necessidades das montadoras, que começaram a "apertar" de forma crescente a partir de 1995 a empresa em termos de redução de estoques, entregas diárias, em janelas, JIT, seqüenciadas e diretas na linha de produção.

A Empresa E passou por uma série de modificações em sua direção. Possui duas unidades: uma em Amparo SP (antiga empresa fabricante de escapamentos, fundada em 1965 
e transferida para Amparo em 1983) em uma em Contagem MG e que foi comprada por outro grupo (em 1994) e este foi comprado pelo atual grupo Controlador da Empresa E entre 1998 e 1999. Na fusão das duas empresas, a influência da fábrica de Amparo sobre a de Contagem foi muito maior (o que não é muito comum, ou seja, a empresa adquirida influir nas operações da empresa compradora). Em Contagem não havia nenhuma destas técnicas JIT implementadas e em Amparo os sistemas já estavam sedimentados.

A iniciativa do uso de técnicas JIT partiu do Diretor Industrial e não foi um processo simples ou fácil. Inúmeras dificuldades tiveram que ser enfrentadas. Dentre as mais significativas destacam-se:

$1^{\mathrm{a}}$ - Nível de escolaridade das pessoas

$2^{\mathrm{a}}$ - Nível de comprometimento das pessoas, o que implica em mudança de cultura. A implementação em Contagem era tida como mais fácil que em Amparo pela experiência já adquirida, mas não foi o que a realidade dos fatos revelou. A implementação em Contagem também é responsabilidade do Diretor Industrial, mas este não tem atuação fixa naquela fábrica. Há um responsável pela área operativa na fábrica de Contagem. Lá há menos suporte técnico que em Amparo.

$3^{a}$ - Nível de experiência técnica das pessoas no assuntoJIT.

Em geral as dificuldades continuam as mesmas, mas hoje existe o adicional de pressão pela maior ênfase em custos e qualidade colocada pelas montadoras do que havia no início da década de 90.

O processo de implementação também passou por grandes acertos na opinião do Diretor Industrial: 'O peso que a alta administração dá para o processo é fundamental. Não se deve ter demasiada ansiedade na implementação. O processo é lento e gradual por natureza. A "calma" da fábrica de Amparo SP foi fator determinante para se chagar ao status atual da implementação das técnicas JIT. É iminentemente um trabalho a longo prazo. Também o uso de sistema Kanban (para gestão interna) e a parceria com fornecedores foram fundamentais para a implementação do JIT na Empresa E”.

Toda implementação de técnicas é baseada num modelo já existente, na maioria das vezes. $\mathrm{O}$ fundamental é adaptar este modelo às realidades da empresa em questão e minimizar as resistências à implementação, destaca o Diretor Industrial. 
De forma geral, a Empresa $\mathbf{E}$ foi muito bem sucedida na implementação das técnicas JIT e ainda não julga o processo como acabado. Mas os resultados já podem ser destacados: os principais indicadores da Empresa E são contrapostos aos índices divulgados pela empresa de consultoria IMAM. E nesta comparação os indicadores mostram uma franca evolução em alguns índices. Por exemplo, o número de níveis hierárquicos, que passou de 6 para três (na produção); os níveis de estoques passaram de 6 meses para 1 mês. A produção, que era de $70 \%$ do volume atual, era realizada com quase o dobro das pessoas. A área ocupada reduziu-se. Na época do Plano Cruzado, a previsão era de uma necessidade de aumento de área construída da ordem de 5000 metros quadrados, o que não se efetivou pela aplicação das técnicas JIT. Houve também redução do tempo médio de entregas. O tamanho dos lotes passou de cerca de 1000 peças para múltiplos de 40 peças. O programa "Clik" (semelhante a um programa de sugestões) também mostra seus resultados no tocante à geração de idéias. Em Amparo, no ano passado atingiu-se o número de 21 idéias por funcionários (a meta era 18) e em Contagem, chegou-se a 13 ou 14 idéias, para uma meta de 10. O nível de refugo atual é de 23 ppm (partes por milhão) contra 196 ppm de Contagem (era 4000 ppm em 1997). Desde 1997 não há greves em Amparo. O nível de ppm dos fornecedores passou de 1500 há dois anos para cerca de 600 em 2002. Há 4 anos o número de fornecedores certificados era reduzido, enquanto hoje a maioria possui certificação.

Uma análise detalhada dos grupos de fatores críticos para a implementação originalmente apontados pela bibliografia é feita a seguir:

Quanto ao apoio da Alta Administração, a disposição por tolerar aumento de estoques na fase inicial da implementação é clara. No início da década de 90 o nível de ineficiência era tal que os resultados apareceram rapidamente e nem houve o inicial aumento dos níveis de estoque pela implementação do JIT. Já na unidade de Contagem, por já ter um nível de estoque menor, está ocorrendo um aumento do nível geral de estoques para a devida adaptação às necessidades do JIT. Portanto, na fase inicial, ocorre um aumento dos estoques até que todos os processos estejam ajustados, mas há o apoio da direção, mesmo nesta situação.

Uma outra manifestação do apoio da Alta Administração às mudanças para o uso de técnicas JIT foram as iniciativas para melhorar o nível de escolaridade do pessoal. A partir do final dos anos 80 (entre 1987 e 1988) a Empresa E iniciou o processo de profissionalização da empresa. Este processo foi muito importante e a Alta Administração da 
época deu total "carta branca" à diretoria. O processo de terceirização colaborou para que as mudanças ocorressem sem criar maiores traumas na empresa.

Outro exemplo ligado ao apoio da Alta Administração é o programa "Clik" que representa o "estalo" de uma idéia. Este programa hoje é benchmarking para toda a organização da Empresa E. Está implementado desde 1995 em Amparo, e em Contagem está em fase final de implementação. Será implementado também em várias outras unidades da controladora da Empresa E pelo mundo. Foi "adaptado" de um conco rrente americano (Arwin). Por sua vez este sistema tinha sido adaptado da empresa americana Motorola. "Nós copiamos o modelo por ser conceitualmente muito bom, pois evitou os caçadores de idéias (pessoas que ficam o dia todo à caça de idéias)" destaca o Diretor Industrial. Este sistema computa pontos de todas as idéias que são geradas. As idéias só podem ser formalizadas em equipe e não individualmente. O objetivo do programa é o comprometimento das pessoas, antes de tudo. O programa "Clik" da Empresa E é coordenado por uma pessoa ligada à área da qualidade.

Como funciona o programa 'Clik'? Forma-se um grupo para implementar uma idéia de forma que inclua pessoas envolvidas com as soluções necessárias. Depois que a idéia é aprovada, são gerados pontos para todos os membros da equipe. A premiação é individual, mas a geração das idéias é coletiva. No início todas as idéias eram aceitas, pois o objetivo era também o de promover a integração entre as pessoas. Hoje os critérios tornaram-se mais seletivos.

O programa "Clik" hoje faz parte dos índices que formam o PLR (Plano de Lucros e Resultados).

Outra manifestação do apoio da Alta Administração é a reunião do 'bom dia”, ocasião em que a supervisão se reúne com os funcionários para comunicados gerais e informações úteis sobre o dia anterior de trabalho e sobre o dia que está se iniciando. Esta reunião ainda existe hoje. Há também a "reunião do café" (mensal ou semanal, dependendo da área envolvida), ocasião em que são passadas aos funcionários informações gerais sobre a fábrica, o que não é muito comum na maioria das empresas. Esta reunião envolve o pessoal de fábrica, incluindo a diretoria, o pessoal de RH e de áreas técnicas. Estas informações envolvem faturamento, custos, qualidade, produtividade, negociação sindical, etc. 
Nestes dois instantes existe a possibilidade de o funcionário contatar diretamente a direção da empresa sobre as suas dúvidas, reclamações e até mesmo agradecimentos sobre alguma providência já tomada em seu favor.

Existe autoridade para parar a linha de produção. Não é mais responsabilidade da área da qualidade e sim de cada funcionário das células controlar a qualidade ao longo do processo de produção.

O treinamento para Gerência em técnicas JIT aconteceu e foi monitorado pela empresa IMAM.

O aspecto da cooperação entre funcionários foi buscado pela consciência de cada funcionário. Procurou-se trabalhar em tudo que agregasse valor para a empresa. O programa “Clik” busca fortalecer o aspecto da cooperação. Criou-se também um programa para trazer a família dos funcionários para dentro da empresa (open house), em 1992, como forma de melhorar a ligação dele à empresa. Hoje o funcionário sabe que sua empresa é uma referência no setor automobilístico.

A Empresa E em Amparo tem um nível de comprometimento muito elevado, conforme constata o gerente de $\mathrm{RH}$, maior até do que as demais empresas do mesmo grupo no Brasil. Todo programa implementado na Empresa E acaba sendo bem-sucedido.

A autoridade do pessoal operacional aumentou muito. O supervisor não é mais um capataz. As responsabilidades estão mais divididas com os operadores. Em Contagem, entretanto, ainda há dificuldades neste sentido.

Não houve o enfoque do emprego vitalício diretamente. Os funcionários sempre foram informados que a empresa tem de ser produtiva, pois num sistema capitalista o que importa é que a empresa tenha lucro, e que sem lucros, a empresa fecha as portas e o funcionário é o primeiro a sofrer as conseqüências pela perda de seu emprego. Entretanto, procurou-se manter o número de funcionários, cerca de 320 a 330, o mais estável possível.

Quanto à classificação de cargos, houve alterações, com uma drástica redução na quantidade de níveis hierárquicos, que passou de doze para quatro (diretor, gerente, supervisor e operador). Foi criado um programa que vincula o salário ao nível de treinamento dos funcionários, que devem evoluir de uma faixa para outra, etapa por etapa.

A Empresa E percebeu claramente a presença de forte concorrência em seu ramo de produtos quando aconteceu a abertura do mercado nacional no início da década de 90 . A 
fusão com a controladora italiana foi inevitável e este processo foi vivido pelo pessoal da produção, que sempre soube claramente das pressões impostas pelo mercado, seja ele do lado dos clientes ou do lado da concorrência.

No fator Educação e treinamento, foi realizado um diagnóstico da condição de escolaridade dos funcionários. Constatou-se uma baixa escolaridade, entre 1992 e 1993. Dos cerca de 200 funcionários, a maioria era de analfabetos ou semi-analfabetos. Os funcionários tiveram oportunidades de estudar com total apoio da empresa. Foi feito um convênio com a Prefeitura local, que cedeu os professores e material didático, pagos pela Empresa E, para que o pessoal fosse treinado (alfabetizado em muitos casos). Iniciou-se em $1992 \mathrm{com} 1^{\circ}$ Grau e depois $2^{\circ}$ grau. $\mathrm{O}$ pessoal de $1^{\circ}$ turno, que trabalhava até às 14 horas e 30 minutos, teve o turno estendido até às 16 horas e 30 minutos para estudar dentro da empresa. Já o pessoal que entrava às 14 horas e 30 minutos, passou a entrar a partir de 12 horas e 30 minutos, para estudar até a hora de início do trabalho. A adesão, naturalmente, não foi plena. Então, todas as vezes em que era necessário fazer algum corte de pessoal, a condição escolar era analisada em primeiro lugar, ou seja, quanto maior a escolaridade, maior a estabilidade. Aqueles que estavam estudando sempre tiveram prioridade sobre os que não estudavam.

O treinamento é montado pelo $\mathrm{RH}$, com base nas necessidades definidas pelos setores de produção, mas quem o realiza é a produção, que forma seus próprios multiplicadores.

O processo de terceirização abriu caminho para a troca do pessoal de fábrica por pessoal mais qualificado e escolarizado. No nível gerencial, hoje, todos têm curso superior. No nível de supervisão, a Empresa E chegou a ter $40 \%$ do pessoal com curso superior. Em 1997, entretanto, pelo grande fluxo de empresas do setor automobilístico ao Brasil, devido às boas expectativas para o setor, a Empresa $\mathbf{E}$ perdeu vários funcionários para outras empresas do ramo (Motorola, Dana, etc.) que colocavam boas condições para supervisores com cursos superiores.

Como o sistema de produção da Empresa E antes da compra pelo atual grupo controlador já estava consolidado, estes supervisores foram substituídos por pessoal com nível colegial técnico, que continuaram estudando. Hoje, dos oito supervisores, três já têm nível superior e os demais estão estudando.

Não houve a fase do CCQ na Empresa $\mathbf{E}$ (não com este nome), mas existem grupos de projeto, que apresentam características semelhantes. 
A multifuncionalidade (cross-training) é obtida por investimento em treinamento. A maior parte das células é composta por dois ou três funcionários. Algumas têm apenas um único funcionário operando três ou quatro máquinas diferentes.

Os critérios de contratação mudaram drasticamente a partir de 1985. A partir do diagnóstico de $\mathrm{RH}$, funcionários de fábrica só seriam contratados se tivessem ao menos a $8^{\mathrm{a}}$ série do ensino médio. A notícia espalhou-se rapidamente pela cidade (que é pequena, com cerca de 60 mil habitantes, e favorece a rápida disseminação deste tipo de informação).

O uso de consultoria externa para implementação se dá apenas nas fases iniciais. Depois, a multiplicação é feita internamente.

Em 1992 foi contratado um consultor de Recursos Humanos para fazer um diagnóstico de "clima de fábrica" e descobriu-se que o nível de supervisão deixava muito a desejar. Era uma empresa nacional que mantinha a mesma cultura de gerenciamento por capatazes (com mais de 17 a 18 anos de empresa).

A partir deste trabalho, foi concretizada a fase da terceirização em Amparo. Nesta ocasião, a empresa era muito verticalizada (fazia tudo internamente, desde as peças menores de estamparia até a montagem final dos conjuntos maiores).

A terceirização iniciou-se pelas atividades convencionais, como restaurante (que nasceu terceirizado), segurança, fabricação de pequenas máquinas e de ferramentas. Em seguida foram terceirizados pequenos componentes estampados e pequenos componentes tubulares. Esta foi a oportunidade para se iniciar a mudança do nível gerencial da empresa. Existiam, nesta época, mini fábricas dentro da Empresa E (uma fazia só os moldados em lã de vidro, outra os componentes de fixação à carroceria do carro, outra fazia componentes estampados, etc.). Então, os gerentes e supervisores destas mini fábricas foram convidados a montar estas fábricas fora do parque da Empresa $\mathbf{E}$ (cerca de 5 mini fábricas, chamadas de satélites). Foram fornecidos equipamentos em comodato e a possibilidade de que levassem também alguns líderes e chefes antigos, "para tocar” o negócio lá fora.

Houve também apoio de consultoria da empresa IMAM na área da qualidade, para formação dos multiplicadores.

A figura do JIT Champion é claramente desempenhada pelo Diretor Industrial. É o grande mentor do processo. Apresenta amplo conhecimento do que se passa no setor de manufatura e promove forte integração entre as partes pela efetiva pela proximidade que mostra nos assuntos ligados ao JIT. 
Quanto ao fator Fornecedores, a Empresa E é importante tanto para os maiores fornecedores quanto para os menores (por exemplo os fornecedores satélites, que têm na Empresa E seu único cliente). Hoje há no máximo dois fornecedores e a tendência é concentrar num único. Os fornecedores satélite são fornecedores para os quais a Empresa $\mathbf{E}$ é o único cliente ou o mais importante. Nas grandes aciarias, a Empresa $\mathbf{E}$ é um grande cliente. Na área automobilística, a Empresa E é o maior cliente das aciarias em certos produtos, como os tubulares, por exemplo.

A escolha de fornecedor JIT é fundamental. Predominam fornecedores certificados.

A grande maioria dos fornecimentos é puxada por Kanban, mesmo das grandes aciarias. As empresas satélite são totalmente geridas pelo Kanban. Os fornecedores satélite estão todos em Amparo. Os demais são de outras regiões.

Hoje, para iniciar o fornecimento, é necessário ao menos a certificação ISO. Dentre os fornecedores antigos ainda há alguns que não possuem a ISO 9000, mas são poucos e não estão recebendo mais contratos para fornecimento de novos projetos. Hoje a maioria dos fornecedores da Empresa E são certificados. Aqueles que não são, recebem todo o apoio da Empresa E para aprimorar seus sistemas de qualidade. Quando o fornecedor não é certificado, a Empresa $\mathbf{E}$ faz auditorias em seus sistemas e realiza uma "certificação" interna, verificando se o processo é capaz e auxiliando no que for necessário.

Houve clara redução do lead time e dos lotes de compra, graças ao uso do Kanban. $\mathrm{O}$ fornecedor recebe diariamente informações sobre os níveis de estoque da Empresa E.

A confiabilidade dos fornecedores é monitorada pelo seu nível de ppm e seu sistema de qualidade. Por hora, a ISO é suficiente, mas em futuro próximo, outras normas mais abrangentes e específicas da indústria automobilística serão exigidas. É fato que a confiabilidade dos fornecedores é muito maior do que já foi no passado em termos de qualidade.

O relacionamento com fornecedores é de fato baseado em parceria. A Empresa $\mathbf{E}$ tem estoque baixo e depende em muito de seus fornecedores para a regularidade de suas operações. Outro ponto importante é o apoio ao fornecedor quanto à criação de seu sistema da qualidade. Por exemplo, os fornecedores de indústrias automobilísticas devem apresentar amostras com PPAP (que é um processo formal de aprovação de amostras às montadoras) e alguns fornecedores não têm noções de como proceder para apresentar o PPAP. Aí entra a parceria da Empresa $\mathbf{E}$ em ajudar o fornecedor. 
Não há contratos formais com os fornecedores, mas predominam os acordos de fornecimento.

Ainda é realizada inspeção de recebimento, mesmo que definida por lotes de entrega. O sistema é informatizado e monitora o lote que deve ser inspecionado em função do desempenho histórico do fornecedor. Há fornecedores de "qualidade assegurada", de acordo com normas próprias do sistema de qualidade. Este sistema já existia e foi adaptado às condições atuais, mas sem interferência do uso de técnicas JIT. Hoje o nível médio de qualidade dos fornecedores é 600 ppm.

O ideal, para as entregas JIT por parte da Empresa E, seria ter um local de entregas dentro da empresa do cliente. Entretanto, em Contagem, as entregas partem de um centro de distribuição localizado a $24 \mathrm{~km}$ da FIAT.

Um fator importante na Empresa E é o fator Produção. Existem células em todos os setores da empresa, que incluem até mesmo operações de solda, ponto mais crítico do processo. O Kanban funciona por toda a fábrica e inclui até os fornecedores (tanto as fábricas satélite como os fornecedores de tubos, por exemplo). A Empresa $\mathbf{E}$ tem um sistema eletrônico de Kanban ao qual a fábrica de Amparo está se adaptando, entretanto sem abandonar o Kanban por cartões já implementado. O trabalho com Kanban é complexo. Envolve operadores treinados para reduzir o set up, perdas de processo pequenas, estoques baixos, fornecedores confiáveis em qualidade e prazo de entrega.

A redução de set up por si só não basta, destaca o Diretor Industrial. Há um problema grave que é a fila de espera que acontece numa célula, mesmo quando os tempos de set up são desprezíveis. Na célula sempre um produto por vez é trabalhado e os demais estão esperando.

O início dos trabalhos de redução de set up deu-se com os operadores ajudando os ajustadores no processo de preparação das máquinas. A princípio somente os ajustadores faziam a preparação, mas ao longo do tempo, os próprios operadores perceberam que poderiam ajudar na preparação, fazendo as atividades mais simples enquanto aguardavam pela chegada dos ajustadores, sempre muito ocupados atendendo a outras preparações. Com o tempo, mais e mais atividades de preparação passaram a ser feitas pelos operadores e hoje a maior parte da preparação externa é feita pelos próprios operadores.

No aspecto da manutenção preventiva foi feito um forte trabalho de conscientização com treinamento intensivo. As primeiras manutenções sempre são feitas pelos operadores (por exemplo, apertar um parafuso de regulagem, lubrificar, limpar, etc.), sendo então ativado 
o pessoal da manutenção. O exemplo da manutenção de um automóvel particular é usado: quem faz as primeiras manutenções é o próprio dono do carro (óleo, limpeza geral, água de bateria, pneus, etc.). O treinamento é feito para habilitar o operador, quantas vezes forem necessárias.

Estes pontos, aliados a outras estratégias, possibilitaram a redução do lote de fabricação, que era de 1000 peças para múltiplos de 40 peças, com a implementação do Kanban.

O Layout foi radicalmente alterado para celular.

A automatização está presente. Há esteiras rolantes para movimentação de produtos acabados e matérias primas.

O CEP só é aplicado a algumas células e em operações escolhidas pela sua complexidade.

Também ligado ao processo de educação empreendido pela empresa desde 1992, aparece o programa de housekeeping. Há relatos de funcionários que mostram que o comportamento das pessoas foi alterado até para a vida pessoal. $\mathrm{O}$ treinamento foi intensivo ao longo deste período.

O sistema de produção mostra-se muito flexível graças à adoção de Kanban ao longo de todo o processo produtivo.

$\mathrm{O}$ enfoque da qualidade mudou radicalmente. Antes a responsabilidade pela qualidade era exclusivamente do pessoal do setor da qualidade, os inspetores e auditores. Após a implementação das técnicas JIT e todo o esforço empreendido em treinamento, a produção passou a atuar diretamente no sistema da qualidade, assumindo toda a responsabilidade pelo processo produtivo e pela qualidade deste processo, ficando reservado ao setor da qualidade a responsabilidade pelos sistemas da qualidade (ISO 9000, ISO 14000, QS 9000 e TS). O atual Gerente de Produção, que trabalhou no setor de qualidade no início de sua carreira na empresa conta um episódio que demonstra como a qualidade era tratada. Na ocasião, por falta da inspeção do auditor, cerca de 300 peças foram produzidas fora do padrão e a responsabilidade foi totalmente creditada ao Auditor. Inconformado com a situação, o auditor tentou fazer com que o operador examinasse algumas peças ao longo do processo, para prevenir novos problemas, mas foi veementemente repreendido pela Gerência de Produção da época, sob a alegação de que a responsabilidade pela qualidade era do Auditor e não do Operador, ao qual cabia apenas fazer o programa de produção estabelecido. No início da década de 90, quando 
este mesmo auditor foi transferido para a produção, iniciou-se o trabalho de colocar a responsabilidade da qualidade à cargo da produção. Hoje a responsabilidade pelo controle da qualidade é totalmente do operador.

Houve grandes alterações tecnológicas principalmente nas matérias-primas. Os materiais usados antigamente eram completamente diferentes dos utilizados hoje (a chapa galvanizada foi substituída pelas chapas de aço inox), muito embora isto não tenha alterado em nada a implementação do JIT.

A simplificação na lista de materiais aconteceu com a transferência da fabricação de muitas peças para as fábricas satélites. Hoje a Empresa E é praticamente uma montadora de escapamentos, recebendo inúmeros subconjuntos prontos de terceiros.

Já no fator Organizacional e Estrutural, destacam-se as condições locais, principalmente quanto ao tamanho da cidade (60 mil habitantes), que cria uma condição especialmente adequada para a implementação do JIT.

A criação das fábricas satélite abriu caminho para a mudança de alguns elementos chave da empresa, o que foi o início da mudança cultural dentro da Empresa E. Hoje a Empresa E não tem nenhum gerente ou supervisor que não tenha nível superior.

Uma fábrica satélite hoje produz algum produto ou componente que antes era feito dentro das instalações da Empresa E. A maioria delas apenas agrega mão-de-obra aos produtos que produz, ou seja, recebem os materiais da Empresa E e entregam os produtos componentes. São empresas pequenas (apenas uma já tem mais de 50 funcionários) e são fornecedores exclusivos da Empresa E. No total empregam diretamente cerca de 300 a 350 pessoas.

Antigamente a qualidade e produtividade eram vistas como pólos opostos (ou se atingia uma ou outra). Acreditava-se que quem fazia a qualidade era o Controle da Qualidade e não a Produção. Esta mudança de enfoque foi importante na Empresa E.

O sindicato, que sempre assume que a empresa está fazendo algo para aumentar a produtividade e reduzir o número de pessoas, não teve influência negativa, destaca o Diretor Industrial. Na Empresa E não ocorreu redução de empregos pelo aumento da produtividade gerada pelo uso das técnicas JIT, muito pelo contrário. A produtividade aumentou, a empresa ganhou mercado e cresceu, aumentando a oferta de vagas. 
Muitos funcionários deixavam a empresa só para sacar o FGTS e depois voltavam, o que não mais ocorre. Se um funcionário deixar a Empresa E, dificilmente será recontratado, salvo em situações muito especiais.

A rotatividade da mão-de-obra é muito importante para a Empresa $\mathbf{E}$ para garantir o funcionamento de seu sistema de produção. Por isso, todo esforço possível é feito a fim de evitar as demissões, mesmo em caso de bruscas e fortes alterações de demanda.

A conjuntura econômica mostra que no início da década de 90, quando deu-se o início da implementação das técnicas JIT em Amparo, a pressão das montadoras em termos de redução de custos e margens eram menores (as margens das autopeças eram maiores e eram permitidos "mais erros" do que hoje, quando as margens estão muito "apertadas"). Por consequiência, as pressões das montadoras hoje são muito maiores em termos de custos e qualidade.

A pressão estrutural força o processo a se conduzir numa velocidade acima da ideal, o que pode levar a que alguns fatores da cultura da empresa não sejam devidamente resolvidos. Como exemplo, pode ser tomado o caso da fábrica de Contagem, que hoje está passando pelas alterações ocorridas em Amparo, porém numa velocidade e pressão muito maiores.

O perfil de exigência e necessidades do cliente foi bastante alterado nos últimos dez anos no Brasil. Para conscientizar o pessoal de fábrica sobre esta mudança no perfil do cliente, iniciou-se um trabalho de levar os responsáveis pela produção para visitar os clientes quando estes apresentavam qualquer tipo de problema. Isto fez com que o pessoal de fábrica ficasse muito mais atento ao processo, pois ninguém mais queria sair para enfrentar a "fúria" de um cliente com problemas em sua produção.

A cada input da montadora, ficava clara a necessidade de reduzir custos. As montadoras representam cerca de 85\% dos negócios da Empresa E e 15\% é mercado de reposição (after market).

Em 1993 a FIAT criou um programa para avaliar os fornecedores e se propôs a ajudálos a atingir um mínimo de 87 pontos. A Empresa E, na época, somava 73 pontos. A FIAT foi a primeira a fazer esta pressão.

A GM, por exemplo, começou há cerca de três anos com a coleta Milk Run (em janelas de entregas). A VW de Taubaté é atendida por Kanban e a da Anchieta com pedidos. Na FIAT, em Contagem, as entregas são JIT e seqüenciadas à produção. A Empresa E está propondo à VW Taubaté também entregar JIT seqüenciado, o que está sendo analisado pela 
VW. Para isto será necessária a construção de um centro de distribuição nas proximidades da VW.

A Ford está saindo do processo Milk Run e voltando para o sistema de entregas contra pedido. No caso dos escapamentos é plenamente compreensível, pois trata-se de um produto muito volumoso.

O fornecimento à Ford é pequeno e limitado a peças diferentes de escapamentos por a Ford tem uma parceria com a Arwin (concorrente), que traz desde os Estados Unidos (sistema follow source).

O fornecimento seqüenciado é uma boa estratégia para inibir a concorrência, pois os concorrentes terão grandes dificuldades de competir com a empresa que tem um sistema já instalado.

Em várias situações a posição da concorrência foi citada com ênfase, mostrando que, caso alguns índices não fossem atingidos, o mercado seria perdido.

As empresas concorrentes também usam técnicas JIT, o que coloca a Empresa $\mathbf{E}$ numa condição de concorrência bem acirrada.

Todas as divisões da controladora da Empresa E estão direcionadas a trabalhar sob os conceitos da Lean Flow Manufacturing. Portanto, existe orientação direta da matriz para trabalhar em JIT, que já customizou as técnicas para as suas necessidades. Pela proximidade conceitual entre o JIT tradicional e a LFM não houve grandes dificuldades de adaptação na incorporação pela Empresa E.

O mix de produção está em constante elevação principalmente devido ao elevado ciclo de vida dos automóveis no Brasil. Aqui existem modelos que ficaram em linha por mais de duas décadas e continuam sendo usados, demandando ainda peças de reposição, as quais continuam a ser produzidas. Exemplos são os escapamentos de Fusca e Brasília, do Chevete e do Opala, entre outros. Além disso, a chegada de montadoras ao Brasil nos últimos 5 anos elevou o número de produtos demandados.

Produtos de baixo volume são terceirizados, sempre que possível. 
Anexo J - Cronologia da Instalação (e desativação) das fábricas de Automóveis, Comerciais Leves, Caminhões e Ônibus no Brasil entre 1957 e 2002
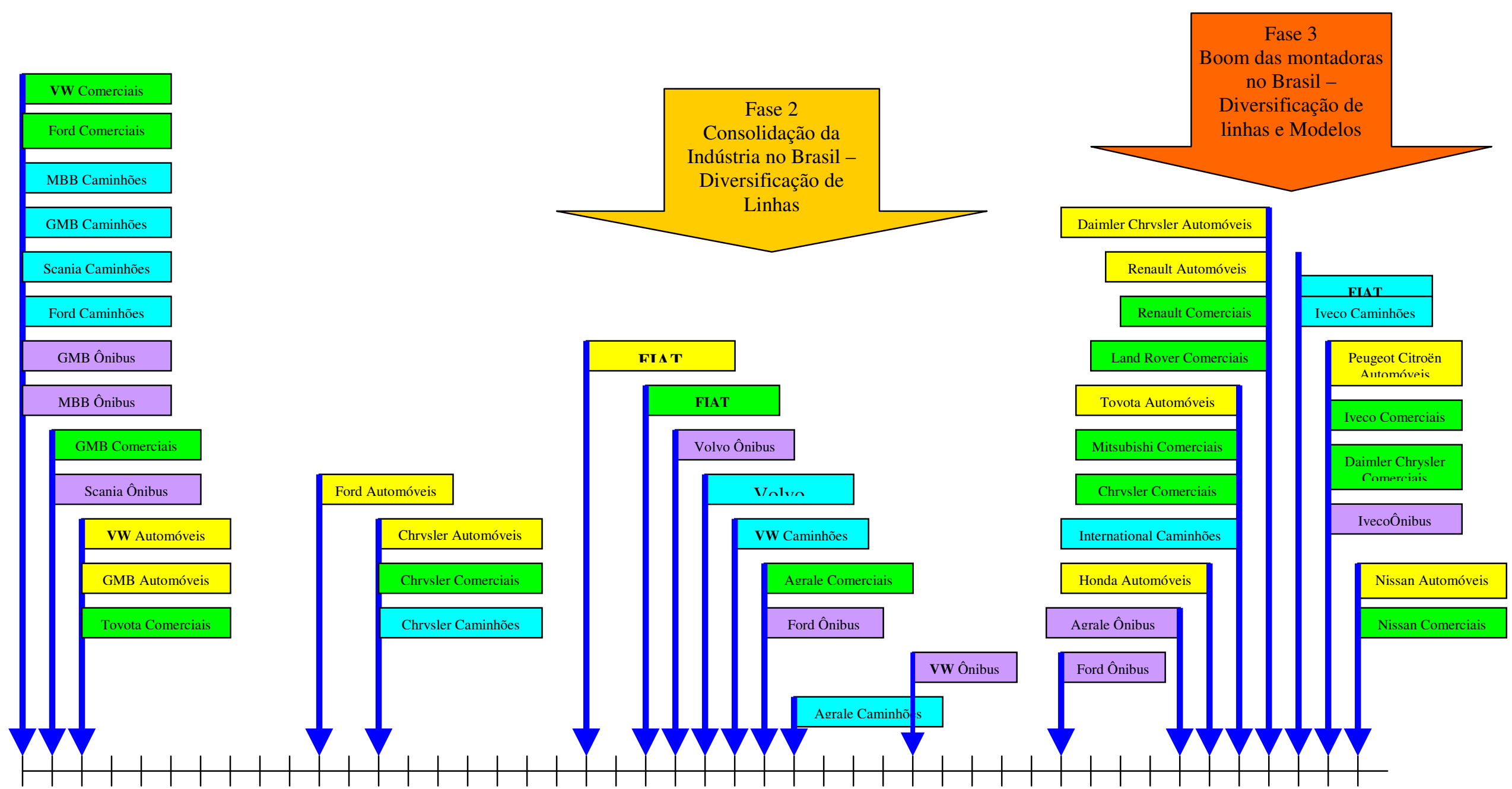

$\begin{array}{llllllllllllllllllllllllllllllllllllllllllllllllllllll}1957 & 58 & 59 & 60 & 61 & 62 & 63 & 64 & 65 & 66 & 67 & 68 & 69 & 70 & 71 & 72 & 73 & 74 & 75 & 76 & 77 & 78 & 79 & 80 & 81 & 82 & 83 & 84 & 85 & 86 & 87 & 88 & 89 & 90 & 91 & 92 & 93 & 94 & 95 & 96 & 97 & 98 & 99 & 2000 & 01 & 02\end{array}$
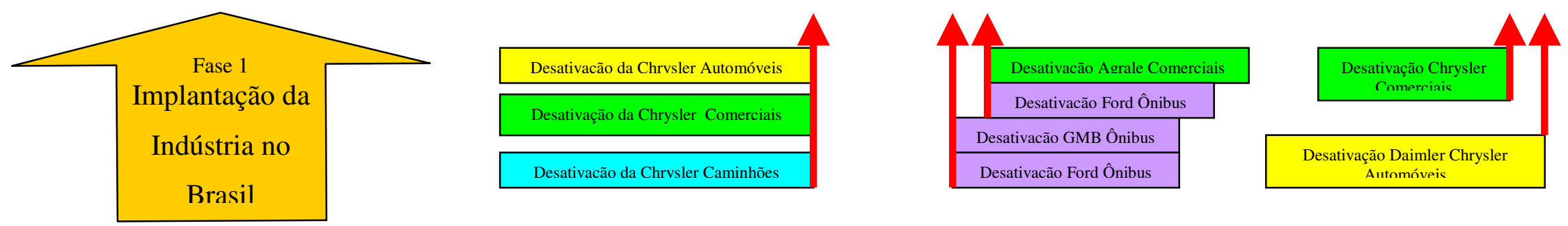
Anexo L - Produção Nacional, Importações e exportações de Autoveículos:

Automóveis, Comerciais leves, Caminhões e ônibus

\begin{tabular}{|c|c|c|c|c|c|c|c|c|c|c|c|c|c|}
\hline Montadora & & 1990 & 1991 & 1992 & 1993 & 1994 & 1995 & 1996 & 1997 & 1998 & 1999 & 2000 & 2001 \\
\hline \multirow{4}{*}{ Agrale } & Produção & 1528 & 1151 & 612 & 1444 & 1475 & 1232 & 444 & 623 & 1262 & 1703 & 3612 & 4135 \\
\hline & Importações & 0 & 0 & 0 & 0 & 0 & 0 & 0 & 0 & 0 & 0 & 0 & 0 \\
\hline & Total & 1528 & 1151 & 612 & 1444 & 1475 & 1232 & 444 & 623 & 1262 & 1703 & 3612 & 4135 \\
\hline & \% Imp/Total & $0 \%$ & $0 \%$ & $0 \%$ & $0 \%$ & $0 \%$ & $0 \%$ & $0 \%$ & $0 \%$ & $0 \%$ & $0 \%$ & $0 \%$ & $0 \%$ \\
\hline & Produção & & & & & & & & & 3651 & 4677 & 4945 & \\
\hline 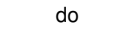 & Importações & & & & & & & 2451 & 10581 & 9457 & 4957 & 3059 & \\
\hline & Total & & & & & & & 2451 & 10581 & 13108 & 9634 & 8004 & \\
\hline & \% Imp/Total & & & & & & & $100 \%$ & $100 \%$ & $72 \%$ & $51 \%$ & $38 \%$ & \\
\hline Daimler & Produção & 31164 & 41484 & 34148 & 33679 & 40525 & 41253 & 30644 & 40477 & 39360 & 45923 & 53949 & 46608 \\
\hline Chrysler & Importações & 107 & 330 & 251 & 865 & 5387 & 10272 & 10533 & 12530 & 14904 & 8530 & 8389 & 7749 \\
\hline (era MBB) & Total & 31271 & 41814 & 34399 & 34544 & 45912 & 51525 & 41177 & 53007 & 54264 & 54453 & 62338 & 54357 \\
\hline & \% Imp/Total & $0 \%$ & $1 \%$ & $1 \%$ & $3 \%$ & $12 \%$ & $20 \%$ & $26 \%$ & $24 \%$ & $27 \%$ & $16 \%$ & $13 \%$ & $14 \%$ \\
\hline & Produção & 223668 & 255556 & 310272 & 393591 & 500738 & 463669 & 539658 & 619166 & 414074 & 399803 & 433781 & 436607 \\
\hline FIAT & Importações & 8 & 865 & 4766 & 19239 & 80685 & 89870 & 8833 & 17752 & 54578 & 7727 & 8442 & 26539 \\
\hline & Total & 223676 & 256421 & 315038 & 412830 & 581423 & 553539 & 548491 & 636918 & 468652 & 407530 & 442223 & 463146 \\
\hline & $\%$ Imp/Total & $0 \%$ & $0 \%$ & $2 \%$ & $5 \%$ & $14 \%$ & $16 \%$ & $2 \%$ & $3 \%$ & $12 \%$ & $2 \%$ & $2 \%$ & $6 \%$ \\
\hline & Produção & 146932 & 151012 & 153283 & 213127 & 222367 & 160043 & 147736 & 230245 & 185722 & 110551 & 122945 & 118026 \\
\hline Ford & Importações & 0 & 3005 & 4256 & 3983 & 7785 & 49076 & 60067 & 89864 & 56616 & \begin{tabular}{|l|}
29848 \\
\end{tabular} & 34530 & 38035 \\
\hline & Total & 146932 & 154017 & 157539 & \begin{tabular}{|l|}
217110 \\
\end{tabular} & \begin{tabular}{|l|}
230152 \\
\end{tabular} & 209119 & \begin{tabular}{|l|}
207803 \\
\end{tabular} & 320109 & 242338 & \begin{tabular}{|l|l|}
140399 \\
\end{tabular} & \begin{tabular}{|l|}
157475 \\
\end{tabular} & 156061 \\
\hline & \% Imp/Total & $0 \%$ & $2 \%$ & $3 \%$ & $2 \%$ & $3 \%$ & $23 \%$ & $29 \%$ & $28 \%$ & $23 \%$ & $21 \%$ & $22 \%$ & $24 \%$ \\
\hline & Produção & 203334 & 196635 & 213375 & 274972 & 289416 & 344431 & 443708 & 507386 & 415672 & 335836 & 442231 & 514333 \\
\hline GM Brasil & Importações & 0 & 297 & 458 & 531 & 2034 & 43054 & 13421 & 17868 & 32311 & 18735 & 10577 & 7974 \\
\hline & Total & 203334 & 196932 & 213833 & \begin{tabular}{|l|}
275503 \\
\end{tabular} & 291450 & 387485 & \begin{tabular}{|l|}
457129 \\
\end{tabular} & 525254 & \begin{tabular}{|l|}
447983 \\
\end{tabular} & \begin{tabular}{|l|}
354571 \\
\end{tabular} & 452808 & 522307 \\
\hline & \% Imp/Total & $0 \%$ & $0 \%$ & $0 \%$ & $0 \%$ & $1 \%$ & $11 \%$ & $3 \%$ & $3 \%$ & $7 \%$ & $5 \%$ & $2 \%$ & $2 \%$ \\
\hline & Produção & & & & & & & & 837 & 17775 & 17957 & 20658 & 22058 \\
\hline Honda & Importações & & & 741 & 4157 & 6822 & 4851 & 2076 & 2048 & 848 & 401 & 637 & 486 \\
\hline & Total & & & 741 & 4157 & 6822 & 4851 & 2076 & 2885 & 18623 & 18358 & 21295 & 22544 \\
\hline & \% Imp/Total & & & $100 \%$ & $100 \%$ & $100 \%$ & $100 \%$ & $100 \%$ & $71 \%$ & $5 \%$ & $2 \%$ & $3 \%$ & $2 \%$ \\
\hline & Produção & & & & & & & & & 315 & 481 & 492 & 811 \\
\hline International & Importações & & & & & & & & & 18 & 19 & 0 & 0 \\
\hline & Total & & & & & & & & & 333 & 500 & 492 & 811 \\
\hline & \% Imp/Total & & & & & & & & & $5 \%$ & $4 \%$ & $0 \%$ & $0 \%$ \\
\hline & Produção & & & & & & & & & & & 980 & 4741 \\
\hline Iveco & Importações & & & & & & & & 46 & 1307 & 3101 & 3459 & 925 \\
\hline & Total & & & & & & & & 46 & 1307 & 3101 & 4439 & 5666 \\
\hline & \% Imp/Total & & & & & & & & $100 \%$ & $100 \%$ & $100 \%$ & $78 \%$ & $16 \%$ \\
\hline & Produção & & & & & & & & & & 363 & 1219 & 1379 \\
\hline Land Rover & Importações & & & 27 & 110 & 253 & 45 & 403 & 820 & 1028 & 628 & 136 & 215 \\
\hline & Total & & & 27 & 110 & 253 & 45 & 403 & 820 & 1028 & 991 & 1355 & 1594 \\
\hline & \% Imp/Total & & & $100 \%$ & $100 \%$ & $100 \%$ & $100 \%$ & $100 \%$ & $100 \%$ & $100 \%$ & $63 \%$ & $10 \%$ & $13 \%$ \\
\hline & Produção & & & & & & & & & 652 & 3098 & 6252 & 8571 \\
\hline MMC & Importações & & 102 & 1055 & 2694 & 5479 & 6838 & 5641 & 7282 & 8679 & 4558 & 6200 & 5989 \\
\hline & Total & & 102 & 1055 & 2694 & 5479 & 6838 & 5641 & 7282 & 9331 & 7656 & 12452 & 14560 \\
\hline (Mitsubishi) & $\%$ Imp/Total & & $100 \%$ & $100 \%$ & $100 \%$ & $100 \%$ & $100 \%$ & $100 \%$ & $100 \%$ & $93 \%$ & $60 \%$ & $50 \%$ & $41 \%$ \\
\hline & Produção & & & & & & & & & & & & \\
\hline Nissan $\left({ }^{*}\right)$ & Importações & & & & 764 & 1270 & 1518 & 916 & 1053 & 1227 & 571 & 266 & 1552 \\
\hline & Total & & & & 764 & 1270 & 1518 & 916 & 1053 & 1227 & 571 & 266 & 1552 \\
\hline & $\%$ Imp/Total & & & & $100 \%$ & $100 \%$ & $100 \%$ & $100 \%$ & $100 \%$ & $100 \%$ & $100 \%$ & $100 \%$ & $100 \%$ \\
\hline & Produção & & & & & & & & & & & & 14422 \\
\hline Peugeot & Importações & & 58 & 374 & 2747 & 11040 & 17186 & 10920 & 8572 & 17168 & 24213 & 30621 & 33842 \\
\hline Citroën & Total & & 58 & 374 & 2747 & 11040 & 17186 & 10920 & 8572 & 17168 & 24213 & 30621 & 48264 \\
\hline & $\%$ Imp/Total & & $100 \%$ & $100 \%$ & $100 \%$ & $100 \%$ & $100 \%$ & $100 \%$ & $100 \%$ & $100 \%$ & $100 \%$ & $100 \%$ & $70 \%$ \\
\hline & Produção & & & & & & & & & & 24809 & 58083 & 71108 \\
\hline Renault & Importações & & & & 1559 & 7740 & 10541 & 8789 & 9460 & 19123 & 14482 & 14419 & 9926 \\
\hline & Total & & & & 1559 & 7740 & 10541 & 8789 & 9460 & 19123 & 39291 & 72502 & 81034 \\
\hline & $\%$ Imp/Total & & & & $100 \%$ & $100 \%$ & $100 \%$ & $100 \%$ & $100 \%$ & $100 \%$ & $37 \%$ & $20 \%$ & $12 \%$ \\
\hline & Produção & 5725 & 6001 & 5453 & 6284 & 7810 & 8625 & 6901 & 9532 & 7372 & 5828 & 7649 & 6990 \\
\hline Scania & Importações & 0 & 0 & 0 & 180 & 354 & 667 & 300 & 307 & 401 & 19 & 0 & 0 \\
\hline & Total & 5725 & 6001 & 5453 & 6464 & 8164 & 9292 & 7201 & 9839 & 7773 & 5847 & 7649 & 6990 \\
\hline & \% Imp/Total & $0 \%$ & $0 \%$ & $0 \%$ & $3 \%$ & $4 \%$ & $7 \%$ & $4 \%$ & $3 \%$ & $5 \%$ & $0 \%$ & $0 \%$ & $0 \%$ \\
\hline & Produção & 5091 & 6696 & 3053 & 2627 & 3734 & 3731 & 3203 & 3791 & 5064 & 11538 & 18809 & 14649 \\
\hline Toyota & Importações & 0 & 0 & 920 & 5228 & 4710 & 9044 & 3177 & 11407 & 12925 & 5651 & 9933 & 10131 \\
\hline & Total & 5091 & 6696 & 3973 & 7855 & 8444 & 12775 & 6380 & 15198 & 17989 & 17189 & 28742 & 24780 \\
\hline & \% Imp/Total & $0 \%$ & $0 \%$ & $23 \%$ & $67 \%$ & $56 \%$ & $71 \%$ & $50 \%$ & $75 \%$ & $72 \%$ & $33 \%$ & $35 \%$ & $41 \%$ \\
\hline & Produção & 288813 & 293445 & 347609 & 459476 & 508403 & 598759 & 626927 & 650972 & 490992 & 389971 & 509453 & 541827 \\
\hline & Importações & 0 & 0 & 3784 & 10252 & 18812 & 63984 & 56562 & 66030 & 71510 & 34909 & 14626 & 14966 \\
\hline Volkswagen & Total & 288813 & 293445 & 351393 & \begin{tabular}{|l|}
469728 \\
\end{tabular} & 527215 & 662743 & \begin{tabular}{|l|}
683489 \\
\end{tabular} & 717002 & \begin{tabular}{|l|}
562502 \\
\end{tabular} & 4424880 & \begin{tabular}{|l|}
524079 \\
\end{tabular} & 556793 \\
\hline & \% Imp/Total & $0 \%$ & $0 \%$ & $1 \%$ & $2 \%$ & $4 \%$ & $10 \%$ & $8 \%$ & $9 \%$ & $13 \%$ & $8 \%$ & $3 \%$ & $3 \%$ \\
\hline & Produção & 4936 & 4318 & 4285 & 4739 & 6829 & 7215 & 5096 & 6674 & 6380 & 4176 & 6272 & 5854 \\
\hline Volvo & Importações & 0 & 0 & 0 & 0 & 454 & 289 & 144 & 177 & 64 & 5 & 0 & 0 \\
\hline & Total & 4936 & 4318 & 4285 & 4739 & 7283 & 7504 & 5240 & 6851 & 6444 & 4181 & 6272 & 5854 \\
\hline & \% Imp/Total & $0 \%$ & $0 \%$ & $0 \%$ & $0 \%$ & $6 \%$ & $4 \%$ & $3 \%$ & $3 \%$ & $1 \%$ & $0 \%$ & $0 \%$ & $0 \%$ \\
\hline & Produção & & & & & & & & & & & & \\
\hline Volvo & Importações & & 31 & 110 & 205 & 551 & 1308 & 557 & 743 & 708 & 432 & 846 & 782 \\
\hline Automóveis & Total & & 31 & 110 & 205 & 551 & 1308 & 557 & 743 & 708 & 432 & 846 & 782 \\
\hline & $\%$ Imp/Total & & $100 \%$ & $100 \%$ & $100 \%$ & $100 \%$ & $100 \%$ & $100 \%$ & $100 \%$ & $100 \%$ & $100 \%$ & $100 \%$ & $100 \%$ \\
\hline & Produção & 911191 & 956298 & 1072090 & 1389939 & 1581297 & 1628958 & 1804317 & 2069703 & 1588291 & 1356714 & 1691330 & 1812119 \\
\hline Total & Importações & 115 & 4688 & 16742 & 52514 & 153376 & 308543 & 184790 & 256540 & \begin{tabular}{|l|}
302872 \\
\end{tabular} & 158786 & 146140 & 159111 \\
\hline & Total & 911306 & 960986 & 1088832 & 1442453 & \begin{tabular}{|l|}
1734673 \\
\end{tabular} & 1937501 & 1989107 & 2326243 & 1891163 & 1515500 & \begin{tabular}{|l|}
1837470 \\
\end{tabular} & 1971230 \\
\hline & Exportações & & 193148 & 341900 & 331552 & 377627 & 263044 & 296273 & 416872 & 400244 & 274799 & 371299 & 388394 \\
\hline & \% Imp/Total & $0 \%$ & $0 \%$ & $2 \%$ & $4 \%$ & $9 \%$ & $16 \%$ & $9 \%$ & $11 \%$ & $16 \%$ & $10 \%$ & $8 \%$ & $8 \%$ \\
\hline
\end{tabular}




\section{Referências Bibliográficas}

AGGARWAL, Sumer C. MRP, JIT, OPT, FMS? Harvard Business Review, p.4-10, September-October 1985.

ALLEN, Richard K. Lean and mean: workforce 2000 in America. Journal of Workplace Learning. Vol. 9 N. 11997 pp. $34-42$.

ANSARI, A.; MODARRESS, B. JIT brings problems and solutions. Purchasing World, p.47-50, March 1990.

ARKADER, Rebeca. Avanços e Barreiras ao fornecimento enxuto da indústria Automobilística brasileira: a perspectiva dos fornecedores. RAC, v. 3, n. 1, jan/abr. p. 07-21, 1999.

ARANHA, Maria Lúcia de Arruda; MARTINS, Maria Helena Pires. Filosofando: introdução à filosofia. 2 ed. São Paulo: Moderna, 1993.

AROGYASWAMY, Bernard; SIMMONS, Ronald P. Production and Inventory Management Journal, p.5660, Third Quarter, 1991.

BARCELLOS, Luiz Fernando. Fatores de êxito na implementação do Just-in-Time na indústria brasileira: um estudo de casos. Rio de Janeiro. 1991. Dissertação de Mestrado (Mestre em Ciências - M. Sc.) Instituto de Pós-Graduação e Pesquisa em Administração, da Universidade Federal do Rio de Janeiro COPPEAD/UFRJ.

BICKMAN, L.; ROG, D. J. Handbook of Applied social research methods. Thousand Oaks: Sage, 1997.

BILLESBACH, Thomas J. A study of the implementation of the Just-in-Time in the United States. Production and Inventory Management Journal, p.1-4, Third Quarter, 1991.

Applying lean production principles to a process facility. Production and Inventory Management Journal, p.40-44, Third Quarter, 1994a.

; SCHNIEDERJANS, Marc J. Applicability of Just-in-Time Techniques in Administration. Production and Inventory Management Journal, p.40-45, Third Quarter, 1989.

; HAYEN, Roger. Long-term impact of Just-in-Time on inventory performance measures. International Journal of Operations \& Production Management, p.62-67, First Quarter 1994b.

BOER, Harry; KRABBENDAM, Koos. The Effective Implementation and Operation of Flexible Manufacturing Systems. Int. Studies of Management \& Org., v.22, n.4, p.33-48. 1992.

BOSE, G.J.; RAO, A. Implementing JIT with MRP II Creates Hybrid Manufacturing Environment. Industrial Engineering, v.20 n. 9, September 1988, pp. 49-53.

BOWMAN, Jerry D. If you don't understand JIT how can you implement it? IE, p. 38-39, February 1991.

BRADBURN, Norman M.; SUDMAN, Seymour. Improving Interview Method and Questionnaire Design. Jossey Bass Publishers, Beverly Hills, CA: 1980.

BRANEEN, Julia. Mixing Methods: qualitative and quantitative research. Avebury, Brookfield: 1992.

BROWN, Karen A. Analysing the role of project consultant: cultural change implementation. Project Management Journal, v. 32, n.3 pp. 52 - 55. 2000.

; MITCHELL, Terence R. A Comparison of Just-in-Time and Batch Manufacturing: The Role of Performance Obstacles. Academy of Management Journal. V. 34, n. 4, p. 905-917, 1991.

BURGESS, Robert G. Field Research: sourcebook and Field Manual. Routledge, Cambrige: 1994.

BYRD, Jack Jr.; CARTER, Mark D. A Just-in-Time Implementation Strategy At Work. IM. Mar./Abr. 1988.

CHEN, Injazz; GUPTA, Atul; CHUNG, Chen-Hua. Employee commitment to the implementation of flexible manufacturing systems. International Journal of Operations \& Production Management, v.16, n.7, p. 4-13, 1996.

CLODE, David, M. A survey of U.K. Manufacturing Control over the past ten years. Production and Inventory Management Journal, p. 53-56, Second Quarter, 1993.

COOK, Paula. Maximizing the oportunities and minimizing the adverse effects of a changing environments. Employee Counselling Today, v. 7, n.7, pp. 4-6, 1995. 
CRAWFORD, Karlene M; COX, James F. Addressing manufacturing problems through the implementation of Just-in-Time. Production and Inventory Management Journal, p.33-36, First Quarter, 1991.

CRESWEL, John W. Research Design: Qualitative and Quantitative Approaches, Sage Publications, Beverly Hills, CA: 1994.

DAHLÉN, Per; ERICSSON, Johan; FUJII, Hiroshi. Labour stability and flexibility - conditions to reach just-intime. International Journal of Operations \& Production Management, v.15, n.9, p.26-43, 1995.

DAVIS, Mark M.; AQUILANO, Nicholas J.; CHASE, Richard B. Fundamentos de Administração da Produção. 3. ed. Porto Alegre: Bookman, 2001.

DAY, Joseph C. The power of lean. Chief Executive, n.101, p. 50-53, May 1995.

DEMING, W. E. Qualidade: A revolução na administração. Rio de Janeiro: Marques Saraiva, 1990.

DENTON, D. Keith. Four Simple Rules for leading Change. Empowerment in Organizations. v.4, n.4 pp. 5-9. 1996.

DENZIN, Norman K.; Lincoln, Yvonna S. Handbook of Qualitative Research, Sage Publications, Beverly Hills, CA: 1994.

DESHPANDE, Satish P.; GOLHAR, Damodar Y. HRM practices in unionized and nonunionized canadian JIT manufacturing firms. Production and Inventory Management Journal, p.15-19, First Quarter 1995.

DUBRIN, Andrew J. Princípios de Administração. 4.ed. Rio de Janeiro: LTC, 1998.

EISENHARDT, Kathleen M. Building Theories from Case Studies Research. Academy of Management Review, v.14, n.4, 532 - 550, 1989.

EPPS, Ruth W. Just-in-Time Inventory Management: Implementation of a Successful Program. Review of Business, p.40-44, Fall 1995.

FERDOWS, Kasra. Made in the World: The Global Spread of Production. Production and Operations Management Society, v.6, n.2, p.102-110, Summer 1997.

FINK, Arlene. How To Ask Survey Questions. Sage Publications, Thousand Oaks, CA: 1995.

FORZA, Cipriano. Work organization in lean production and traditional plants. What are the differences? International Journal of Operations \& Production Management, v.16, n.2, p.42-62, 1996.

FOWLER, Floyd J. Survey Reseach Methods. Sage Publications, Beverly Hills, CA, 1988.

FREELAND, James R. A Survey of Just-in-Time Purchasing Practices in the United States. Production and Inventory Management Journal. p. 43-50, Second Quarter 1991.

GAITHER, N. Production and Operations Management. 6TH ed. Fort Worth, TX: Dryden, 1994.

GARG, Dixit; KAUL, O.N.; DESHMUKH, S.G. JIT implementation: a case study. Production and Inventory Management Journal, p.26-31. Third Quarter, 1998.

GERMAIN, Richard; DRÖGE, Cornelia; SPEARS, Nancy. The implications of Just-in-Time for logistics organization management and performance. Journal of Business Logistics, v.17, n.2, p.19-34, 1996.

GIUNIPERO, L.C; LAW, W.K. Organizational Support for Just-in-Time Implementation. The International Journal of Logistics Management, v.1, n.2, 1990, pp. 35-40.

; LAW, Wai K. Organizational Changes and JIT Implementation. Production and Inventory Management Journal, p.71-73, Third Quarter, 1990.

GOLHAR, D.; STAMM, C.L. The just-in-time philosophy: a literature review. International Journal of Production Research, v. 29, n.4, 1991, pp. 657-76.

; DESHPANDE, Satish P. An Empirical Investigation of HRM Practices in JIT firms. Production and Inventory Management Journal, p.28-32, Fourth Quarter, 1993.

; STAMM, Carol L.; SMITH, Wayland P. JIT implementation in small manufacturing firms. Production and Inventory Management Journal, p.44-48, Second Quarter, 1990.

GREEN, F.B.; AMENKHIENAN, Cma; JOHNSON, George. Performance measures and JIT. Management Accounting, p.50-53, February 1991.

GREINER, Larry E. Patterns of Organization Change. Harvard Business Review, p.120-128, May-June 1967. 
GROEBNER, David; MERZ, Mike C. The Impact of Implementing JIT on Employees' Job Attitudes. International Journal of Operations \& Production Management, v.14, n.1, p. 26-37, 1994.

HAGUENAUER, L. Competitividade: conceitos e medidas - uma resenha da bibliografia recente com ênfase no caso brasileiro. Rio de Janeiro, UFRJ/IEI, 1989. (texto para discussão 211)

HALL, R. Zero Inventories. Dow Jones-Irwin, Homewood, IL, 1983 .

HANKOCK, M Walton; ZAYKO, J Matthew. Lean Production: implementation Problems. IIE Solutions; Norcross, Jun 1998.

HARMON, R.; L. PETERSON. Reinventing the Factory: Productivity Breakthroughs in Manufacturing Today. New York: The Free Press, 1990.

HAY, E.J. The Just-in-Time Breakthrough - Implementing the New Manufacturing Basics, John Wiley \& Sons, New York, NY, 1988.

HELMS, Marylin M. Communication: the key to JIT success. Production and Inventory Management Journal, p.18-21, Second Quarter, 1990.

HENDRICKS, James A. Performance measures for a JIT manufacturer: the role of the IE. Industrial Engineering, p.26-29, January 1994.

HUM, Sin-Hoon; NG, Yong-Tjoon. A study on just-in-time practices in Singapore. International Journal of Operations \& Production Management, v.15, n.6, p.5-24, 1995.

IM, Jin H. How does Kanban work in american companies? Production and Inventory Management Journal, p. 22-24, Fourth Quarter, 1989.

; HARTMAN, Sandra J., BONDI, Philip J. How do JIT systems affect human resource management ? Production and Inventory Management Journal, p. 1-4, First Quarter, 1994.

IMAI, Masaaki. Will America's Corporate Theme Song Be 'Just in Time "? The Journal for Quality and Participation, p.26-28, Mar/Apr 1998.

INMAN, Robert A. Are You Implementing a Pull System By Putting the Cart Before the Horse? Production and Inventory Management Journal, p.67-71, Second Quarter 1999.

; BRANDON, Larry D. An undesirable effect of JIT. Production and Inventory Management Journal, p.55-58, First Quarter, 1992.

; MEHRA, Satish. JIT Applications for Service Environments. Production and Inventory Management Journal, p.16-21, Third Quarter 1991.

MEHRA, Satish. Potential union conflict in JIT implementation? Production and Inventory Management Journal, p.19-21. Fourth Quarter, 1989.

Instituto Brasileiro de Geografia e Estatística. Contas Nacionais. Disponível em <http://www.ibge.gov.br>. Acesso em 10/02/2003.

JOHNSTON, Stan K. JIT: Maximizing its success potential. Production and Inventory Management Journal, p.82-86, First Quarter, 1989.

JUSKO, Jill. A look at lean: Efforts to reduce inventory and eliminate waste propel good performances. Census of Manufacturers, p.88-91, December 1999.

KARLSSON, Christer; AHLSTROM, Pär. Assessing changes towards lean production. International Journal of Operations \& Production Management, v. 16, n. 2, p.24-41, 1996.

; NORR, Christer. Total Effectiveness in a Just-in-Time System. International Journal of Operations \& Production Management, v.14, n.3, p.46-65, 1994.

KEYS, David E. Five Critical Barriers to Successful Implementation of JIT and Total Quality Control. IE, p.2224, January 1991.

KIM, Gyu C.; TAKEDA, Eiji. The JIT philosophy is the culture in Japan. Production and Inventory Management Journal, p.47-51, First Quarter, 1996.

; SCHNIEDERJANS, Marc J. An evaluation of computer-integrated Just-in-Time production systems. Production and Inventory Management Journal, p. 4-7, First Quarter, 1990. 
KIRK, Jerome; MILLER, Marc L. Reliability and Validity in Qualitative Research. Sage Publications, Beverly Hills, CA: 1986.

KRAJEWISK, I.; L. RITZMAN. Operations Management: Strategy and Analysis. 3ed. Reading, MA: Addison-Wesley, 1992.

LAWRENCE, John J.; LEWIS, Holly S. JIT manufacturing in Mexico: Obstacles to implementation. Production and Inventory Management Journal, p31-35, Third Quarter, 1993.

LESCHKE, John P. The set up reduction process: Part 1. Production and Inventory Management Journal, p.32-37, First Quarter 1997.

LUMMUS, Rhonda, R.; DUCLOS-WILSON, Leslie. When JIT is not JIT. Production and Inventory Management Journal, p. 61-65, Second Quarter, 1992.

MALLEY, John C.; RAY Ruthann. Informational and organizational impacts of implementing a JIT system. Production and Inventory Management Journal, p.66-70, Second Quarter 1988.

MANOOCHEHRI. G. H. JIT for small manufacturers. Journal of Small Business Management, p. 22-30, October 1988.

MARKHAM, Ina S.; McCART, Christina D. The road to successful implementation of just-in-time systems. Production and Inventory Management Journal, v. 36, n. 3, p. 67 -71, $3^{\circ}$ trimestre 1995.

MAZANY, Pete. A Case Study - Lesson from the progressive implementation of just-in-time in a small knitwear manufacturer. International Journal of Operations \& Production Management, v. 15, n. 9, p. 271-288, 1995.

MEHRA, Satish; INMAN, R. Anthony. Determining the Critical Elements of Just-in-Time Implementation. Decision Sciences, v.23, p.160-174, 1992.

MILEHAM, A.R.; CULlEY, S.J.; OWEN, G.W.; McINTOSH, R.I. Rapid changeover - a pre-requisite for responsive manufacture. International Journal of Operations \& Production Management, v. 19, n. 8, p.785-796, 1999.

MILES, Mathew B.; HUBERMAN, A . Michael. Qualitative data Analysis, Sage Publications, Thousand Oaks, CA: 1994.

MORAS, Rafael G.; DIECK, Antonio J. Industrial applications of Just-in-Time: Lessons to be learned. Production and Inventory Management Journal, p.25-29, Third Quarter, 1992.

MUCHNIK, Michael A.; SHIPLEY, Margaret F.; SHANE, Hugh M. Why JIT Can't Bear Fruit in American Plants. Business Forum, p.12-14, Summer 1990.

MULLARKEY, S.; JACKSON, P.R.; PARKER, S.K. Employee reactions to JIT manufacturing practices: a two phase investigation. International Journal of Operations \& Production Management, v. 15, n. 11, p. 62-79, 1995.

NORRIS, Daniel; SWANSON, Robert D.; CHU, Yung-Lin. Just-in-Time Production Systems: A Survey of Managers. Production and Inventory Management Journal, p.63-66, Second Quarter, 1994.

OHNO, Taiichi. The Toyota Production System: Beyond Large Scale Production, Productivity Press, Cambridge, MA, 1988.

OLIVER, Nick; DELBRIDGE, Rick; LOWE, Jim. The European auto components industry. International Journal of Operations \& Production Management, v.16, n. 11, p.85-97, 1996.

ORTH, D.; HYBIL, R.; KORZAN, D. Analysis of a JIT implementation at Dover Corporation. Production \& Inventory Management Journal, v. 31, n. 3, 1990, pp. 79-83.

PAYNE, Terry E. ACME Manufacturing: A case study in JIT implementation. Production and Inventory Management Journal, p. 82-86, Second Quarter, 1993.

PLOSSL, Keith R. Engineering for the Control of Manufacturing. Prentice-Hall, Inc., Englewood Cliffs, NJ, 1987.

PORTER, Michael E. Estratégia competitiva: técnicas para análise de indústrias e da concorrência. Rio de Janeiro: Campus, 1986

PRASAD, Biren. JIT quality matrices for strategic planning and implementation. International Journal of Operations \& Production Management, v.15, n.9, p. 116-142, 1995. 
RAMARAPU, Narender K.; MEHRA, Satish; FROLICK, Mark N. A comparative analysis and review of JIT 'implementation” research. International Journal of Operations \& Production Management, v.15, n. 1, p. $38-49,1995$.

RAOUF, A. Improving Capital Productivity through Maintenance. International Journal of Operations \& Production Management, v.14, n.7, p.44-52, 1994.

RITZMAN, Larry P.; KRAJEWSKI, Lee P. Operations Management - Strategy and Analysis. AddisonWesley longman, Cambridge, MA, 1998.

ROBINSON, A . Modern Approachs to Manufacturing Improvements: the Shongo System. Cambridge, MA: Productivity Press, 1990.

ROMERO, Bernardo Prida. The other side of JIT in Supply Mangement. Production and Inventory Management Journal, p. 1-3, Fourth Quarter, 1991.

SALANT, Priscilla; DILlMAN, Don A. How To Conduct Your own Survey. NY: John Wiley \& Sons, 1994.

SAMBASIVARAO, K.V.; DESHMUKH, S.G. Selection and implementation of advanced manufacturing technologies. Classification and literature review of issues. International Journal of Operations \& Production Management, v.15, n.10, p. 43-62, 1995.

SCHONBERGER R.J., Japanese Manufacturing Techniques: Nine Hidden Lessons in Simplicity, The Free Press, New York, NY, 1982.

SCHMENNER, Roger W. The Merit of Making Things Fast. Sloan Management Review, p.11-17, Fall 1998.

SCHUMAN, Howard; PRESSER, Stanley. Questions and Answers in attitude Surveys. Sage Publications, Thousand Oaks, CA: 1996.

SEIDMAN, I. E. Interviewing as Qualitative Research. Teachers College Press, New York, NY: 1991.

SEVIER, Amy. Managing Employee Resistance to JIT: Creating an Atmosphere that Facilitates Implementation. Production and Inventory Management Journal, v. 33, n. 1, p.83 - 92, 1992.

SHAHABUDDIN, Syed. Is JIT really appropriate for American Manufacturing ? IM, p.26-28, May/June 1992.

SILVA, Christian Luiz da. Competitividade e estratégia empresarial: um estudo de caso da indústria automobilística brasileira na década de 1990. FAE, Curitiba, v. 4, p. 35-48, jan./abr. 2001.

SILVERMAN, David. Interpreting Qualitative Data: Methods for Analysing Talk, Text and Interaction. London: Sage Publications, 1993.

SOHAL, Amrik S. Developing a lean production organization: an Australian case study. International Journal of Operations \& Production Management, v.16, n.2, p.91-102, 1996.

; EGGLESTONE, Adrian. Lean Production: Experience among Australian Organizations. International Journal of Operations \& Production Management, v.14, n.11, p.35-51, 1994.

; NAYLOR, Derek. Implementation of JIT in a small manufacturing firm. Production and Inventory Management Journal, p. 20-26, First Quarter 1992.

SPENCER, Michael S.; GUIDE, Daniel V. An exploration of the components of JIT: Case study and survey results. International Journal of Operations \& Production Management, v.15, n.5, p.72-83, 1995.

STASEY, R., C. MC NAIR. Crossroads:A JIT Success Story. Homewood, IL: Dow Jones-Irwin, 1990.

STORHAGEN, Nils G. The Human Aspects of JIT implementation. International Journal of Operations \& Production Management, v. 25, n. 3, p. 4-23, 1995.

STRAUSS, Anselm; CORBIN, Juliet. Basics os Qualitative Research. Sage Publications, New Park, CA: 1990.

SUGIMORI, Y.; K. Kusonoki; F. Cho; S. Uchikawa. Toyota Production System and Kanban System: Materialization of Just-in-time anda Respect-for-Human System. International Journal of Production Research v.6, n. 6, pp. 553-564, 1997.

TAYLOR, D. Stockless Productionor: How to Tame American Industry Just-in-Time. Proceedings of yhe APICS Zero Inventories Seminar. Orlando, FL: APICS (1983): 8 - 13.

TOOMEY, John W. MRPII - Planning for Manufacturing Excellence. New York, Chapman \& Hall: 1996. 
UDO, Godwin; EHIE, Ike C. Advanced manufacturing technologies: Determinants of implementation success. International Journal of Operations \& Production Management, v.16, n.12, p.6-26, 1996.

UPTON, David. Just-in-Time and performance measurement systems. International Journal of Operations \& Production Management, v.18, n.11, p. 1101-1110, 1998.

VICKERY, Shawnee K. International Sourcing: Implications for Just-in-Time Manufacturing. Production and Inventory Management Journal, p.66-72, Third Quarter, 1989.

VOKURKA, Robert J.; DAVIS, Robert A. Just-in-time: the evolution of a philosophy. Production and Inventory Management Journal, p.56-59, Second Quarter, 1996.

VORA, Jay A.; SARAPH, Jayant V.; PETERSEN, Dietrich L. JIT Implementation Practices. Production and Inventory Management Journal, p. 57-59, Third Quarter, 1990.

VUPPALAPATI, Kiran; AHIRE, Sanjay L.; GUPTA, Tarun. JIT and TQM : a case for joint implementation. International Journal of Operations \& Production Management, v.15, n. 5, p. 84-94, 1995.

WAFA, Marwan A.; YASIN, Mahmoud M. A conceptual framework for effective implementation of JIT. An empirical investigation. International Journal of Operations \& Production Management, v. 18, n. 11, p. 1111-1124, 1998

WALLEIGH, Richard C. What's Your Excuse for Not Using JIT? Harvard Business Review, p.2-7, MarchApril 1986.

WHITE, Richard E. An Empirical Assessment of JIT in U.S. Manufacturers. Production and Inventory Management Journal, p.38-42, Second Quarter 1993.

WILLIS, Hillman T.; SUTER, William C. Jr. The five M's of Manufacturing: A JIT Conversion Life Cycle. Production and Inventory Management Journal, p.53-57, First Quarter, 1989.

WOMACK, James P.; JONES, Daniel T.; ROOS, Daniel. A Máquina que mudou o mundo. Rio de Janeiro: Campus, 1992.

YASIN, Mahmoud M.; WAFA, Marwan A. An empirical examination of factors influencing JIT success. International Journal of Operations \& Production Management, v.16, n.1, p.19-26, 1996.

YIN, R.K. Case Study Research - Design and Methods, Sage, London: 1989.

ZAYKO, Matthew J.; BROGHMAN, Douglas J.; HANCOCK, Walton M. Lean Manufacturing Yields WorldClass Improvements for Small Manufacturer. IIE Solutions, p. 36-40, April 1997.

ZHU, Zhhiwei; MEREDITH, Paul. Defining critical elements in JIT implementation : a survey. Industrial Management and Data Systems, v. 95, n. 8, p. 21-28, 1995. 